University of Louisville

ThinkIR: The University of Louisville's Institutional Repository

Electronic Theses and Dissertations

$8-2018$

\title{
Material-process-property relationships of 17-4 stainless steel fabricated by laser-powder bed fusion followed by hot isostatic pressing.
}

Harish Irrinki

University of Louisville

Follow this and additional works at: https://ir.library.louisville.edu/etd

Part of the Other Mechanical Engineering Commons

\section{Recommended Citation}

Irrinki, Harish, "Material-process-property relationships of 17-4 stainless steel fabricated by laser-powder bed fusion followed by hot isostatic pressing." (2018). Electronic Theses and Dissertations. Paper 3024. https://doi.org/10.18297/etd/3024

This Doctoral Dissertation is brought to you for free and open access by ThinkIR: The University of Louisville's Institutional Repository. It has been accepted for inclusion in Electronic Theses and Dissertations by an authorized administrator of ThinkIR: The University of Louisville's Institutional Repository. This title appears here courtesy of the author, who has retained all other copyrights. For more information, please contact thinkir@louisville.edu. 
MATERIAL-PROCESS-PROPERTY RELATIONSHIPS OF

\title{
17-4 PH STAINLESS STEEL FABRICATED BY LASER-POWDER BED FUSION
}

FOLLOWED BY HOT ISOSTATIC PRESSING

\author{
By \\ Harish Irrinki \\ A Thesis \\ Submitted to the Faculty of the \\ J.B. Speed School of Engineering of the University of Louisville \\ in Partial Fulfillment of the Requirements \\ for the Degree of \\ Doctor of Philosophy in \\ Mechanical Engineering \\ Department of Mechanical Engineering \\ University of Louisville \\ Louisville, KY
}

August, 2018 
CCopyright 2018 by Harish Irrinki

All Rights Reserved 

MATERIAL-PROCESS-PROPERTY RELATIONSHIPS OF

\section{7-4 PH STAINLESS STEEL FABRICATED BY LASER-POWDER BED FUSION}

FOLLOWED BY HOT ISOSTATIC PRESSING

By

Harish Irrinki

A Dissertation Approved on

July 20, 2018

by the following Dissertation Committee:

Director: Dr. Sundar V. Atre

Dr. Thomas A. Berfield

Dr. Li Yang

Dr. Kunal H. Kate

ii 
I dedicate this thesis to

my parents Sri Rama Murthy and Dhana Lakshmi Irrinki and grandfather Sri Gopala Krishna Murthy Sanku who have supported through the various obstacles in my life with their incessant generosity, support, and love. 


\section{ACKNOWLEDGEMENT}

First and foremost, I would like to express my sincerest gratitude for Dr. Sundar V. Atre, who has been a teacher, mentor, and friend throughout this study. Without his unfailing patience, guidance and motivation, none of this work would have been possible. He has certainly contributed to my growth as an individual and as a researcher providing me with an outstanding example of professionalism and intelligence.

I would also like to thank Dr. Thomas Berfield, Dr. Li Yang and Dr. Kunal Kate, for being on my dissertation committee and for providing their constructive advice during my research at the University of Louisville. Furthermore, I must show my appreciation for various faculty and staff at the University of Louisville, especially in the Mechanical Engineering Department. I would like to thank the Mechanical Engineering Department and Walmart Foundation for supporting my research. I would like to thank Jason Stitzel (Metal Technologies) for his help with the metal 3D printer experiments. I would like to thank Dr. Gautam Gupta (University of Louisville) for his help and guidance with corrosion experiments. I would like to thank North American Hoganas for providing the 17-4 PH stainless steel powders and Mr. Magnus Ahlfors (Quintus Technologies) and Mr. Craig Beaumier (Quintus Technologies) for their help with the hot isostatic pressing experiments. I would like to thank Mr. Jim Adams and his team from Metal Powders 
Industries Federation (MPIF) for their support to attend various international conferences to present my work.

Additionally, I would like to thank Dr. Sunil Badwe (Divergent 3D), Dr. Somayeh Pasebani (Oregon State University), Dr. Ozkan Gulsoy (Maramara University), Dr. Dilip Jangam (HP Labs), Dr. Kevin Walsh (University of Louisville), Dr. Jacek Jasinski (University of Louisville) and Dr. Roger Bardshaw (University of Louisville) for their technical support to my experiments and input on my research. I would also like to thank my laboratory fellows Subrata Deb Nath, Paramjot Singh, Mohith Buxani for their support and friendship. 


\begin{abstract}
MATERIAL-PROCESS-PROPERTY RELATIONSHIPS OF 17-4 PH STAINLESS STEEL FABRICATED BY LASER-POWDER BED FUSION FOLLOWED BY HOT ISOSTATIC PRESSING
\end{abstract}

\author{
Harish Irrinki
}

July 20, 2018

17-4 PH stainless steel is commonly used in medical, tooling, automotive, chemical and aerospace industries due to its excellent strength and corrosion properties. Additive manufacturing processes such as laser-powder bed fusion (L-PBF) have gained attention and importance due to the potential to produce complex-shaped three-dimensional parts for various industries. In order to manufacture three-dimensional components from 17-4 PH stainless steel powder using L-PBF, it is critical for design and manufacturing engineers to have an awareness of various material options and corresponding processing and postprocessing conditions to obtain useful mechanical properties from the process. The goal of this dissertation is to establish a fundamental understanding of the material-processproperty relationships of 17-4 PH stainless steel processed by laser-powder bed fusion (LPBF). The investigation was carried out to understand the effects of post-processing 
treatment cycles such as hot isostatic pressing (HIP) on the densification, mechanical properties, corrosion properties and microstructures of L-PBF parts fabricated at various energy densities using 17-4 PH stainless steel gas- and water-atomized powders. The microstructure formation and its impact on mechanical and corrosion properties due to different HIP treatment cycles were studied for 17-4 PH stainless steel gas and wateratomized L-PBF parts at various energy densities. The most significant aspect of this work is that density, microstructures, mechanical and corrosion properties of $17-4 \mathrm{PH}$ stainless steel can be vastly improved and reliable properties can be achieved irrespective of starting powder attributes and L-PBF process conditions by using HIP treatment. Further, the properties obtained after the HIP treatment was less sensitive to variations in powder characteristics (size distribution and shape) and energy density during processing and were superior to known reported properties of 17-4 PH stainless steel fabricated by L-PBF, powder metallurgy, metal injection molding, or wrought samples. 


\section{TABLE OF CONTENTS}

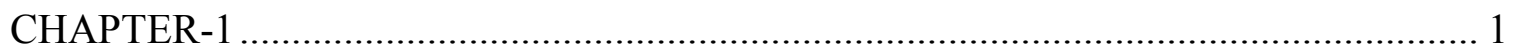

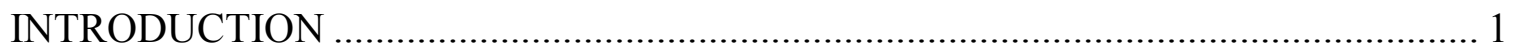

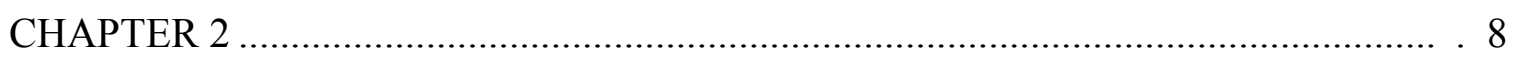

EFFECTS OF HOT ISOSTATIC PRESSING ON THE DENSIFICATION, MECHANICAL PROPERTIES AND MICROSTRUCTURES OF ................................ 8

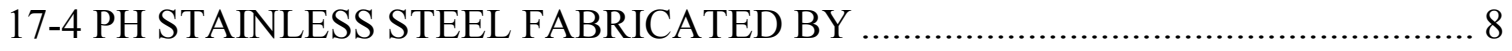

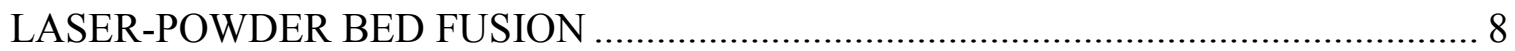

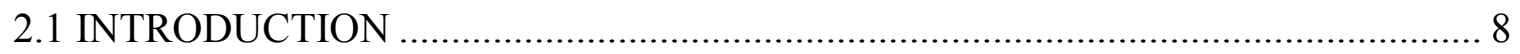

2.2 EXPERIMENTAL MATERIALS AND METHODS .......................................... 9

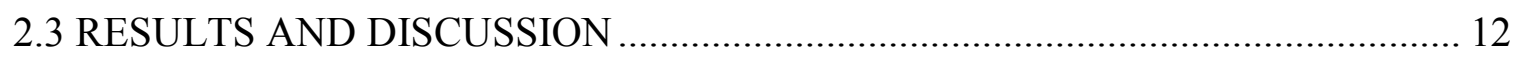

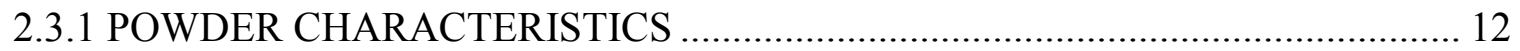

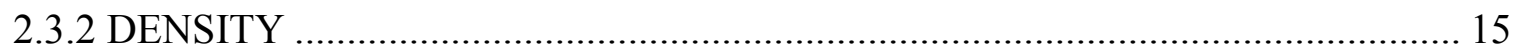

2.3.3 MECHANICAL PROPERTIES AND MICROSTRUCTURES ........................... 18

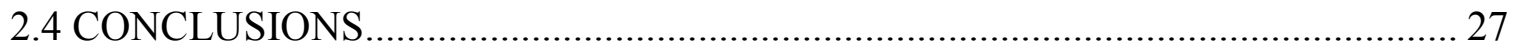

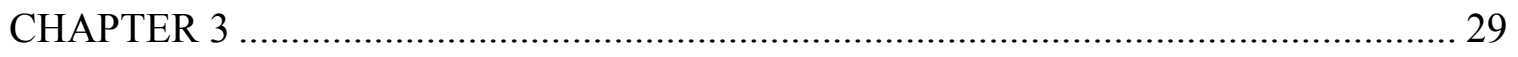

PROPERTY GAINS FROM HOT ISOSTATIC PRESSING OF 17-4 PH STAINLESS

STEEL GAS AND WATER-ATOMIZED PARTS FABRICATED BY LASER-

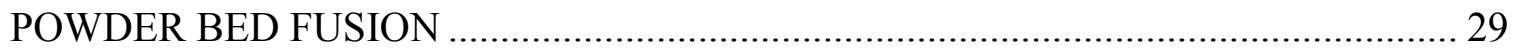

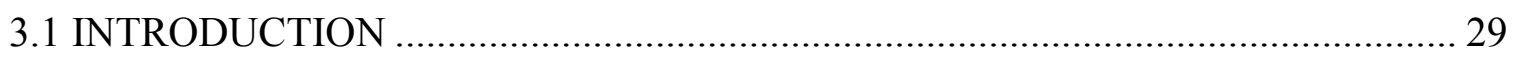




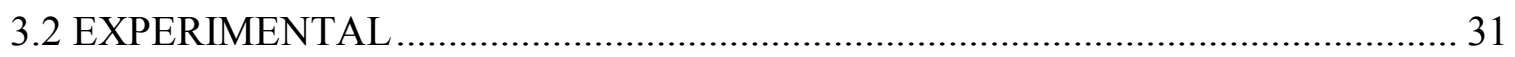

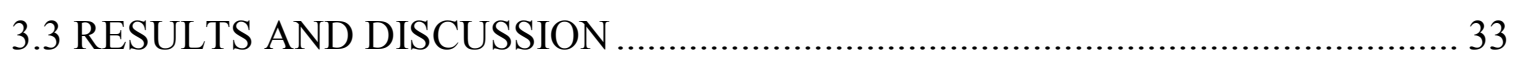

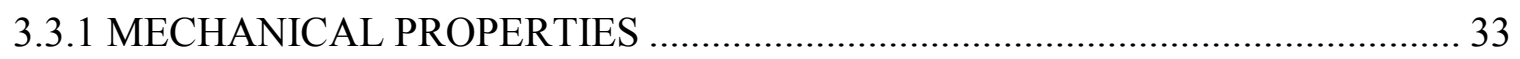

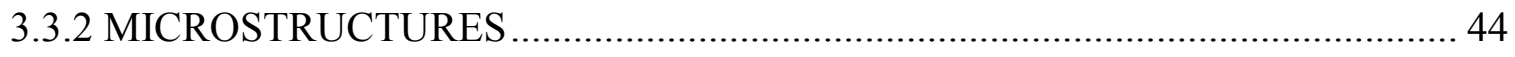

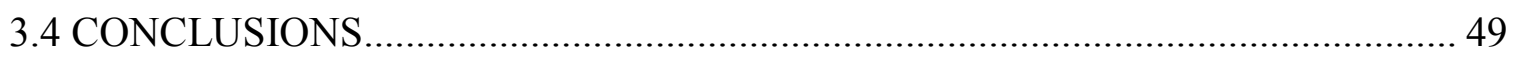

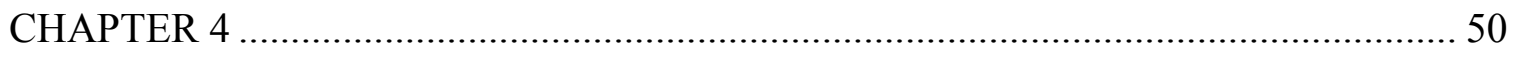

EFFECTS OF POWDER CHARACTERISTICS AND PROCESSING CONDITIONS

ON THE CORROSION PERFORMANCE OF 17-4 PH STAINLESS STEEL

FABRICATED BY LASER-POWDER BED FUSION.............................................. 50

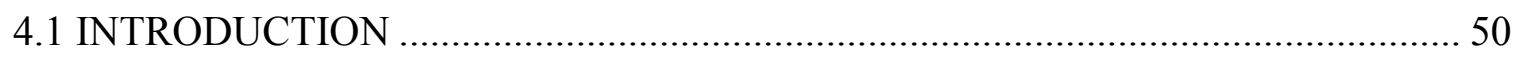

4.2 EXPERIMENTAL MATERIALS AND METHODS ............................................. 53

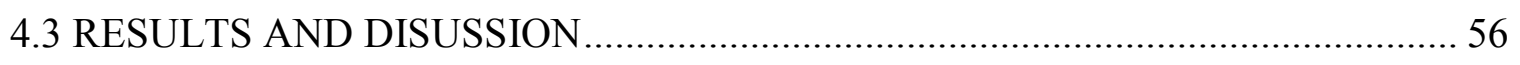

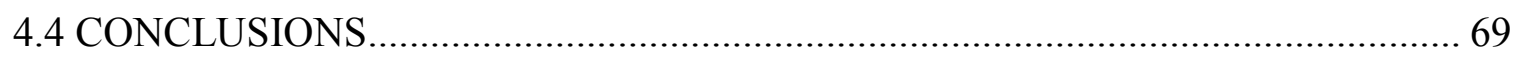

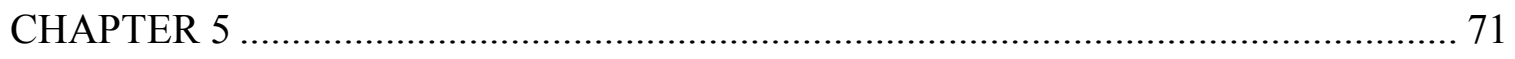

EFFECTS OF HOT ISOSTATIC PRESSING ON THE CORROSION PERFORMANCE OF 17-4 PH STAINLESS STEEL GAS -AND WATER-ATOMIZED PARTS

FABRICATED USING LASER-POWDER BED FUSION ………………………....... 71

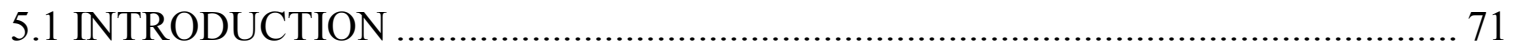

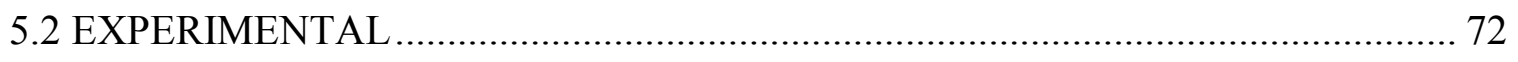

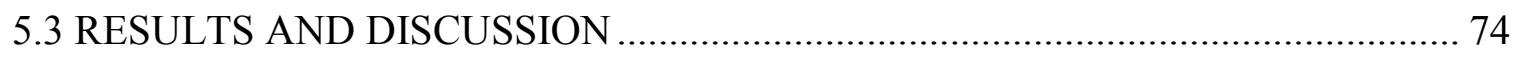

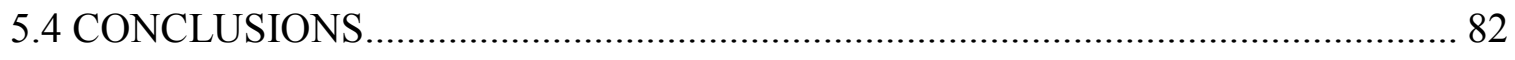

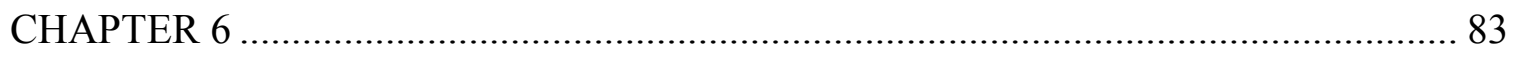

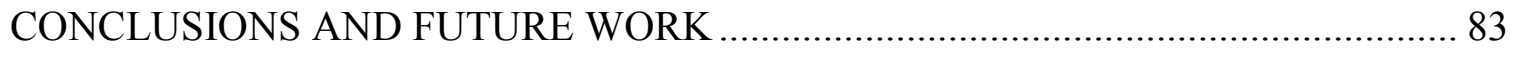




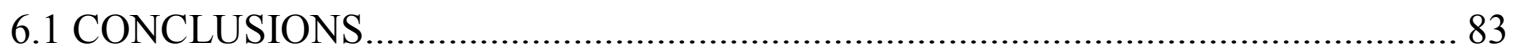

6.1.1 MECHANICAL PROPERTIES AND MICROSTRUCTURES ............................ 84

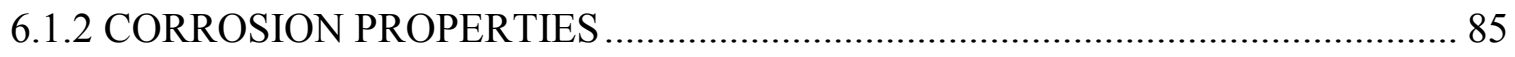

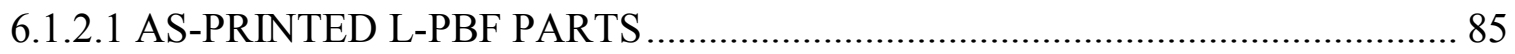

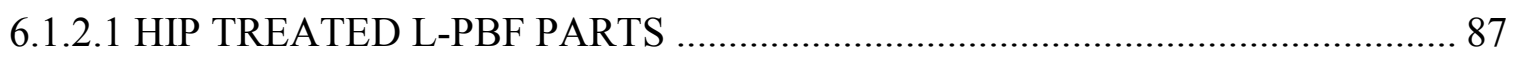

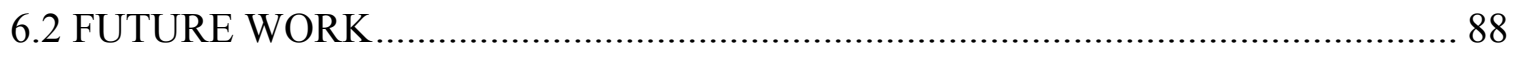

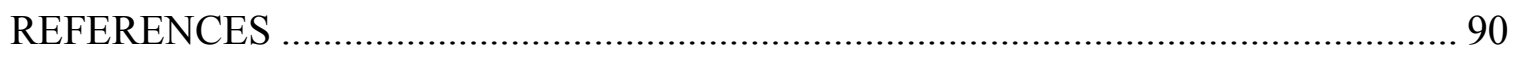

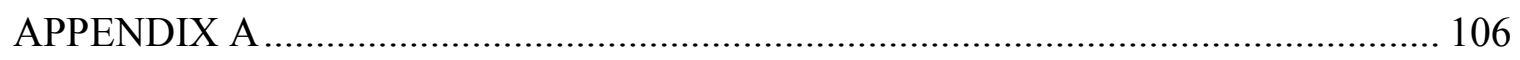

EFFECTS OF ATOMIZING MEDIA AND POST PROCESSING ON MECHANICAL

PROPERTIES OF 17-4 PH STAINLESS STEEL MANUFACTURED VIA

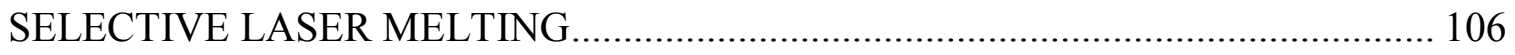

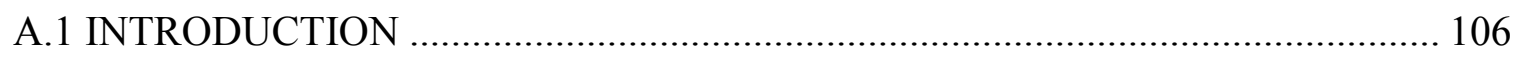

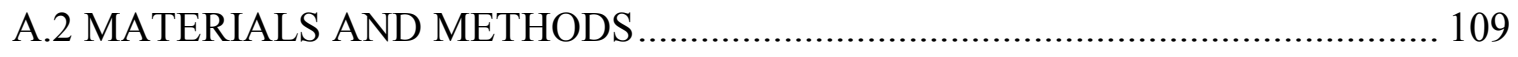

A.3 RESULTS AND DISCUSSION ..................................................................... 111

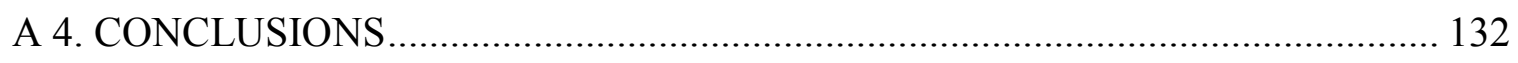

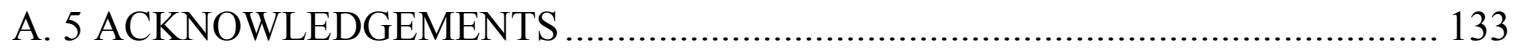

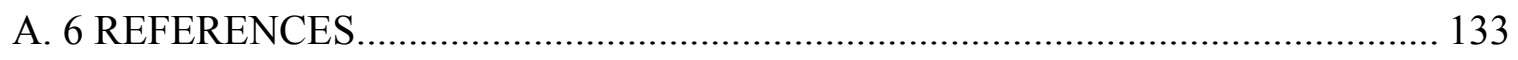

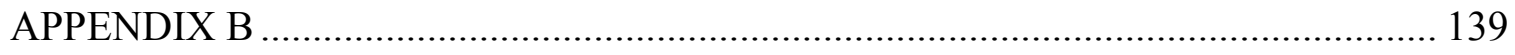

HEAT TREATMENT STUDIES ON 17-4 PH STAINLESS STEEL PARTS

FABRICATED BY LASER-POWDER BED FUSION ............................................. 139

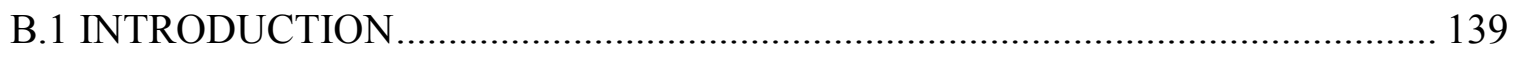

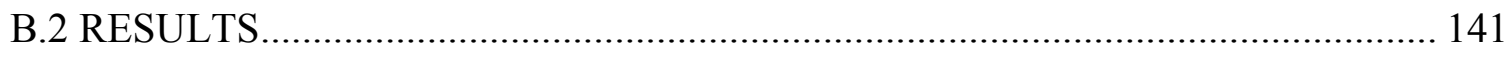

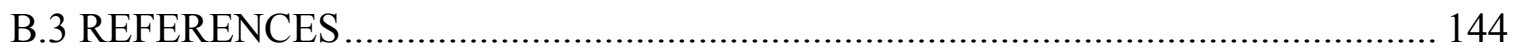


APPENDIX C 146 EFFECTS OF INITIAL POWDER ATTRIBUTES AND PROCESS CONDITIONS ON THE RECYCLABILITY OF 17-4 PH STAINLESS STEEL POWDER IN

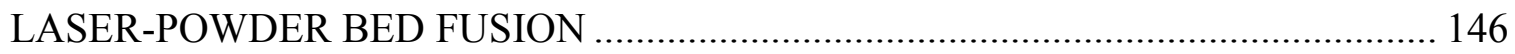

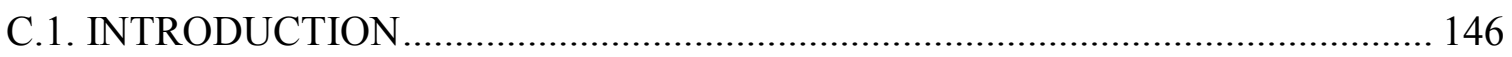

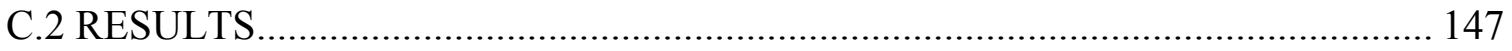

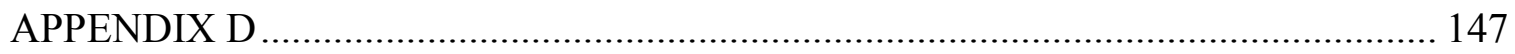

UOFL 3D PRINTING BUSINESS INCUBATOR: INTEGRATING PRODUCT

DESIGN, PROCESSING AND MARKET ANALYSIS FOR MANUFACTURING

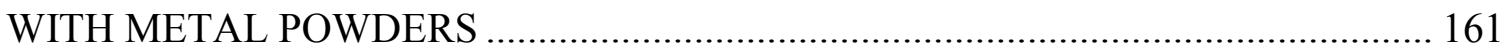

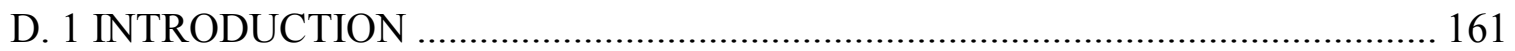

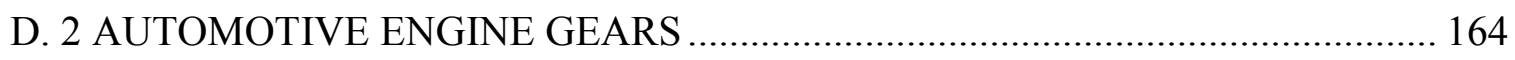

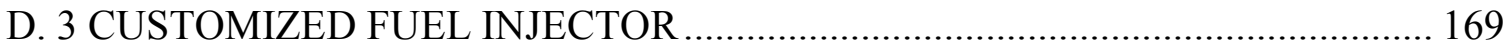

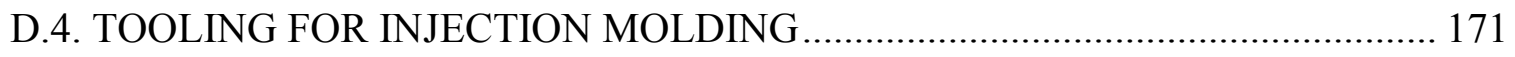

D.5. SUMMARY AND FUTURE OUTLOOK …………....................................... 174

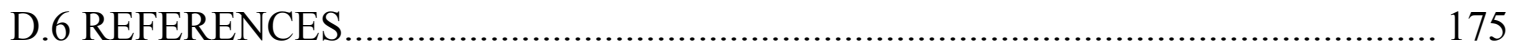

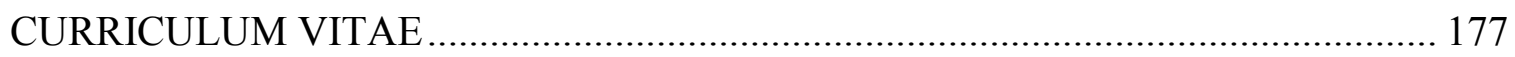




\section{LIST OF TABLES}

PAGE

2.1. L-PBF processing conditions and the corresponding energy densities used in this study.

2.2. The chemical composition of 17-4 PH stainless steel gas and water-atomized powders.

2.3. Particle characteristics of the17-4 PH stainless steel gas- and water-atomized powders

3.1. The density, mechanical properties and microstructure variation in $17-4 \mathrm{PH}$ stainless steel gas-and water-atomized L-PBF parts following HIP

treatment

4.1. Particle characteristics of the17-4 PH stainless steel gas- and water-atomized powders

4.2. Densities (expressed as \% theoretical) of the $17-4 \mathrm{PH}$ stainless steel gas- and wateratomized L-PBF parts fabricated under energy densities ranging from 64 to 104

$\mathrm{J} / \mathrm{mm}^{3}$

5.1. The variation in density, hardness, martensite content and average grain size of fabricated from various powders by L-PBF at an energy density $104 \mathrm{~J} / \mathrm{mm}^{3}$, before and after HIP treatment. .78 
5.2. The variation in corrosion current and corrosion potential of 17-4 PH stainless steel parts fabricated by L-PBF at an energy density $104 \mathrm{~J} / \mathrm{mm}^{3}$, before and after HIP treatment.

5.3. The variation in polarization resistance and corrosion rate of 17-4 PH stainless steel parts fabricated by L-PBF at an energy density $104 \mathrm{~J} / \mathrm{mm}^{3}$, before and after HIP treatment.

A.1. Chemical composition of 17-4 PH stainless steel for gas-atomized and wateratomized powders (wt.\%)

A.2. Particle size distribution of the17-4 PH stainless steel gas-atomized and wateratomized powders.

A.3. Mechanical properties at energy density of 64 and $104 \mathrm{~J} / \mathrm{mm}^{3}$ - solutionized at 1051

${ }^{\circ} \mathrm{C}$ and aged at $482{ }^{\circ} \mathrm{C}$ (wrought values are taken from literature).

A.4. Variation in mechanical properties at energy density of 64 and $104 \mathrm{~J} / \mathrm{mm}^{3}$ -

solutionized at $1315^{\circ} \mathrm{C}$ and aged at $482{ }^{\circ} \mathrm{C}$

B.1. The variation in density $\left(\mathrm{g} / \mathrm{cm}^{3}\right)$ of $17-4 \mathrm{PH}$ stainless steel L-PBF parts due to heat treatment at energy density $64 \mathrm{~J} / \mathrm{mm}^{3}$ 146

B.2. The variation in density $\left(\mathrm{g} / \mathrm{cm}^{3}\right)$ of $17-4 \mathrm{PH}$ stainless steel L-PBF parts due to heat treatment at energy density $104 \mathrm{~J} / \mathrm{mm}^{3}$ 146

D.1. Comparison of dimensions of 3D printed, powder metallurgy gears with $\mathrm{CAD}$ model

D.2. Performance comparison of 3D printed fuel injector with and without cooling channels 


\section{LIST OF FIGURES}

Figure 1.1. The material-process-property relationship in 17-4 PH stainless steel gas- and water-atomized L-PBF parts when fabricated at energy density $104 \mathrm{~J} / \mathrm{mm} 3[1]-[4] \ldots \ldots . . .3$ Figure 1.2.The material-process-property relationship in 17-4 PH stainless steel gas- and water-atomized L-PBF parts when fabricated at energy density $64 \mathrm{~J} / \mathrm{mm} 3[1]-[4] \ldots \ldots \ldots . . .4$ Figure 2.1.Particle size distributions of the 17-4 PH stainless steel powders used in this study (a) gas-atomized powder D50 $=13 \mu \mathrm{m}$ (b) water-atomized powder D50 $=43 \mu \mathrm{m} .13$ Figure 2.2.SEM images of the 17-4 PH stainless steel powders used in this study (a) gasatomized powder $(\mathrm{D} 50=13 \mu \mathrm{m})(\mathrm{b})$ water-atomized powder $(\mathrm{D} 50=43 \mu \mathrm{m})$ 14 Figure 2.3.XRD analysis for the 17-4 PH stainless steel gas- and water-atomized powders showing the presence of $\alpha$ and $\gamma$ phases 15 Figure 2.4.The \% theoretical density values of 17-4 PH stainless gas- and water-atomized L-PBF parts produced at energy densities $64,80,84,104 \mathrm{~J} / \mathrm{mm}^{3}$ before and after HIP treatment

Figure 2.5.Optical micrographs of HIP and as-printed water-atomized $\mathrm{D}_{50}=43 \mu \mathrm{m} \ldots \ldots .18$

Figure 2.6.Optical micrographs of HIP and as-printed gas-atomized $\mathrm{D}_{50}=13 \mu \mathrm{m} \ldots \ldots \ldots 18$ Figure 2.7.Variation of the ultimate tensile strength of 17-4 PH stainless gas- and wateratomized L-PBF parts before and after HIP treatment as a function of energy density ... 19 
Figure 2.8.XRD patterns of HIP and as-printed 17-4 PH stainless water-atomized L-PBF parts perpendicular to the build direction produced at energy densities $64,80,84$ and 104 $\mathrm{J} / \mathrm{mm}^{3}$ 20

Figure 2.9.XRD patterns of HIP and as-printed 17-4 PH stainless gas-atomized L-PBF parts perpendicular to the build direction produced at energy densities 64, 80, 84 and 104 $\mathrm{J} / \mathrm{mm}^{3}$ 21

Figure 2.10.The hardness of HIP and as-printed 17-4 PH stainless gas- and wateratomized L-PBF parts produced at energy densities $64,80,84,104 \mathrm{~J} / \mathrm{mm}^{3}$.............. 23 Figure 2.11.The yield strength of HIP and as-printed 17-4 PH stainless gas- and wateratomized L-PBF parts produced at energy densities 64, 80, 84, $104 \mathrm{~J} / \mathrm{mm}^{3}$ 24 Figure 2.12.Microstructures of HIP and as-printed 17-4 PH stainless water-atomized LPBF parts produced at energy densities $64,80,84,104 \mathrm{~J} / \mathrm{mm}^{3}$ 25 Figure 2.13.Microstructures of HIP and as-printed 17-4 PH stainless gas-atomized L-PBF parts produced at energy densities $64,80,84,104 \mathrm{~J} / \mathrm{mm}^{3}$ 25

Figure 2.14. The \% elongation of HIP and as-printed 17-4 PH stainless gas- and wateratomized L-PBF parts produced at energy densities $64,80,84,104 \mathrm{~J} / \mathrm{mm}^{3}$. 27 Figure 3.1.SEM micrographs of the four 17-4 PH stainless steel powders (a) gasatomized powder $\mathrm{D}_{50}=13 \mu \mathrm{m}$ (b) water-atomized powder $\mathrm{D}_{50}=17 \mu \mathrm{m}$, (c) wateratomized powder $\mathrm{D}_{50}=24 \mu \mathrm{m},(\mathrm{d})$ water-atomized powder $\mathrm{D}_{50}=43 \mu \mathrm{m}$ 31 Figure 3.2.Hot-isostatic pressing processing conditions (temperature, pressure and time) used for post-processing as-printed 17-4 PH stainless steel gas-and water-atomized L-PBF parts. 
Figure 3.3.The density of 17-4 PH stainless steel gas-and water-atomized L-PBF parts before and after HIP treatment as a function of energy density. 36

Figure 3.4.The variation in ultimate tensile strength with energy density for 17-4 PH stainless steel gas-and water-atomized L-PBF parts before and after HIP treatment...... 40 Figure 3.5.The variation in hardness with energy density for 17-4 PH stainless steel gasand water-atomized L-PBF parts before and after HIP treatment. 41 Figure 3.6.The variation in yield strength with energy density for 17-4 PH stainless steel gas-and water-atomized L-PBF parts before and after HIP treatment. 42 Figure 3.7.The variation in elongation with energy density for 17-4 PH stainless steel gas-and water-atomized L-PBF parts before and after HIP treatment. 43 Figure 3.8.The XRD phases in gas and water-atomized L-PBF parts before and after HIP treatment for parts fabricated at energy densities of $64,80,84$ and $104 \mathrm{~J} / \mathrm{mm}^{3}$ 45 Figure 3.9.The microstructures of gas and water-atomized L-PBF parts before and after HIP treatment for parts fabricated at energy densities of 64 and $104 \mathrm{~J} / \mathrm{mm}^{3}$. 46 Figure 4.1.17-4 PH stainless steel L-PBF parts fabricated by our research group in design collaboration with various industries (a) Fuel injector with conformal cooling channels (Cummins, Columbus, OH) (b) helicopter engine part (Helicopter Transport Services, Portland, OR) (c) automotive engine gear (Cummins, Columbus, OH) (d) plastic injection mold with conformal cooling channels (Amaray Plastic Inc., Elizabethtown, $\mathrm{KY})$. 51

Figure 4.2.Electrochemical corrosion studies setup used in this study 54 Figure 4.3.SEM images of the 17-4 PH stainless steel gas- and water-atomized powders used in this study (a) gas-atomized powder $\left(\mathrm{D}_{50}=13 \mu \mathrm{m}\right)(\mathrm{b})$ water-atomized powder $\left(\mathrm{D}_{50}\right.$ xvi 
$=17 \mu \mathrm{m})(\mathrm{c})$ water-atomized powder $\left(\mathrm{D}_{50}=24 \mu \mathrm{m}\right)$ and $(\mathrm{d})$ water-atomized powder $\left(\mathrm{D}_{50}=\right.$

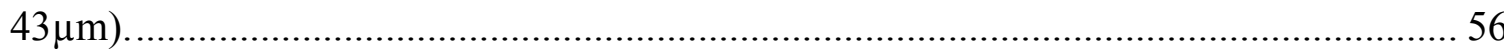

Figure 4.4.Tafel plots of the components fabricated from four 17-4 PH stainless steel powders fabricated at (a) energy density $64 \mathrm{~J} / \mathrm{mm}^{3}$ (b) energy density $80 \mathrm{~J} / \mathrm{mm}^{3}$ (c) energy density $84 \mathrm{~J} / \mathrm{mm}^{3}$ and (d) energy density $104 \mathrm{~J} / \mathrm{mm}^{3}$.

Figure 4.5. Schematic diagram showing the extracting of corrosion current and constants from a Tafel plot.

Figure 4.6.Variation in corrosion current with \% theoretical density and energy density for samples fabricated using (a) gas-atomized $\left(\mathrm{D}_{50}=13 \mu \mathrm{m}\right)$ and water-atomized $\left(\mathrm{D}_{50}=17\right.$ $\mu \mathrm{m})$ powders (b) water-atomized ( $\mathrm{D}_{50}=24 \mu \mathrm{m}$ and $43 \mu \mathrm{m}$ ) powders. The symbols represent the four powders and the colors represent the four energy densities used in the fabrication. 61

Figure 4.7.Variation in polarization resistance as a function of $\%$ theoretical density and energy density for samples fabricated using (a) gas-atomized $\left(\mathrm{D}_{50}=13 \mu \mathrm{m}\right)$ and wateratomized $\left(\mathrm{D}_{50}=17 \mu \mathrm{m}\right)$ powders $(\mathrm{b})$ water-atomized $\left(\mathrm{D}_{50}=24 \mu \mathrm{m}\right.$ and $\left.43 \mu \mathrm{m}\right)$ powders. The symbol represent the four powders and the colors represent the four energy densities used in the fabrication. 64

Figure 4.8.Variation in corrosion rate as a function of $\%$ theoretical density and energy density for samples fabricated using (a) gas-atomized $\left(\mathrm{D}_{50}=13 \mu \mathrm{m}\right)$ and water-atomized $\left(\mathrm{D}_{50}=17 \mu \mathrm{m}\right)$ powders $(\mathbf{b})$ water-atomized $\left(\mathrm{D}_{50}=24 \mu \mathrm{m}\right.$ and $\left.43 \mu \mathrm{m}\right)$ powders. The symbols represent the four powders and the colors represent the four energy densities used in the fabrication. 
Figure 4.9. Optical microscopy of samples fabricated at energy density $64 \mathrm{~J} / \mathrm{mm}^{3}$ using four 17-4 PH stainless steel powders acquired before and after conducting potentiostatic polarization experiments in $0.5 \mathrm{M} \mathrm{NaCl}$ solution. 68

Figure 4.10.Optical microscopy of samples fabricated at energy density $104 \mathrm{~J} / \mathrm{mm}^{3}$ using four 17-4 PH stainless steel powders acquired before and after conducting potentiostatic polarization experiments in $0.5 \mathrm{M} \mathrm{NaCl}$ solution. 68

Figure 5.1.SEM micrographs of the four 17-4 PH stainless steel powders (a) gasatomized powder $\mathrm{D}_{50}=13 \mu \mathrm{m}$ (b) water-atomized powder $\mathrm{D}_{50}=17 \mu \mathrm{m}$, (c) wateratomized powder $\mathrm{D}_{50}=24 \mu \mathrm{m},(\mathrm{d})$ water-atomized powder $\mathrm{D}_{50}=43 \mu \mathrm{m}$ 73 Figure 5.2.Optical micrographs of 17-4 PH stainless steel parts fabricated using various powders by L-PBF at an energy density $104 \mathrm{~J} / \mathrm{mm}^{3}$, before and after HIP treatment...... 77 Figure 5.3.Tafel plots of 17-4 PH stainless steel parts fabricated with various powder by L-PBF at an energy density $104 \mathrm{~J} / \mathrm{mm}^{3}$, before and after HIP treatment. 78 Figure 5.4.Optical micrographs following corrosion tests of HIP treated and as-printed 17-4 PH stainless steel parts fabricated by L-PBF at energy density $104 \mathrm{~J} / \mathrm{mm}^{3}$ using gas and water-atomized powders. 81 Figure A.1.Morphology of 17-4 PH SS powder: (a) gas atomized powder and (b) water atomized powder [29]. 113 Figure A.2.The XRD pattern of 17-4 PH powders (a) gas-atomized and (b) wateratomized. 116 Figure A.3.Optical micrographs of as printed 17-4 PH SS powder perpendicular to the build direction: (a) gas-atomized at $64 \mathrm{~J} / \mathrm{mm}^{3}$, (b) gas-atomized at $104 \mathrm{~J} / \mathrm{mm}^{3}$, (c) wateratomized at $64 \mathrm{~J} / \mathrm{mm}^{3}$ and (d) water-atomized at $104 \mathrm{~J} / \mathrm{mm}^{3}$. 117 
Figure A.4. The XRD patterns of gas-atomized and water-atomized powder printed at (a) $64 \mathrm{~J} / \mathrm{mm}^{3}$ and (b) $104 \mathrm{~J} / \mathrm{mm}^{3}$ 119

Figure A.5. Optical micrographs, parallel to the build direction, of as printed 17-4 PH SS powder at $64 \mathrm{~J} / \mathrm{mm}^{3}$ (a) gas-atomized, (b) water-atomized and at $104 \mathrm{~J} / \mathrm{mm}^{3}$ (c) gasatomized, (d) water-atomized.

Figure A.6. The optical micrographs of heat treated parts (solutionized at $1051{ }^{\circ} \mathrm{C}$ and aged at $482{ }^{\circ} \mathrm{C}$ ) perpendicular to the build direction: (1) gas-atomized at $64 \mathrm{~J} / \mathrm{mm}^{3}, \ldots .122$ Figure A.7. The XRD pattern of (a) gas-atomized and (b) water-atomized printed at 64 and $104 \mathrm{~J} / \mathrm{mm}^{3}$ and heat treated (solutionized at $1051^{\circ} \mathrm{C}$ and aged at $482{ }^{\circ} \mathrm{C}$ ). 122 Figure A.8. The optical micrographs of heat treated parts (solutionized at $1315^{\circ} \mathrm{C}$ and aged at $482{ }^{\circ} \mathrm{C}$ ) perpendicular to the build direction: (1) gas-atomized at $64 \mathrm{~J} / \mathrm{mm}^{3}, \ldots .124$ Figure A.9.Scheil mnon-equilibrium solidification of (a) gas-atomized and (b) wateratomized powder simulation show solid phase during solidification. Figure A.10. TEM micrographs from gas-atomized 17-4 PH powder after SLM at energy density of $104 \mathrm{~J} / \mathrm{mm}^{3}$ - followed by solutionizing at $1315^{\circ} \mathrm{C}$ and aging at $482{ }^{\circ} \mathrm{C}: \ldots . .130$ Figure A..11. TEM micrographs from water-atomized 17-4 PH powder after SLM at energy density of $104 \mathrm{~J} / \mathrm{mm}^{3}$ - followed by solutionizing at $1315^{\circ} \mathrm{C}$ and aging at...... 131 Figure B.2. The variation in the ultimate tensile strength of 17-4 PH stainless steel wateratomized $\mathrm{D}_{50}=43 \mu \mathrm{m}$ L-PBF parts due to heat treatment at various energy densities.. 143 Figure B.2. The microstructures of 17-4 PH stainless steel water- atomized $\mathrm{D}_{50}=43 \mu \mathrm{m}$ L-PBF parts due to heat treatment-1 at various energy densities 143 Figure C.1. SEM images of recycled 17-4 PH stainless steel gas-atomized $\left(\mathrm{D}_{50}=13 \mu \mathrm{m}\right)$ powder at energy density $104 \mathrm{~J} / \mathrm{mm}^{3}$ 159 
Figure C.2.XRD pattern of the recycled 17-4 PH stainless steel gas-and water-atomized

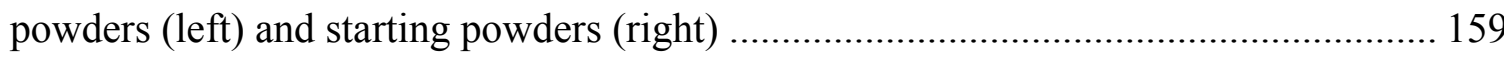

Figure C.3. XRD pattern of the recycled 17-4 PH stainless steel gas-and water-atomized powders (left) and corresponding L-PBF parts (right) processed at an energy density of

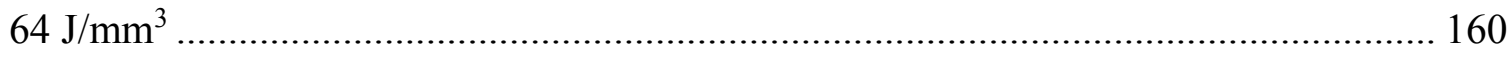




\section{CHAPTER 1}

\section{INTRODUCTION}

Laser powder bed fusion (L-PBF), popularly known as selective laser melting (SLM) process uses a focused laser beam to melt metal powders layer-by-layer into threedimensional parts, based on CAD file [1]-[4]. To fabricate three-dimensional components using the L-PBF process, a design engineer needs understand the metal powder-laser interactions during the L-PBF process and their impact on the mechanical properties and microstructures of the L-PBF parts. In L-PBF, it is widely recognized that laser-powder interactions are affected by processing conditions (e.g. laser power, scan speed, hatch spacing and layer thickness) and powder characteristics ( e.g. size, shape, and purity) for the successful fabrication of parts with desired properties [5]-[9]. However, there remains a wide gap in the understanding material-process-property relationships affected by powder attributes and processing conditions in L-PBF.

Typically, gas-atomized powders with a spherical shape and narrow particle size distribution (5 to $45 \mu \mathrm{m}$ ) have been preferred for fabricating parts using L-PBF [2], [3], [6], [8], [10]-[12]. However, such powders are inherently expensive as they use large amounts of inert process gas as well as only a small fraction (typically $30 \pm 15 \mu \mathrm{m}$ ) of the production lot in each atomization run [2], [3], [6], [13]. 
On the other hand, water-atomized powders are relatively less expensive but are irregular in shape with variation in particle size distribution. The ability to fabricate high-density LPBF parts from irregular water-atomized powders with properties competitive to parts fabricated using gas-atomized powders has not been convincingly demonstrated in the open literature [2], [3], [6], [13]. In this regard, previous studies reported by our group have shown the feasibility of fabricating L-PBF parts using 17-4 PH stainless steel fine wateratomized powders and achieving the properties similar or higher than 17-4 PH stainless steel gas-atomized parts in certain processing conditions, e.g. at an energy density of 104 $\mathrm{J} / \mathrm{mm}^{3}$ as shown in Figure 1.1 [1]-[4]. However, some porosity and variation in phase content in the microstructure still existed in water-atomized powders that impacted the mechanical properties of the 17-4 PH stainless steel L-PBF parts, especially at lower energy density, e.g. at an energy density of $64 \mathrm{~J} / \mathrm{mm}^{3}$ (Figure 1.2). The results obtained from these research studies were published in three peer-reviewed journal papers [1], [2], [14]. 


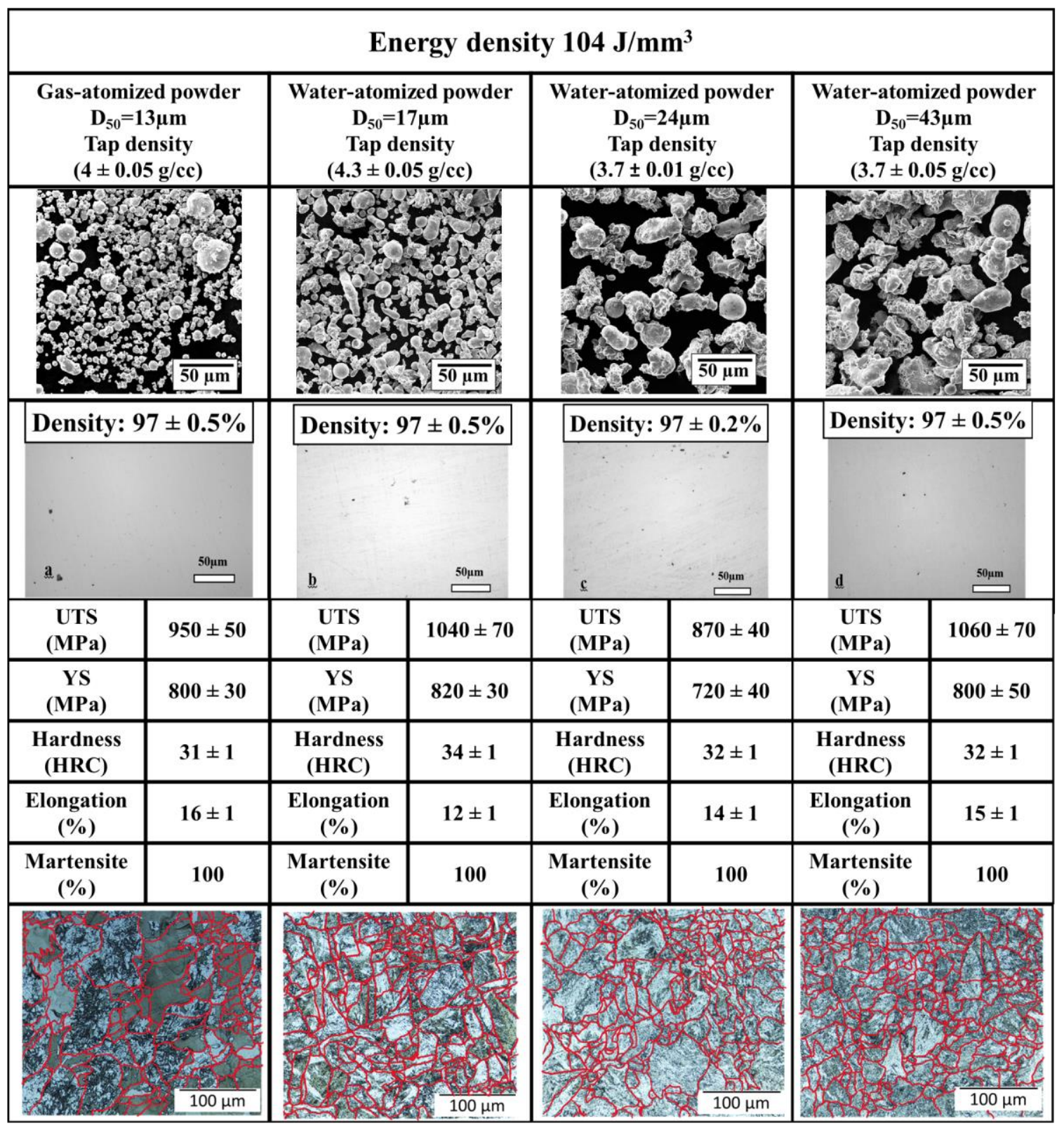

Figure 0.1. The material-process-property relationship in 17-4 PH stainless steel gas- and water-atomized L-PBF parts when fabricated at energy density $104 \mathrm{~J} / \mathrm{mm} 3$ [1]-[4] 


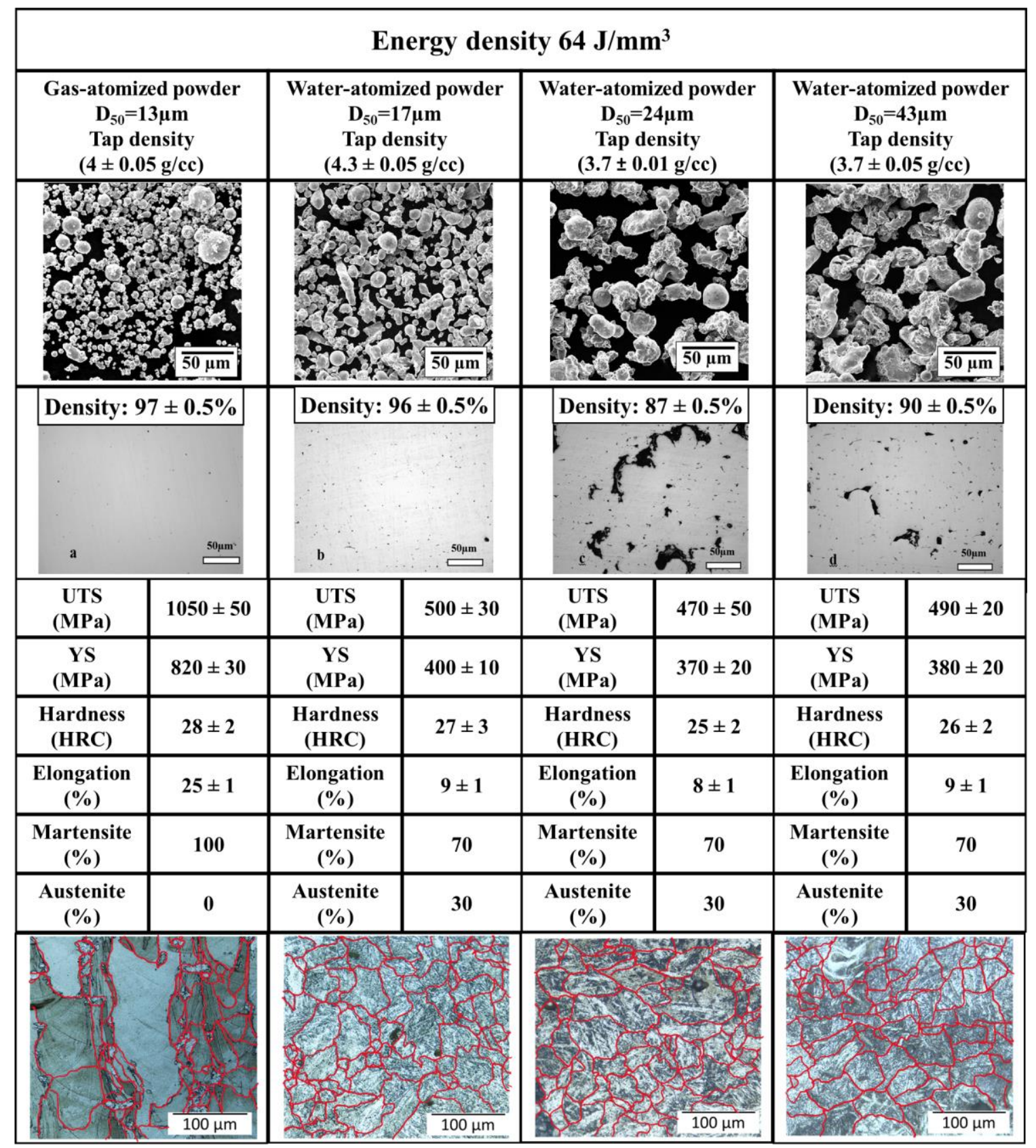

Figure 0.2.The material-process-property relationship in 17-4 PH stainless steel gas- and water-atomized L-PBF parts when fabricated at energy density $64 \mathrm{~J} / \mathrm{mm} 3$ [1]-[4]

In powder metallurgy, hot isostatic pressing (HIP) is routinely performed to eliminate porosity and anisotropy in the metal parts. Several HIP studies have emerged in recent times to improve the densification and mechanical properties of L-PBF parts using various materials such as Hastelloy, 316L stainless steel, CoCr and Ti-6Al-4V alloys [15]-[24]. 
However, no study in the literature studies the effect of HIP on the densification, mechanical properties and microstructures of 17-4 PH stainless steel L-PBF parts. In order to address the above gap, the current thesis builds off our earlier work [25] focuses on the effects of HIP and heat treatment on the densification, mechanical properties, corrosion properties and microstructures of the 17-4 PH stainless steel gas and water-atomized LPBF parts when fabricated at various energy densities.

Chapter 2 presents an understanding on the effects of a standard HIP cycle on the densification, mechanical properties and microstructures L-PBF parts fabricated from 17$4 \mathrm{PH}$ stainless steel gas and water-atomized powders at various L-PBF processing conditions. The results from the current study will provide a better understanding of the effect of post-processing method such as HIP on the densification, mechanical properties and microstructure of L-PBF parts. The work presented in Chapter $\mathbf{2}$ has been submitted to a peer-reviewed journal Journal of the American Ceramic Society in 2018 and is currently under review.

Chapter 3 builds from the work presented in Chapter 2 and the effects of modified HIP cycle is scaled to L-PBF parts fabricated from four different powders with varying shape and size attributes at different processing conditions. Chapter 3 presents the effect of HIP on the densification behavior, mechanical properties, phase and microstructure development of the 17-4 PH stainless steel gas- and water-atomized parts processed by LPBF. A part of the research presented in Chapter 3 presented in "Additive ManufacturingPowder Metallurgy Conference" 2018 and the entire work presented in Chapter 3 is currently under preparation for submission to the Additive Manufacturing refereed journal. 
Chapter 4 of the thesis examines the role of powder characteristics and processing conditions on the corrosion properties of 17-4 PH stainless steel fabricated using L-PBF. Our previous studies indicated that powder characteristics and processing conditions are known to strongly influence the densification and mechanical properties of parts fabricated by the L-PBF process. However, the influence of powder attributes and L-PBF process parameters on the corrosion performance of parts has not been studied extensively. In this regard, the work present in Chapter 4 compares the corrosion performance of the 17-4 PH stainless steel L-PBF parts fabricated from powders of different characteristics such as shape, size and the method utilized for atomization (gas-atomized or water-atomized) at various processing conditions. The corrosion performance of the L-PBF parts was evaluated using corrosion current, polarization resistance and corrosion rate values from the linear sweep voltammetry curves. The collected data from the Chapter 4 is expected to provide a better understanding of the effect of porosity, density and microstructures on the corrosion performance of 17-4 PH stainless steel L-PBF gas- and water-atomized parts. The work presented in Chapter 4 was published in the peer-reviewed journal Progress in Additive Manufacturing in 2018 [26].

Chapter 5 of this thesis builds form the wrok presented in Chapters 3 and $\mathbf{4}$ and studies the effects of modified hot isostatic pressing on the corrosion perfomance of 17-4 PH stainless steel gas- and water-atomized L-PBF parts. The entire work presented in Chapter 2 is currently under preparation for submission to the Journal of the Minerals, Metals and Materials Society referred journal. 
The work presented in Appendix A is a collaboration work with Prof. Somayeh Pasebani's group at the Oregon State University. The work focuses on the effects of post-processing (solution annealing and aging) on mechanical properties and microstructures of 17-4 PH stainless steel gas- and water-atomized L-PBF parts when fabricated at various energy densities. The work was published in peer-reviewed journal Additive Manufacturing in $2018[3]$.

Appendix B reports the mechanical properties and microstructures data of the L-PBF parts fabricated from 17-4 PH stainless steel gas- and water- atomized powders when they are post-processed using various heat-treatment cycles. The work presented in Appendix B is an expansion of the work in Appendix A and will be the subject of future work to scale it into a refereed journal paper.

The desire to improve the sustainability and efficiency of the L-PBF process drives the requirement for recycling of starting powders that are unused during part fabrication. The data presented in Appendix $\mathbf{C}$ provides an initial understanding (qualitatively and quantitively) on how the powder shape and size varies as a function of starting powder characteristics and L-PBF processing conditions.

Appendix D provides data on the applications that have been developed using L-PBF process for aerospace, healthcare and automotive industries. The applications were developed based on materials-design-process relationship work presented in this thesis. A part of this work was published in "Powder Metallurgy Review" magazine in 2018 [27]. 


\title{
CHAPTER 2
}

\author{
EFFECTS OF HOT ISOSTATIC PRESSING ON THE DENSIFICATION, \\ MECHANICAL PROPERTIES AND MICROSTRUCTURES OF \\ 17-4 PH STAINLESS STEEL FABRICATED BY \\ LASER-POWDER BED FUSION
}

\subsection{INTRODUCTION}

Laser powder bed fusion (L-PBF), alternately known as selective laser melting (SLM) is a powder-based process that uses focused laser energy to melt the metallic powders into solid parts. In the L-PBF process, the laser-powder interactions are largely affected by processing conditions such as laser power, scan speed, hatch spacing and layer thickness [28], [9], [29]-[34], [7], [35]. In general, the above processing conditions along with powder characteristics such as size, shape, and purity, significantly determine the density, microstructures and properties obtained from L-PBF parts [6], [32]-[34], [36]-[41]. In our former work [1], [2], a comprehensive study was performed to understand the role powder characteristics such as powder type, shape and size along with L-PBF processing conditions on densification, mechanical properties and microstructure of 17-4 PH stainless steel L-PBF parts. It was found that the \% theoretical density, ultimate tensile strength, hardness of L-PBF parts are sensitive to L-PBF processing conditions and starting powder shape, size and type. An 
important result of that study was a large variation in density, mechanical properties and microstructures were observed L-PBF parts printed with different powder attributes. Most of the research studies indicated that defects and anisotropy in the mechanical properties of L-PBF parts could be eliminated using post-processing methods such as hot isostatic pressing (HIP). Tillmann et al [20] discussed the efficiency of the HIP in decreasing the porosity and enhancing the mechanical properties of IN718 L-PBF parts. Many research groups performed HIP studies on various materials such as HastealloyX [15], [18], [42], 316L stainless steel [16], [17], CoCr [19]and Ti-6Al-4V alloys [23], [24]. However, there has been limited work performed on the elimination of the defects in 17-4 PH stainless steel L-PBF parts using HIP process [10], [22], [43].

In this regard, the present study was performed to understand the effect of HIP on the densification, mechanical properties and microstructures L-PBF parts fabricated from different powder size and types at various L-PBF processing conditions. The results from the current study will provide a better understanding of the effect of post-processing method such as HIP on the densification, mechanical properties and microstructure of LPBF parts.

\subsection{EXPERIMENTAL MATERIALS AND METHODS}

The 17-4 PH stainless steel gas-atomized powder used for this study was supplied by 3D Systems and the 17-4 PH stainless steel water-atomized powder was produced by North American Hoganas. The particle size distributions of the17-4 PH stainless steel powders used in this study are measured using a Microtrac S3000 particle size analyzer. A highresolution FEI Quanta 600F scanning electron microscope (SEM) and a Bruker D8 
DISCOVER X-ray diffraction (XRD) spectroscope were used for morphology analysis of the powders. L-PBF experiments were performed on a 3D Systems ProX 200 machine under argon. The process parameters used in the L-PBF experiments consisted of laser power, scan speed, layer thickness and hatch spacing as given in Table 2.1.

Table 2.1. L-PBF processing conditions and the corresponding energy densities used in

\begin{tabular}{|c|c|c|c|c|}
\hline $\begin{array}{c}\text { Laser power } \\
(\mathbf{W})\end{array}$ & $\begin{array}{c}\text { Scan speed } \\
(\mathbf{m m} / \mathbf{s})\end{array}$ & $\begin{array}{c}\text { Hatch spacing } \\
(\boldsymbol{\mu m})\end{array}$ & $\begin{array}{c}\text { Layer thickness } \\
(\boldsymbol{\mu \mathbf { m }})\end{array}$ & $\begin{array}{c}\text { Energy density } \\
\left(\mathbf{J} / \mathbf{m m}^{\mathbf{3}}\right)\end{array}$ \\
\hline 150 & 1550 & 50 & 30 & 64 \\
\hline 150 & 1250 & 50 & 30 & 80 \\
\hline 195 & 1550 & 50 & 30 & 84 \\
\hline 195 & 1250 & 50 & 30 & 104 \\
\hline
\end{tabular}

The laser power was varied between 150 and $195 \mathrm{~W}$ and scan speed was varied between 1250 and $1550 \mathrm{~mm} / \mathrm{s}$. The layer thickness and hatch spacing were kept constant at $30 \mu \mathrm{m}$ and $50 \mu \mathrm{m}$ to fabricate tensile parts using the L-PBF process (Table 2.1). The set of process parameters considered for the L-PBF experiments were further used to calculate laser energy density using Equation 2.1.

$$
E_{p}=\frac{P}{h * v * t}
$$

where, $E_{p}$ is energy density $\left(\mathrm{J} / \mathrm{mm}^{3}\right), \mathrm{P}$ is laser power $(\mathrm{W}), \mathrm{v}$ is scan speed $(\mathrm{mm} / \mathrm{s})$, $\mathrm{t}$ is layer thickness $(\mathrm{mm})$, and $\mathrm{h}$ is hatch spacing $(\mathrm{mm})$.

Sixteen samples per type of powder were fabricated for each process condition. Thus, a total of 256 samples were fabricated during the study. Of the 256 parts, 4 parts of each powder type and process condition were selected for Archimedes density, mechanical testing and microstructure analysis. The tensile samples were thermally stress relieved at 
$1200^{\circ} \mathrm{F}$ for 1 hour in the air before their removal (electrical discharge machining) from the build plate. The tensile samples were cut by wire electrical discharge machining (EDM) into samples that were $0.68 \mathrm{~m} \times 0.13 \mathrm{~m} \times 0.318 \mathrm{~m}$.

Standard HIP post-treatment was subsequently applied to the tensile samples using a commercial service provided by Quintus Technologies, USA. The HIP treatment was conducted for $2 \mathrm{~h}$ under a temperature of $1120{ }^{\circ} \mathrm{C}$ and pressure of $105 \mathrm{MPa}$ applied through Ar gas, followed by rapid cooling to $200{ }^{0} \mathrm{C}$ at a rate of $100{ }^{\circ} \mathrm{C} / \mathrm{min}$. The HIP treated tensile samples were analyzed for their mechanical properties as per ASTM E8M standard and physical properties as well as microstructures. Hardness testing was performed using a Rockwell ' $\mathrm{C}$ ' hardness tester at $150 \mathrm{~kg}$ load. Tensile testing was performed using an Instron 5982 dual column machine.

Density measurements were conducted using a method based on Archimedes law on a Mettler Toledo XS104 weighing balance. The density values of the L-PBF parts reported in this paper were expressed as a percentage of the density of a 17-4 PH stainless steel cast part. The 17-4 PH stainless steel cast part was purchased from McMaster-Carr and density of the cast part was measured using the Archimedes method. The porosity of L-PBF parts was calculated using Equation 2.2.

$$
\phi=1-\frac{\rho(l)}{\rho(t)}
$$

Where, $\phi$ is the porosity of the L-PBF parts, $\rho(l)$ is the density of the L-PBF parts, $\rho(t)$ is the density of 17-4 PH stainless cast part. 
XRD of the L-PBF parts was performed perpendicular to the build direction on the BRUKER D8 machine. Rietveld analysis was performed to quantify the phases in the XRD data. Microstructures of the L-PBF parts were analyzed using an Olympus BX53 microscope. Metallographic specimen preparation was carried out following standard procedures for microstructure characterization. The carpenter's etchant was used as an etchant to reveal the austenite and martensitic phases typically found 17-4PH stainless steel parts [26], [30]. The tensile testing of the L-PBF parts, microstructural characterization of the polished and etched L-PBF parts was performed in the horizontal plane perpendicular to the build direction.

\subsection{RESULTS AND DISCUSSION}

\subsubsection{POWDER CHARACTERISTICS}

The chemical compositions of the 17-4 PH stainless steel gas- and water- atomized powders are presented in Table 2.2.

Table 2.2. The chemical composition of $17-4 \mathrm{PH}$ stainless steel gas and water-atomized powders

\begin{tabular}{|c|c|c|c|c|c|c|c|c|c|}
\hline Powder type & $\mathbf{C}$ & $\mathbf{C r}$ & $\mathbf{C u}$ & $\mathbf{M n}$ & $\mathbf{N i}$ & $\mathbf{P}$ & $\mathbf{S}$ & $\mathbf{S i}$ & $\mathbf{N b}$ \\
\hline Gas-atomized & 0.03 & 15 & 3.5 & 0.5 & 4.6 & 0.04 & 0.03 & 1 & 0.2 \\
\hline Water-atomized & 0.2 & 18 & 4 & 0.1 & 3.5 & 0.01 & 0.01 & 0.3 & 0.3 \\
\hline
\end{tabular}

The gas-atomized powder used in this study had a bimodal particle size distribution with a median particle size of $13 \mu \mathrm{m}$ as shown in Figure 2.1. The water-atomized powder particle size distribution is monomodal and had median particle size $43 \mu \mathrm{m}$ (Figure 2.1). Cumulative values of 10,50 , and $90 \%$ particle diameters are represented by $D_{10}, D_{50}, D_{90}$ values, respectively and are presented in Table 2.3 The morphology of the powders was 
characterized using SEM and represented in Figure 2.2, showing the gas-atomized powders to be spherical while the water-atomized powders are irregular in shape.
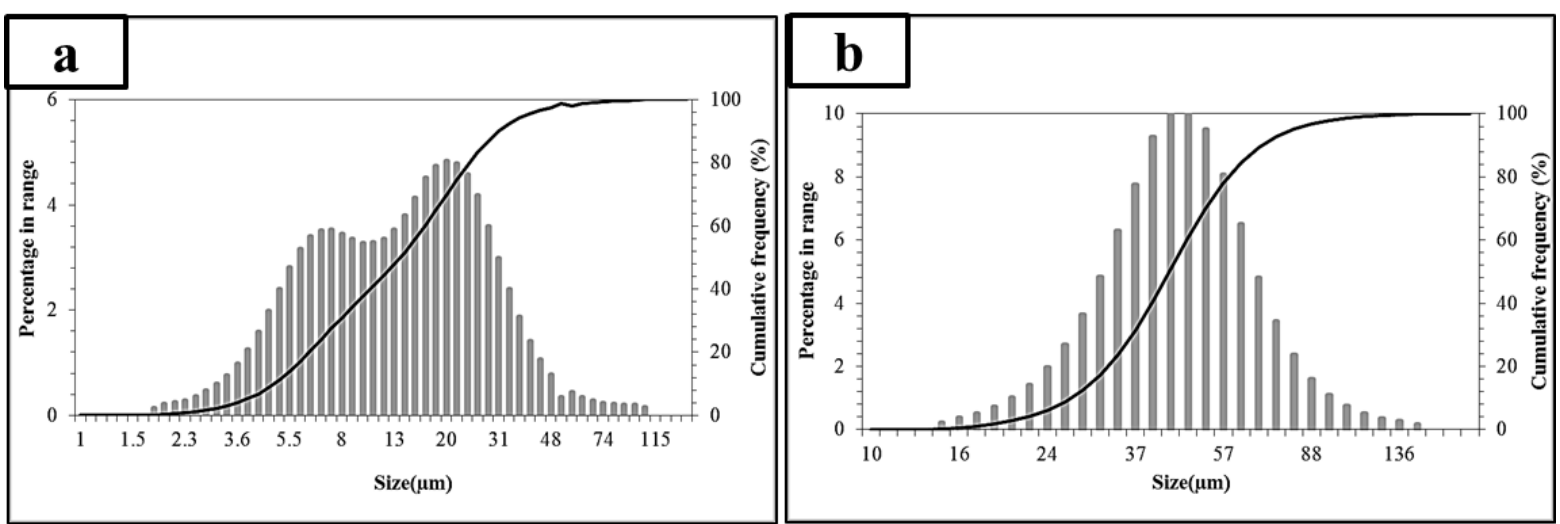

Figure 0.1.Particle size distributions of the 17-4 PH stainless steel powders used in this study (a) gas-atomized powder D50 $=13 \mu \mathrm{m}$ (b) water-atomized powder D50 $=43 \mu \mathrm{m}$

Table 2.3. Particle characteristics of the 17-4 PH stainless steel gas- and water-atomized powders

\begin{tabular}{|c|c|c|c|c|c|c|}
\hline \multirow[b]{2}{*}{ Powder } & \multicolumn{3}{|c|}{$\begin{array}{c}\text { Particle } \\
\text { distribution }\end{array}$} & \multirow{2}{*}{$\begin{array}{c}\text { Size width } \\
2.56 \\
\log _{10}\left(\mathrm{D}_{91} / \mathrm{D}_{10}\right)\end{array}$} & \multirow{2}{*}{$\begin{array}{c}\text { Tap } \\
\text { density } \\
\text { (g/cc) }\end{array}$} & \multirow{2}{*}{$\begin{array}{c}\text { Apparent } \\
\text { density } \\
\text { (g/cc) }\end{array}$} \\
\hline & $\begin{array}{c}\mathrm{D}_{10} \\
(\mu \mathrm{m})\end{array}$ & $\begin{array}{c}D_{50} \\
(\mu \mathrm{m})\end{array}$ & $\begin{array}{c}\text { D90 } \\
(\mu \mathrm{m})\end{array}$ & & & \\
\hline Gas-atomized (G) & 5 & 13 & 27 & 3.5 & $4 \pm 0.05$ & $3 \pm 0.002$ \\
\hline Water-atomized (W) & 26 & 43 & 67 & 6.2 & $3.7 \pm 0.05$ & $2.8 \pm 0.05$ \\
\hline
\end{tabular}



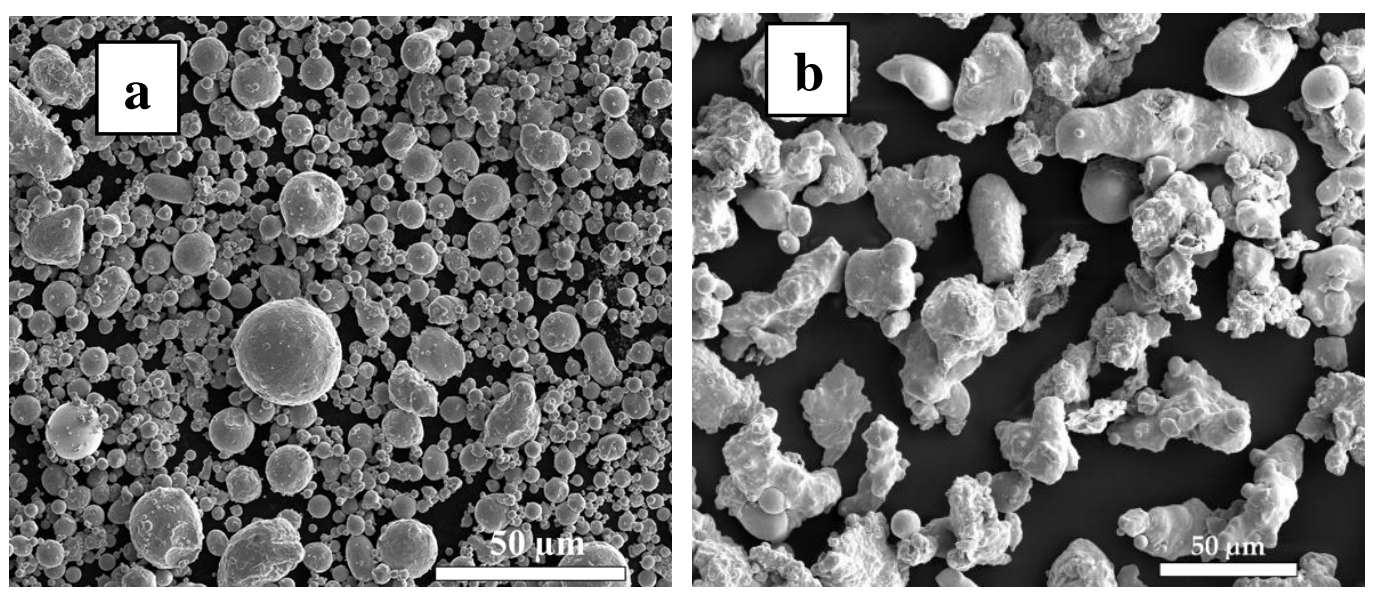

Figure 0.2.SEM images of the 17-4 PH stainless steel powders used in this study (a) gasatomized powder $(\mathrm{D} 50=13 \mu \mathrm{m})(\mathrm{b})$ water-atomized powder $(\mathrm{D} 50=43 \mu \mathrm{m})$

Figure 2.3 shows the XRD patterns of gas- and water-atomized powders. The XRD pattern showed that martensite and austenite phases are present in both gas- and water-atomized powders. Rietveld analysis showed that the gas-atomized powder consisted of $70 \%$ martensite phase and $30 \%$ austenite phase whereas the water-atomized powders consisted of $80 \%$ austenite phase and $20 \%$ martensite phase. The phase difference between the gasand water-atomized powders could be due to the difference in the atomization methods and chemistry of the starting powders. The cooling rate for water-atomized powders is 10 to 100 times higher than gas-atomize powders [13]. This variation in solidification rate resulted in high volume fraction of austenite phase in the water-atomized powders [33]. Furthermore, the austenite phase in gas-atomized powders could be due to the nitrogen gas which is used as atomizing media during the powder production process [33].

The porosity, phases, microstructure and properties of the L-PBF parts fabricated using 17$4 \mathrm{PH}$ stainless steel gas and water-atomized powders were correlated with process 
conditions using the energy density parameter calculated using Equation 2.2. The results are discussed in turn based on four values of increasing energy density.

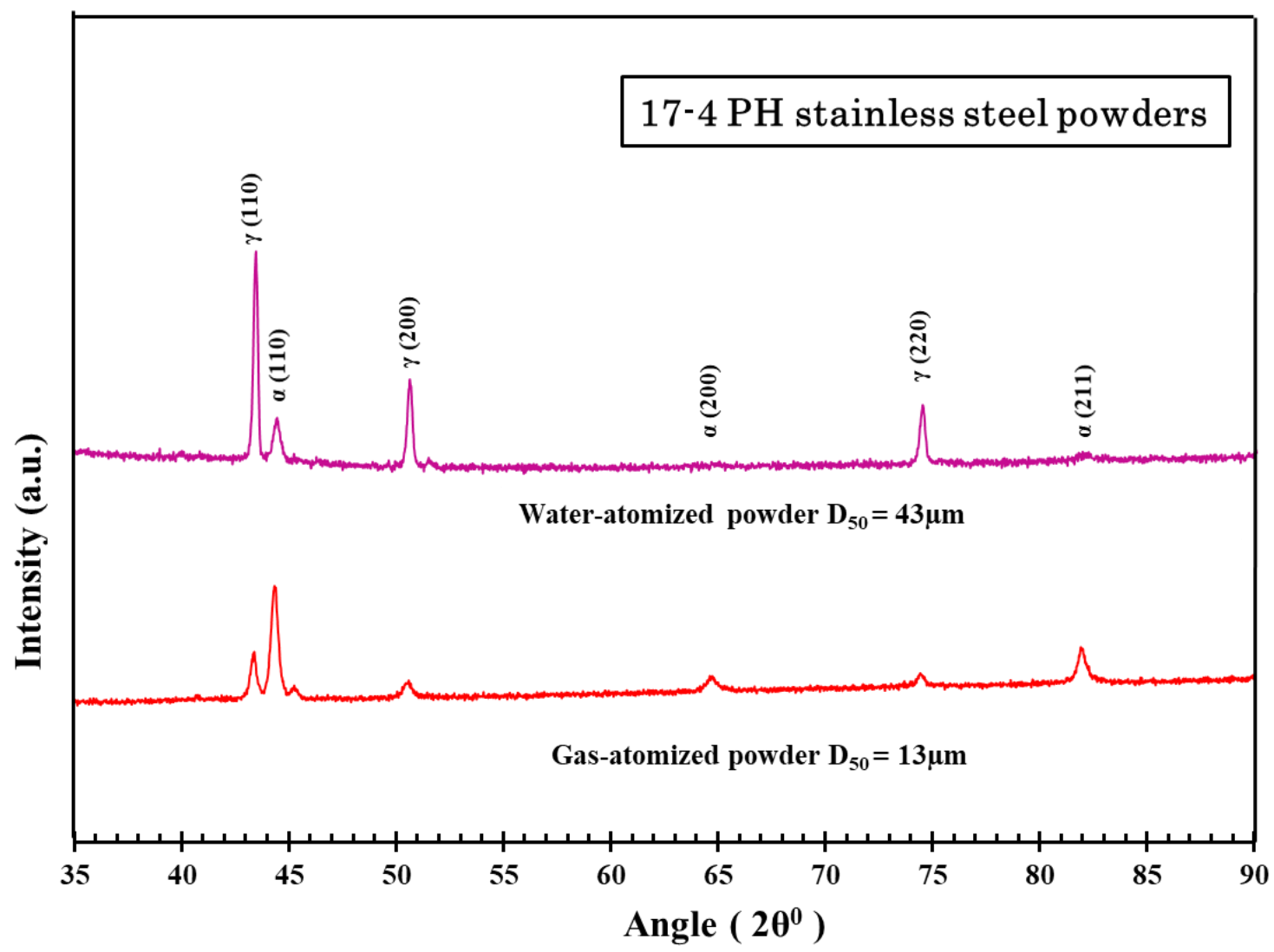

Figure 0.3.XRD analysis for the 17-4 PH stainless steel gas- and water-atomized powders showing the presence of $\alpha$ and $\gamma$ phases

\subsubsection{DENSITY}

The variation of $\%$ theoretical density of gas- and water-atomized L-PBF parts before and after HIP treatment with energy density is shown in Figure 2.4. The \% theoretical density of water-atomized L-PBF parts after HIP treatment was found to increase with increased energy density while the \% theoretical density of gas-atomized L-PBF parts remained constant (99 $\pm 0.5 \%$ ) with the increased energy density (Figure 2.4). Among all energy densities, the post-densification after HIP treatment was significant for water-atomized L- 
PBF parts when compared to gas-atomized L-PBF parts (Figures 2.5 and 2.6). A comparison of Figure 2.5a and 2.5b, which respectively show the cross-section images of the water-atomized L-PBF parts before and after HIP treatments at energy densities 64 and $80 \mathrm{~J} / \mathrm{mm}^{3}$, reveals that the HIP treatment closed large irregular pores in the as-printed LPBF parts. In comparison to $\%$ theoretical density of as-printed L-PBF parts, the $\%$ theoretical density of water-atomized L-PBF parts after HIP treatment had increased between 3 to $6 \%$ whereas the $\%$ increase in gas- atomized L-PBF parts were $2 \%$. The HIP treatment provides the high temperature and hydrostatic pressure, which evidently eliminated the pores in the L-PBF parts according to creep and diffusion densification law [28]. However, 3 to $4 \%$ of porosity still exists in water-atomized L-PBF parts after the HIP treatment at energy densities 64 and $80 \mathrm{~J} / \mathrm{mm}^{3}$ as shown in Figure 2.5a and 2.5b. Furthermore, HIP experiments with increased temperature and hold time on various wateratomized L-PBF parts are currently being performed in our group and results will be reported elsewhere.

A notable aspect of this data is the highest \% theoretical density $(99 \pm 0.5 \%)$ after HIP treatment was observed for both gas- and water-atomized L-PBF parts at energy densities of 84 and $104 \mathrm{~J} / \mathrm{mm}^{3}$. Tillmann et al.[20] suggested that practically it might be impossible to achieve a $100 \%$ dense L-PBF parts by HIP treatment. The possible reason for this being the open surface porosity and entrapped gas pores in the as-printed L-PBF parts hinder the post-densification during HIP Figures 2.5c, 2.5d and 2.6. During the HIP process, the heat treatment leads to an increase in pressure and expansion of these pores. This increase in inner pressure counteracts the densification during HIP process, thereby resulting in micro pores [15], [20], [23], [24], [47], [48]. 


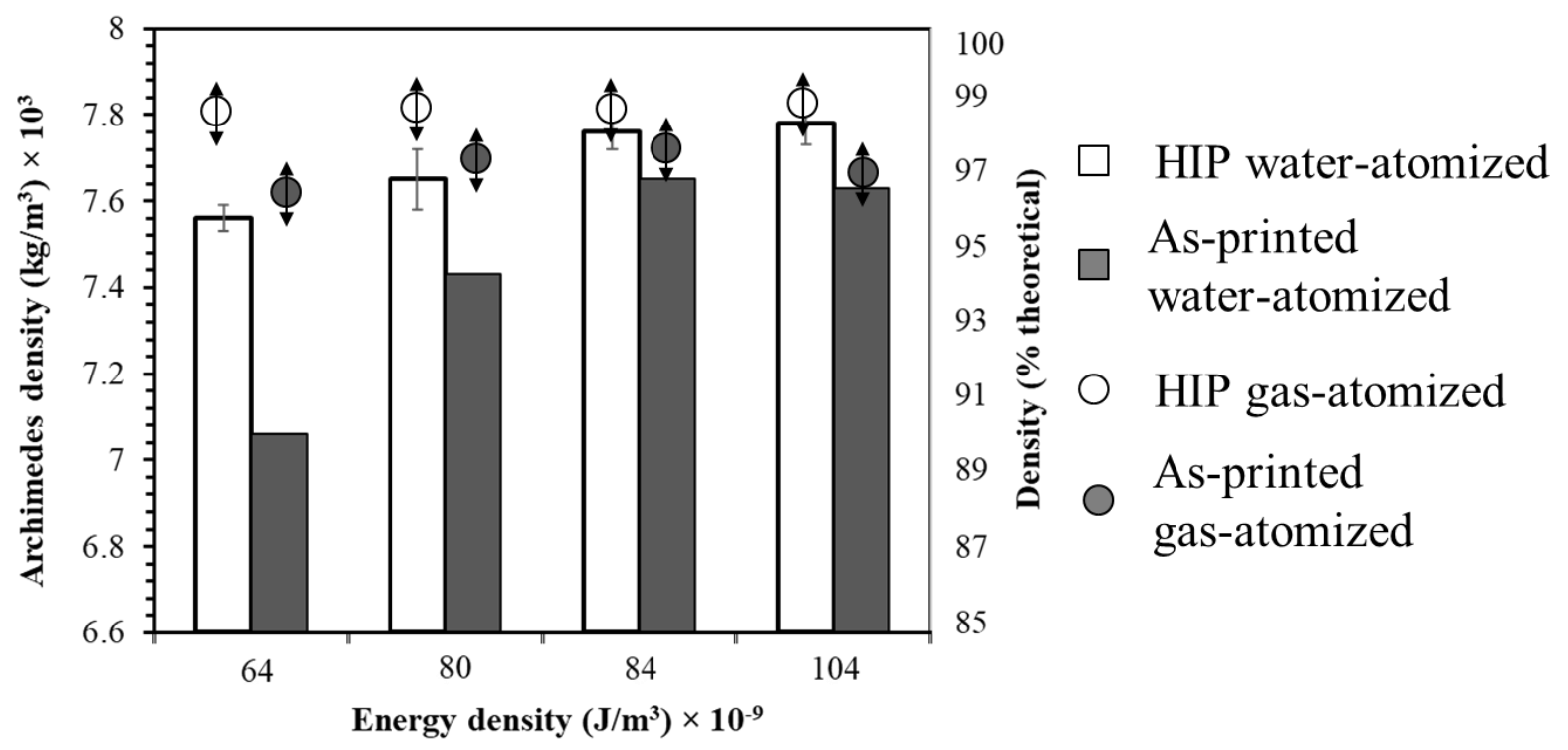

Figure 0.4.The \% theoretical density values of 17-4 PH stainless gas- and water-atomized L-PBF parts produced at energy densities $64,80,84,104 \mathrm{~J} / \mathrm{mm}^{3}$ before and after HIP treatment

Nevertheless, the results of the present study show that HIP treatment is effective in achieving high dense $(99 \pm 0.5 \%)$ gas- and water-atomized L-PBF parts. These results indicate that using same processing and post-processing conditions, L-PBF parts with similar density can be achieved using inexpensive coarser water-atomized powders compared to relatively expensive finer gas-atomized powders that are typically used for LPBF. 

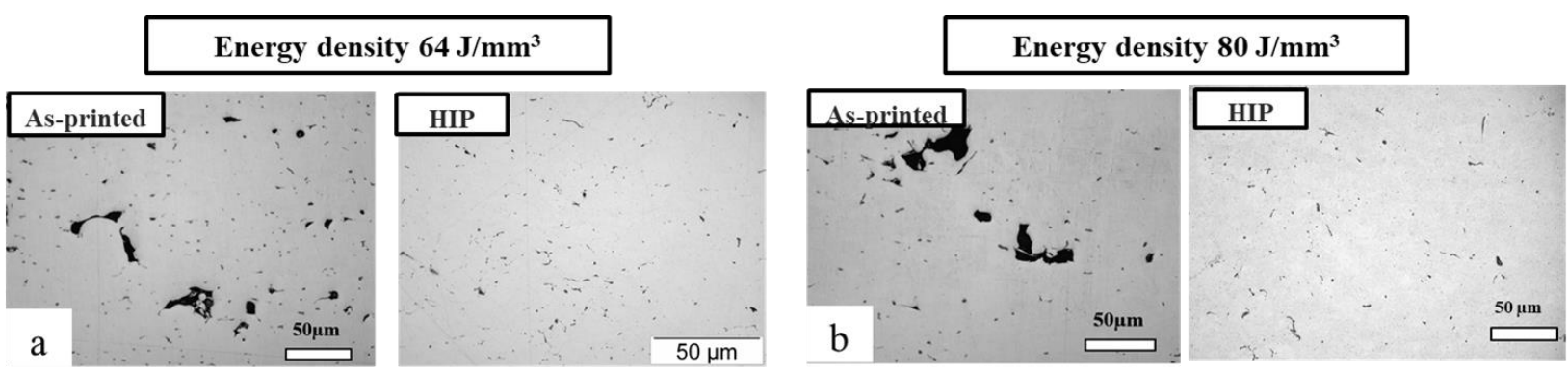

Energy density $84 \mathrm{~J} / \mathrm{mm}^{3}$

Energy density $104 \mathrm{~J} / \mathrm{mm}^{3}$
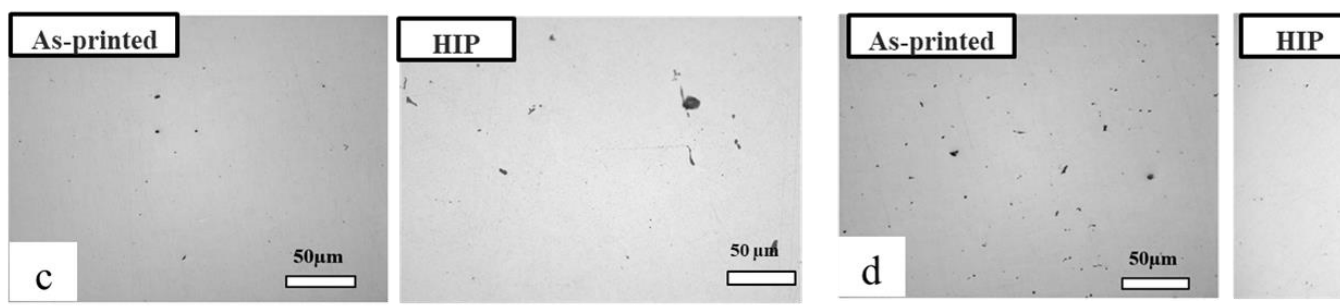

Figure 0.5.Optical micrographs of HIP and as-printed water-atomized $\mathrm{D}_{50}=43 \mu \mathrm{m}$
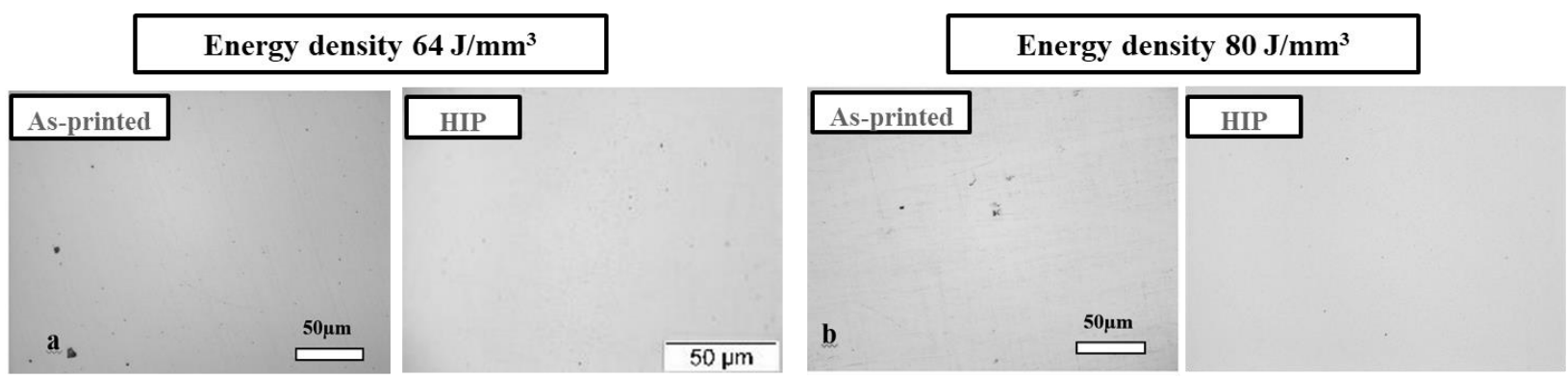

Energy density $84 \mathrm{~J} / \mathrm{mm}^{3}$

Energy density $104 \mathrm{~J} / \mathrm{mm}^{3}$
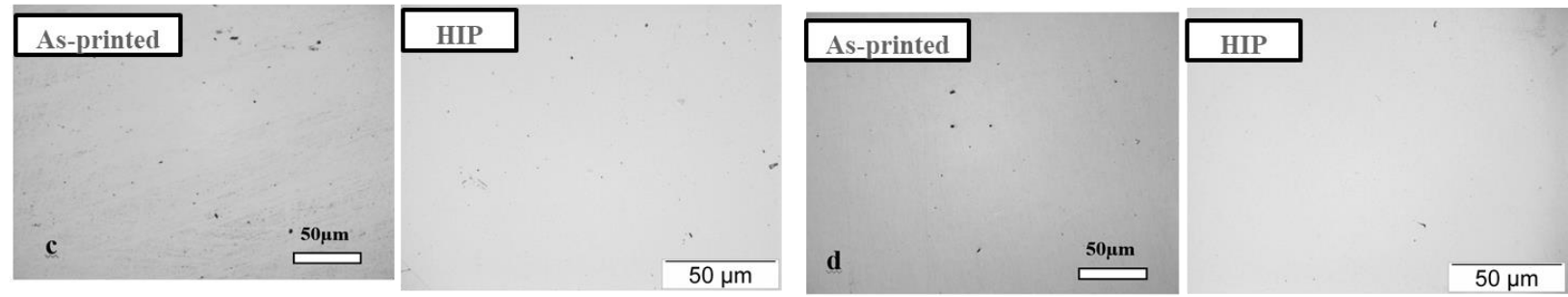

Figure 0.6.Optical micrographs of HIP and as-printed gas-atomized $\mathrm{D}_{50}=13 \mu \mathrm{m}$

\subsubsection{MECHANICAL PROPERTIES AND MICROSTRUCTURES}

The variation in the ultimate tensile strength of the L-PBF gas- and water-atomized parts before and after HIP treatment with energy density is shown in Figure 2.7. The ultimate 
tensile strength of the L-PBF water-atomized parts after HIP treatment increased with increase in energy density and varied between 700 and $1050 \mathrm{MPa}$. Furthermore, at energy densities of 64,80 and $84 \mathrm{~J} / \mathrm{mm}^{3}$, there was 20 to $50 \%$ increase in the ultimate tensile strength of the L-PBF water-atomized parts after HIP treatment \% when compared to the tensile strength of water-atomized L-PBF parts before the HIP treatment (Figure 2.7). This significant increase in the ultimate tensile strength of the water-atomized L-PBF parts after the HIP treatment could be attributed to the increase in density of L-PBF parts (3 to $6 \%$ ) (Figure 2.4). This relation between the ultimate tensile strength and the porosity of the LPBF parts after the HIP treatment was observed in previous studies [15], [16], [18], [19], [21], [23], [24], [48].

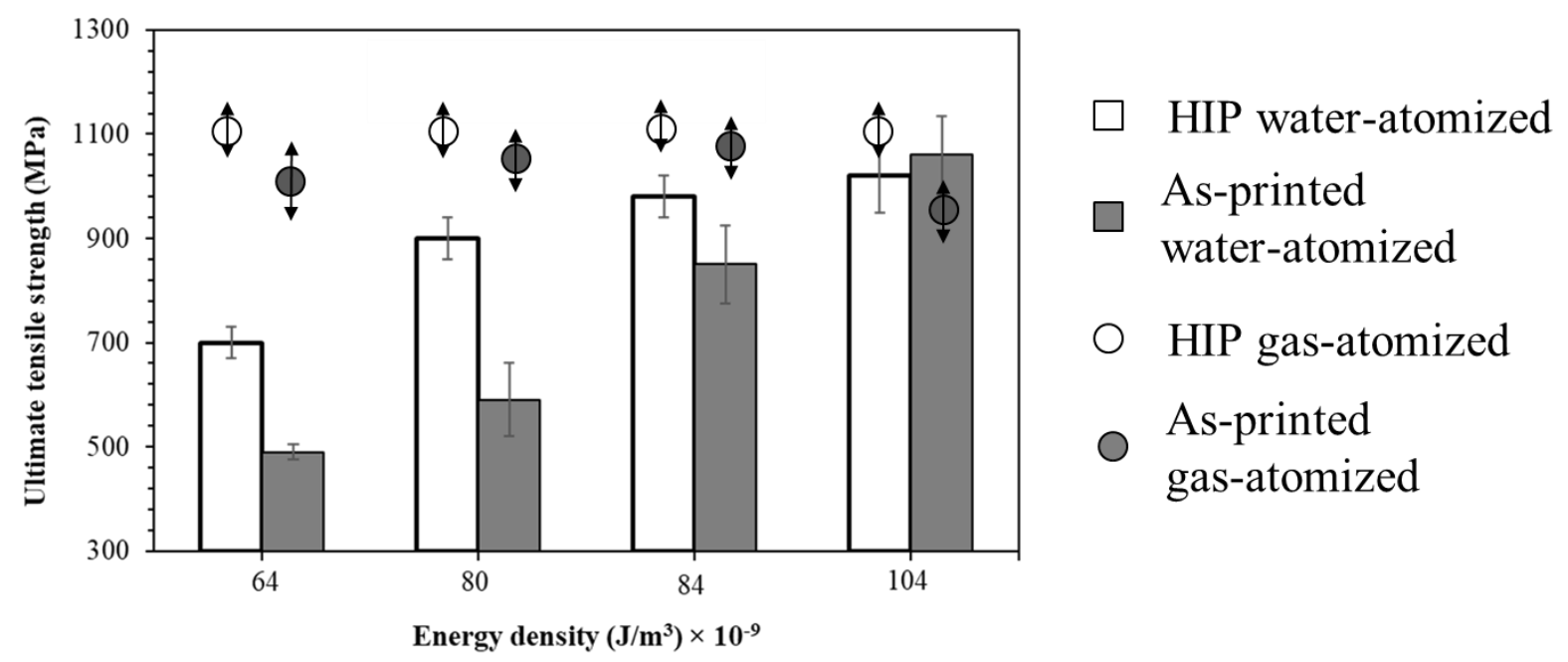

Figure 0.7.Variation of the ultimate tensile strength of 17-4 PH stainless gas- and wateratomized L-PBF parts before and after HIP treatment as a function of energy density

However, the gas-atomized L-PBF parts after the HIP treatment showed significantly higher tensile strength $(\sim 1100 \mathrm{MPa})$ when compared to the tensile strength water-atomized L-PBF parts before and after the HIP treatment as shown in Figure 2.7. However, at the high energy density of $104 \mathrm{~J} / \mathrm{mm}^{3}$, the ultimate tensile strength of water-atomized L-PBF 
parts $(\sim 950 \mathrm{MPa})$ after the HIP treatment was higher than the tensile strength as-printed gas-atomized L-PBF parts ( $950 \mathrm{MPa})$ but lower than the as-printed water-atomized LPBF parts. Furthermore, at high energy densities of 84 and $104 \mathrm{~J} / \mathrm{mm}^{3}$, high dense $(99 \pm$ $0.5 \%)$ L-PBF parts were produced after the HIP treatment but the variation in tensile strength ranged between 950 and $1150 \mathrm{MPa}(20 \%$ variation). To understand this variation in the ultimate tensile strength of the high dense $(99 \pm 0.5 \%)$ L-PBF parts, X-ray diffraction (XRD) analysis was performed on the L-PBF parts (perpendicular to the build direction) as shown in Figure 8a and $8 \mathbf{b}$ (water-atomized L-PBF parts) and 9a and 9b (gas-atomized L-PBF parts).

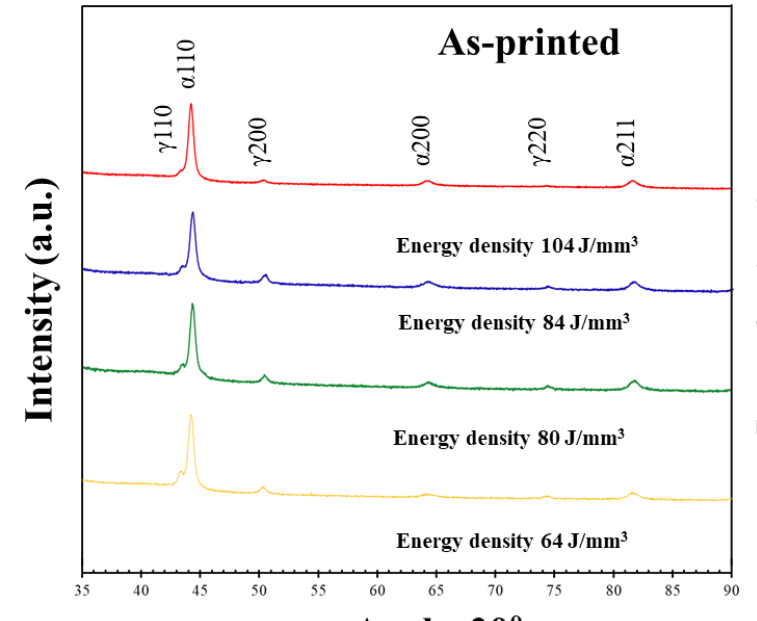

Angle, $\mathbf{2 \theta}^{0}$

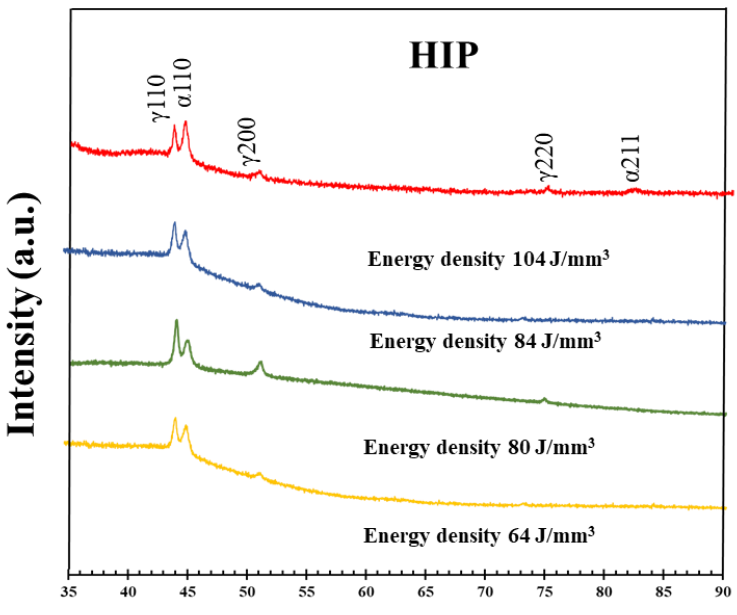

Angle, $\mathbf{2 \theta}^{0}$

Figure 0.8.XRD patterns of HIP and as-printed 17-4 PH stainless water-atomized L-PBF parts perpendicular to the build direction produced at energy densities 64, 80, 84 and 104 $\mathrm{J} / \mathrm{mm}^{3}$ 

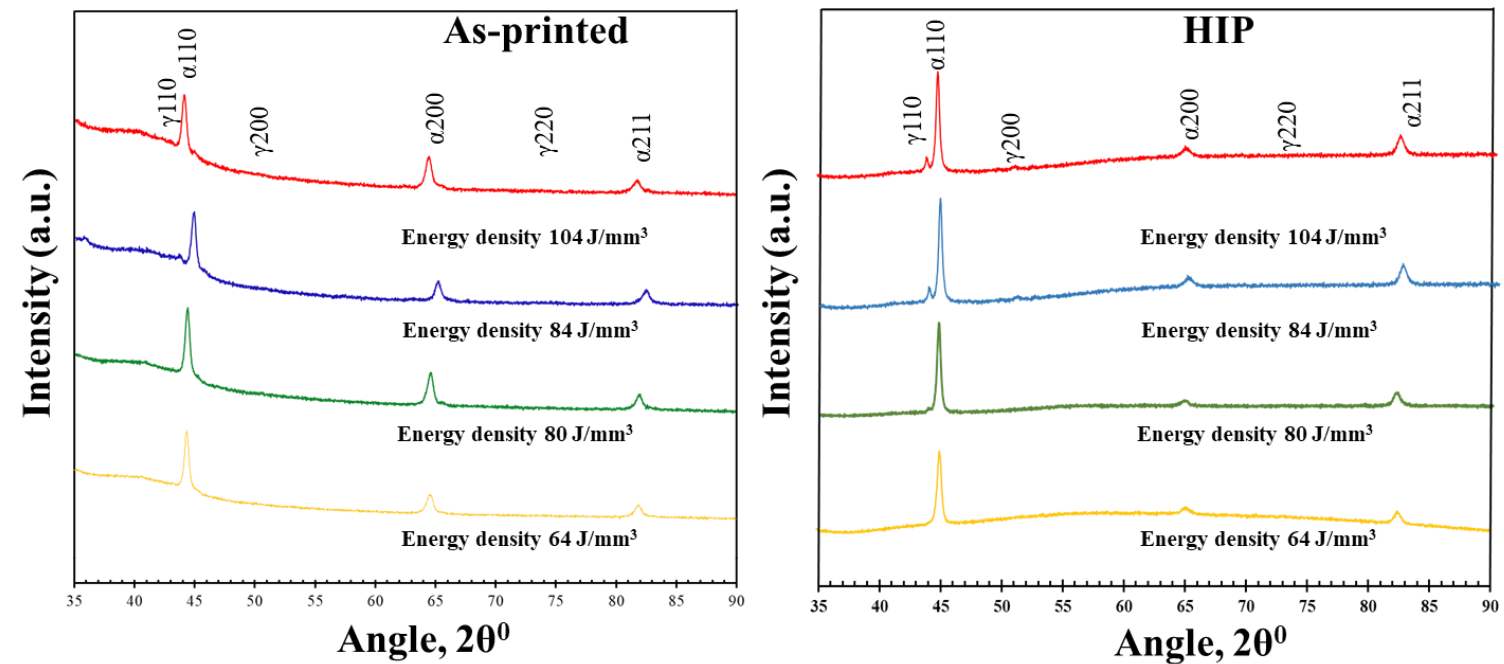

Figure 0.9.XRD patterns of HIP and as-printed 17-4 PH stainless gas-atomized L-PBF parts perpendicular to the build direction produced at energy densities 64, 80, 84 and 104 $\mathrm{J} / \mathrm{mm}^{3}$

The XRD patterns of gas- and water- atomized L-PBF parts at high energy densities of 84 and $104 \mathrm{~J} / \mathrm{mm}^{3}$ were completely different before and after the HIP treatment Figure 2.8a and 2.8b and Figure 2.9a and 2.9b. After the HIP treatment, the gas- atomized L-PBF parts at high energy densities of 84 and $104 \mathrm{~J} / \mathrm{mm}^{3}$, consisted of $95 \%$ martensite phase and $5 \%$ austenite phase (Rietveld analysis) whereas the water-atomized L-PBF parts consisted of $45 \%$ martensite phase and $55 \%$ austenite phase. The high-volume fraction of retained austenite $(55 \%)$ in the water-atomized L-PBF parts after the HIP treatment could have attributed to $20 \%$ decrease in the ultimate tensile strength of water-atomized L-PBF parts when compared to highly martensitic gas-atomized powder L-PBF parts. The gasatomized L-PBF parts with $95 \%$ martensite phase after the HIP treatment showed significantly higher tensile strength when compared to the tensile strength of as-printed gas- and water-atomized L-PBF parts and HIP water-atomized L-PBF parts. 
Figure 2.8 and 2.9 also show that the XRD patterns of water- atomized L-PBF parts after the HIP treatment were significantly different from the XRD patterns of L-PBF parts before the HIP treatment (Figure 2.8a) and starting powder (Figure 2.3). The quantitative analysis showed that the volume fraction of retained austenite phases in water-atomized LPBF parts before the HIP treatment varied between 10 and $30 \%$ whereas after the HIP treatment the volume fraction of retained austenite varied between 45 and $55 \%$. This increase in volume percentage of austenite phase in water-atomized L-PBF parts could be attributed to the cooling rates during the HIP treatment. However, the formation of retained austenite in gas-atomized L-PBF parts after the HIP treatment was minimal (5\%) owing to its predominantly high martensite content in as-printed L-PBF parts (Figure 2.9a) and the starting powder (Figure 2.3). On-going uniform rapid quenching (URQ) experiments are expected to favor the formation of martensite in water-atomized L-PBF parts because of the rapid cooling rates during the HIP process. The interesting result from this data is both starting powder characteristics and L-PBF processing conditions effects the XRD phases in as-printed and HIP L-PBF parts. 


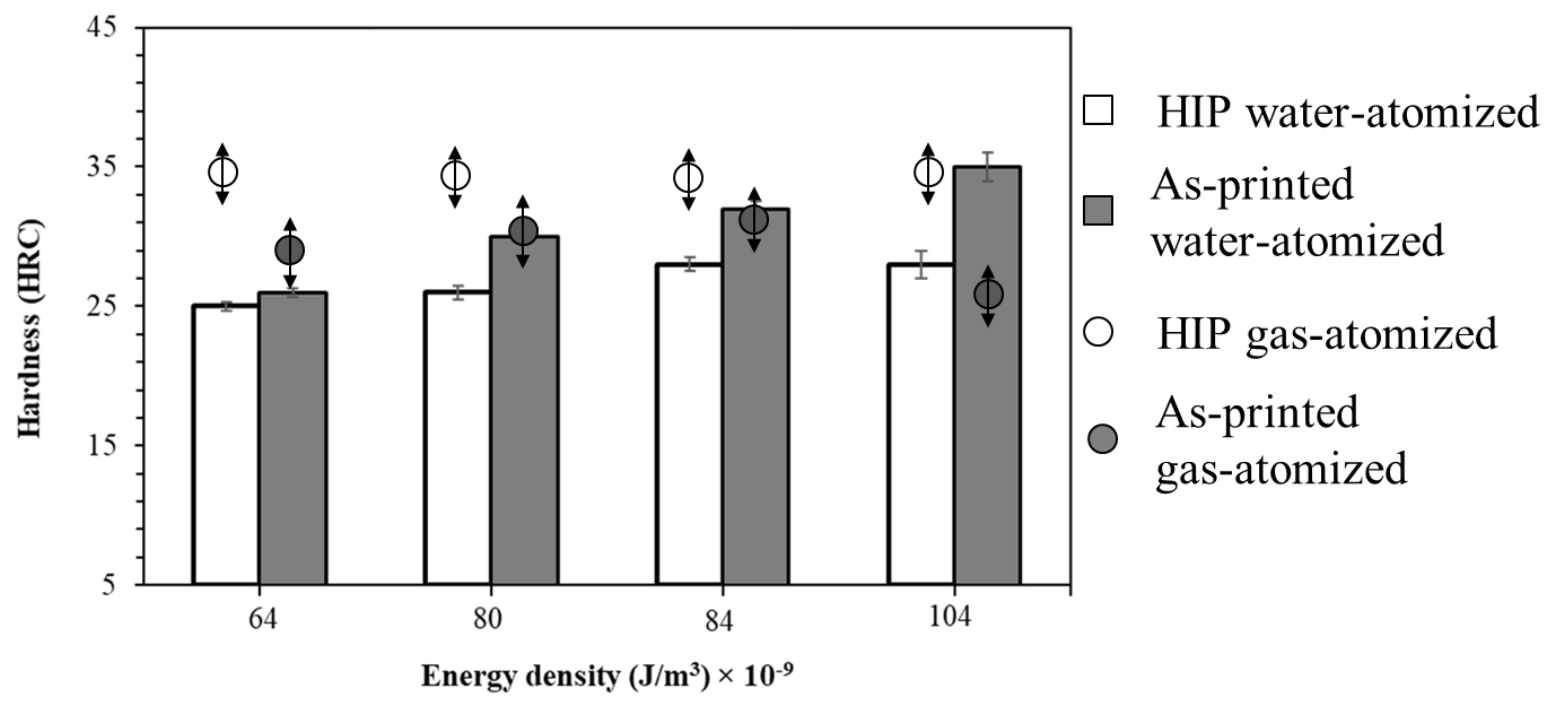

Figure 0.10.The hardness of HIP and as-printed 17-4 PH stainless gas- and wateratomized L-PBF parts produced at energy densities $64,80,84,104 \mathrm{~J} / \mathrm{mm}^{3}$

Figure 2.10 shows the after the HIP treatment, hardness values of the gas-atomized L-PBF parts ( 35 HRC) were higher than hardness values of the water-atomized L-PBF parts ( $\sim 25 \mathrm{HRC})$. The predominant percentage (95\%) of martensite in HIP treated gas-atomized L-PBF parts could have contributed to the high hardness when compared to HIP treated water-atomized L-PBF parts. However, the hardness values of the gas- and water-atomized L-PBF parts did not change significantly with the increase in the energy density when subjected to HIP treatment. This behavior remains in consistent with the XRD phases present in the respective parts. Furthermore, the 10 to $30 \%$ decrease in hardness of the HIP treated water-atomized L-PBF parts when compared to hardness as-printed parts ( 25 HRC) with the increase in energy density could be correlated to the 45 to $55 \%$ decrease in martensite phase in HIP treated L-PBF parts.

Figure 2.11 shows the variation of the yield strength of L-PBF parts before and after HIP treatment with energy density is similar to the variation of tensile strengths of L-PBF parts. 
The yield strength of both gas- and water-atomized L-PBF parts after HIP treatment increased with the energy density and are higher than the yield strength of as-printed LPBF parts. After the HIP treatment, the yield strength of water-atomized L-PBF parts varied between 400 and $800 \mathrm{MPa}$ whereas the yield strength of gas-atomized L-PBF parts remained constant at $850 \pm 15 \mathrm{MPa}$. According to Hall-Petch relationship [49], the yield strength of the L-PBF parts can be significantly affected by grain size in their microstructures. Microstructure analysis was performed on the L-PBF parts before and after the HIP treatment to understand the variation in grain strength with energy density as shown in Figure 2.12 and 2.13. The average grain intercept (AGI) method was used to quantify the grain size in the L-PBF parts.

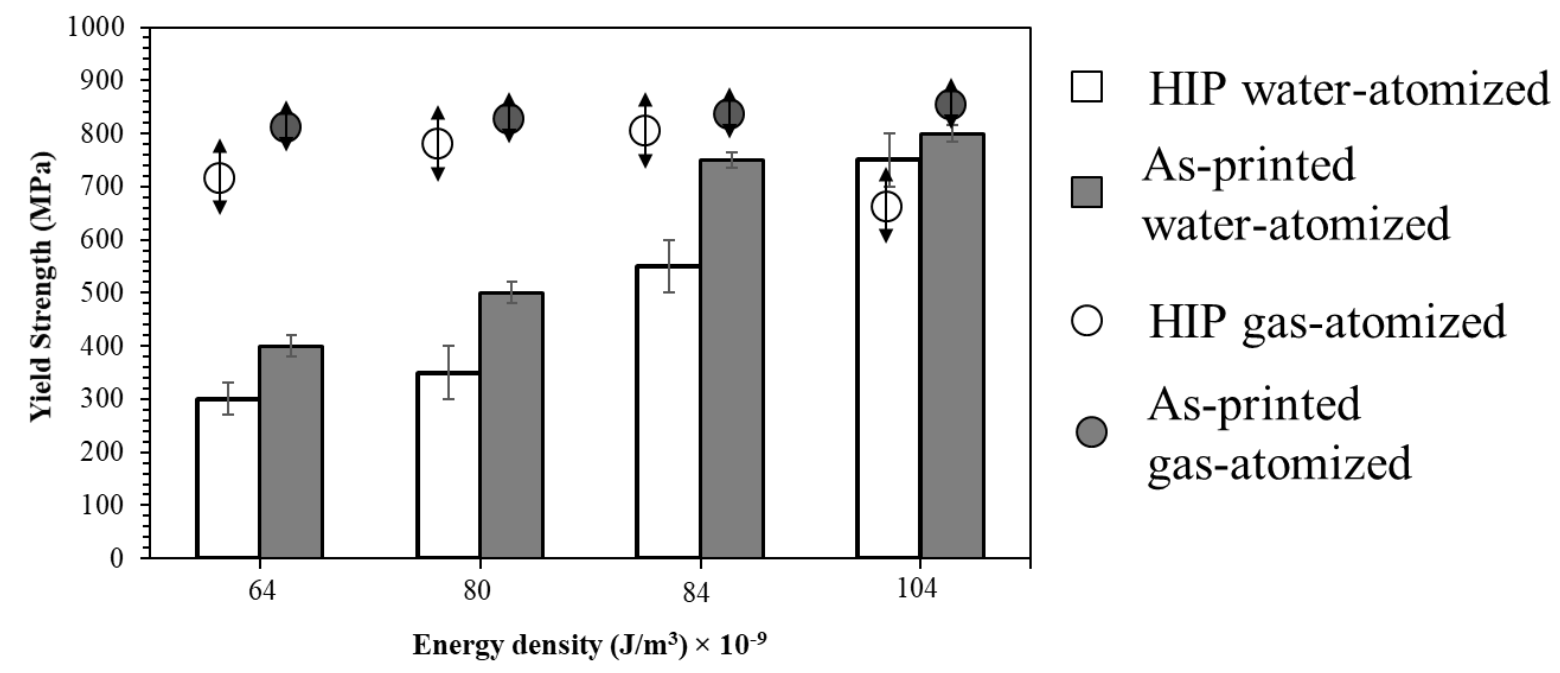

Figure 0.11 . The yield strength of HIP and as-printed 17-4 PH stainless gas- and wateratomized L-PBF parts produced at energy densities $64,80,84,104 \mathrm{~J} / \mathrm{mm}^{3}$ 

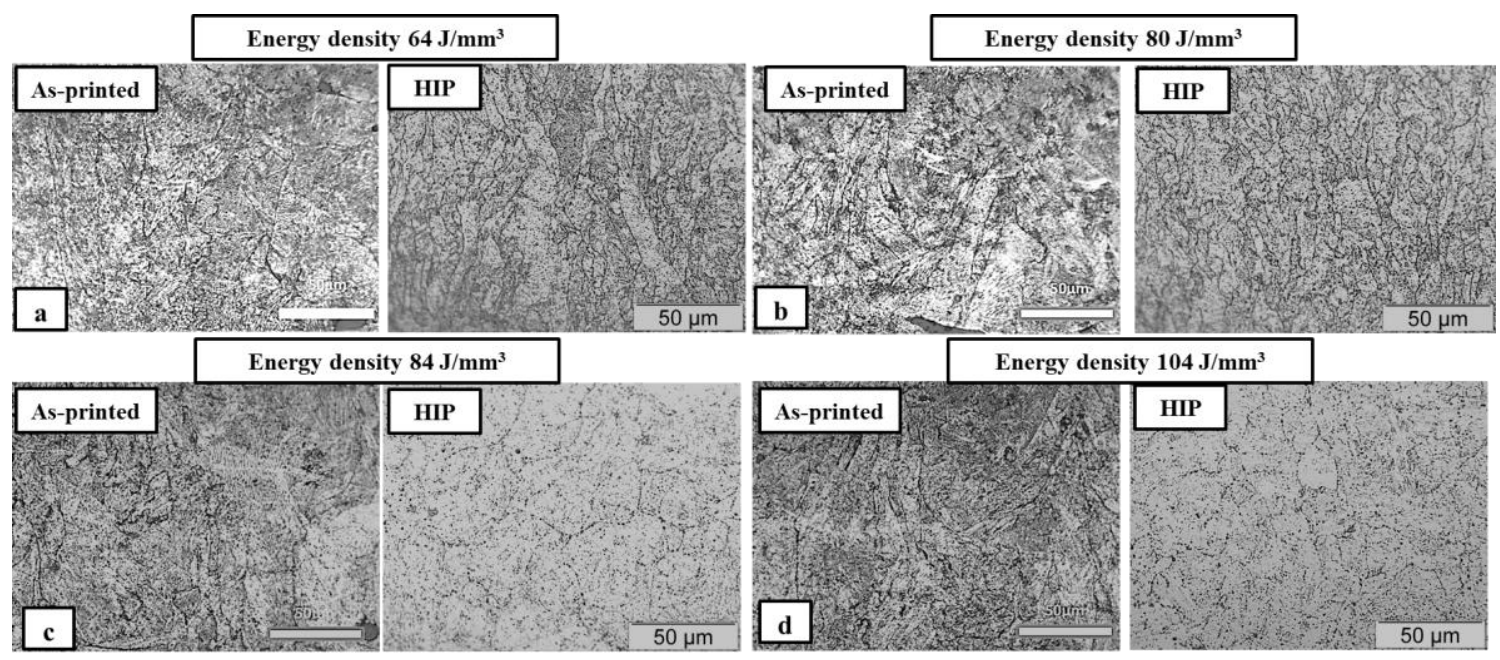

Figure 0.12.Microstructures of HIP and as-printed 17-4 PH stainless water-atomized LPBF parts produced at energy densities $64,80,84,104 \mathrm{~J} / \mathrm{mm}^{3}$
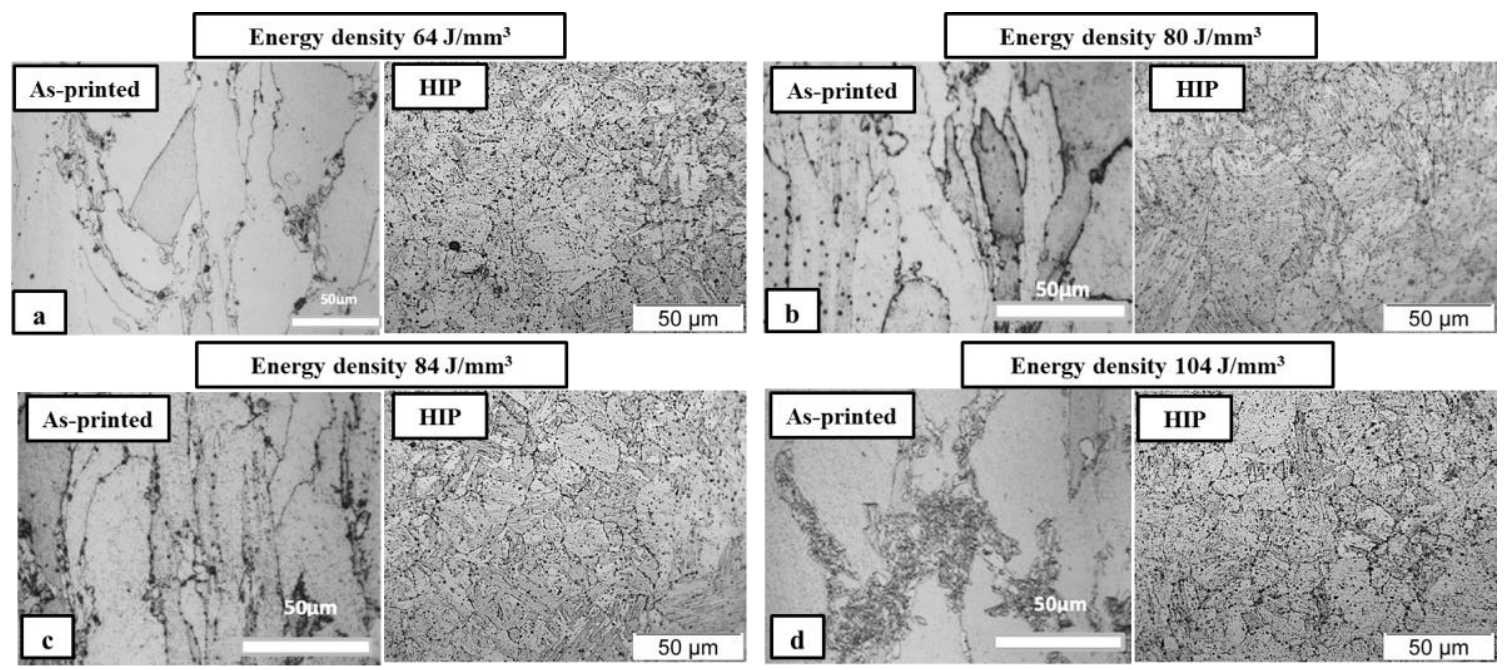

Figure 0.13.Microstructures of HIP and as-printed 17-4 PH stainless gas-atomized L-PBF parts produced at energy densities $64,80,84,104 \mathrm{~J} / \mathrm{mm}^{3}$

The microstructures of gas- and water-atomized L-PBF parts at low energy densities 64 and $80 \mathrm{~J} / \mathrm{mm}^{3}$ were significantly different when subjected to HIP treatment as shown in

Figure 2.12 and 2.13. Figure 2.12a and 2.12b show that at energy densities 64 and 80 $\mathrm{J} / \mathrm{mm}^{3}$, the columnar grains in the as-printed L-PBF parts did not change significantly after the HIP treatment whereas the columnar grains present in as-printed gas-atomized L-PBF 
parts completely disappeared when subjected to HIP treatment (Figure 2.13a and 2.13b). At energy densities of 64 and $80 \mathrm{~J} / \mathrm{mm}^{3}$, the fine equiaxed grains of $15 \pm 1 \mu \mathrm{m}$ in size were observed in gas-atomized L-PBF parts after the HIP treatment whereas large columnar grains of $20 \pm 5 \mu \mathrm{m}$ in size was observed in HIP treated water-atomized L-PBF parts. This change in grains and grain size could explain the variation in the yield strength of L-PBF parts when fabricated from different powders at energy densities 64 and $80 \mathrm{~J} / \mathrm{mm}^{3}$. Furthermore, the increase in yield strength of HIP treated water-atomized L-PBF parts when compared to the yield strength of as-printed L-PBF parts could be attributed to the decrease in porosity after the HIP treatment rather than on the grain size. Further analysis will be performed to understand the variation in grain diffusion as a function of starting powder and results will be reported elsewhere.

However, at high energy densities of 84 and $104 \mathrm{~J} / \mathrm{mm}^{3}$, the columnar grains in as-printed L-PBF gas-and water-atomized L-PBF parts were changed to equiaxed grains and showed a higher level of homogenization when subjected to HIP treatment (Figure 2.12 and 2.13). The equiaxed grains of $5 \sim 10 \mu \mathrm{m}$ and $5 \mu \mathrm{m}$ in size were observed in the HIP-treated waterand gas- atomized L-PBF parts, respectively. According to Hall-Petch strengthening mechanism [49], the decrease in the grain size could have contributed to the increase in yield strength of water- and gas- atomized L-PBF parts after the HIP treatment.

Figure 2.14 shows the elongation of L-PBF gas- and water-atomized parts decreased with energy density when subjected to HIP treatment. These decrease in elongation of the HIP treated water-and gas-atomized L-PBF parts could be correlated to the decrease in the grain size (Figure 2.12 and 2.13). The HIP treated water-atomized L-PBF parts with long 
columnar grains showed higher elongation (15 to $17 \%$ ) at energy densities 64 and 80 $\mathrm{J} / \mathrm{mm} 3$.

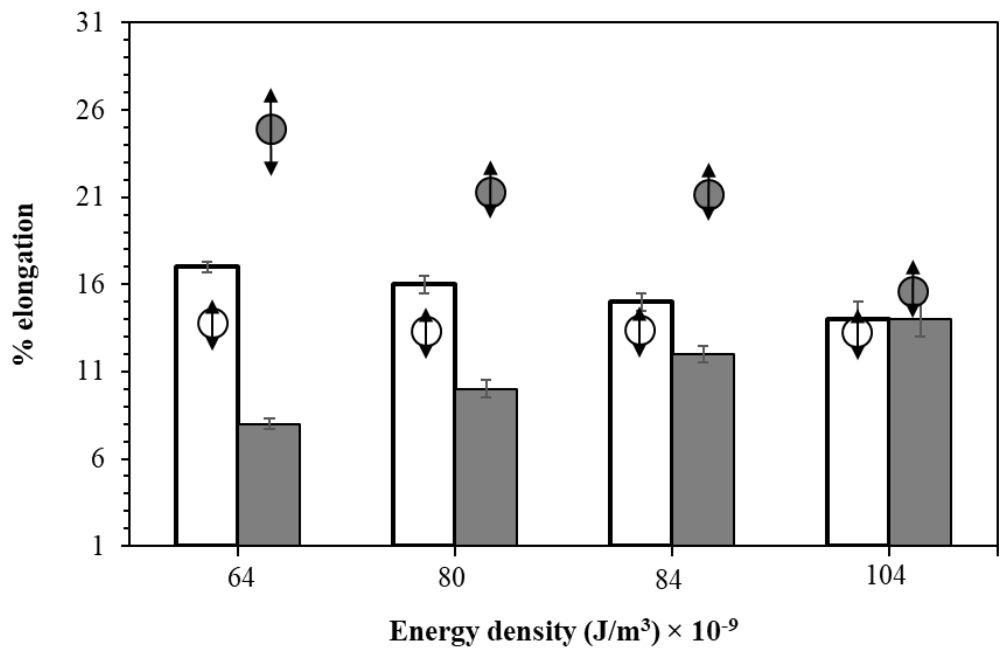

HIP water-atomized

As-printed

water-atomized

HIP gas-atomized

As-printed

gas-atomized

Figure 0.14 .The $\%$ elongation of HIP and as-printed 17-4 PH stainless gas- and wateratomized L-PBF parts produced at energy densities $64,80,84,104 \mathrm{~J} / \mathrm{mm}^{3}$

\subsection{CONCLUSIONS}

This work presents a comprehensive study of the densification behavior and microstructure development of 17-4 PH stainless steel gas- and water-atomized L-PBF parts when subject to HIP treatment. The important result from this data is that both starting powder characteristics and L-PBF processing conditions affect the density, mechanical properties and microstructures of as-printed and HIP L-PBF parts. At low energy densities of 64 and $80 \mathrm{~J} / \mathrm{mm}^{3}$, after the HIP treatment, large irregular pores in as-printed water-atomized LPBF parts were eliminated and density increased from 90 to $97 \%$. For all the energy densities, the gas-atomized L-PBF parts after the HIP treatment showed significantly higher tensile strength, yield strength and hardness when compared to water-atomized LPBF parts properties. The high-volume fraction of retained austenite $(55 \%)$ in the wateratomized L-PBF parts after the HIP treatment could have attributed to decrease in the 
ultimate tensile strength, the hardness of water-atomized L-PBF parts when compared to highly martensitic gas-atomized powder L-PBF parts.

At low energy densities of 64 and $80 \mathrm{~J} / \mathrm{mm}^{3}$, the columnar grains in the as-printed L-PBF parts did not change significantly after the HIP treatment whereas the columnar grains present in as-printed gas-atomized L-PBF parts completely disappeared when subjected to HIP treatment. However, at high energy densities of 84 and $104 \mathrm{~J} / \mathrm{mm}^{3}$, long columnar grains in as-printed L-PBF gas-and water-atomized L-PBF parts were changed to equiaxed grains and showed a higher level of homogenization when subjected to HIP treatment. This variation in grains and grain size had significantly affected the yield strength and elongation of HIP treated gas- and water-atomized L-PBF parts. Furthermore, HIP experiments with increased temperature and hold time on various water-atomized L-PBF parts are currently being performed in our group and results will be reported elsewhere. 


\section{CHAPTER 3}

\section{PROPERTY GAINS FROM HOT ISOSTATIC PRESSING OF 17-4 PH STAINLESS \\ STEEL GAS AND WATER-ATOMIZED PARTS FABRICATED BY LASER- POWDER BED FUSION}

\subsection{INTRODUCTION}

Laser powder bed fusion (L-PBF) process, popularly known as selective laser melting (SLM) has received a lot of interest for fabricating complex three-dimensional components for automotive, aerospace, medical and tooling industries [1]-[3], [7], [26]. In the L-PBF process, three-dimensional components were fabricated using a fine focused laser beam as an energy source to selectively melt powders layer-by-layer based on CAD file [50]-[55]. Many research studies have been carried out in the past decade on iron, steel, nickel, aluminum, titanium and cobalt alloys to fabricate defect-free parts using the L-PBF process [6], [8], [15], [32], [50], [51], [56]-[68]. Most of the studies indicated that defects and porosities still exist in L-PBF parts when they were fabricated using powders of different shape and size attributes [6], [8], [15], [32], [50], [51], [56]-[68].

Typically, gas-atomized powders $(<50 \mu \mathrm{m})$ with a spherical shape and narrow size distribution were preferred for fabricating defect-free parts using L-PBF process [2], [3], [6], [8], [10]-[12]. However, such powders are inherently expensive as they use large 
amounts of inert process gas as well as a small fraction of the production lot in each atomization run [2], [3], [6], [13]. On the other hand, water-atomized powders are relatively less expensive but the ability to fabricate high density L-PBF parts from wateratomized powders with properties competitive to parts using gas-atomized powders has not been convincingly demonstrated in the open literature [2], [3], [6], [13]. In this regard, previous studies conducted within our group have shown the feasibility of fabricating 17$4 \mathrm{PH}$ stainless steel L-PBF parts using fine water-atomized powders and achieving the properties similar or higher than gas-atomized parts in certain processing conditions [1][4]. However, some porosity still existed in coarser size fractions of water-atomized L-PBF parts.

In powder metallurgy, hot isostatic pressing (HIP) is routinely performed to eliminate porosity and anisotropy. Several HIP studies have emerged in recent times to improve the densification and mechanical properties of L-PBF parts using various materials such as Hastelloy, 316L stainless steel, CoCr and Ti-6Al-4V alloys [15]-[24]. For example, Lavery et al [16] and Tillmann et al [20] discussed the effect of the HIP on decreasing the porosity and its impact on the mechanical properties for 316L stainless steel and Inconel $718 \mathrm{~L}-\mathrm{PBF}$ parts, respectively. However, there are no reported studies in the literature that demonstrated fundamental understanding on effect of HIP on minimizing porosity and maximizing the properties of 17-4 PH stainless steel L-PBF parts.

In this regard, the present study was performed to understand the effect of the HIP on the densification, mechanical properties and microstructures of 17-4 PH stainless steel gas and 
water-atomized as-printed L-PBF parts when they are fabricated at various energy densities. The current study builds from our initial work [69] on the effect of HIP on gas and water-atomized L-PBF parts.

\subsection{EXPERIMENTAL}

17-4 PH stainless steel water-atomized powders of median particle size 17, 24 and $43 \mu \mathrm{m}$ and a gas-atomized powder of median particle size $13 \mu \mathrm{m}$ were used as starting powders.

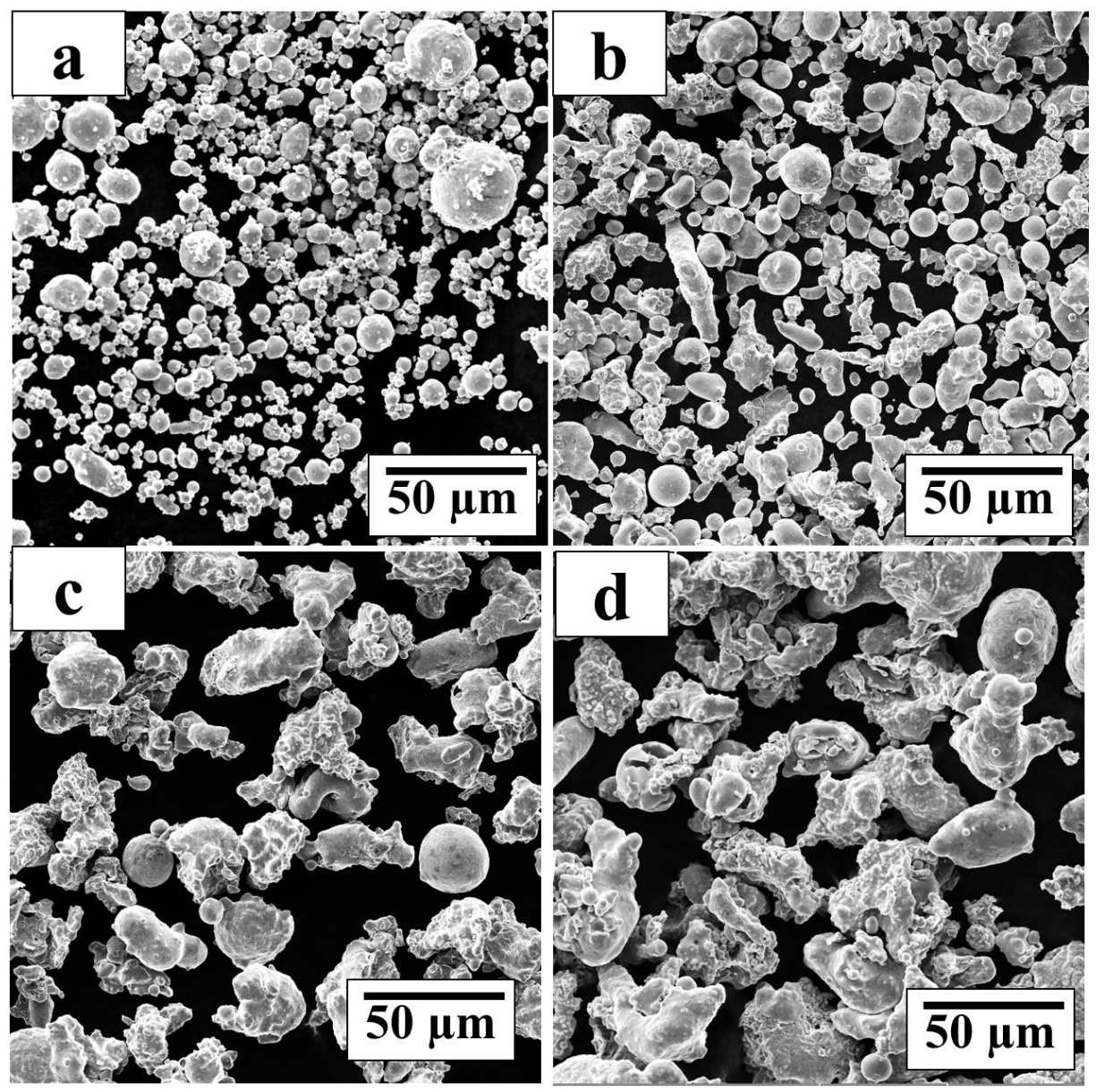

Figure 0.1.SEM micrographs of the four 17-4 PH stainless steel powders (a) gasatomized powder $\mathrm{D}_{50}=13 \mu \mathrm{m}(\mathrm{b})$ water-atomized powder $\mathrm{D}_{50}=17 \mu \mathrm{m}$, (c) wateratomized powder $\mathrm{D}_{50}=24 \mu \mathrm{m}$, (d) water-atomized powder $\mathrm{D}_{50}=43 \mu \mathrm{m}$ 
The morphology of the powders was characterized using an FEI Quanta 600F scanning electron microscope (SEM). The morphology of the gas and water-atomized powders used in the present study is shown in Figure 3.1. The SEM micrographs show typical spherical and irregular morphology for gas and water-atomized powders, respectively. The particle size measurement data, tap and apparent densities of 17-4 PH stainless steel water and gasatomized powders used in the study are listed in previous journal papers published by the authors [1], [2].

L-PBF experiments using the gas and water-atomized 17-4 PH stainless steel powders were carried out using a 3D Systems ProX 320 machine in Ar atmosphere. Four different energy densities $64,80,84$ and $104 \mathrm{~J} / \mathrm{mm}^{3}$ were used to fabricate the L-PBF parts using gas and water-atomized powders used in this study. Detailed information about processing conditions used for calculating the energy densities for fabricating the L-PBF parts has reported previously [1]-[3], [26]. The tensile parts of dimensions $0.68 \mathrm{~m} \times 0.13 \mathrm{~m} \times 0.318$ $m$ was cut by wire electrical discharge machining (EDM) to test for mechanical properties as per ASTM E8M standard.

Three tensile parts of each water-atomized powder type at energy densities $64,80,84$ and $104 \mathrm{~J} / \mathrm{mm}^{3}$ and three tensile parts of gas- water-atomized powder type at energy densities 84 and $104 \mathrm{~J} / \mathrm{mm}^{3}$ were selected for HIP treatment. The HIP cycle used in this experiment is shown in Figure 3.2. The density of the HIP treated parts was measured using Mettler Toledo XS104 weighing balance based on Archimedes density principle. The mechanical properties of the HIP treated L-PBF parts were measured with an MTS hydraulic dual 
column testing system equipped with a $100 \mathrm{kN}$ load cell at a strain rate of $0.001 \mathrm{~s}-1$. The hardness of the HIP treated parts parallel to the build direction was measured using a Rockwell ' $\mathrm{C}$ ' hardness scale at $150 \mathrm{~kg}$ load. The phases present in the L-PBF parts perpendicular to the build direction were estimated using a BRUKER D8 X-ray diffraction (XRD) machine. Metallographic specimens were prepared perpendicular to the build direction and analyzed using an Olympus BX53 microscope. Carpenter's etchant was used to reveal the grain size and phases in the microstructures of as-printed and HIP treated 174PH stainless steel parts [26], [30].

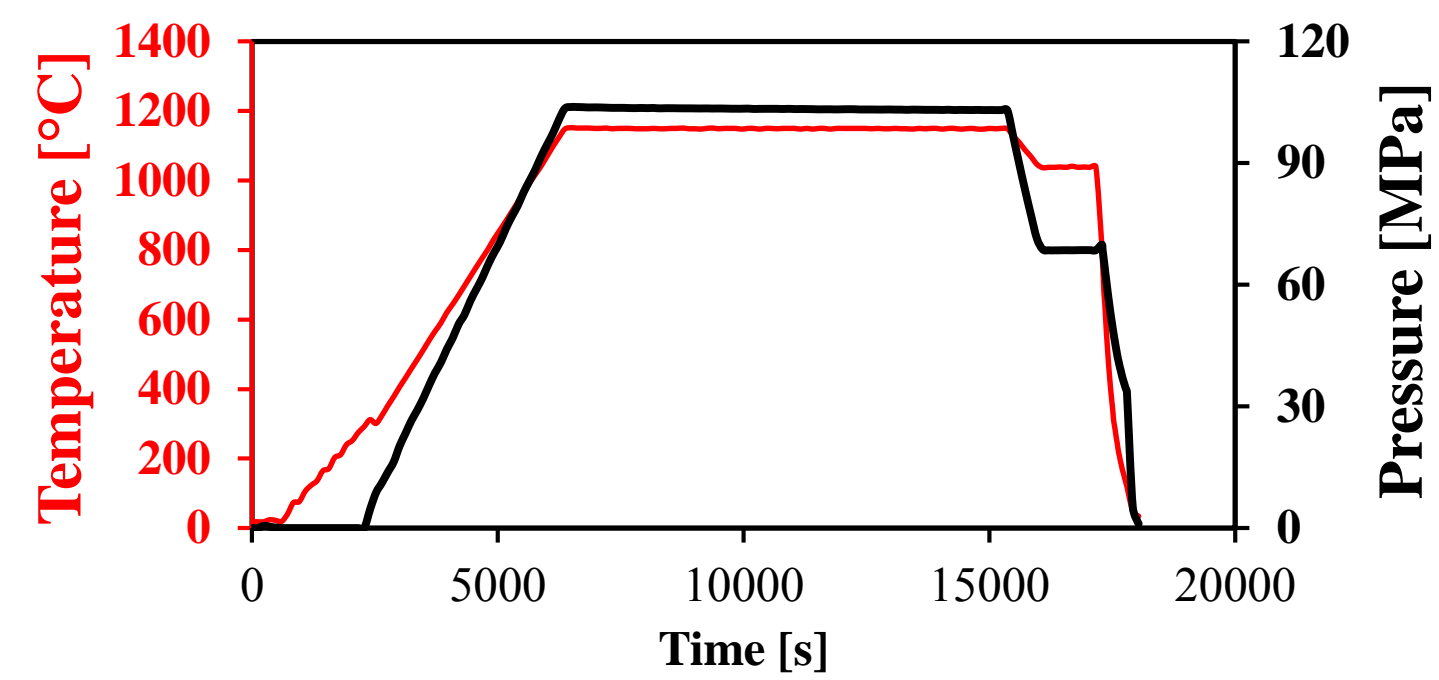

Figure 0.2.Hot-isostatic pressing processing conditions (temperature, pressure and time) used for post-processing as-printed 17-4 PH stainless steel gas-and water-atomized L-PBF parts.

\subsection{RESULTS AND DISCUSSION}

\subsubsection{MECHANICAL PROPERTIES}

The density of HIP treated samples fabricated using 17-4 PH gas and water-atomized powders at various energy densities is shown in Figure 3.3. The density was found to 
increase after HIP treatment when compared to the density of as-printed parts for four 174 PH stainless steel powders at various energy densities. The density of HIP treated gas and water-atomized L-PBF parts under all energy densities ranged around $\sim 99 \pm 0.5 \%$ whereas the density of as-printed L-PBF parts using the four powders varied between $89 \pm$ 0.5 and $98 \pm 0.5 \%[1],[2]$.

The fractional increase in densification of the L-PBF parts following HIP treatment was significant for coarser water-atomized L-PBF parts $\left(D_{50}=24\right.$ and $\left.43 \mu \mathrm{m}\right)$ when fabricated at energy densities of 64 and $80 \mathrm{~J} / \mathrm{mm}^{3}$. These results shows that densification and reduction in porosity in the as-printed L-PBF parts can be achieved using HIP treatment and does not depend significantly on the powder shape and size or the energy density used to fabricate the parts. An another important result of this study is that the minimum starting density of L-PBF parts in order to achieve $99 \pm 0.5 \%$ dense parts after HIP treatment, was $92 \pm 1 \%$ (water-atomized $\mathrm{D}_{50}=43 \mu \mathrm{m}$ at energy density $80 \mathrm{~J} / \mathrm{mm}^{3}$ ). A similar increase in density due to HIP treatment was observed in previous studies for L-PBF parts fabricated from other compositions [15]-[24]. Further, the densities of gas- $\left(\mathrm{D}_{50}=13 \mu \mathrm{m}\right)$ and wateratomized ( $\left.\mathrm{D}_{50}=43 \mu \mathrm{m}\right) \mathrm{L}-\mathrm{PBF}$ parts obtained from the current study is higher than densities of L-PBF parts fabricated from the same powders when they were post-processed using a different HIP cycle [69]. The HIP cycle used in the current study had an additional step in the cycle (Figure 3.2), at a solutionizing temperature of $1050^{\circ} \mathrm{C}$ and $70 \mathrm{MPa}$ pressure for 20 minutes which could have accelerated the densification of the L-PBF parts [69]. Atkinson et al. [70] indicated that addition of solutionizing temperature step at high 
pressures would lead to accelerated densification as per the plasticity/power-law creep for low-alloy steels. 


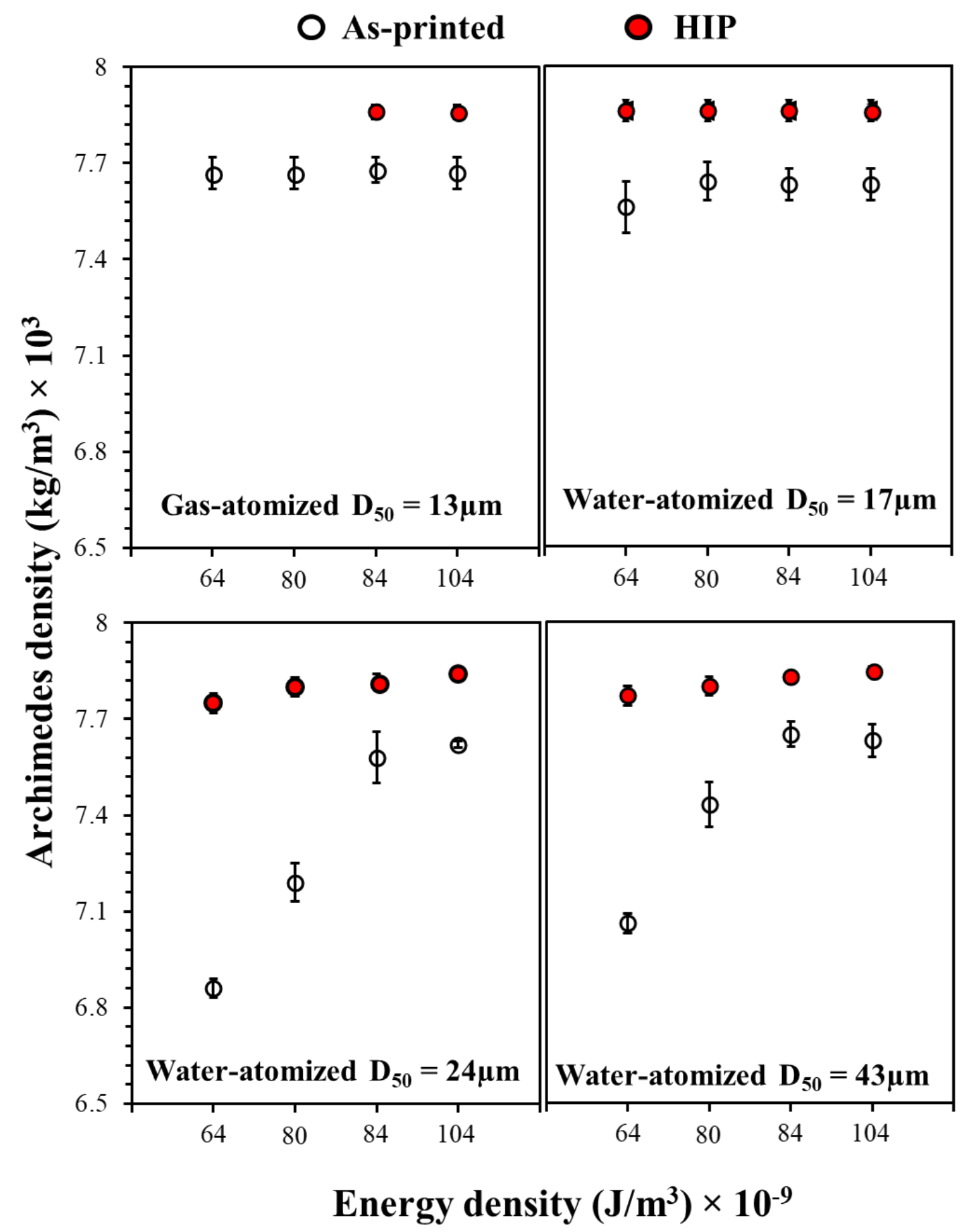

Figure 0.3 .The density of 17-4 PH stainless steel gas-and water-atomized L-PBF parts before and after HIP treatment as a function of energy density. 
The variation in the ultimate tensile strength of the HIP treated L-PBF parts with energy density for four 17-4 PH stainless steel powders is shown in Figure 3.4. The ultimate tensile strength of the L-PBF parts was found to increase due to HIP treatment. The increase in the ultimate tensile strength of the L-PBF parts can be attributed to the increase in density following HIP treatment (Figure 3.3). The HIP treated L-PBF parts fabricated using fine gas- $\left(\mathrm{D}_{50}=13 \mu \mathrm{m}\right)$ and water-atomized $\left(\mathrm{D}_{50}=17 \mu \mathrm{m}\right)$ powders showed significantly higher tensile strength $(1450 \pm 50 \mathrm{MPa})$ compared to as-printed L-PBF parts at all energy densities. Similar ultimate tensile strength values $(1450 \pm 50 \mathrm{MPa})$ were observed for HIP treated coarser water-atomized powder $\left(\mathrm{D}_{50}=43 \mu \mathrm{m}\right)$ for the L-PBF parts fabricated at energy densities 84 and $104 \mathrm{~J} / \mathrm{mm}^{3}$. However, the ultimate tensile strength of L-PBF parts fabricated using one of the water-atomized powder lots $\left(\mathrm{D}_{50}=24 \mu \mathrm{m}\right)$ was slightly lower; ranging between $1300 \pm 50 \mathrm{MPa}$ and $1400 \pm 20 \mathrm{MPa}$ after HIP treatment but still higher than the corresponding value for as-printed L-PBF parts. The fractional increase in ultimate tensile strength due to HIP treatment is significant for as-printed wateratomized L-PBF parts when compared to gas-atomized L-PBF parts (Figure 3.3). Further, the ultimate tensile strength of gas $\left(\mathrm{D}_{50}=13 \mu \mathrm{m}\right)$ and water-atomized $\left(\mathrm{D}_{50}=43 \mu \mathrm{m}\right) \mathrm{L}-\mathrm{PBF}$ parts after HIP treatment used in the current study is higher than the tensile strength of the L-PBF parts obtained after the HIP cycle used in our previous study [69].

The data obtained from the current study shows the effectiveness of HIP treatment on improving the ultimate tensile strength of the gas and water-atomized L-PBF parts. Overall, the data clearly shows the after using the current HIP treatment cycle, similar ultimate tensile strength values can be obtained using both water-atomized and gas-atomized L-PBF 
powders. Further, the ultimate tensile strength of L-PBF parts after HIP treatment obtained in the current study is higher than the ultimate tensile strength of the L-PBF parts when they were heat treated as shown in previous studies [3], [62], [71], [72]. For reference, the ultimate tensile strength of 17-4 PH stainless steel L-PBF parts in various studies after solutionizing and aging treatment ranged around $1275 \pm 75 \mathrm{MPa}$ [3], [62], [71], [72].

The hardness of gas and water-atomized L-PBF parts increased following HIP treatment and was found to be higher than the hardness of as-printed L-PBF parts at all energy densities, as shown in Figure 3.4. The hardness of the L-PBF parts after HIP treatment varied between $36 \pm 3$ and $40 \pm 3 \mathrm{HRC}$ and was higher than as-printed, and comparable to MIM and wrought values [2], [3], [13]. For reference, Murr et al. [45], [73] and Kumapty et al. [74] reported hardness values of $35 \pm 2 \mathrm{HRC}$ for 17-4 PH stainless gas-atomized LPBF parts. For further comparison, the hardness of $17-4 \mathrm{PH}$ stainless steel in the wrought state was reported to be $38 \pm 2 \mathrm{HRC}$ while parts fabricated using casting and MIM were reported to be $37 \pm 2 \mathrm{HRC}$ after heat treatment [75].

Figure 3.5 shows the effect of HIP treatment on the yield strength of gas and wateratomized L-PBF parts fabricated at various energy densities. It can be seen that the yield strength of the L-PBF parts increased due to the HIP treatment and higher than as-printed properties. The trends observed in Figure 3.5 are similar to the trends observed for ultimate tensile strength and hardness (Figure 3.3 and 3.4). The yield strength of the L-PBF parts fabricated using the fine gas $\left(\mathrm{D}_{50}=13 \mu \mathrm{m}\right)$ and water-atomized $\left(\mathrm{D}_{50}=17 \mu \mathrm{m}\right)$ powders after HIP treatment was $1200 \pm 30 \mathrm{MPa}$ irrespective of variation in energy density. These yield 
strength values are higher than the yield of coarser water-atomized parts at energy densities 64 and $80 \mathrm{~J} / \mathrm{mm}^{3}$. However, no difference in yield strength was observed between gas and water-atomized parts after HIP treatment at an energy density of $104 \mathrm{~J} / \mathrm{mm}^{3}$. Furthermore, the yield strength of the L-PBF parts after HIP treatment obtained in the current study is higher than the yield strength of L-PBF parts when they heat treated data reported in the literature [3], [62], [71], [72].

The elongation of gas and water-atomized L-PBF parts decreased due to HIP treatment and was lower than the elongation of the corresponding as-printed L-PBF parts at all energy densities, as shown in Figure 3.6. The trends observed in Figure 3.6 contrasted with the trends observed in the ultimate tensile strength, yield strength and hardness trends in this study. The elongation of the gas and water-atomized L-PBF parts after HIP treatment ranged between 5-11\% but was higher than the elongation of heat-treated 17-4 PH stainless steel L-PBF parts reported in previous studies [3], [62], [71], [72]. For comparison, the elongation of 17-4 PH stainless steel L-PBF parts in various studies after solutionizing and aging ranged between $2-5 \%$ [3], [62], [71], [72].

Overall, the current data suggest after HIP treatment that similar densities and mechanical properties can be achieved using a wide number of particle sizes for water-atomized powders compared to gas-atomized powders. Further, the values of HIP treated properties in this study were higher than values reported in literature for L-PBF 17-4 PH stainless steel using several heat treatment cycles. In the next section, results from x-ray diffraction 
and microstructure analysis performed on the HIP treated and as-printed L-PBF parts were to understand the origins of mechanical properties.

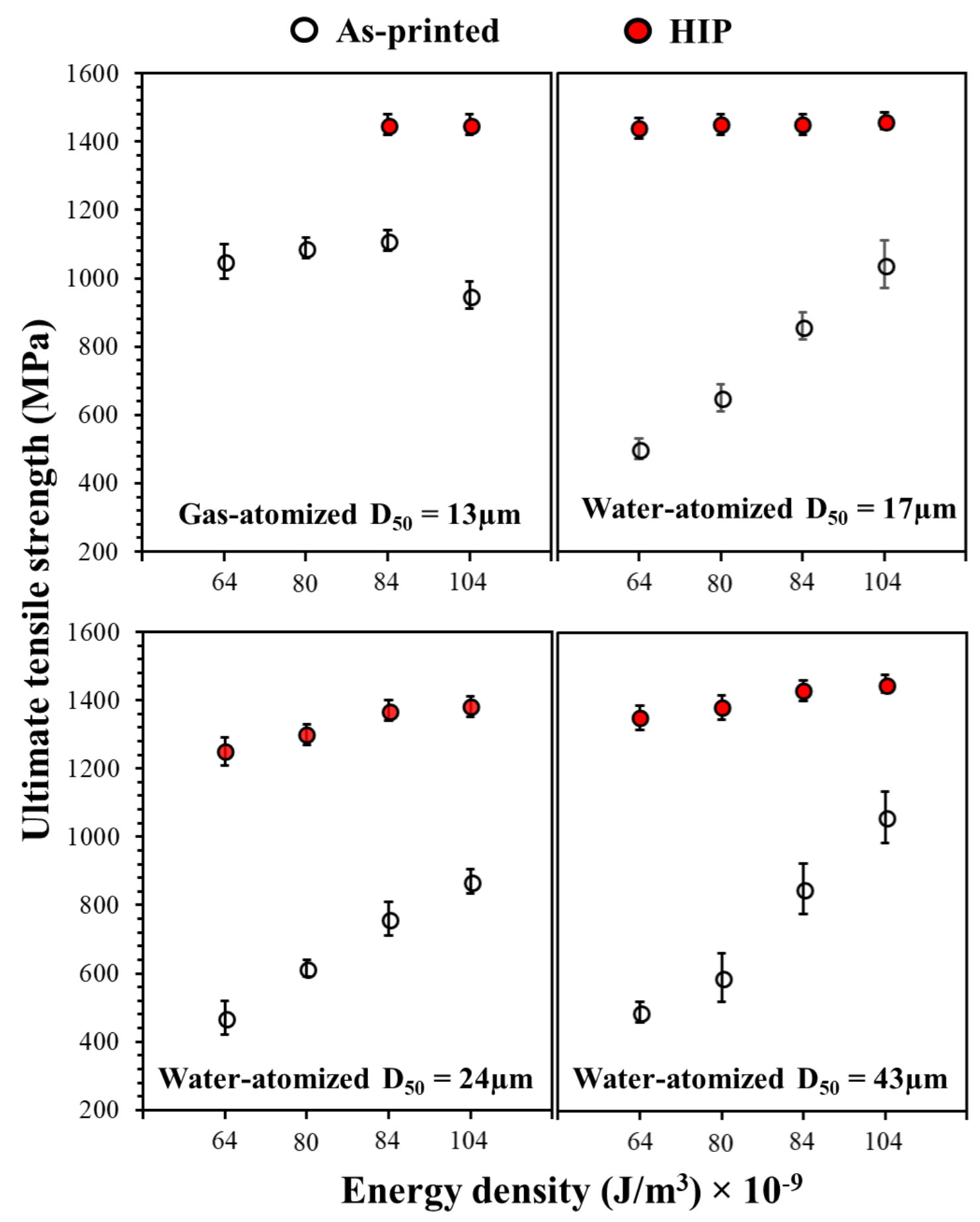

Figure 0.4.The variation in ultimate tensile strength with energy density for 17-4 PH stainless steel gas-and water-atomized L-PBF parts before and after HIP treatment. 


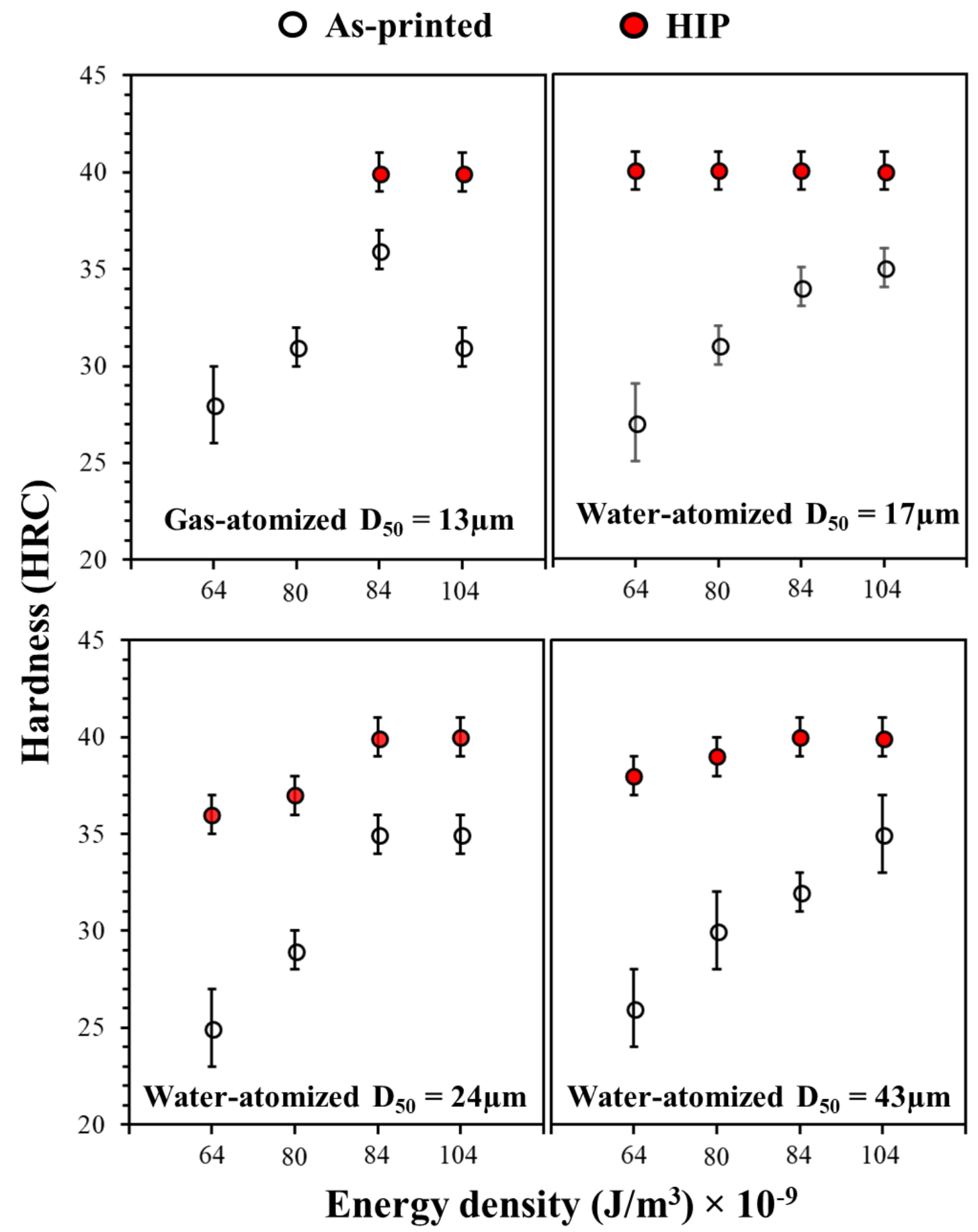

Figure 0.5.The variation in hardness with energy density for 17-4 PH stainless steel gasand water-atomized L-PBF parts before and after HIP treatment. 


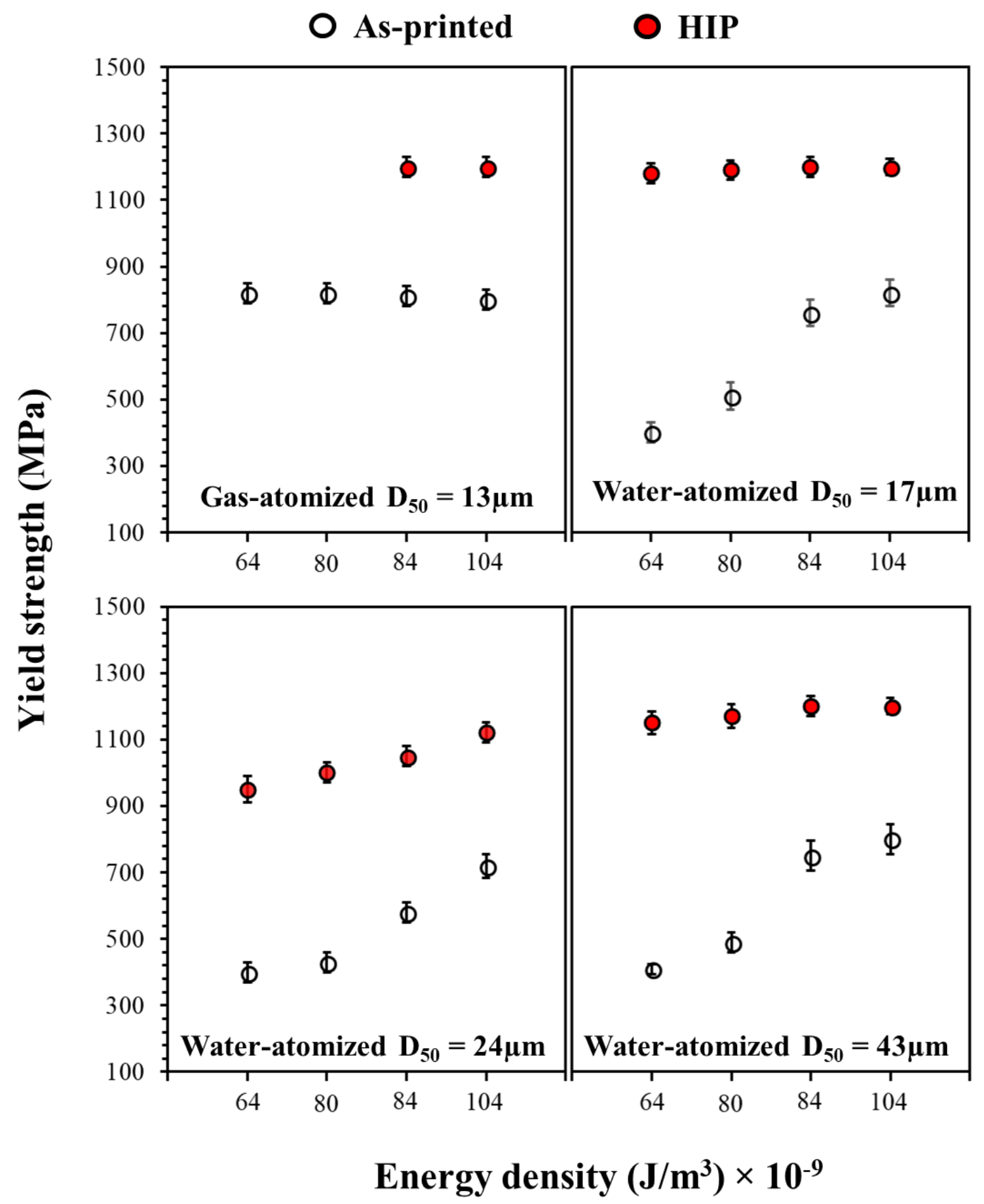

Figure 0.6.The variation in yield strength with energy density for 17-4 PH stainless steel gas-and water-atomized L-PBF parts before and after HIP treatment. 


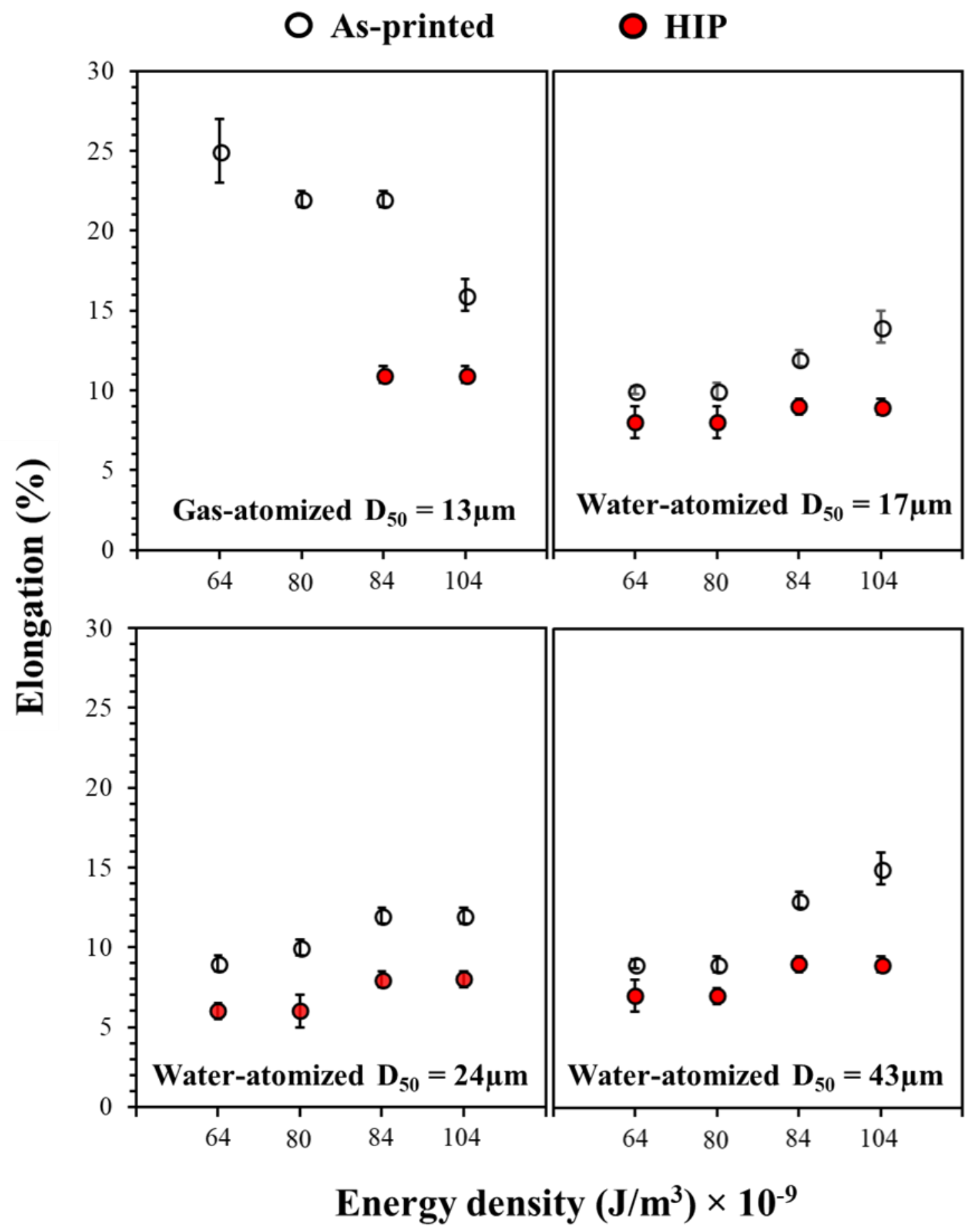

Figure 0.7.The variation in elongation with energy density for 17-4 PH stainless steel gas-and water-atomized L-PBF parts before and after HIP treatment. 


\subsubsection{MICROSTRUCTURES}

Figure 3.8 shows the XRD data on the effects of HIP treatment on gas and water-atomized L-PBF parts at all energy densities. HIP treatment resulted in predominantly forming the martensite phase in the L-PBF parts irrespective of the initial phases present in the asprinted parts. Further, the phases in the HIP treated L-PBF parts were not significantly sensitive to the size and shape of the powder. It is expected that the martensite phase present in the HIP treated L-PBF parts would have also contributed (in addition to density increase) to the increase in ultimate tensile strength as shown in Figure 3.3 when compared to asprinted parts. The phase change is significant for water-atomized L-PBF parts after the HIP treatment when compared to gas-atomized L-PBF parts. The increase in martensite content in the L-PBF parts may be attributed to the rapid cooling rates during the HIP treatment [21 -30]. According to continuous cooling transformation (CCT) curves, martensite forms in the L-PBF parts when the austenite phase in the starting condition is rapidly cooled to room temperature [32].

The microstructures of the L-PBF parts before and after the HIP treatment at energy densities 84 and $104 \mathrm{~J} / \mathrm{mm}^{3}$ for gas-atomized powders and at energy densities 64 and 104 $\mathrm{J} / \mathrm{mm}^{3}$ for water-atomized powders were shown in Figure 3.9. The following symbols were used in Figure 3.9 to distinguish the microstructures (G-13: gas-atomized $D_{50}=13 \mu \mathrm{m} ; \mathrm{W}$ 17: water-atomized $\mathrm{D}_{50}=17 \mu \mathrm{m}$; W-24: water-atomized $\mathrm{D}_{50}=24 \mu \mathrm{m}$; W-43: water-atomized $\mathrm{D}_{50}=43 \mu \mathrm{m}$ and 64 and $104 \mathrm{~J} / \mathrm{mm}^{3}$ represent energy densities). 

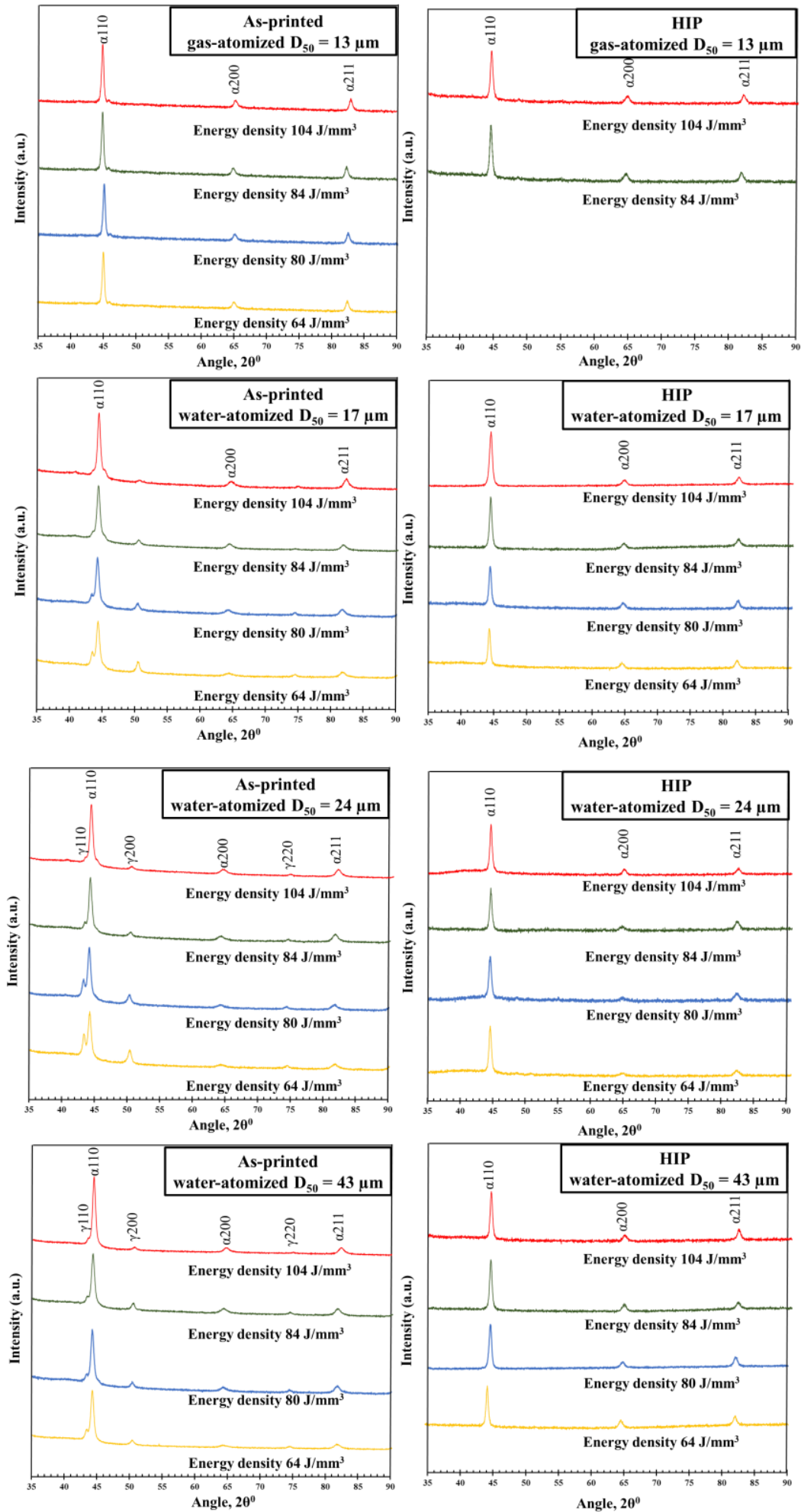

Figure 0.8.The XRD phases in gas and water-atomized L-PBF parts before and after HIP treatment for parts fabricated at energy densities of $64,80,84$ and $104 \mathrm{~J} / \mathrm{mm}^{3}$ 

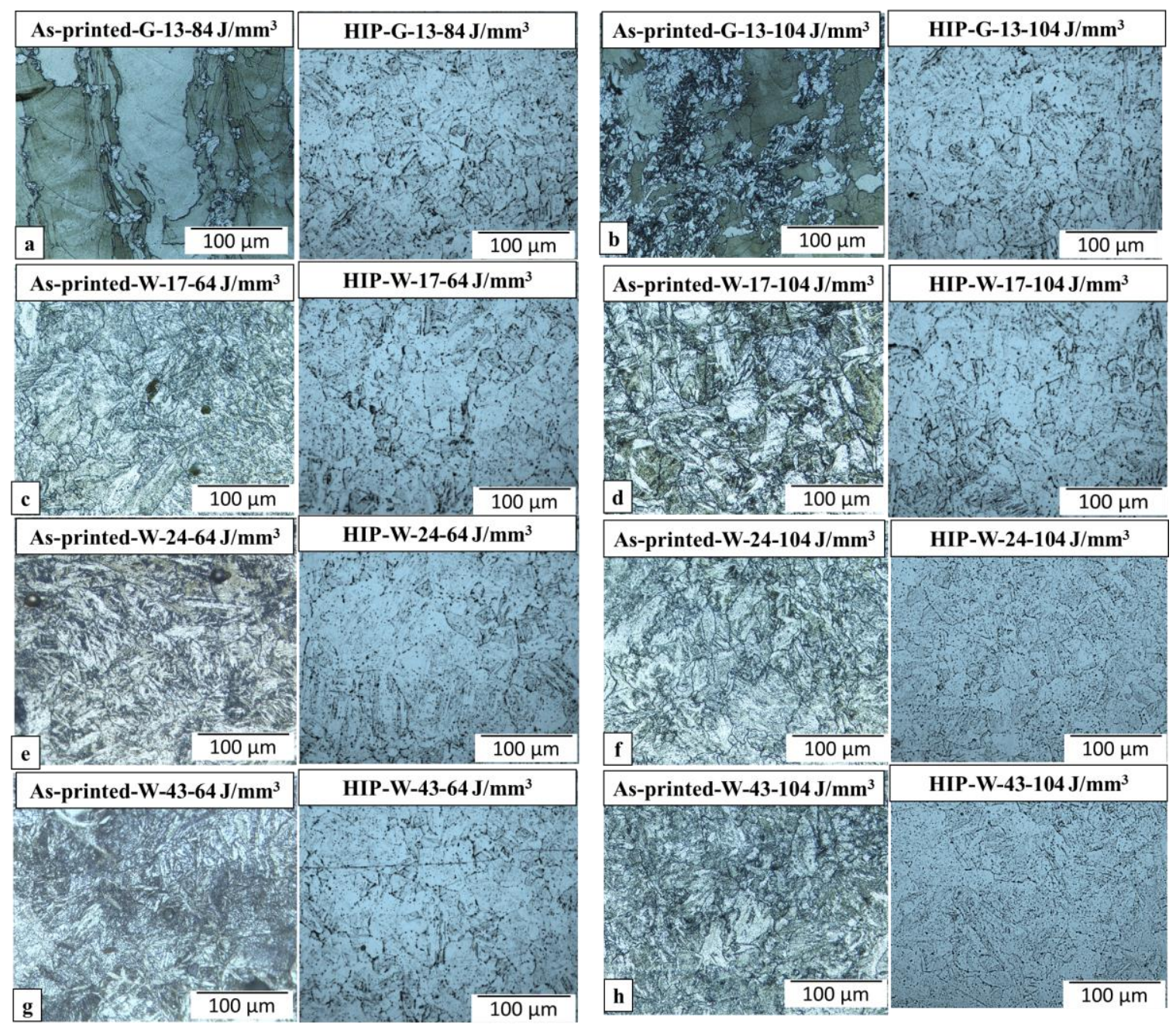

Figure 0.9.The microstructures of gas and water-atomized L-PBF parts before and after HIP treatment for parts fabricated at energy densities of 64 and $104 \mathrm{~J} / \mathrm{mm}^{3}$.

It can be clearly seen that the microstructural features present in the as-printed parts were completely different from the HIP'ed gas and water-atomized L-PBF parts as shown in

Figure 3.9. The microstructure formation trends which were observed in the L-PBF parts after the HIP treatment is a contrast to the trends observed in the as-printed L-PBF parts microstructures. The long columnar grains of average size $25 \pm 5 \mu \mathrm{m}$ and $20 \pm 5 \mu \mathrm{m}$ present in as-printed gas and water-atomized L-PBF parts, respectively, were translated to homogeneous equiaxed grains $18 \pm 1 \mu \mathrm{m}$ and $15 \pm 1 \mu \mathrm{m}$, respectively, after the HIP 
treatment. This variation in grain shape and size could have also influenced the ultimate tensile strength, yield, and elongation of the L-PBF parts as shown in Figures 3.4, 3.6 and 3.7. During HIP treatment, the fluid at high temperature exhibits an isotropic pressure on the L-PBF parts, resulting in creep and diffusion phenomena that could cause the densification and microstructure variation in the L-PBF parts [70]. It is surmised that the creep and diffusion phenomena could result in strengthening grain boundaries and increasing dislocations along the grain boundaries. During tensile testing, larger stresses are needed to move these dislocations resulting in an increase in the yield strength of the material [70]. Previous studies by Tillman et al.[20] , Lavery et al. [16] and Wu et al.[24] showed the transformation of long columnar grains to equiaxed grain structure for various materials after the HIP treatment.

A notable aspect of the current study is the achievement of similar densities, mechanical properties and microstructures in the L-PBF parts from both gas and water-atomized powders after the HIP treatment. The density, mechanical properties and microstructures variation data for the four 17-4 PH stainless steel L-PBF parts are summarized in Table 3.1. 
Table 3.1. The density, mechanical properties and microstructure variation in $17-4 \mathrm{PH}$ stainless steel gas-and water-atomized L-PBF parts following HIP treatment.

\begin{tabular}{|c|c|}
\hline $\begin{array}{l}\text { 17-4 PH stainless steel } \\
\text { L-PBF parts from: }\end{array}$ & Effects on properties following HIP treatment \\
\hline $\begin{array}{l}\text { Gas-atomized powder } \\
\mathrm{D}_{50}=13 \mu \mathrm{m}\end{array}$ & $\begin{array}{c}\text { Increased } \\
\text { Density: } 98 \pm 1 \text { to } 99.5 \pm 0.2 \%, \\
\text { Ultimate tensile strength: } 950 \pm 50 \text { to } 1450 \pm 20 \mathrm{MPa} \text {, } \\
\text { Hardness: } 30 \pm 1 \text { to } 40 \pm 1 \mathrm{HRC}, \\
\text { Yield strength: } 800 \pm 50 \text { to } 1200 \pm 20 \mathrm{MPa} \\
\text { Other changes } \\
\text { Elongation: } 22 \pm 1 \text { to } 11 \pm 1 \% \\
\text { Martensite phase did not change } \\
\text { Long columnar grains }(25 \pm 5 \mu \mathrm{m}) \text { transformed to } \\
\text { equiaxed grains }(18 \pm 1 \mu \mathrm{m})\end{array}$ \\
\hline $\begin{array}{l}\text { Water-atomized powder } \\
\qquad \mathrm{D}_{50}=17 \mu \mathrm{m}\end{array}$ & $\begin{array}{c}\text { Increased } \\
\text { Density: } 96 \pm 1 \text { to } 99.5 \pm 0.2 \%, \\
\text { Ultimate tensile strength: } 500 \pm 50 \text { to } 1450 \pm 20 \mathrm{MPa} \text {, } \\
\text { Hardness: } 27 \pm 1 \text { to } 40 \pm 1 \mathrm{HRC}, \\
\text { Yield strength: } 400 \pm 50 \text { to } 1200 \pm 20 \mathrm{MPa} \\
\text { Other changes } \\
\text { Elongation: } 14 \pm 1 \text { to } 8 \pm 1 \% \\
\text { Austenite phase transformed to the martensite phase } \\
\text { Long columnar grains }(20 \pm 5 \mu \mathrm{m}) \text { transformed to } \\
\text { equiaxed grains }(15 \pm 1 \mu \mathrm{m})\end{array}$ \\
\hline $\begin{array}{l}\text { Water-atomized powder } \\
\qquad \mathrm{D}_{50}=24 \mu \mathrm{m}\end{array}$ & $\begin{array}{c}\text { Increased } \\
\text { Density: } 88 \pm 1 \text { to } 99 \pm 0.2 \%, \\
\text { Ultimate tensile strength: } 480 \pm 30 \text { to } 1400 \pm 20 \mathrm{MPa} \text {, } \\
\text { Hardness: } 25 \pm 1 \text { to } 40 \pm 1 \mathrm{HRC}, \\
\text { Yield strength: } 400 \pm 50 \text { to } 1100 \pm 20 \mathrm{MPa} \\
\text { Other changes } \\
\text { Elongation: } 12 \pm 1 \text { to } 6 \pm 1 \% \\
\text { Austenite phase transformed to the martensite phase } \\
\text { Long columnar grains }(20 \pm 5 \mu \mathrm{m}) \text { transformed to } \\
\text { equiaxed grains }(14 \pm 1 \mu \mathrm{m})\end{array}$ \\
\hline $\begin{array}{l}\text { Water-atomized powder } \\
\qquad \mathrm{D}_{50}=43 \mu \mathrm{m}\end{array}$ & $\begin{array}{c}\text { Increased } \\
\text { Density: } 90 \pm 1 \text { to } 99 \pm 0.2 \%, \\
\text { Ultimate tensile strength: } 490 \pm 30 \text { to } 1440 \pm 20 \mathrm{MPa} \text {, } \\
\text { Hardness: } 27 \pm 1 \text { to } 40 \pm 1 \mathrm{HRC}, \\
\text { Yield strength: } 400 \pm 50 \text { to } 1180 \pm 20 \mathrm{MPa} \\
\text { Other changes } \\
\text { Elongation: } 14 \pm 1 \text { to } 7 \pm 1 \% \\
\text { Austenite phase transformed to the martensite phase } \\
\text { Long columnar grains }(20 \pm 5 \mu \mathrm{m}) \text { transformed to } \\
\text { equiaxed grains }(16 \pm 1 \mu \mathrm{m})\end{array}$ \\
\hline
\end{tabular}




\subsection{CONCLUSIONS}

A comprehensive study was performed to understand the effects of HIP treatment on the densification, mechanical properties and microstructures of 17-4 PH stainless steel gas and water-atomized L-PBF parts at various energy densities. The results from the current study show the strong dependence of densification, mechanical properties and microstructures on temperature, pressure and time during the HIP cycle. The density, ultimate tensile strength, hardness and yield strength of gas and water-atomized L-PBF parts increased due to HIP treatment and were higher than as-printed properties. Following HIP treatment, 99.5 $\pm 0.2 \%$ dense L-PBF parts with ultimate tensile strength: $1450 \pm 20 \mathrm{MPa}$, hardness: $40 \pm$ $1 \mathrm{HRC}$, yield strength: $1180 \pm 20 \mathrm{MPa}$ and elongation: $10 \pm 1 \%$ were achieved using both water and gas-atomized powders. The density, martensite content and equiaxed microstructure in L-PBF parts after the HIP treatment were consistent with the trends in mechanical properties of the L-PBF parts. The austenite phase present in the as-printed water-atomized parts transformed to martensite phase after HIP treatment and contributed to the increase ultimate tensile strength of the L-PBF parts at all energy densities. Further, the long columnar grains present in the as-printed gas and water-atomized L-PBF parts (20 $\pm 5 \mu \mathrm{m})$ translated to homogeneous equiaxed grains $(15 \pm 1 \mu \mathrm{m})$ in HIP treated L-PBF parts at all energy densities. This variation in grain structure and grain size significantly affected the yield strength, ultimate tensile strength and elongation of HIP treated gas and water-atomized L-PBF parts. 


\section{CHAPTER 4}

\section{EFFECTS OF POWDER CHARACTERISTICS AND PROCESSING CONDITIONS ON THE CORROSION PERFORMANCE OF 17-4 PH STAINLESS STEEL}

\section{FABRICATED BY LASER-POWDER BED FUSION}

\subsection{INTRODUCTION}

Stainless steel alloys have been used in many applications due to their excellent strength and corrosion properties [1-4]. The laser-powder bed fusion (L-PBF) process has gained attention and importance due to its potential to produce complex-shaped parts for medical, tooling, automotive and aerospace industries [1,5-8]. The L-PBF process is layer by laser melting or fusion process which uses a laser beam to melt the starting powder for fabricating a desired 3D component [1-4]. Among stainless steels, 17-4 PH stainless steel is desirable for fabrication of parts using L-PBF process in transportation (engine components, gears, fuel injectors) and injection molding industries (injection mold with conformal cooling channels) within our research group as shown in Figure 4.1. 


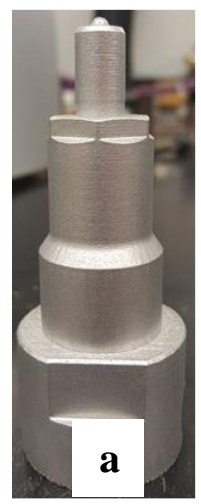

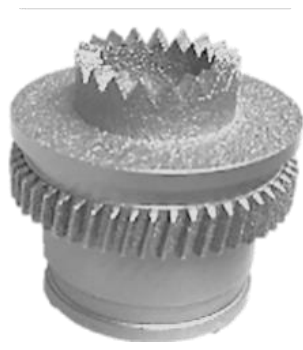

b

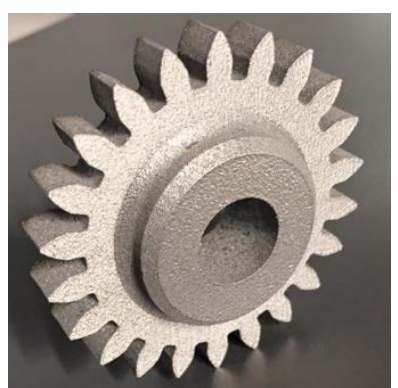

c

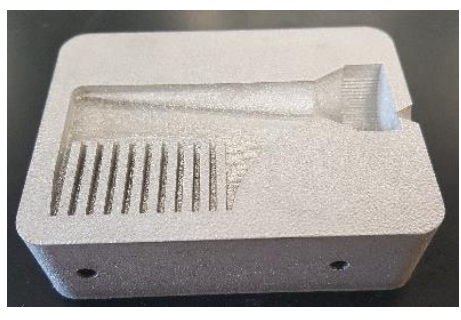

d

Figure 0.1.17-4 PH stainless steel L-PBF parts fabricated by our research group in design collaboration with various industries (a) Fuel injector with conformal cooling channels (Cummins, Columbus, OH) (b) helicopter engine part (Helicopter Transport Services,

Portland, OR) (c) automotive engine gear (Cummins, Columbus, OH) (d) plastic injection mold with conformal cooling channels (Amaray Plastic Inc., Elizabethtown, $\mathrm{KY}$ ).

Many research studies have been carried out to understand the effects of powder and processing conditions on the densification behavior and structural attributes of components fabricated by the L-PBF process $[1,3,7,9-15]$. Most of the prior studies indicated that quality of parts produced using the L-PBF process depends on many factors, the most important being processing conditions and powder characteristics. The effect of processing conditions such as laser power, scan speed, layer thickness, scan spacing on the densification of powders has been extensively studied in recent years [1-4]. On the other hand, in-depth experimental studies on the influence of powder characteristics such as powder shape, size on the densification behavior have been reported only in the recent past $[2,5]$. The variation in densification phenomena of the powder as a function of powder type and processing conditions could lead to porosities in the parts fabricated using L-PBF process $[1,3,7,9-15]$. 
The porosity in L-PBF parts fabricated using stainless steel powders could not only affects the mechanical properties but also influence the sensitivity to localized corrosion attack, especially in the corrosion environments [16-19]. However, the corrosion properties of LPBF components fabricated from powders with different characteristics and in different processing conditions have not received much attention in the literature. The corrosion resistance of stainless steel parts results from a thin and protective passive film chromium oxide $\left(\mathrm{Cr}_{2} \mathrm{O}_{3}\right)$ or iron oxide $\left(\mathrm{Fe}_{2} \mathrm{O}_{3}\right)$ based passive film. The chromium or iron oxide passive film acts as a partial barrier between the metal and the corrosive species present in the environment $[16,18,20-23]$. The stability of the passive film when exposed to aggressive corrosive species such as chloride ions is important in preventing corrosion $[16,18,20,22-25]$. However, the porosity in L-PBF parts can be expected to compromise the passive film layer stability and could result in enhanced corrosion of the L-PBF parts $[16-19,26]$. Therefore, it is important to understand the corrosion behavior of 17-4 PH stainless steel components built using L-PBF process in natural service conditions.

Independent corrosion studies in various electrolytes have been reported on 17-4 PH stainless steel L-PBF parts fabricated using gas -atomized powders [16, 18, 20, 23, 25, 27]. However, few studies have been reported that compare the corrosion resistance of the 174 PH stainless steel L-PBF parts fabricated from powders of different characteristics such as shape, size and the method utilized for atomization (gas-atomized or water-atomized) $[16,18]$. In order to address this gap in the literature, the present study was carried out to understand the effect of powder characteristics and processing conditions on the corrosion performance of 17-4 PH stainless steel L-PBF parts. The results from the current study will 
provide a better understanding of the effect of porosity, density and microstructures on the corrosion performance of 17-4 PH stainless steel L-PBF gas- and water-atomized parts.

\subsection{EXPERIMENTAL MATERIALS AND METHODS}

One 17-4 PH stainless steel gas-atomized powder and three water-atomized powders were used in this study. The gas-atomized 17-4 PH stainless steel powder utilized for this study was supplied by 3D Systems. The water-atomized 17-4 PH stainless steel powders were obtained from North American Höganäs. A high-resolution FEI Quanta 600F scanning electron microscope (SEM) was used for morphology analysis of the powders. The L-PBF experiments were performed on a 3D Systems ProX 200 machine in an argon environment. The tensile geometries were fabricated using four energy densities to melt the powders, i.e. $64,80,84$ and $104 \mathrm{~J} / \mathrm{mm}^{3}$. The energy densities were calculated using the laser processing parameters like laser power, scan speed, hatch spacing and layer thickness. In this study, two laser powers (150 and $195 \mathrm{~W})$ and two scan speeds (1250 and $1550 \mathrm{~mm} / \mathrm{s})$ were used to fabricate the tensile geometries while layer thickness and hatch spacing were kept constant at $30 \mu \mathrm{m}$ and $50 \mu \mathrm{m}$, respectively.

A total of 64 parts from four powders in four processing conditions were fabricated during the study. Of the 64 parts, four parts fabricated from each powder type and in one processing condition were selected for Archimedes density and corrosion performance analysis. Density measurements were conducted using the Archimedes method on a Mettler Toledo XS104 weighing balance. The density values of the 17-4 PH stainless steel gas- and water-atomized L-PBF parts were expressed as a percentage relative to the density 
of the 17-4 PH stainless steel cast part $\left(7.87 \mathrm{~g} / \mathrm{cm}^{3}\right)$. The porosity of L-PBF parts was calculated using Equation 4.1.

$$
\phi=1-\frac{\rho(l)}{\rho(t)}
$$

Where, $\phi$ is the porosity of the L-PBF parts, $\rho(l)$ is the density of the L-PBF parts, $\rho(t)$ is the density of 17-4 PH stainless cast part.

Potentiostatic polarization experiments were used to compare the electrochemical or corrosion behavior of the test coupons. All polarization experiments were conducted in an electrochemical glass cell shown in Figure 2.2. Metrohm Autolab PGSTAT100N was used to perform three electrode electrochemical measurement. $\mathrm{Ag} / \mathrm{AgCl}$ was used as a reference electrode and the platinum was used as a counter electrode. The polarization experiments were carried out on L-PBF parts by varying the potential from $1 \mathrm{~V} / \mathrm{Ag} / \mathrm{AgCl}$ to $-1 \mathrm{~V} /$ $\mathrm{Ag} / \mathrm{AgCl}$. The surface area of $1 \mathrm{~cm}^{2}$ of each L-PBF part, which was finished with 1200 grit $\mathrm{SiC}$ paper, was exposed to the $0.5 \mathrm{M} \mathrm{NaCl}$ solution in ambient conditions. All experiments were carried out at room temperatures and were repeated 3 times for each specimen.

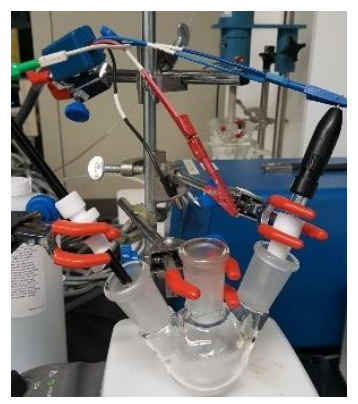

Figure 0.2.Electrochemical corrosion studies setup used in this study. 
A summary of 17-4 PH stainless steel particle characteristics used in this study is reported in Table $4.1[28,29]$. The morphology (shape and size) of the powders was characterized using SEM and shown in Figure 4.3, showing the gas-atomized powders to be spherical while the water-atomized powders were irregular in shape.

Table 4.1. Particle characteristics of the 17-4 PH stainless steel gas- and water-atomized powders.

\begin{tabular}{|c|c|c|c|c|c|}
\hline \multirow{2}{*}{ Powder } & \multicolumn{3}{|c|}{ Particle distribution } & \multirow{2}{*}{} \\
\cline { 2 - 5 } & $\begin{array}{c}\mathbf{D}_{10} \\
(\boldsymbol{\mu m})\end{array}$ & $\begin{array}{c}\mathbf{D}_{\mathbf{5 0}} \\
(\boldsymbol{\mu \mathbf { m } )}\end{array}$ & $\begin{array}{c}\mathbf{D}_{\mathbf{9 0}} \\
(\boldsymbol{\mu m})\end{array}$ & $\begin{array}{c}\text { Tap density } \\
(\mathbf{g} / \mathbf{c c})\end{array}$ & $\begin{array}{c}\text { Apparent } \\
\mathbf{d e n s i t y ~ ( g / c c )}\end{array}$ \\
\hline Gas-atomized (G) & 5 & 13 & 27 & $4 \pm 0.05$ & $3 \pm 0.002$ \\
\hline Water-atomized (W) 1 & 10 & 17 & 28 & $4.3 \pm 0.05$ & $3 \pm 0.05$ \\
\hline Water-atomized (W) 2 & 16 & 24 & 37 & $3.7 \pm 0.01$ & $2.8 \pm 0.05$ \\
\hline Water-atomized (W) 3 & 26 & 43 & 67 & $3.7 \pm 0.05$ & $2.8 \pm 0.05$ \\
\hline
\end{tabular}




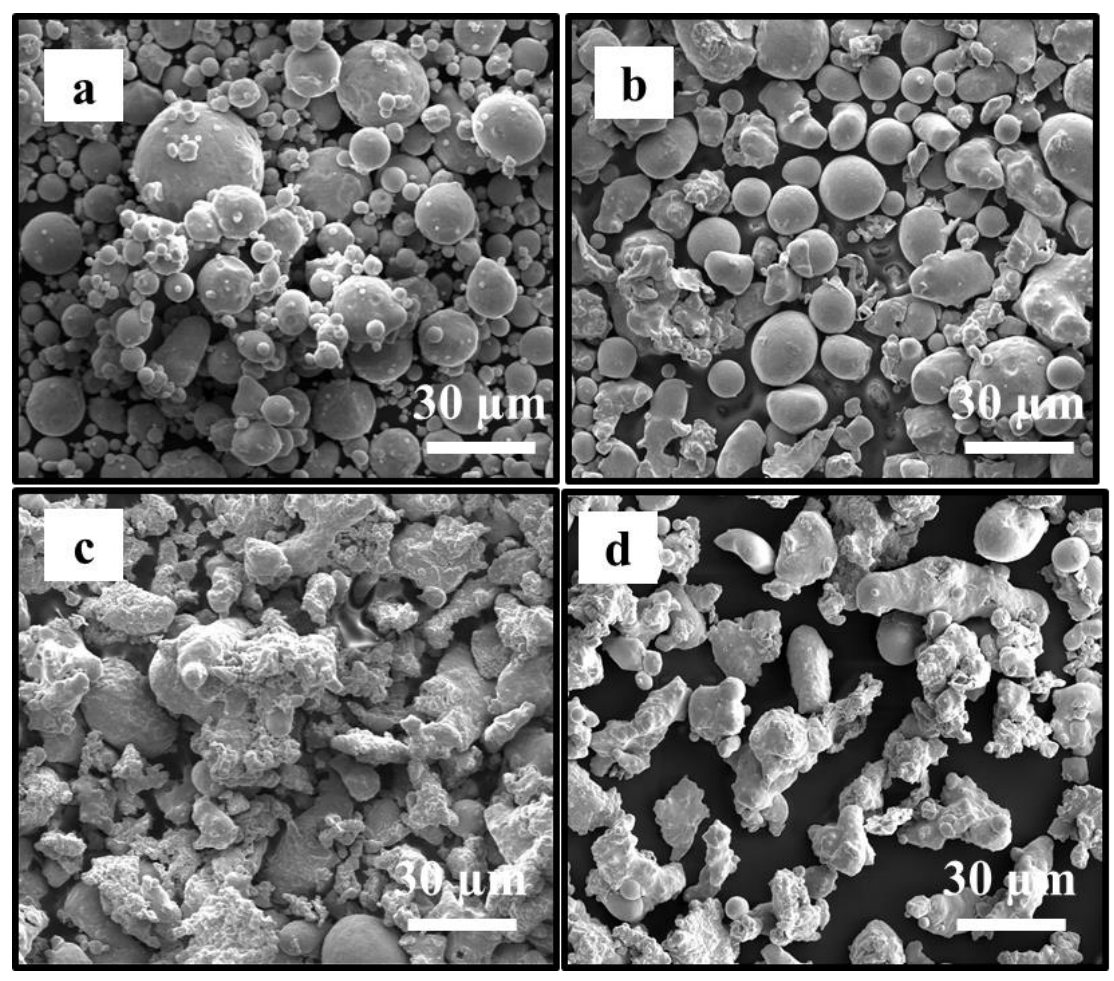

Figure 0.3.SEM images of the 17-4 PH stainless steel gas- and water-atomized powders used in this study (a) gas-atomized powder $\left(\mathrm{D}_{50}=13 \mu \mathrm{m}\right)(\mathrm{b})$ water-atomized powder $\left(\mathrm{D}_{50}\right.$ $=17 \mu \mathrm{m})(\mathrm{c})$ water-atomized powder $\left(\mathrm{D}_{50}=24 \mu \mathrm{m}\right)$ and $(\mathrm{d})$ water-atomized powder $\left(\mathrm{D}_{50}=\right.$ $43 \mu \mathrm{m})$.

\subsection{RESULTS AND DISUSSION}

The variation of density as a function of the energy density used to fabricate L-PBF parts using four 17-4 PH stainless steel powders are reported in Table 4.2. 
Table 4.2. Densities (expressed as \% theoretical) of the 17-4 PH stainless steel gas- and water-atomized L-PBF parts fabricated under energy densities ranging from 64 to 104

\begin{tabular}{|c|c|c|c|c|}
\hline $\begin{array}{c}\text { L-PBF parts } \\
\text { from }\end{array}$ & $\begin{array}{c}\text { Energy } \\
\text { density } \\
\mathbf{6 4} \mathbf{~ J} / \mathbf{m m}^{3}\end{array}$ & $\begin{array}{c}\text { Energy } \\
\text { density } \\
\mathbf{8 0 ~ J / \mathbf { m m } ^ { 3 }}\end{array}$ & $\begin{array}{c}\text { Energy } \\
\text { density } \\
\mathbf{8 4} \mathbf{~ J} / \mathbf{m m}^{3}\end{array}$ & $\begin{array}{c}\text { Energy } \\
\text { density } \\
\mathbf{1 0 4} \mathbf{~ J} / \mathbf{m m}^{3}\end{array}$ \\
\hline $\begin{array}{c}\text { Gas-atomized } \\
\mathrm{D}_{50}=13 \mu \mathrm{m}\end{array}$ & $97 \pm 0.5 \%$ & $97.5 \pm 0.5 \%$ & $97.5 \pm 0.5 \%$ & $97.5 \pm 0.5 \%$ \\
\hline $\begin{array}{c}\text { Water-atomized } \\
\mathrm{D}_{50}=17 \mu \mathrm{m}\end{array}$ & $96 \pm 1 \%$ & $97 \pm 0.5 \%$ & $97 \pm 0.5 \%$ & $97 \pm 0.5 \%$ \\
\hline $\begin{array}{c}\text { Water-atomized } \\
\mathrm{D}_{50}=24 \mu \mathrm{m}\end{array}$ & $87 \pm 0.5 \%$ & $91 \pm 0.5 \%$ & $96 \pm 1 \%$ & $97 \pm 0.5 \%$ \\
\hline $\begin{array}{c}\text { Water-atomized } \\
\mathrm{D}_{50}=43 \mu \mathrm{m}\end{array}$ & $89 \pm 0.5 \%$ & $95 \pm 0.5 \%$ & $97 \pm 0.5 \%$ & $97 \pm 0.5 \%$ \\
\hline
\end{tabular}

The densities of L-PBF parts produced using coarser water-atomized powders $\left(\mathrm{D}_{50}=24 \mu \mathrm{m}\right.$ and $43 \mu \mathrm{m}$ ) were lower when compared to the density of L-PBF parts produced using the finer gas-atomized $\left(\mathrm{D}_{50}=13 \mu \mathrm{m}\right)$ and water-atomized $\left(\mathrm{D}_{50}=17 \mu \mathrm{m}\right)$ powders $(97 \pm 0.5 \%)$ at low energy densities of 64 and $80 \mathrm{~J} / \mathrm{mm}^{3}$. The high density of the L-PBF parts $(97 \pm 0.5$ $\%)$ fabricated using finer gas-atomized $\left(\mathrm{D}_{50}=13 \mu \mathrm{m}\right)$ and water-atomized $\left(\mathrm{D}_{50}=17 \mu \mathrm{m}\right)$ powders can be attributed to their high tap $(4 \pm 0.05 \mathrm{~g} / \mathrm{cc})$ and apparent density $(3 \pm 0.05$ g/cc) (Table 4.2). Lee et al. [30] showed that high apparent density of powders could result in better packing density of the powder bed. The high packing density of the powder bed presumably results in better melt pool hydrodynamic stabilities ensuing enhance densification of the powders during the L-PBF process [1], [96]-[99]. However, the density of three 17-4 PH stainless steel water-atomized powders is similar $(97 \pm 0.5 \%)$ and comparable to 17-4 $\mathrm{PH}$ stainless steel gas-atomized powders when processed at high energy densities 84 and $104 \mathrm{~J} / \mathrm{mm}^{3}$. At higher energy densities, a large amount of molten 
pool with low viscosity and better wettability properties is likely to be formed in the powder bed producing high dense L-PBF parts[28, 30-33].
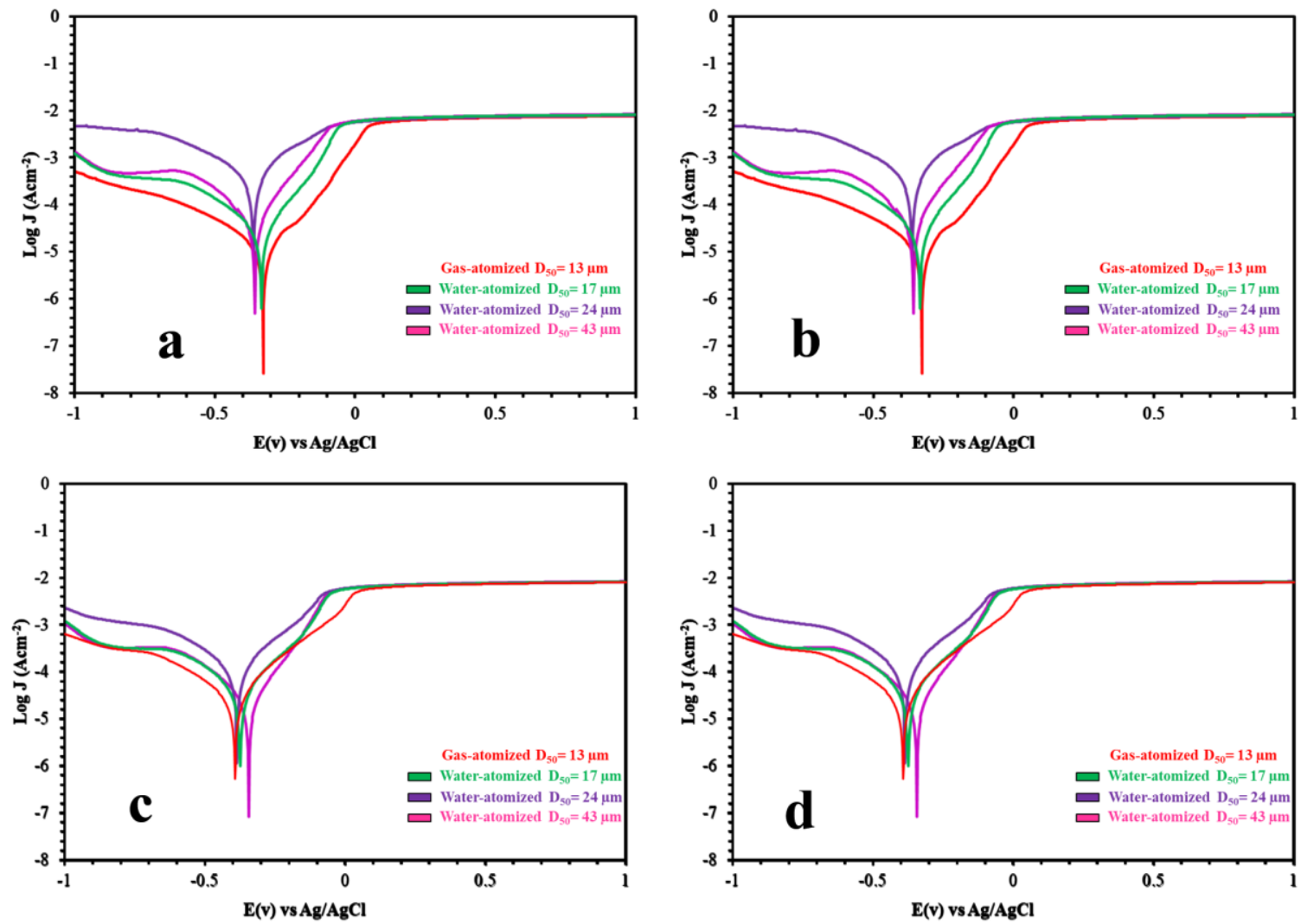

Figure 0.4.Tafel plots of the components fabricated from four 17-4 PH stainless steel powders fabricated at (a) energy density $64 \mathrm{~J} / \mathrm{mm}^{3}$ (b) energy density $80 \mathrm{~J} / \mathrm{mm}^{3}$ (c) energy density $84 \mathrm{~J} / \mathrm{mm}^{3}$ and (d) energy density $104 \mathrm{~J} / \mathrm{mm}^{3}$.

The variation in Tafel plots curves as a function of the energy density used to fabricate LPBF parts from the four 17-4 PH stainless steel powders is shown in Figure 4.4. The Tafel plots curves shown in Figure 4.4 qualitatively indicated different anode and cathode curve behavior in 17-4 PH stainless steel gas- and water-atomized L-PBF parts when fabricated at different energy densities. The quantification of the Tafel plots behavior was 
subsequently performed to further understand the effect of density on the corrosion performance of four 17-4 PH stainless steel powders. Using the Tafel plot quantification method [84], [86], the 17-4 PH stainless steel L-PBF parts Tafel plots were analyzed as shown in Figure 4.5 for calculating the corrosion current, $i_{\text {corr }}$ and Tafel constants. The corrosion current, $\mathrm{i}_{\text {corr }}$ and Tafel constants were used to determine the polarization resistance $\mathrm{R}_{\mathrm{p}}$ and corrosion rate from Equation 4.2 and 4.3, respectively

$$
\text { Polarization resistance, } \mathrm{R}_{\mathrm{p}}=\frac{1}{i_{\text {corr }}}\left(\frac{\beta_{a} \beta_{c}}{\beta_{a}+\beta_{C}}\right)
$$

Where the Tafel constants $\left(\beta_{\mathrm{a}}\right.$ and $\left.\beta_{\mathrm{c}}\right)$ represent the anodic and cathodic slopes, respectively.

$$
\text { Corrosion rate, } \mathrm{CR}=\frac{i_{\text {corr }}}{d A}(k \times E W)
$$

Where, $\mathrm{d}$ is the density of the material $\left(\mathrm{Kg} / \mathrm{m}^{3}\right)$, $\mathrm{A}$ is exposed surface area of the material to corrosion $\left(\mathrm{m}^{2}\right)$, $\mathrm{k}$ is a constant $(3.272 \mathrm{~m} /$ year $)$, and $\mathrm{EW}$ is the equivalent weight of the material. 


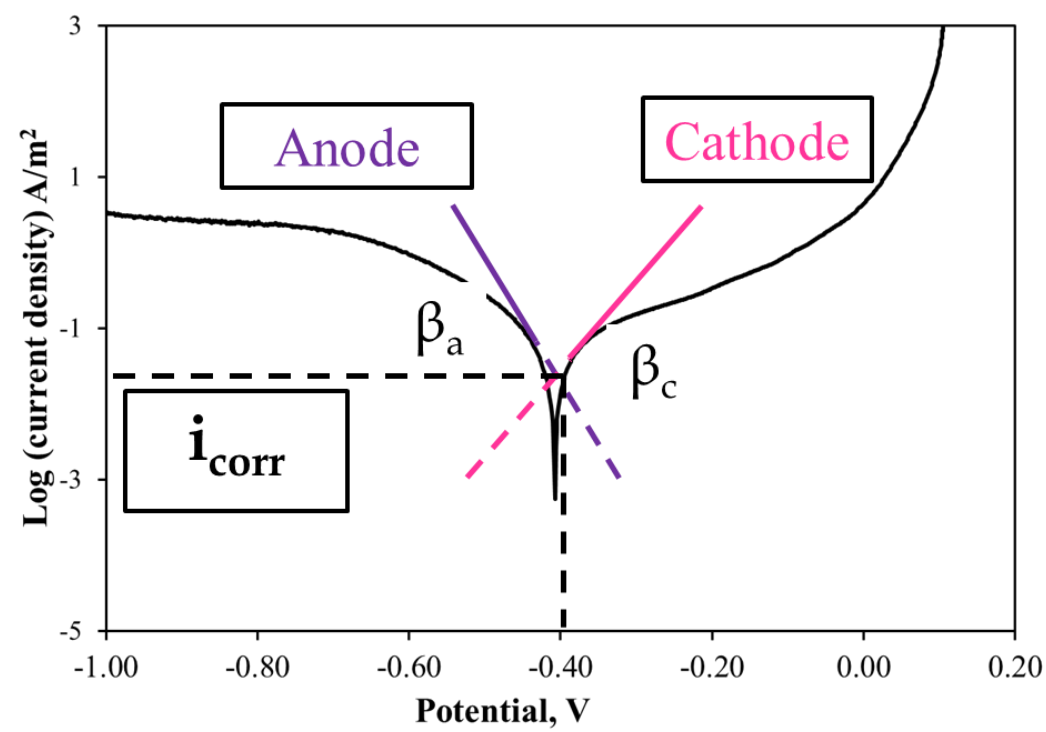

Figure 0.5.Schematic diagram showing the extracting of corrosion current and constants from a Tafel plot.

The variation in corrosion current with the density of the L-PBF parts fabricated using finer gas- atomized $\left(\mathrm{D}_{50}=13 \mu \mathrm{m}\right)$ and water-atomized $\left(\mathrm{D}_{50}=17 \mu \mathrm{m}\right)$ powders are shown in Figure 4.6a. High density and low corrosion current were observed for the 17-4 PH stainless steel L-PBF parts irrespective of the atomization technique to produce starting powders and the energy density of these two systems. The corrosion current of the gasatomized $\left(\mathrm{D}_{50}=13 \mu \mathrm{m}\right)$ and water-atomized $\left(\mathrm{D}_{50}=17 \mu \mathrm{m}\right)$ L-PBF parts ranged between 0.1 and $1.0 \mu \mathrm{A}$, which is lower than the wrought sample $(0.9 \pm 0.1 \mu \mathrm{A})$. It can also be seen from Figure 4.6a that the corrosion current of the L-PBF parts was not significantly varied for finer gas $\left(D_{50}=13 \mu \mathrm{m}\right)$ and water-atomized $\left(D_{50}=17 \mu \mathrm{m}\right)$ powders when fabricated at different energy densities. Previous studies by Frankel et al. [100] showed that the low corrosion current could be an indication that the rate of electrochemical reaction is slow either because of the thick oxide film or low porosity on the surface of the L-PBF parts. 
Further, no systematic variation in the corrosion current was observed for high dense (97 $\pm 0.5 \%)$ gas-atomized $\left(\mathrm{D}_{50}=13 \mu \mathrm{m}\right)$ and water-atomized $\left(\mathrm{D}_{50}=17 \mu \mathrm{m}\right)$ L-PBF parts when fabricated at different energy densities.

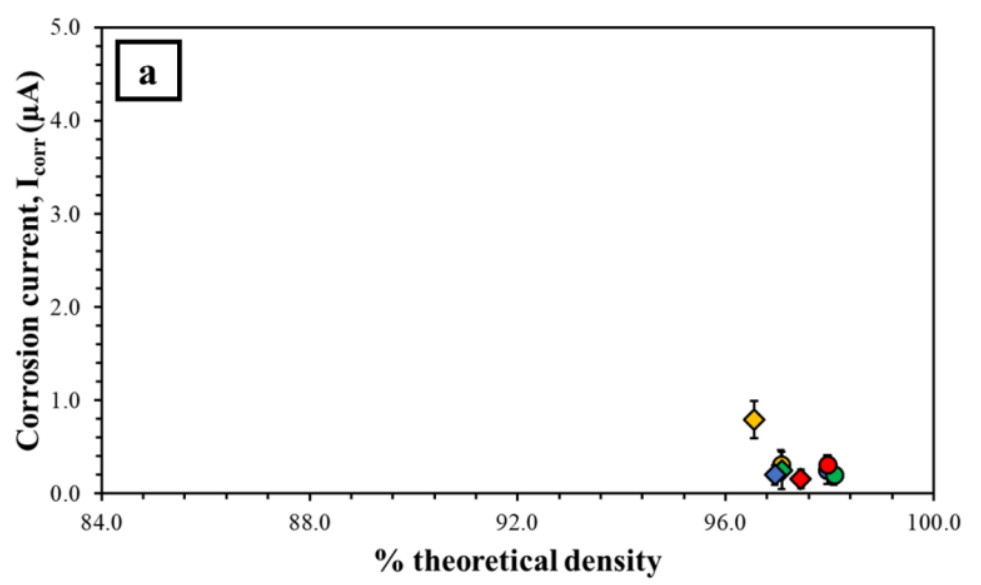

$\bigcirc$ Gas atomized $\mathrm{D}_{50}=13 \mu \mathrm{m}$

$\diamond$ Water atomized $\mathrm{D}_{50}=17 \mu \mathrm{m}$

$\triangle$ Water atomized $\mathrm{D}_{50}=24 \mu \mathrm{m}$

Water atomized $\mathrm{D}_{50}=43 \mu \mathrm{m}$

Energy density $64 \mathrm{~J} / \mathrm{mm}^{3}$

(P: $150 \mathrm{~W} \& \mathrm{v}: 1550 \mathrm{~mm} / \mathrm{s}$ )

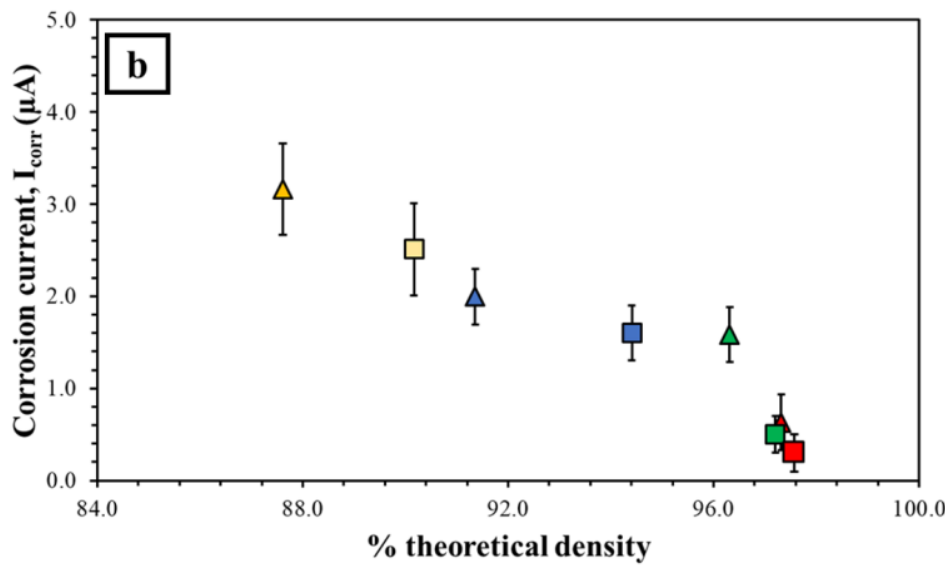

$\Rightarrow$ Energy density $80 \mathrm{~J} / \mathrm{mm}^{3}$

(P: $150 \mathrm{~W} \& \mathrm{v}: 1250 \mathrm{~mm} / \mathrm{s}$ )

$\Rightarrow$ Energy density $84 \mathrm{~J} / \mathrm{mm}^{3}$

(P: $195 \mathrm{~W} \& \mathrm{v}: 1550 \mathrm{~mm} / \mathrm{s}$ )

$\Rightarrow$ Energy density $104 \mathrm{~J} / \mathrm{mm}^{3}$

(P: $195 \mathrm{~W} \& \mathrm{v}: 1250 \mathrm{~mm} / \mathrm{s}$ )

Figure 0.6 .Variation in corrosion current with $\%$ theoretical density and energy density for samples fabricated using (a) gas-atomized $\left(\mathrm{D}_{50}=13 \mu \mathrm{m}\right)$ and water-atomized $\left(\mathrm{D}_{50}=17\right.$

$\mu \mathrm{m}$ ) powders (b) water-atomized ( $\mathrm{D}_{50}=24 \mu \mathrm{m}$ and $43 \mu \mathrm{m}$ ) powders. The symbols represent the four powders and the colors represent the four energy densities used in the fabrication.

Figure 4.6b shows that the density and consequently corrosion current significantly varied as a function of energy density for coarser water-atomized powders $\left(D_{50}=24 \mu \mathrm{m}\right.$ and 43 $\mu \mathrm{m})$ powders when compared to gas $\left(\mathrm{D}_{50}=13 \mu \mathrm{m}\right)$ and water-atomized $\left(\mathrm{D}_{50}=17 \mu \mathrm{m}\right)$ 
powders (Figure 4.6a). The corrosion current decreased with increased density of the water-atomized ( $\mathrm{D}_{50}=24 \mu \mathrm{m}$ and $\left.43 \mu \mathrm{m}\right)$ L-PBF parts. At a high energy density of 104 $\mathrm{J} / \mathrm{mm}^{3}$ and with densities higher than $97 \%$, the corrosion current of the water-atomized $\left(\mathrm{D}_{50}=24 \mu \mathrm{m}\right.$ and $\left.43 \mu \mathrm{m}\right) \mathrm{L}-\mathrm{PBF}$ parts was found to be lower than the wrought samples and similar to the corrosion current of gas $\left(\mathrm{D}_{50}=13 \mu \mathrm{m}\right)$ and water-atomized $\left(\mathrm{D}_{50}=17 \mu \mathrm{m}\right)$ L-PBF parts (Figure 4.6). The corrosion currents of the 17-4 PH stainless gas- and wateratomized L-PBF parts with densities higher than $97 \%$ varied between 0.1 and $0.8 \mu \mathrm{A}$ (Figure 4.6b) whereas the corrosion current value wrought sample is $0.9 \pm 0.1 \mu \mathrm{A}$. Similar corrosion current values for high dense 17-4 PH stainless steel parts fabricated with gasatomized powders have been reported in previous L-PBF research studies [84]-[87], [94]. For example, Stoudt et al. [16] carried out potentiostatic polarization studies on L-PBF parts fabricated using 17-4 $\mathrm{PH}$ stainless steel gas-atomized powders in $0.5 \mathrm{M} \mathrm{NaCl}$ solution and reported that corrosion potential of the nearly fully dense $(99 \pm 0.5 \%)$ varied between 0.5 and $0.8 \mu \mathrm{A}$. Furthermore, at a high energy density of $104 \mathrm{~J} / \mathrm{mm}^{3}$, the corrosion current is independent of starting powder characteristics (shape and size) and atomization method (gas or water-atomization) used to produce these powders (Figure 4.6).

In Figure 4.7, the polarization resistance is plotted as a function of the density of L-PBF parts when fabricated using four 17-4 PH stainless powders at various energy densities. It was seen that the polarization resistance of the high dense $(99 \pm 0.5 \%)$ L-PBF parts fabricated using finer gas-atomized $\left(\mathrm{D}_{50}=13 \mu \mathrm{m}\right)$ and water-atomized $\left(\mathrm{D}_{50}=17 \mu \mathrm{m}\right)$ powders showed high polarization resistance $(26,000 \pm 2,000 \Omega)$ when fabricated at different energy densities (Figure 4.7a). For comparison, these values are higher than 
wrought sample $(25,000 \pm 1,000 \Omega)$ and similar to the polarization resistance values (25,000-28,000 $\Omega)$ of 17-4 PH stainless steel L-PBF parts fabricated using gas-atomized powders as reported in the literature [14]. The high polarization resistance value of the LPBF parts indicates that the resistance of the samples in the corrosion environment is high $[27,40,41]$.

The density and consequently, the polarization resistance of coarser water-atomized powders $\left(\mathrm{D}_{50}=24 \mu \mathrm{m}\right.$ and $\left.43 \mu \mathrm{m}\right)$ powders were found to be strongly dependent on energy density used to fabricate the samples (Figure 4.7b). The polarization resistance of coarser water-atomized powders ( $\mathrm{D}_{50}=24 \mu \mathrm{m}$ and $\left.43 \mu \mathrm{m}\right) \mathrm{L}-\mathrm{PBF}$ parts increased with an increase in energy density and density of the L-PBF parts. At low energy densities of 64 to 84 $\mathrm{J} / \mathrm{mm}^{3} \mathrm{~J} / \mathrm{mm}^{3}$, the polarization resistance samples fabricated using coarser water-atomized powders $\left(\mathrm{D}_{50}=24 \mu \mathrm{m}\right.$ and $\left.43 \mu \mathrm{m}\right)$ powders is $11,000 \pm 3,000 \Omega$ and $15,000 \pm 4,000 \Omega$, respectively. These polarization resistance values are lower than that of the finer gas$\left(\mathrm{D}_{50}=13 \mu \mathrm{m}\right)$ and water-atomized $\left(\mathrm{D}_{50}=17 \mu \mathrm{m}\right)$ L-PBF parts as shown in Figure 4.7.

Figure 4.7b also indicate that at high energy density of $104 \mathrm{~J} / \mathrm{mm}^{3}$, samples fabricated using coarser water-atomized powders $\left(D_{50}=43 \mu \mathrm{m}\right)$ exhibited a slightly higher polarization resistance $(28,000 \pm 500 \Omega)$ than samples fabricated using gas-atomized $\left(\mathrm{D}_{50}=13 \mu \mathrm{m}\right)$ powders $(23,000 \pm 1000 \Omega)$ and wrought samples $(25,000 \pm 1,000 \Omega)$. Thus, the corrosion performance of the 17-4 PH stainless steel L-PBF parts is strongly dependent on their density, which in turn depends on the powder characteristics and L-PBF processing conditions. 


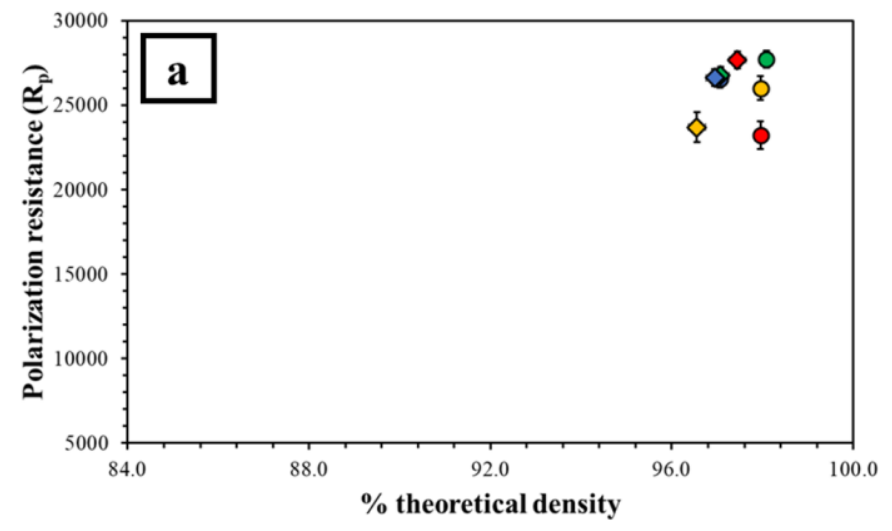

$\bigcirc$ Gas atomized $\mathrm{D}_{50}=13 \mu \mathrm{m}$

$\diamond$ Water atomized $\mathrm{D}_{50}=17 \mu \mathrm{m}$

$\triangle$ Water atomized $\mathrm{D}_{50}=24 \mu \mathrm{m}$

Water atomized $\mathrm{D}_{50}=43 \mu \mathrm{m}$

Energy density $64 \mathrm{~J} / \mathrm{mm}^{3}$

(P: $150 \mathrm{~W} \& \mathrm{v}: 1550 \mathrm{~mm} / \mathrm{s}$ )

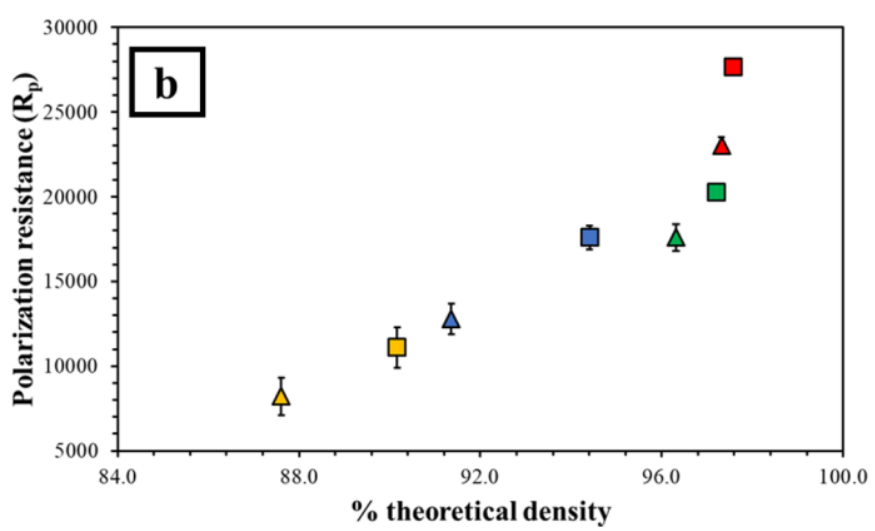

$\Rightarrow$ Energy density $80 \mathrm{~J} / \mathrm{mm}^{3}$

(P: $150 \mathrm{~W} \& \mathrm{v}: 1250 \mathrm{~mm} / \mathrm{s}$ )

$\rightarrow$ Energy density $84 \mathrm{~J} / \mathrm{mm}^{3}$

(P: $195 \mathrm{~W} \& \mathrm{v}: 1550 \mathrm{~mm} / \mathrm{s}$ )

$\Rightarrow$ Energy density $104 \mathrm{~J} / \mathrm{mm}^{3}$

(P: $195 \mathrm{~W} \& \mathrm{v}: 1250 \mathrm{~mm} / \mathrm{s})$

Figure 0.7 .Variation in polarization resistance as a function of $\%$ theoretical density and energy density for samples fabricated using (a) gas-atomized $\left(\mathrm{D}_{50}=13 \mu \mathrm{m}\right)$ and wateratomized $\left(\mathrm{D}_{50}=17 \mu \mathrm{m}\right.$ ) powders $(\mathrm{b})$ water-atomized $\left(\mathrm{D}_{50}=24 \mu \mathrm{m}\right.$ and $\left.43 \mu \mathrm{m}\right)$ powders. The symbol represent the four powders and the colors represent the four energy densities used in the fabrication.

Figure 4.8 shows the variation in corrosion rate as a function of the L-PBF parts density when fabricated at various energy densities using the four 17-4 PH stainless steel powders. The L-PBF parts fabricated using the finer gas $\left(\mathrm{D}_{50}=13 \mu \mathrm{m}\right)$ and water-atomized $\left(\mathrm{D}_{50}=17\right.$ $\mu \mathrm{m})$ powders ranged between 1 to $8 \mu \mathrm{m} /$ year at different energy densities as shown in the Figure 4.8a. For further comparison, the corrosion rates of finer gas $\left(D_{50}=13 \mu \mathrm{m}\right)$ and water-atomized $\left(\mathrm{D}_{50}=17 \mu \mathrm{m}\right) \mathrm{L}-\mathrm{PBF}$ parts were lower than that of the wrought 17-4 PH 
stainless steel is $3 \pm 0.5 \mu \mathrm{m} /$ year except at an energy density $64 \mathrm{~J} / \mathrm{mm}^{3}$. However, the corrosion rate for samples fabricated using the coarser water-atomized $\left(D_{50}=24 \mu \mathrm{m}\right.$ and 43 $\mu \mathrm{m})$ powders decreased with an increase in energy density (Figure 4.8b). At energy densities of 64 and $80 \mathrm{~J} / \mathrm{mm}^{3}$, the corrosion rate of the coarser water-atomized ( $D_{50}=24 \mu \mathrm{m}$ and $43 \mu \mathrm{m}) \mathrm{L}-\mathrm{PBF}$ parts varied between 20 to $45 \mu \mathrm{m} /$ year. These corrosion rate values are higher than that of the finer gas $\left(\mathrm{D}_{50}=13 \mu \mathrm{m}\right)$ and water-atomized $\left(\mathrm{D}_{50}=17 \mu \mathrm{m}\right) \mathrm{L}-\mathrm{PBF}$ parts fabricated at the same energy densities as well as the wrought samples. However, at an energy density of $104 \mathrm{~J} / \mathrm{mm}^{3}$, the corrosion rates were similar for L-PBF parts fabricated using all four powders (Figure 4.8).

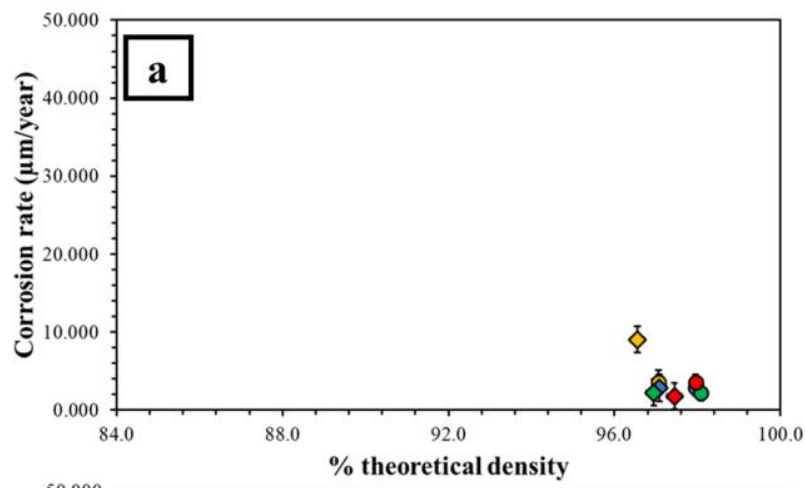

O Gas atomized $\mathrm{D}_{50}=13 \mu \mathrm{m}$

$\diamond$ Water atomized $\mathrm{D}_{50}=17 \mu \mathrm{m}$

$\triangle$ Water atomized $\mathrm{D}_{50}=24 \mu \mathrm{m}$

Water atomized $\mathrm{D}_{50}=43 \mu \mathrm{m}$

$\Rightarrow$ Energy density $64 \mathrm{~J} / \mathrm{mm}^{3}$

(P: $150 \mathrm{~W} \& \mathrm{v}: 1550 \mathrm{~mm} / \mathrm{s}$ )

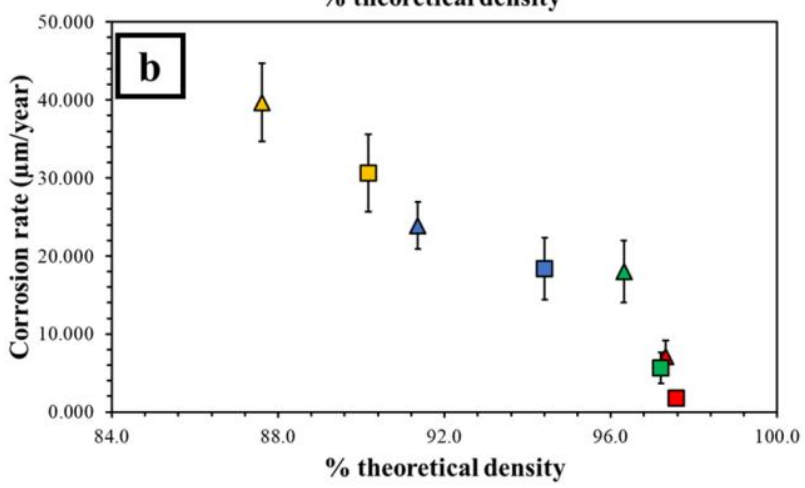

$\Rightarrow$ Energy density $80 \mathrm{~J} / \mathrm{mm}^{3}$

(P: $150 \mathrm{~W} \& \mathrm{v}: 1250 \mathrm{~mm} / \mathrm{s}$ )

$\Rightarrow$ Energy density $84 \mathrm{~J} / \mathrm{mm}^{3}$

(P: $195 \mathrm{~W} \& \mathrm{v}: 1550 \mathrm{~mm} / \mathrm{s}$ )

$\Rightarrow$ Energy density $104 \mathrm{~J} / \mathrm{mm}^{3}$

(P: $195 \mathrm{~W} \& \mathrm{v}: 1250 \mathrm{~mm} / \mathrm{s}$ )

Figure 0.8 .Variation in corrosion rate as a function of $\%$ theoretical density and energy density for samples fabricated using (a) gas-atomized $\left(\mathrm{D}_{50}=13 \mu \mathrm{m}\right)$ and water-atomized

$\left(\mathrm{D}_{50}=17 \mu \mathrm{m}\right)$ powders $(\mathbf{b})$ water-atomized $\left(\mathrm{D}_{50}=24 \mu \mathrm{m}\right.$ and $\left.43 \mu \mathrm{m}\right)$ powders. The symbols represent the four powders and the colors represent the four energy densities used in the fabrication. 
Figure 4.9 shows the optical microscopy images of the surfaces of samples fabricated at $64 \mathrm{~J} / \mathrm{mm}^{3}$ obtained before and after conducting potentiostatic polarization experiments. It can be found that there is a significant difference in the images before and after the corrosion tests for the coarser water-atomized $\left(\mathrm{D}_{50}=24 \mu \mathrm{m}\right.$ and $\left.43 \mu \mathrm{m}\right)$ L-PBF parts at energy density $64 \mathrm{~J} / \mathrm{mm}^{3}$ as evidenced by an increase in a number of pores. Large pores are seen in the coarser water-atomized $\left(\mathrm{D}_{50}=24 \mu \mathrm{m}\right.$ and $\left.43 \mu \mathrm{m}\right)$ L-PBF parts images whereas small pores can be found in finer gas $\left(D_{50}=13 \mu \mathrm{m}\right)$ and water-atomized $\left(D_{50}=17\right.$ $\mu \mathrm{m})$ L-PBF parts images before and after the potentiostatic polarization experiments. The presence of minor pores in the finer gas $\left(\mathrm{D}_{50}=13 \mu \mathrm{m}\right)$ and water-atomized $\left(\mathrm{D}_{50}=17 \mu \mathrm{m}\right) \mathrm{L}$ PBF parts after the corrosion tests could indicate the high resistance of the L-PBF parts to the corrosion phenomena $[20,22,34-36]$. The pore formation in the L-PBF parts after the corrosion tests is consistent with the corrosion performance data when fabricated at energy density $64 \mathrm{~J} / \mathrm{mm}^{3}$ (Figure 4.6, 4.7 and 4.8). The corrosion performance of the L-PBF parts fabricated using finer gas $\left(\mathrm{D}_{50}=13 \mu \mathrm{m}\right)$ and water-atomized $\left(\mathrm{D}_{50}=17 \mu \mathrm{m}\right)$ powders are better than the water-atomized powders $\left(D_{50}=17 \mu \mathrm{m}\right.$ and $\left.43 \mu \mathrm{m}\right)$ at energy density 64 $\mathrm{J} / \mathrm{mm}^{3}$.

Figure 4.10 shows the optical microscopy images of the surfaces of samples fabricated at $104 \mathrm{~J} / \mathrm{mm}^{3}$ obtained before and after conducting potentiostatic polarization experiments. Compared to the images presented in Figure 4.9, only minor pitting-induced pores can be found in the images before and after the corrosion tests for all L-PBF parts. Further, the minor pits seen in all L-PBF parts at energy density $104 \mathrm{~J} / \mathrm{mm}^{3}$ is consistent with the 
corrosion performance data extracted from the Tafel plots (Figure 4.6, 4.7 and 4.8). The corrosion performance of the L-PBF parts fabricated using water-atomized powders ( $\mathrm{D}_{50}=17 \mu \mathrm{m}$ and $43 \mu \mathrm{m}$ ) at energy density $104 \mathrm{~J} / \mathrm{mm}^{3}$ is better than the wrought sample.

The porosity formed during the L-PBF process play a critical role in the initiation of pitting corrosion in the L-PBF parts. The pore geometry at low densities appears to be favorable for pitting corrosion since the pores would lead to stagnation of the sodium chloride solution in part $[20,22,34-36]$. The stagnation of chloride solution could cause a breakdown the passive layer ensuing favorable sites for initiation of pitting corrosion and increases the rate of corrosion [20,22,34-36]. The L-PBF parts with densities higher than $97 \%$, available pore sites desirable for pitting corrosion were less and could have decreased the rate of corrosion in the L-PBF parts [20,37-39]. The rate of electrochemical corrosion reaction can be expressed as corrosion current in the L-PBF parts and decreases for the dense parts of the thick oxide layer. The decrease in the rate of electrochemical corrosion reactions could decrease the corrosion current of the L-PBF parts densities higher than $97 \%$ $[20,37-39]$. 

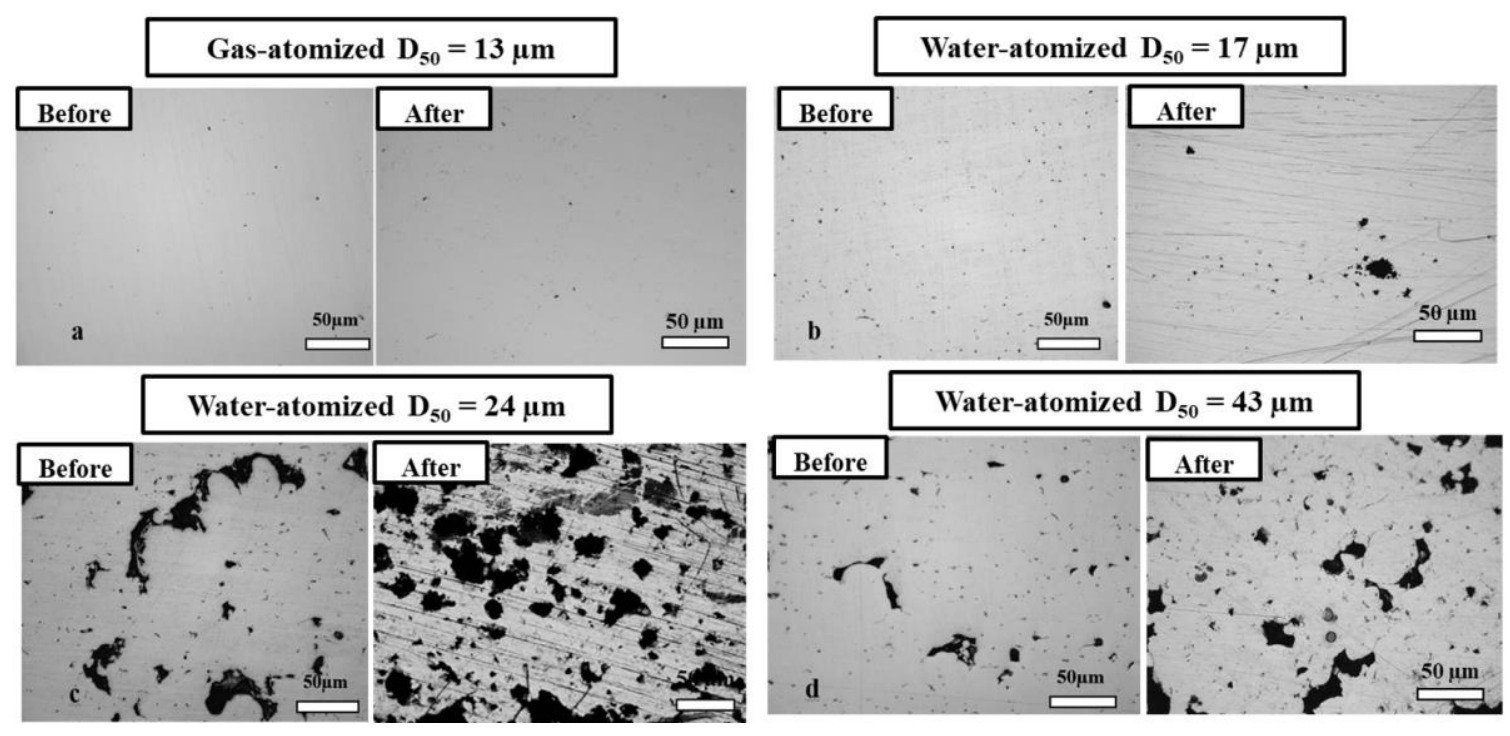

Figure 0.9 . Optical microscopy of samples fabricated at energy density $64 \mathrm{~J} / \mathrm{mm}^{3}$ using four 17-4 PH stainless steel powders acquired before and after conducting potentiostatic polarization experiments in $0.5 \mathrm{M} \mathrm{NaCl}$ solution.
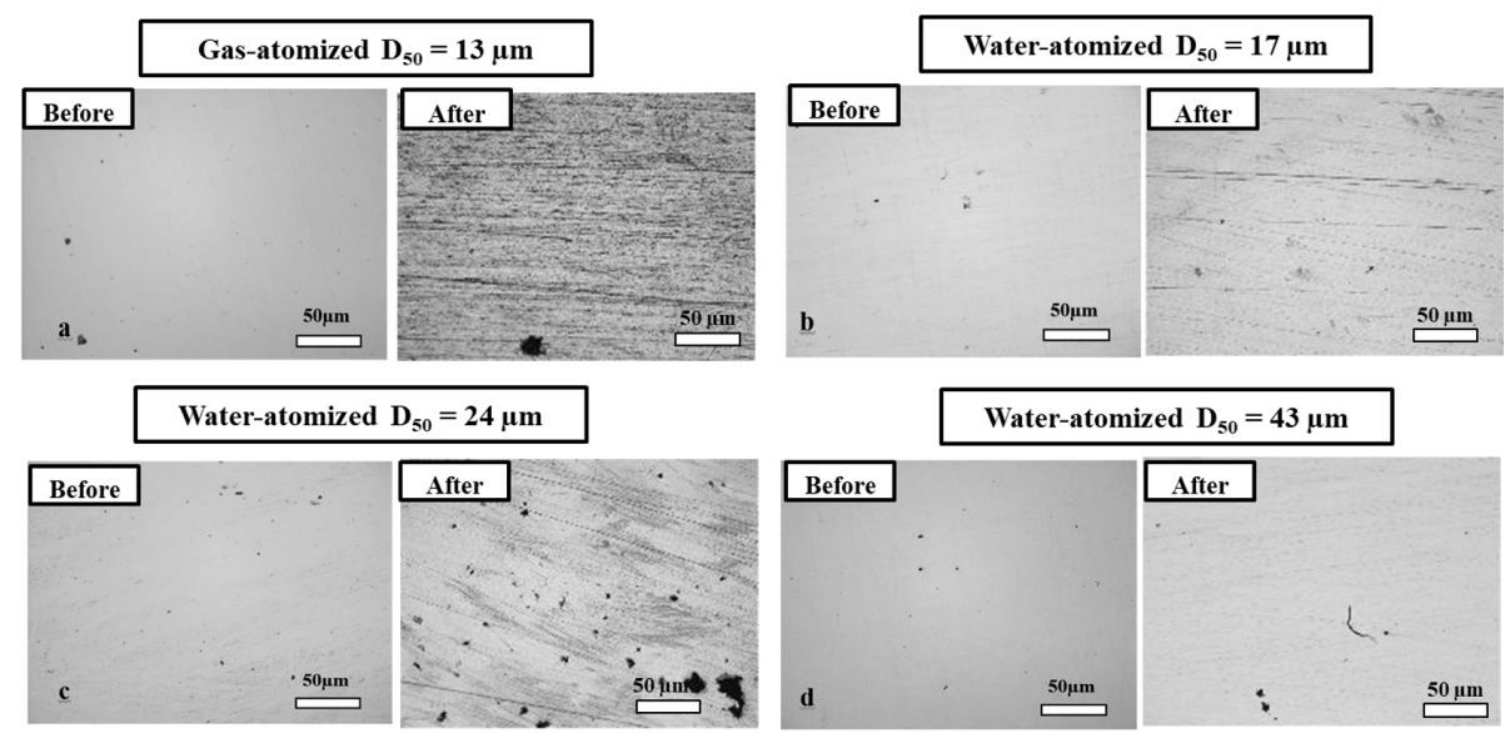

Figure 0.10 . Optical microscopy of samples fabricated at energy density $104 \mathrm{~J} / \mathrm{mm}^{3}$ using four 17-4 PH stainless steel powders acquired before and after conducting potentiostatic polarization experiments in $0.5 \mathrm{M} \mathrm{NaCl}$ solution.

Future experiments on densification and corrosion performance of 17-4 PH stainless steel L-PBF parts are currently being performed using hot isostatic pressing (HIP). Additionally, 
impedance tests will be performed to compare the corrosion performance of the L-PBF parts with the experimental data reported in this study. Further, surface analysis and impedance tests will be performed on the gas-and water-atomized L-PBF parts to understand the mechanisms of pit formation and corrosion performance as a function of microstructure and the results will be reported elsewhere.

\subsection{CONCLUSIONS}

The following conclusions were drawn from this study to understand the effects of processing conditions (energy density) and powder characteristics (shape and size) on the corrosion performance of 17-4 PH stainless steel parts produced by laser-powder bed fusion (L-PBF):

1) The corrosion performance of the 17-4 PH stainless steel L-PBF parts fabricated using gas-and water-atomized powders strongly depend on their density. The density and consequently the corrosion current, polarization resistance, corrosion rate of the L-PBF parts did not significantly vary for high dense $(97 \pm 0.5 \%)$ finer gas $\left(\mathrm{D}_{50}=13 \mu \mathrm{m}\right)$ and water-atomized $\left(\mathrm{D}_{50}=17 \mu \mathrm{m}\right)$ powders when fabricated using energy densities in the range from 64-104 J/mm³ . Furthermore, the corrosion performance of L-PBF parts of high density $(97 \pm 0.5 \%)$ showed slightly higher corrosion performance compared to the wrought sample. 
2) The density and consequently the corrosion performance of coarser water-atomized powders $\left(\mathrm{D}_{50}=24 \mu \mathrm{m}\right.$ and $\left.43 \mu \mathrm{m}\right)$ of L-PBF parts increased with energy density when fabricated in the same range of energy densities $64-104 \mathrm{~J} / \mathrm{mm}^{3}$.

3) At energy densities of $64,80,84 \mathrm{~J} / \mathrm{mm}^{3}$, L-PBF parts fabricated using the finer gasatomized $\left(\mathrm{D}_{50}=13 \mu \mathrm{m}\right)$ and water-atomized $\left(\mathrm{D}_{50}=17 \mu \mathrm{m}\right)$ powders showed significantly better corrosion performance compared to coarser water-atomized powders $\left(D_{50}=24 \mu \mathrm{m}\right.$ and $43 \mu \mathrm{m}) \mathrm{L}-\mathrm{PBF}$ parts.

4) At the energy density of $104 \mathrm{~J} / \mathrm{mm}^{3}$, the corrosion performance is independent of starting powder characteristics (shape and size) and atomization method (gas or water-atomization) used to produce these powders.

5) At the energy densities of $104 \mathrm{~J} / \mathrm{mm}^{3}$, the L-PBF parts fabricated using water-atomized powders $\left(\mathrm{D}_{50}=17 \mu \mathrm{m}\right.$ and $\left.43 \mu \mathrm{m}\right)$ powders exhibited higher polarization resistance $(28000$ $\pm 500 \Omega)$ than wrought samples $(25000 \pm 1000 \Omega)$ in the $0.5 \mathrm{M} \mathrm{NaCl}$ environment. 


\section{CHAPTER 5}

\section{EFFECTS OF HOT ISOSTATIC PRESSING ON THE CORROSION PERFORMANCE OF 17-4 PH STAINLESS STEEL GAS -AND WATER-ATOMIZED PARTS \\ FABRICATED USING LASER-POWDER BED FUSION \\ 5.1 INTRODUCTION}

Laser powder bed fusion (L-PBF) process has received a lot of interest for fabricating complex three-dimensional components for automotive, aerospace, medical and tooling industries using various materials [1]-[3], [7], [26]. Among engineering alloys, 17-4 PH stainless steel is used in many applications that take advantage of its high mechanical properties in combination with its excellent corrosion resistance [26], [84], [90], [101], [104], [107]. Several research studies have been carried in our group as well as literature to fabricate defect-free L-PBF parts from 17-4 PH stainless steel and enhance the resulting mechanical properties using the post-processing operations such as hot isostatic pressing (HIP) and heat-treatment [2], [3], [6], [8], [15], [32], [50], [51], [56]-[69].

The enhanced densification, reduction in porosity, increased martensite phase content, as well as changes in grain size and shape resulted in an increase in mechanical properties for 17-4 PH stainless steel L-PBF parts when they were HIP treated at various conditions [69], [108]. These results are consistent with previous powder metallurgy studies on stainless 
steel, magnesium, aluminum alloys on the effects of post-processing on microstructural features such as phase variation and grain refinement [16], [18]-[20], [24], [109]-[111]. Other studies have indicated how microstructural features can also affect the corrosion properties of post-processed [32], [40]-[42]L-PBF parts [87], [109], [112], [113]. For example, Ralston and Birbilis [114] reviewed the effect of grain size and phase variation on the corrosion performance of $\mathrm{Co}-\mathrm{Cr}$, steel, $\mathrm{Al}$ and $\mathrm{Mg}$ alloys. They have suggested that grain refinement and phase variation in the parts could change the electrochemical behavior and corrosion performance of the parts in different corrosion environments. They also indicated that grain refinement which occurs due to post-processing treatment could decrease or increase the pitting corrosion rate in the parts depending on passive layer formation in the corrosion environment.

To the best of our knowledge, there are no studies in the open literature on the effects of grain size and phase content on corrosion performance of 17-4 PH stainless steel L-PBF parts following HIP treatment. In order to address this gap, the present study was performed to understand the effects of HIP treatment on the corrosion resistance of 17-4 PH stainless steel parts fabricated by L-PBF using gas and water-atomized powders. The current study builds from our initial work on the role of powder attributes and processing conditions on the corrosion performance of as-printed 17-4 PH stainless steel L-PBF parts.

\subsection{EXPERIMENTAL}

L-PBF parts were fabricated from 17-4 PH stainless steel water-atomized powders of median particle size 17, 24 and $43 \mu \mathrm{m}$ and a gas-atomized powder of median particle size 
$13 \mu \mathrm{m}$ as shown in Figure 5.1 at energy densities 64 and $104 \mathrm{~J} / \mathrm{mm}^{3}$. The detailed information about powder characteristics and L-PBF processing conditions used in the study were listed in previous journal papers published by the authors [1], [2].

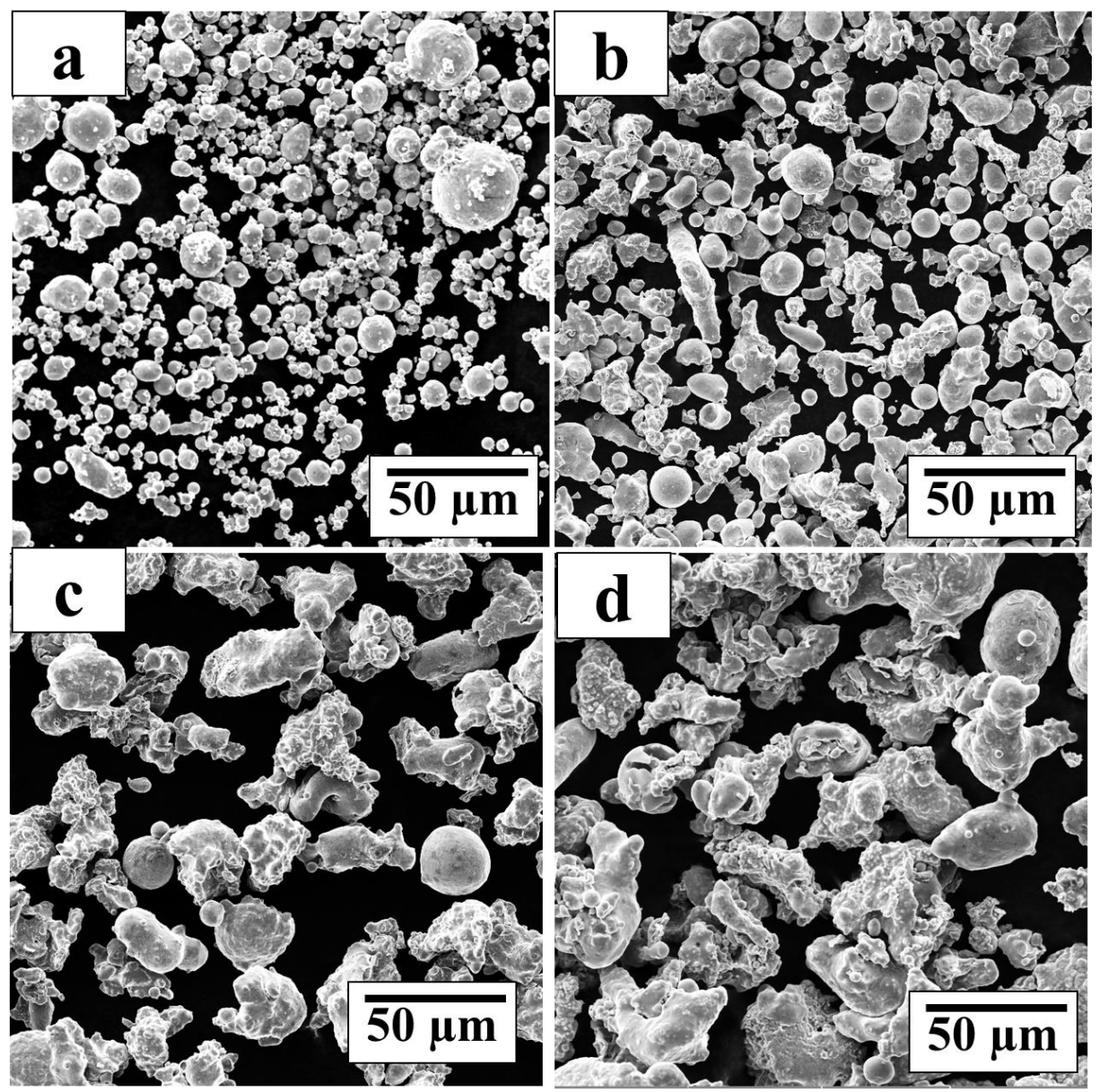

Figure 0.1.SEM micrographs of the four 17-4 PH stainless steel powders (a) gasatomized powder $\mathrm{D}_{50}=13 \mu \mathrm{m}$ (b) water-atomized powder $\mathrm{D}_{50}=17 \mu \mathrm{m}$, (c) wateratomized powder $\mathrm{D}_{50}=24 \mu \mathrm{m}$, (d) water-atomized powder $\mathrm{D}_{50}=43 \mu \mathrm{m}$

HIP post-treatment was performed on as-printed L-PBF parts using a commercial service provided by Quintus Technologies, USA. The HIP treatment was conducted for $2.5 \mathrm{~h}$ under a temperature of $1120{ }^{\circ} \mathrm{C}$ and pressure of $105 \mathrm{MPa}$ and solutionized at a temperature of $1050{ }^{\circ} \mathrm{C}$ and pressure of $70 \mathrm{MPa}$ for 20 minutes applied through Argon gas, followed by 
rapid cooling to room temperature at a rate of $200{ }^{\circ} \mathrm{C} / \mathrm{min}$ [108]. Three L-PBF parts from each powder type were used for linear-sweep voltammetry experiments in $0.5 \mathrm{M} \mathrm{NaCl}$ solution at ambient conditions. to evaluate their electrochemical corrosion behavior. The electrochemical environment was exposed to the surface of the L-PBF parts parallel to the build direction. The exposed surface area of each HIP treated L-PBF part was $1 \mathrm{~cm}^{2}$ and was finished by diamond polishing using a $1 \mu \mathrm{m}$ grade medium. Detailed information about the experimental setup was discussed in our previous paper [26]. The optical images of the HIP treated L-PBF parts before and after corrosion were analyzed using an Olympus BX53 microscope.

\subsection{RESULTS AND DISCUSSION}

The properties such as density, martensite content and average grain size of 17-4 PH stainless steel L-PBF parts before and after HIP treatment are represented in Table 5.1. It is clear from the Table 5.1 that the density, hardness of the L-PBF parts increased following HIP treatment when compared to the properties of as-printed parts. The density and hardness of all the HIP treated L-PBF parts was $\sim 99.5 \pm 0.2 \%$ and $\sim 40 \pm 1 \mathrm{HRC}$, respectively, whereas the density and hardness of as-printed L-PBF parts slightly varied ( $97 \pm 0.2 \%$ and $32 \pm 2 \mathrm{HRC}$ ) depending on the starting powder type. However, there was no measurable effect of starting powder type and size observed on the density and hardness of HIP treated L-PBF parts. Further, the increase in density and hardness in the HIP treated L-PBF parts was accompanied by a decrease in grain size when compared to as-printed LPBF parts. Figure 5.2 shows the optical microstructures of the HIP treated and as-printed L-PBF parts parallel to the build direction which is also the surface exposed to corrosion 
environment in electrochemical corrosion tests. The microstructures of the HIP treated gasand water-atomized L-PBF parts were noticeably different when compared to the microstructure of as-printed L-PBF parts. The scan patterns which were clearly observed in the as-printed L-PBF parts were transformed to equiaxed grains following HIP treatment. Further, the grain size in the L-PBF parts decreased following HIP treatment when compared to as-printed L-PBF parts. A similar transformation in microstructure was observed in Inconel 718 parts following HIP treatment [20]. Atkinson et al [70] indicated that the post-treatment of parts at high temperature and pressure followed by rapid cooling resulted in grain refinement. 
Table 5.1. The variation in density, hardness, martensite content and average grain size of fabricated from various powders by L-PBF at an energy density $104 \mathrm{~J} / \mathrm{mm}^{3}$, before and after HIP treatment.

\begin{tabular}{|c|c|c|c|c|c|}
\hline \multirow[b]{2}{*}{ Condition } & \multicolumn{5}{|c|}{ Properties at energy density $104 \mathrm{~J} / \mathrm{mm}^{3}$} \\
\hline & Property & $\begin{array}{c}\text { Gas- } \\
\text { atomized } \\
\text { powder } \\
\text { D50=13 } \mu \mathrm{m}\end{array}$ & $\begin{array}{c}\text { Water- } \\
\text { atomized } \\
\text { powder } \\
\text { D50=17 } \mu \mathrm{m}\end{array}$ & $\begin{array}{c}\text { Water- } \\
\text { atomized } \\
\text { powder } \\
\text { D50=24 } \mu \mathrm{m}\end{array}$ & $\begin{array}{c}\text { Water- } \\
\text { atomized } \\
\text { powder } \\
\text { D50=43 } \mu \mathrm{m}\end{array}$ \\
\hline HIP & $\begin{array}{c}\text { Density } \\
(\%)\end{array}$ & $99.5 \pm 0.2$ & $99.5 \pm 0.2$ & $99.5 \pm 0.2$ & $99.5 \pm 0.2$ \\
\hline As-Printed & $\begin{array}{c}\text { Density } \\
(\%)\end{array}$ & $97 \pm 0.5$ & $97.5 \pm 0.5$ & $97 \pm 0.2$ & $97.5 \pm 0.5$ \\
\hline HIP & $\begin{array}{c}\text { Hardness } \\
\text { (HRC) }\end{array}$ & $40 \pm 1$ & $40 \pm 1$ & $40 \pm 1$ & $40 \pm 1$ \\
\hline As-Printed & $\begin{array}{c}\text { Hardness } \\
\text { (HRC) }\end{array}$ & $31 \pm 1$ & $34 \pm 1$ & $32 \pm 1$ & $32 \pm 1$ \\
\hline HIP & $\begin{array}{c}\text { Martensite } \\
(\%)\end{array}$ & 100 & 100 & 100 & 100 \\
\hline As-Printed & $\begin{array}{c}\text { Martensite } \\
(\%)\end{array}$ & 100 & 100 & 100 & 100 \\
\hline HIP & $\begin{array}{c}\text { Grain size } \\
\quad(\mu \mathrm{m})\end{array}$ & $15 \pm 3$ & $15 \pm 2$ & $15 \pm 2$ & $15 \pm 3$ \\
\hline As-Printed & $\begin{array}{c}\text { Grain size } \\
\qquad(\mu \mathrm{m})\end{array}$ & $35 \pm 2$ & $25 \pm 3$ & $28 \pm 3$ & $25 \pm 2$ \\
\hline
\end{tabular}

The average grain size of HIP treated and as-printed gas and water-atomized parts are also shown in Table 5.1. The average grain intersect method (AGI) [115] was used for quantifying the grain size present in the optical microstructures (Figure 5.2). The average grain size of the HIP treated L-PBF parts was $\sim 15 \pm 3 \mu \mathrm{m}$ whereas the grain size of the as-printed L-PBF parts was dependent on starting powder type, ranging between $25 \pm 2$ $\mu \mathrm{m}$ and $35 \pm 2 \mu \mathrm{m}$. A notable aspect of the study is the increase in mechanical properties of the HIP treated L-PBF parts was accompanied by not only an increase in density but 
also a decrease in grain size. Therefore, it is essential to understand the variation in grain size and density on the corrosion performance of the HIP treated L-PBF parts.

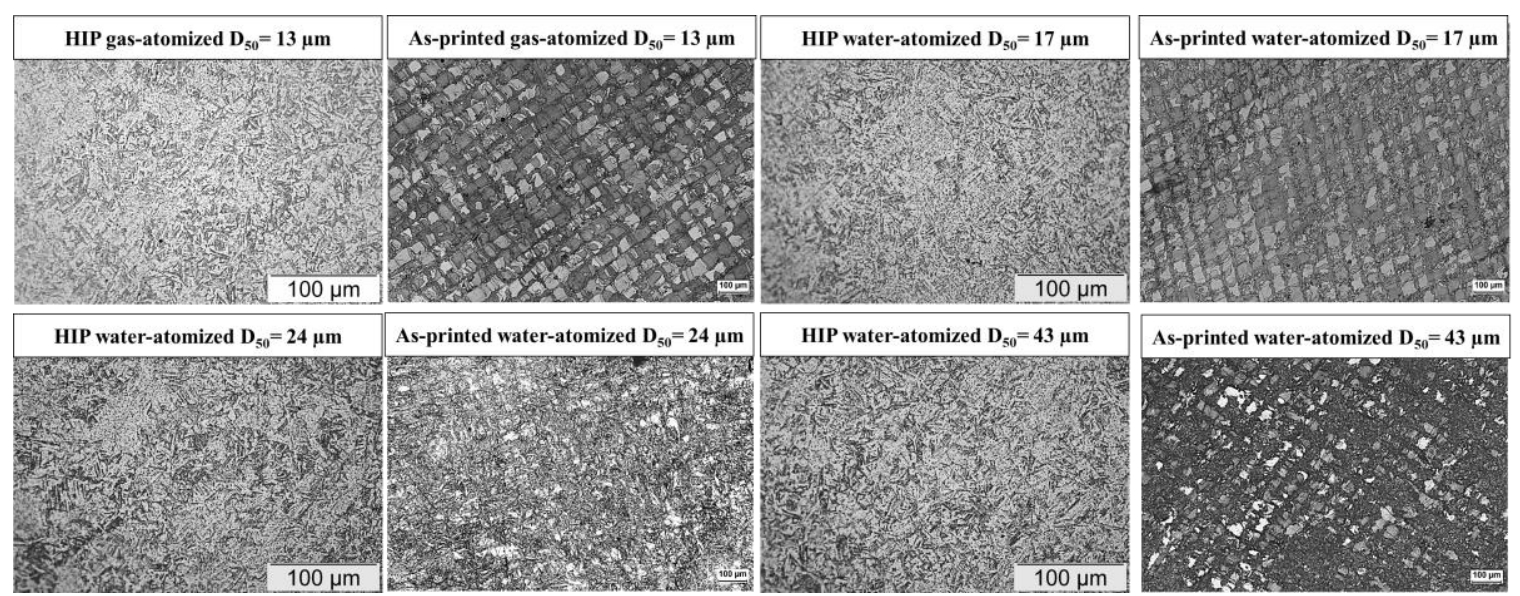

Figure 0.2.Optical micrographs of 17-4 PH stainless steel parts fabricated using various powders by L-PBF at an energy density $104 \mathrm{~J} / \mathrm{mm}^{3}$, before and after HIP treatment.

Potentiostatic polarization tests were performed on HIP treated L-PBF parts in $0.5 \mathrm{M} \mathrm{NaCl}$ solution and the Tafel plots of were shown in Figure 5.3. Figure 5.3 shows that the anodic and cathodic behavior of HIP treated L-PBF parts were noticeably different from the asprinted L-PBF parts. The Tafel plots of the HIP treated L-PBF parts slightly moved to positive direction on $\mathrm{X}$-axis (potential) and negative direction on $\mathrm{Y}$-axis (corrosion current density) when compared to as-printed Tafel plots of both gas and water-atomized powders. This indicates that the corrosion current density of the L-PBF parts decreased and corrosion potential increased following HIP treatment. Further, the passive region in the L-PBF parts increased following HIP treatment. Previous electrochemical corrosion study by Stoudt et al [113] on 17-4 PH stainless steel gas-atomized L-PBF parts have shown the similar cathodic behavior in Tafel plots when they are heat-treated. 


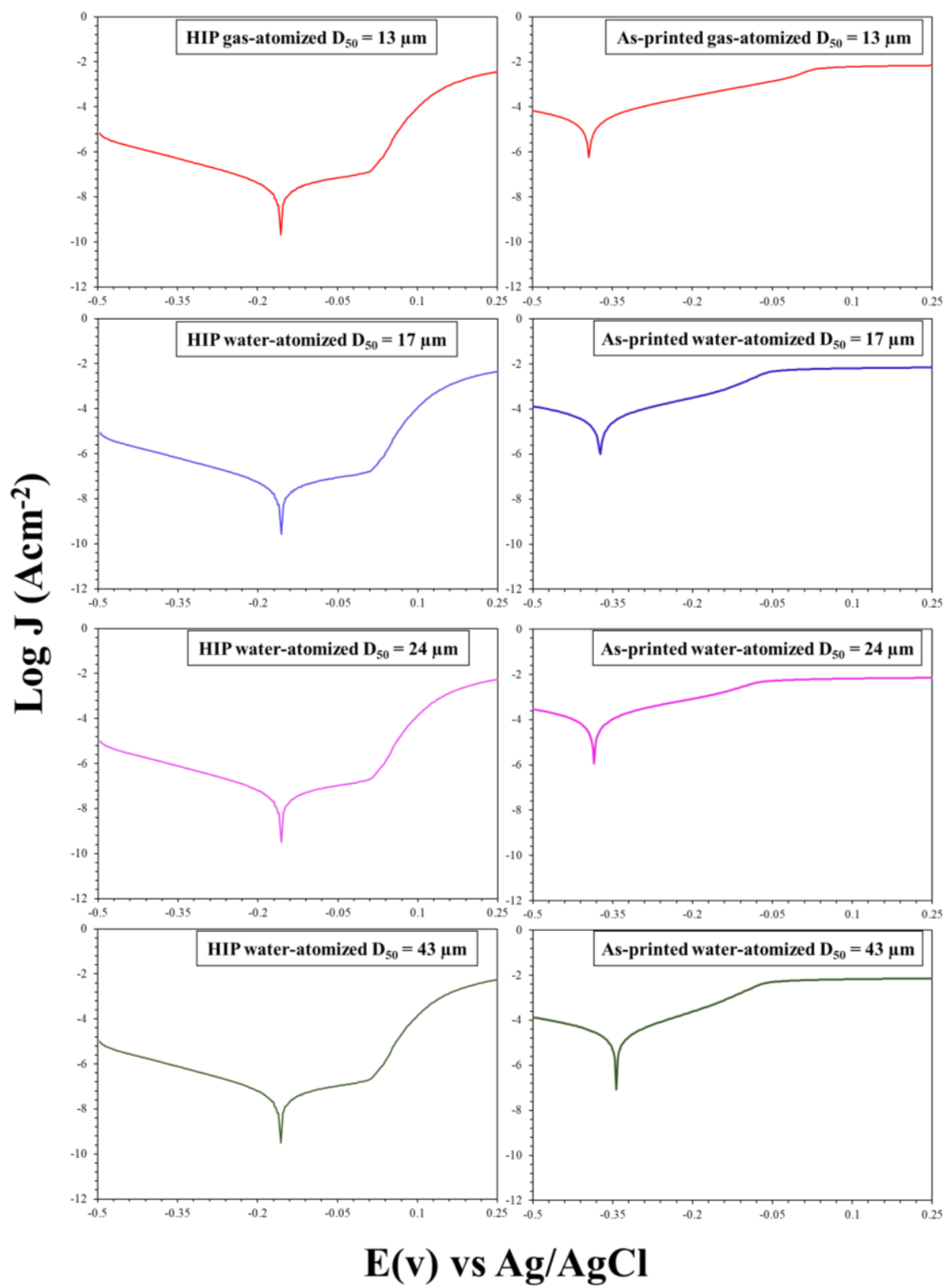

Figure 0.3.Tafel plots of 17-4 PH stainless steel parts fabricated with various powder by L-PBF at an energy density $104 \mathrm{~J} / \mathrm{mm}^{3}$, before and after HIP treatment. 
Table 5.2. The variation in corrosion current and corrosion potential of 17-4 PH stainless steel parts fabricated by L-PBF at an energy density $104 \mathrm{~J} / \mathrm{mm}^{3}$, before and after HIP treatment.

\begin{tabular}{|c|c|c|c|c|}
\hline Property & \multicolumn{2}{|c|}{ Corrosion current $(\mathbf{A})$} & \multicolumn{2}{c|}{ Corrosion potential $(\mathrm{mV})$} \\
\hline L-PBF parts from & HIP & As-printed & HIP & As-printed \\
\hline Gas-atomized $\mathbf{D}_{\mathbf{5 0}}=\mathbf{1 3} \boldsymbol{\mu \mathrm { m }}$ & $0.008 \pm 0.001$ & $0.35 \pm 0.05$ & $-150 \pm 5$ & $-380 \pm 30$ \\
\hline Water-atomized $\mathbf{D}_{\mathbf{5 0}}=\mathbf{1 7} \boldsymbol{\mu \mathrm { m }}$ & $0.008 \pm 0.001$ & $0.3 \pm 0.04$ & $-150 \pm 3$ & $-380 \pm 10$ \\
\hline Water-atomized $\mathbf{D}_{\mathbf{5 0}}=\mathbf{2 4} \boldsymbol{\mu \mathrm { m }}$ & $0.008 \pm 0.001$ & $0.6 \pm 0.07$ & $-150 \pm 7$ & $-380 \pm 20$ \\
\hline Water-atomized $\mathbf{D}_{\mathbf{5 0}}=\mathbf{4 3} \boldsymbol{\mu m}$ & $0.008 \pm 0.001$ & $0.3 \pm 0.05$ & $-150 \pm 5$ & $-380 \pm 10$ \\
\hline
\end{tabular}

The corrosion current of L-PBF parts decreased due to HIP treatment when compared to as-printed L-PBF parts and remained constant at $0.008 \pm 0.001 \mu \mathrm{A}$. However, the corrosion current of the as-printed L-PBF parts slightly varied between $0.03 \pm 0.005$ and $0.6 \pm 0.07$ $\mu \mathrm{A}$ depending on the starting powder type. Further, an increase in the corrosion potential was observed for the HIP treated L-PBF parts $(-150 \pm 5 \mathrm{mV})$ when compared to corrosion potential of the as-printed L-PBF parts $(-380 \pm 20 \mathrm{mV})$. The increase in corrosion potential and a decrease in the corrosion current in the HIP treated L-PBF parts can be attributed to to the reduced grain size $(15 \pm 3 \mu \mathrm{m})$ and increased density $(99 \pm 0.5 \%)$. Previous studies by Gollapudi et al [116] and Obayi et al [117] have reported a similar behavior for annealed ferrous parts. For futher comparaison, the corrosion current and corrosion potential of the wrought 17-4 PH stainless steel is $0.9 \pm 0.1 \mu \mathrm{A}$ and $-400 \pm 20 \mathrm{mV}$, respectively.

The corrosion current values were used for the calculation of polarization resistance and corrosion rate of the L-PBF parts in $0.5 \mathrm{M} \mathrm{NaCl}$ solution as shown in Table 5.2. The equations used for calculation of the above-mentioned parameters have been listed in previous papers published by authors [26]. 
Table 5.3. The variation in polarization resistance and corrosion rate of 17-4 PH stainless steel parts fabricated by L-PBF at an energy density $104 \mathrm{~J} / \mathrm{mm}^{3}$, before and after HIP treatment.

\begin{tabular}{|c|c|c|c|c|}
\hline Property & \multicolumn{2}{|c|}{ Polarization resistance $\left(\Omega \mathrm{cm}^{-2}\right)$} & \multicolumn{2}{c|}{ Corrosion rate $(\mu \mathrm{m} /$ year $)$} \\
\hline L-PBF parts from & HIP & As-printed & HIP & As-printed \\
\hline Gas-atomized $\mathbf{D}_{\mathbf{5 0}}=\mathbf{1 3} \mathbf{\mu m}$ & $40000 \pm 500$ & $23500 \pm 500$ & $1 \pm 0.3$ & $3.5 \pm 0.5$ \\
\hline Water-atomized $\mathbf{D}_{\mathbf{5 0}}=\mathbf{1 7} \mathbf{~ \mathbf { m }}$ & $40500 \pm 200$ & $27500 \pm 500$ & $1 \pm 0.2$ & $1.8 \pm 0.5$ \\
\hline Water-atomized $\mathbf{D}_{\mathbf{5 0}}=\mathbf{2 4} \mathbf{\mu m}$ & $40000 \pm 700$ & $23000 \pm 500$ & $1.2 \pm 0.1$ & $7 \pm 1$ \\
\hline Water-atomized $\mathbf{D}_{\mathbf{5 0}}=\mathbf{4 3} \mathbf{~ \mathbf { m }}$ & $40200 \pm 500$ & $27500 \pm 200$ & $1 \pm 0.2$ & $1.7 \pm 0.5$ \\
\hline
\end{tabular}

The polarization resistance of the L-PBF parts increased following HIP treatment when compared to the polarization resistance of as-printed L-PBF parts. The polarization resistance of the HIP treated gas- and water-atomized L-PBF parts was $\sim 40,000 \pm 500 \Omega$ $\mathrm{cm}^{-2}$ whereas the polarization resistance of the as-printed gas- and water-atomized L-PBF parts ranged between $23,000 \pm 500 \Omega \mathrm{cm}^{-2}$ and 27,500 $\pm 500 \Omega \mathrm{cm}^{-2}$. However, the corrosion rate of the HIP treated samples was significantly lower than the corrosion rate of as-printed L-PBF parts. The corrosion rate of the HIP treated gas- and water-atomized LPBF parts was found to be $\sim 1 \pm 0.3 \mu \mathrm{m} /$ year whereas the corrosion rate of the as-printed gas- and water-atomized L-PBF parts ranged between $1.7 \pm 0.5 \mu \mathrm{m} /$ year and $7 \pm 1 \mu \mathrm{m} /$ year, depending on powder type used for the parts fabrication. For further comparison, the polarization rate and corrosin rate of wrought $17-4 \mathrm{PH}$ stainless steel is $25,000 \pm 1,000 \Omega$ $\mathrm{cm}^{-2}$ and $3 \pm 0.5 \mu \mathrm{m} /$ year, respectively.

The low corrosion rate in the HIP treated L-PBF parts could be correlated to their optical images after corrosion testing as shown in Figure 5.4. The pits observed in the HIP treated L-PBF parts for all powders after the corrosion experiment was lower than for as-printed parts, which was consistent with the quantitative Tafel parameters presented in Table 5.3. 
This high polarization resistance and low corrosion rate in the L-PBF parts after HIP treatment is consistent with the increased density as well as reduced grain size in the microstructures. An important result of this study is the corrosion resistance of 17-4 PH stainless steel L-PBF parts were enhanced due to HIP treatment and did not significantly depend on the powder type used for the L-PBF parts fabrication, in conrats to the corrosion trends in as-printed parts. These results also demonstrated the feasibility of achieving similar corrosion performance from both gas and water-atomized L-PBF parts following HIP treatment.

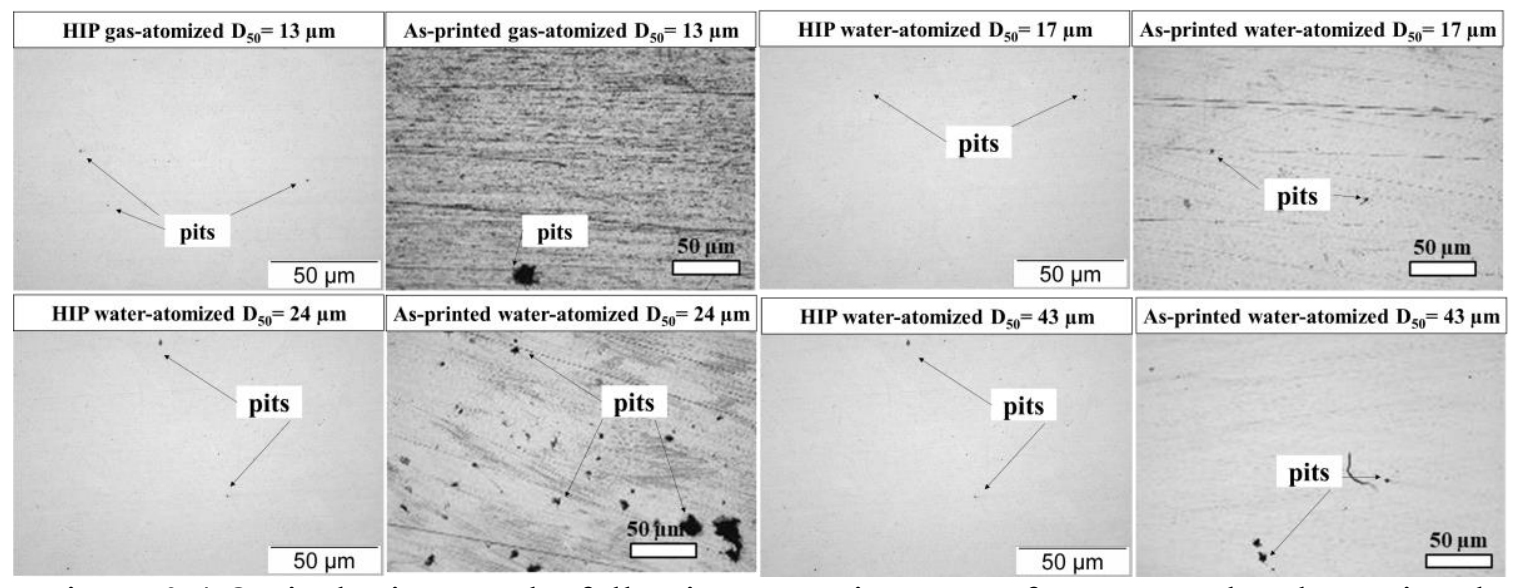

Figure 0.4.Optical micrographs following corrosion tests of HIP treated and as-printed 17-4 PH stainless steel parts fabricated by L-PBF at energy density $104 \mathrm{~J} / \mathrm{mm}^{3}$ using gas and water-atomized powders.

HIP treated gas and water-atomized L-PBF parts have a smaller grain size compared to asprinted L-PBF parts which will result in a high volume of grain boundaries. It is probable that the high volume grain boundaries would enhance the chemical activity and dissolution rate in the corrosion environment. This increase in chemical activity could favor the formation of a thick and stable oxide layer on the surface. The thick and stable oxide layer could, in turn, inhibit the adsorption of the $\mathrm{Cl}^{-}$ions on the surface of HIP treated L-PBF parts [114], [116]-[118]. 


\subsection{CONCLUSIONS}

A study was performed to understand the effect of hot isostatic pressing on the corrosion performance of 17-4 PH stainless steel gas- and water-atomized parts produced by laserpowder bed fusion (L-PBF). The corrosion resistance of the L-PBF parts was evaluated using linear-sweep voltammetry curves (Tafel plots) obtained from the electrochemical corrosion tests. The anodic and cathodic behavior as well as the location of passive region in Tafel plots HIP treated L-PBF parts were significantly different from Tafel plots of asprinted L-PBF parts. The density $(99.5 \pm 0.2 \%)$, corrosion potential $(-150 \pm 5 \mathrm{mV})$, and polarization resistance $\left(40000 \pm 500 \Omega \mathrm{cm}^{-2}\right)$ of the L-PBF parts increased due to HIP treatment and higher than as-printed properties. Further, the corrosion rate of the HIP treated L-PBF parts was lower than the as-printed L-PBF parts irrespective of starting powder type. The superior corrosion performance of the HIP treated L-PBF parts could be correlated to the decrease in grain size when compared to as-printed L-PBF parts. A similar corrosion performance was observed for both expensive gas- atomized and inexpensive water-atomized L-PBF parts when they are HIP treated. 


\section{CHAPTER 6}

\section{CONCLUSIONS AND FUTURE WORK}

\subsection{CONCLUSIONS}

The goal of this dissertation is to establish a fundamental understanding of the materialprocess-property relationships of 17-4 PH stainless steel processed by laser-powder bed fusion (L-PBF). The investigation was carried out to understand the effects of postprocessing treatment cycles such as hot isostatic pressing (HIP) (Chapters 2 and 3) on the densification, mechanical properties, corrosion properties (Chapters 4 and 5) and microstructures of L-PBF parts fabricated using 17-4 PH stainless steel gas- and wateratomized powders at various energy densities. The microstructure formation and its impact on mechanical and corrosion properties due to different HIP treatment cycles were studied for 17-4 PH stainless steel gas and water-atomized L-PBF parts at various energy densities. The most significant aspect of this work is that density, microstructures, mechanical and corrosion properties of 17-4 PH stainless steel can be vastly improved irrespective of starting powder attributes and L-PBF process conditions by using HIP treatment and are superior to known reported properties of 17-4 PH stainless steel fabricated by L-PBF or wrought samples. The conclusions emerging from this dissertation are summarized in the following sections. 


\subsubsection{MECHANICAL PROPERTIES AND MICROSTRUCTURES}

A detailed study was performed using different HIP treatment cycles on L-PBF parts fabricated at various energy densities using 17-4 PH stainless steel gas and water-atomized powders. The results from this work show the strong dependence of densification, mechanical properties and microstructures on temperature, pressure and time during the HIP cycle microstructures on temperature, pressure and time during the HIP cycle.

- The mechanical properties of both gas and water-atomized L-PBF parts improved following HIP treatment.

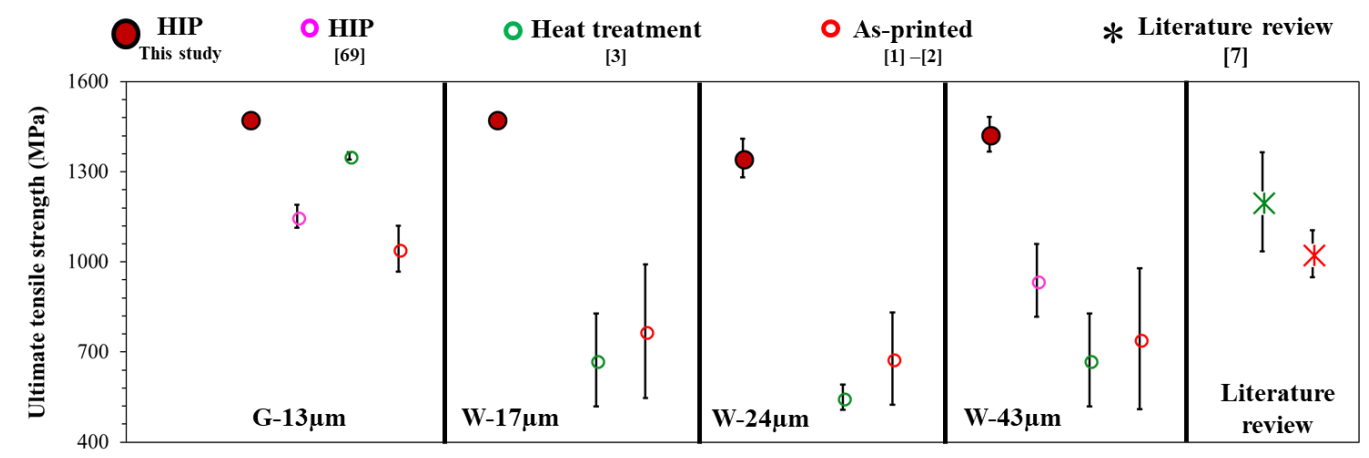

Figure. 6.1. Ultimate tensile strength of HIP treated gas and water-atomized LPBF parts when compared to other approaches

- The ultimate tensile strength of both gas and water-atomized L-PBF parts increased due to HIP treatment and less sensitive to powder and process varaiations compared to other approaches as shown in Figure 6.1.

- Similar trends were observed when yield strength and hardness values of HIP treated gas and water-atomized L-PBF parts were compared to other approaches.

- Following HIP treatment, $99.5 \pm 0.2 \%$ dense L-PBF parts with ultimate tensile strength: $1450 \pm 20 \mathrm{MPa}$, hardness: $40 \pm 1 \mathrm{HRC}$, yield strength: $1180 \pm 20 \mathrm{MPa}$ and elongation: $10 \pm 1 \%$ were achieved using both water and gas-atomized 
powders. For reference, the as-printed properties ranged as follows: Density: $88 \pm$ 1 to $97.5 \pm 0.2 \%$, Ultimate tensile strength: $480 \pm 30$ to $1070 \pm 50 \mathrm{MPa}$, Hardness: $27 \pm 1$ to $36 \pm 1 \mathrm{HRC}$, Yield strength: $400 \pm 50$ to $800 \pm 50 \mathrm{MPa}$.

- The density, martensite content and equiaxed microstructure in L-PBF parts after HIP treatment were consistent with the trends in the mechanical properties of the L-PBF parts.

- Martensite phase and equiaxed microstructures after HIP treatment was less sensitive to powder/process variations compared to other approaches.

- Robust and reliable properties were obtained after the HIP treatment from both gas and water-atomized powders at various energy densities. The properties obtained after the HIP treatment were less sensitive to variations in powder characteristics (size distribution and shape) and energy density during processing and were superior to known reported properties of 17-4 PH stainless steel fabricated by LPBF, powder metallurgy, metal injection molding, or wrought samples.

\subsubsection{CORROSION PROPERTIES}

The following conclusions were drawn from the corrosion performance evaluation studies performed on as-printed (Chapter 4) and HIP treated L-PBF parts (Chapter 5):

\subsubsection{AS-PRINTED L-PBF PARTS}

Corrosion studies were conducted to understand the effects of processing conditions (energy density) and powder characteristics (shape and size distribution) on the corrosion 
performance of as-printed 17-4 PH stainless steel parts produced by laser-powder bed fusion (L-PBF):

- The corrosion performance of the as-printed 17-4 PH stainless steel L-PBF parts fabricated using gas and water-atomized powders strongly depend on their density. The density and consequently the corrosion current, polarization resistance, and corrosion rate of the as-printed L-PBF parts did not vary significantly for highly dense $(97 \pm 0.5 \%)$, finer gas $\left(\mathrm{D}_{50}=13 \mu \mathrm{m}\right)$ and water-atomized $\left(\mathrm{D}_{50}=17 \mu \mathrm{m}\right)$ powders when fabricated using energy densities in the range from 64-104 J/mm³. Furthermore, the corrosion performance of as-printed L-PBF parts of high density $(97 \pm 0.5 \%)$ showed slightly higher corrosion performance compared to the wrought sample.

- The density and consequently the corrosion performance of as-printed L-PBF parts fabricated using the coarser water-atomized powders $\left(D_{50}=24 \mu \mathrm{m}\right.$ and $\left.43 \mu \mathrm{m}\right)$ increased with energy density when fabricated in the same range of energy densities 64-104 J/mm

- At energy densities of 64,80 , and $84 \mathrm{~J} / \mathrm{mm}^{3}$, as-printed L-PBF parts fabricated using the finer gas-atomized $\left(\mathrm{D}_{50}=13 \mu \mathrm{m}\right)$ and water-atomized $\left(\mathrm{D}_{50}=17 \mu \mathrm{m}\right)$ powders showed significantly better corrosion performance compared to coarser water-atomized powders $\left(\mathrm{D}_{50}=24 \mu \mathrm{m}\right.$ and $\left.43 \mu \mathrm{m}\right) \mathrm{L}-\mathrm{PBF}$ parts.

- At the energy density of $104 \mathrm{~J} / \mathrm{mm}^{3}$, the corrosion performance does not vary significantly as a function of starting powder characteristics (shape and size) and atomization method (gas or water-atomization) used to produce these powders. 
- At the energy densities of $104 \mathrm{~J} / \mathrm{mm}^{3}$, the as-printed L-PBF parts fabricated using water-atomized powders $\left(\mathrm{D}_{50}=17 \mu \mathrm{m}\right.$ and $\left.43 \mu \mathrm{m}\right)$ powders exhibited a slightly higher polarization resistance $(28000 \pm 500 \Omega)$ compared to wrought samples $(25000 \pm 1000 \Omega)$ in $0.5 \mathrm{M} \mathrm{NaCl}$

\subsubsection{HIP TREATED L-PBF PARTS}

A study was performed to understand the effect of hot isostatic pressing on the corrosion performance of 17-4 PH stainless steel gas and water-atomized parts produced by laserpowder bed fusion (L-PBF) at an energy density $104 \mathrm{~J} / \mathrm{mm}^{3}$.

- The anodic and cathodic behavior as well as the breakdown of the passive region in Tafel plots HIP treated L-PBF parts were significantly different from the corresponding attributes found in Tafel plots of as-printed L-PBF parts.

- The corrosion potential $(-150 \pm 5 \mathrm{mV})$, polarization resistance $(40000 \pm 500 \Omega \mathrm{cm}$ 2) of the L-PBF parts increased following HIP treatment and was higher than the corresponding as-printed properties, consistent with the increase in density (99.5 \pm $0.2 \%)$.

- The corrosion rate $(1 \pm 0.3 \mu \mathrm{m} /$ year $)$ of the HIP treated L-PBF parts was lower than the as-printed L-PBF parts $(1.7 \pm 0.5 \mu \mathrm{m} /$ year to $7 \pm 1 \mu \mathrm{m} /$ year $)$ irrespective of starting powder type.

- The superior corrosion performance of the HIP treated L-PBF parts could also be correlated to the decrease in grain size when compared to as-printed L-PBF parts. 
- A similar corrosion performance (corrosion current: $0.008 \pm 0.001 \mu \mathrm{A}$, corrosion potential: $-150 \pm 5 \mathrm{mV}$, polarization resistance: $40000 \pm 500 \Omega \mathrm{cm}-2$, corrosion rate: $1 \pm 0.3 \mu \mathrm{m} /$ year) was observed for both gas and water-atomized L-PBF parts following HIP treatment

\subsection{FUTURE WORK}

This dissertation was undertaken to understand several new aspects affecting materialprocess-property- microstructure relationships when 17-4 PH stainless steel gas and wateratomized powders were used for fabricating L-PBF parts. The findings of this work have identified several areas for further work to build from the studies presented in this dissertation. They are:

- An understanding of the fatigue life of 17-4 PH stainless steel L-PBF parts as a function of powder attributes, L-PBF processing conditions and post-processing operations such as HIP and heat treatment needs to be undertaken

- A three-dimensional porosity, phase and grain distribution analysis of 17-4 PH stainless steel L-PBF parts can provide further insight into the formation as well as influence of pore, phase and grain distributions on mechanical and corrosion properties

- Understanding the effects of part build orientation on the mechanical and corrosion properties as well as microstructures can provide an insight on the impact of HIP treatment on anisotropic L-PBF parts 
- The experimental results from the present study need to help refine modeling and simulation to further understand the effects of powder packing, flow and densification as a function of initial powder attributes (shape, chemistry and size) to improve process reliability, revise methodologies to evenly distribute powders to a high packing density in powder bed process and enhance design process tools for L-PBF.

- The results from this work on 17-4 PH stainless steel should be extended to other alloy systems as well as revised water-atomization procedures that enhance powder packing and flow attributes by modifying shape and size distributions. 


\section{REFERENCES}

[1] H. Irrinki, M. Dexter, B. Barmore, R. Enneti, S. Pasebani, S. Badwe, J. Stitzel, R. Malhotra, and S. V. Atre, "Effects of Powder Attributes and Laser Powder Bed Fusion (LPBF) Process Conditions on the Densification and Mechanical Properties of 17-4 PH Stainless Steel,” JOM, vol. 68, no. 3, pp. 860-868, Jan. 2016.

[2]H. Irrinki, J.J. Dilip, S. Pasebani, S. Badwe, J. Stitzel, O. Gulsoy, K. Kate and S. V. Atre,"Effects of particle characteristics on the microstructure and mechanical properties of 17-4 PH stainless steel fabricated by laser-powder bed fusion," Powder Technol., vol. 331, Mar. 2018.

[3]S. Pasebani, M. Ghayoor, S. Badwe, H. Irrinki, and S. V. Atre, "Effects of atomizing media and post processing on mechanical properties of 17-4 $\mathrm{PH}$ stainless steel manufactured via selective laser melting," Addit. Manuf., vol. 22, pp. 127-137, Aug. 2018. [5]A.B. Spierings, N. Herres, and G. Levy, "Influence of the particle size distribution on surface quality and mechanical properties in AM steel parts," Rapid Prototyp. J., vol. 17, no. 3, pp. 195-202, Apr. 2011.

[6]R. Li, Y. Shi, Z. Wang, L. Wang, J. Liu, and W. Jiang, "Densification behavior of gas and water atomized 316L stainless steel powder during selective laser melting," Appl. Surf. Sci., vol. 256, no. 13, pp. 4350-4356, Apr. 2010. 
[7]H. Irrinki, B. Barmore, K. H. Kate, and S. V. Atre, "Material selection for the production of injection moulding tooling by Additive Manufacturing," Metal Additive Manufacturing, vol. 2, no. Summer 2016, pp. 77-89.

[8]H. . Niu and I. T. . Chang, "Selective laser sintering of gas and water atomized high speed steel powders," Scr. Mater., vol. 41, no. 1, pp. 25-30, Jun. 1999.

[9]H. Irrinki et al., "Effects of Powder Attributes and Laser Powder Bed Fusion (L-PBF) Process Conditions on the Densification and Mechanical Properties of 17-4 PH Stainless Steel," JOM, vol. 68, no. 3, pp. 860-868, Jan. 2016.

[10]B. AlMangour and J.-M. Yang, "Understanding the deformation behavior of 17-4 precipitate hardenable stainless steel produced by direct metal laser sintering using micropillar compression and TEM," Int. J. Adv. Manuf. Technol., vol. 90, no. 1-4, pp. 119126, Apr. 2017.

[11]M. Badrossamay and T. H. C. Childs, "Further studies in selective laser melting of stainless and tool steel powders," Int. J. Mach. Tools Manuf., vol. 47, no. 5, pp. 779-784, Apr. 2007.

[12]A.B. Spierings, N. Herres, and G. Levy, "Influence of the particle size distribution on surface quality and mechanical properties in AM steel parts," Rapid Prototyp. J., vol. 17, no. 3, pp. 195-202, Apr. 2011.

[13]R. M. German, Powder metallurgy of iron and steel. Wiley, 1998.

[14]H. Irrinki, B. Brenton, K. Kate, and S. V. Atre, "Materials For Additive Manufacturing Of Production Tooling For Injection Molding Using Laser-Powder Bed Fusion (L-PBF),” Metal Additive Manufacturing, vol. 2, no. 2, pp. 77-89, 2016. 
[15]A. Kreitcberg, V. Brailovski, S. Turenne, C. Chanal, and V. Urlea, "Influence of Thermo- and HIP Treatments on the Microstructure and Mechanical Properties of IN625 Alloy Parts Produced by Selective Laser Melting: A Comparative Study," Mater. Sci. Forum, vol. 879, pp. 1008-1013, 2017.

[16]N. P. Lavery et al., "Effects of hot isostatic pressing on the elastic modulus and tensile properties of 316L parts made by powder bed laser fusion," Mater. Sci. Eng. A, vol. 693, pp. 186-213, May 2017.

[17]K. Geenen, A. Röttger, and W. Theisen, "Corrosion behavior of 316L austenitic steel processed by selective laser melting, hot-isostatic pressing, and casting," Mater. Corros., vol. 68, no. 7, pp. 764-775, Jul. 2017.

[18]J. Li, C. Yuan, J. Guo, J. Hou, and L. Zhou, "Effect of hot isostatic pressing on microstructure of cast gas-turbine vanes of K452 alloy," Prog. Nat. Sci. Mater. Int., vol. 24, no. 6, pp. 631-636, Dec. 2014.

[19]J. Haan, M. Asseln, M. Zivcec, J. Eschweiler, R. Radermacher, and C. Broeckmann, "Effect of subsequent Hot Isostatic Pressing on mechanical properties of ASTM F75 alloy produced by Selective Laser Melting," Powder Metall., vol. 58, no. 3, pp. 161-165, Jul. 2015.

[20]W. Tillmann, C. Schaak, J. Nellesen, M. Schaper, M. E. Aydinöz, and K.-P. Hoyer, "Hot Isostatic Pressing of IN718 Components Manufactured by Selective Laser Melting," Addit. Manuf., vol. 13, Nov. 2016.

[21]M. N. Gussev, N. Sridharan, Z. Thompson, K. A. Terrani, and S. S. Babu, "Influence of hot isostatic pressing on the performance of aluminum alloy fabricated by ultrasonic additive manufacturing," Scr. Mater., vol. 145, pp. 33-36, Mar. 2018. 
[22]T. M. Mower and M. J. Long, "Mechanical behavior of additive manufactured, powder-bed laser-fused materials," Mater. Sci. Eng. A, vol. 651, pp. 198-213, Jan. 2016. [23]S. Tammas-Williams, P. J. Withers, I. Todd, and P. B. Prangnell, “The Effectiveness of Hot Isostatic Pressing for Closing Porosity in Titanium Parts Manufactured by Selective Electron Beam Melting,” Metall. Mater. Trans. A, vol. 47, no. 5, pp. 1939-1946, May 2016.

[24]M.-W. Wu and P.-H. Lai, "The positive effect of hot isostatic pressing on improving the anisotropies of bending and impact properties in selective laser melted Ti-6Al-4V alloy," Mater. Sci. Eng. A, vol. 658, pp. 429-438, Mar. 2016.

[25]H. Irrinki, “'Mechanical properties and microstructure evolution of 17-4 PH stainless' by Harish Irrinki,” University of Louisville, 2016.

[26]H. Irrinki et al., "Effects of powder characteristics and processing conditions on the corrosion performance of 17-4 PH stainless steel fabricated by laser-powder bed fusion,” Prog. Addit. Manuf., vol. 3, no. 2, pp. 39-49, 2018.

[27]H. Irrinki and S. V. Atre, "University of Louisville team examines use of Additive Manufacturing in development of PM components," Powder Metallurgy Review, vol. 7, no. $2,2018$.

[28]H. Gu, H. Gong, D. Pal, K. Rafi, T. Starr, and B. Stucker, "Influences of energy density on porosity and microstructure of selective laser melted 17-4PH stainless steel." In Proceedings of Solid Freeform Fabrication Symposium (pp. 474-479).

[29]P. B. M. Averyanova, "Studying the influence of initial powder characteristics on the properties of final parts manufactured by the selective laser melting technology," Virtual Phys. Prototyp., pp. 1-9, 2011. 
[30]D. Gu and Y. Shen, "Processing conditions and microstructural features of porous 316L stainless steel components by DMLS," Appl. Surf. Sci., vol. 255, no. 5, Part 1, pp. 1880-1887, Dec. 2008.

[31]A. Simchi, "Direct laser sintering of metal powders: Mechanism, kinetics and microstructural features," Mater. Sci. Eng. A, vol. 428, no. 1-2, pp. 148-158, Jul. 2006. [32]A. Simchi and H. Pohl, "Effects of laser sintering processing parameters on the microstructure and densification of iron powder," Mater. Sci. Eng. A, vol. 359, no. 1, pp. 119-128, 2003.

[33]R. Rashid, S. H. Masood, D. Ruan, S. Palanisamy, R. A. Rahman Rashid, and M. Brandt, "Effect of scan strategy on density and metallurgical properties of 17-4PH parts printed by Selective Laser Melting (SLM)," J. Mater. Process. Technol., vol. 249, pp. 502511, Nov. 2017.

[34]L. E. Murr et al., "Microstructures and Properties of 17-4 PH Stainless Steel Fabricated by Selective Laser Melting," J. Mater. Res. Technol., vol. 1, no. 3, pp. 167-177, Oct. 2012. [35]Z. Hu, H. Zhu, H. Zhang, and X. Zeng, "Experimental investigation on selective laser melting of 17-4PH stainless steel," Opt. Laser Technol., vol. 87, pp. 17-25, Jan. 2017. [36]W.-N. Su, P. Erasenthiran, and P. M. Dickens, "Investigation of fully dense laser sintering of tool steel powder using a pulsed Nd: Yag (neodymium-doped yttrium aluminium garnet) laser," Proc. Inst. Mech. Eng. Part C J. Mech. Eng. Sci., vol. 217, no. 1, pp. 127-138, Jan. 2003.

[37]M. M. Dewidar, K. W. Dalgarno, and C. S. Wright, "Processing conditions and mechanical properties of high-speed steel parts fabricated using direct selective laser 
sintering," Proc. Inst. Mech. Eng. Part B J. Eng. Manuf., vol. 217, no. 12, pp. 1651-1663, Jan. 2003.

[38]V. E. Beal, P. Erasenthiran, N. Hopkinson, P. Dickens, and C. H. Ahrens, "Scanning strategies and spacing effect on laser fusion of $\mathrm{H} 13$ tool steel powder using high power Nd:YAG pulsed laser,” Int. J. Prod. Res., vol. 46, no. 1, pp. 217-232, 2008.

[39]T. H. C. Childs, C. Hauser, and M. Badrossamay, "Selective laser sintering (melting) of stainless and tool steel powders: Experiments and modelling," Proc. Inst. Mech. Eng. Part B J. Eng. Manuf., vol. 219, no. 4, pp. 339-357, Apr. 2005.

[40]A. Simchi and H. Asgharzadeh, "Densification and microstructural evaluation during laser sintering of M2 high speed steel powder," Mater. Sci. Technol., vol. 20, no. 11, pp. 1462-1468, Nov. 2004.

[41]M. Mahmoudi, A. Elwany, A. Yadollahi, S. M. Thompson, L. Bian, and N. Shamsaei, "Mechanical properties and microstructural characterization of selective laser melted 17-4 PH stainless steel,” Rapid Prototyp. J., vol. 23, no. 2, pp. 280-294, Mar. 2017.

[42]T. Prater, "Study of Material Consolidation at Higher Throughput Parameters in Selective Laser Melting of Inconel 718," presented at the The Materials Society 2016 Annual Meeting and Exhibition, 14-18 Feb. 2016, United States, 2016.

[43]S. Kumpaty et al., "Effect of Heat Treatment on Mechanical/Metallurgical Properties of Direct Metal Laser Sintered 17-4 Precipitate Hardened Stainless Steel," Adv. Mater. Res., vol. 699, pp. 795-801, May 2013.

[44]P. B. M. Averyanova and V. B, "Effect of initial powder properties on final microstructure and mechanical properties of parts manufactured by selective laser melting." 
[45]L. E. Murr et al., "Microstructures and Properties of 17-4 PH Stainless Steel Fabricated by Selective Laser Melting,” J. Mater. Res. Technol., vol. 1, no. 3, pp. 167-177, Oct. 2012. [46]L. L. A J Pinkerton, “An analytical model of energy distribution in laser direct metal deposition," Proc. Inst. Mech. Eng. Part B-J. Eng. Manuf. - PROC INST MECH ENG B-J ENG MA, vol. 218, no. 4, pp. 363-374, 2004.

[47]I. Radomir, V. Geamăn, and M. Stoicănescu, "Densification Mechanisms Made During Creep Techniques Applied to the Hot Isostatic Pressing," Procedia - Soc. Behav. Sci., vol. 62, pp. 779-782, Oct. 2012.

[48]K. Essa, P. Jamshidi, J. Zou, M. M. Attallah, and H. Hassanin, "Porosity control in 316L stainless steel using cold and hot isostatic pressing," Mater. Des., vol. 138, pp. 2129, Jan. 2018.

[49]J. S. C. Jang and C. C. Koch, "The hall-petch relationships in mechanically alloyed Ni3Al with oxide dispersoids," Scr. Metall., vol. 22, no. 5, pp. 677-682, Jan. 1988.

[50]A. Simchi and H. Pohl, "Direct laser sintering of iron-graphite powder mixture," Mater. Sci. Eng. A, vol. 383, no. 2, pp. 191-200, Oct. 2004.

[51]F. Abe, K. Osakada, M. Shiomi, K. Uematsu, and M. Matsumoto, "The manufacturing of hard tools from metallic powders by selective laser melting," J. Mater. Process. Technol., vol. 111, no. 1-3, pp. 210-213, Apr. 2001.

[52]D. T. Pham and S. S. Dimov, Rapid Manufacturing. London: Springer London, 2001. [53]D. King and T. Tansey, "Alternative materials for rapid tooling," J. Mater. Process. Technol., vol. 121, no. 2-3, pp. 313-317, Feb. 2002. 
[54]J. P. Kruth, L. Froyen, J. Van Vaerenbergh, P. Mercelis, M. Rombouts, and B. Lauwers, "Selective laser melting of iron-based powder," J. Mater. Process. Technol., vol. 149, no. 1-3, pp. 616-622, Jun. 2004.

[55]D. Atkinson, Rapid prototyping and tooling: a practical guide. Welwyn Garden City: Strategy Publications, 1997.

[56]L. E. Murr et al., "Microstructures and Properties of 17-4 PH Stainless Steel Fabricated by Selective Laser Melting," J. Mater. Res. Technol., vol. 1, no. 3, pp. 167-177, Oct. 2012. [57]P. Fischer, V. Romano, H. P. Weber, N. P. Karapatis, E. Boillat, and R. Glardon, "Sintering of commercially pure titanium powder with a Nd:YAG laser source," Acta Mater., vol. 51, no. 6, pp. 1651-1662, Apr. 2003.

[58]G. Sun, R. Zhou, J. Lu, and J. Mazumder, "Evaluation of defect density, microstructure, residual stress, elastic modulus, hardness and strength of laser-deposited AISI 4340 steel,” Acta Mater., vol. 84, pp. 172-189, Feb. 2015.

[59]A. Simchi, "Direct laser sintering of metal powders: Mechanism, kinetics and microstructural features," Mater. Sci. Eng. A, vol. 428, no. 1-2, pp. 148-158, 2006.

[60]H. J. Niu and I. T. H. Chang, "Selective laser sintering of gas and water atomized high speed steel powders," Scr. Mater., vol. 41, no. 1, pp. 25-30, 1999.

[61]A. Yadollahi, N. Shamsaei, S. M. Thompson, A. Elwany, and L. Bian, "Effects of building orientation and heat treatment on fatigue behavior of selective laser melted 17-4 PH stainless steel," Int. J. Fatigue, vol. 94, pp. 218-235, Jan. 2017.

[62]T. LeBrun, T. Nakamoto, K. Horikawa, and H. Kobayashi, "Effect of retained austenite on subsequent thermal processing and resultant mechanical properties of selective laser melted 17-4 PH stainless steel," Mater. Des., vol. 81, pp. 44-53, Sep. 2015. 
[63]L. Thijs, F. Verhaeghe, T. Craeghs, J. V. Humbeeck, and J.-P. Kruth, "A study of the microstructural evolution during selective laser melting of Ti-6Al-4V," Acta Mater., vol. 58, no. 9, pp. 3303-3312, May 2010.

[64]F. Caiazzo, S. L. Campanelli, F. Cardaropoli, N. Contuzzi, V. Sergi, and A. D. Ludovico, "Manufacturing and characterization of similar to foam steel components processed through selective laser melting," Int. J. Adv. Manuf. Technol., vol. 92, no. 5-8, pp. 2121-2130, Sep. 2017.

[65]A. P. Ventura, "Microstructural Evolution and Mechanical Property Development of Selective Laser Melted Copper Alloys," p. 190.

[66]B. AlMangour, D. Grzesiak, and J. M. Yang, "Effect of Scanning Methods in the Selective Laser Melting of 316L/TiC Nanocomposities," p. 8.

[67]S. Scudino et al., "Additive manufacturing of Cu-10Sn bronze," Mater. Lett., vol. 156, pp. 202-204, Oct. 2015.

[68]P. G. E. Jerrard, L. Hao, and K. E. Evans, "Experimental investigation into selective laser melting of austenitic and martensitic stainless steel powder mixtures," Proc. Inst. Mech. Eng. Part B J. Eng. Manuf., vol. 223, no. 11, pp. 1409-1416, Nov. 2009.

[69]H. Irrinki, S. D. Nath, M. Alhofors, O. Gulsoy, and S. V. Atre, "Microstructures, properties and applications of laser sintered metal powders," J. Am. Ceram. Soc., vol. under review.

[70]H. V. Atkinson and S. Davies, "Fundamental aspects of hot isostatic pressing: An overview," Metall. Mater. Trans. A, vol. 31, no. 12, pp. 2981-3000, Dec. 2000. 
[71]A. Yadollahi, N. Shamsaei, S. M. Thompson, A. Elwany, and L. Bian, "Effects of building orientation and heat treatment on fatigue behavior of selective laser melted 17-4 PH stainless steel,” Int. J. Fatigue, vol. 94, pp. 218-235, Jan. 2017. [72]M. Mahmoudi, A. Elwany, A. Yadollahi, S. M. Thompson, L. Bian, and N. Shamsaei, "Mechanical properties and microstructural characterization of selective laser melted 17-4 PH stainless steel,” Rapid Prototyp. J., vol. 23, no. 2, pp. 280-294, Mar. 2017.

[73]L. E. Murr et al., "Fabrication of Metal and Alloy Components by Additive Manufacturing: Examples of 3D Materials Science," J. Mater. Res. Technol., vol. 1, no. 1, pp. 42-54, Apr. 2012.

[74]S. Kumpaty et al., "Effect of Heat Treatment on Mechanical/Metallurgical Properties of Direct Metal Laser Sintered 17-4 Precipitate Hardened Stainless Steel," Adv. Mater. Res., vol. 699, pp. 795-801, May 2013.

[75]R. M. German, Powder Metallurgy of Iron and Steel, 1 edition. New York: WileyInterscience, 1998.

[76]G. Hengfeng, G. Haijin, P. Deepankar, R. Khalid, S. Thomas, and S. Brent, "Influences of Energy Density on Porosity and Microstructure of Selective Laser Melted 17-4PH Stainless Steel," Dec. 2014.

[77]T. LeBrun, T. Nakamoto, K. Horikawa, and H. Kobayashi, "Effect of retained austenite on subsequent thermal processing and resultant mechanical properties of selective laser melted 17-4 PH stainless steel," Mater. Des., vol. 81, pp. 44-53, Sep. 2015.

[78]S. A.B, W. K, and L. G, "Designing Material Properties Locally with Additive Manufacturing Technology SLM,” Dec. 2014. 
[79]B. Song, S. Dong, P. Coddet, H. Liao, and C. Coddet, "Fabrication of NiCr alloy parts by selective laser melting: Columnar microstructure and anisotropic mechanical behavior," Mater. Des., vol. 53, pp. 1-7, Jan. 2014.

[80]N. V. J. Luca Facchini, "Metastable Austenite in 17-4 Precipitation-Hardening Stainless Steel Produced by Selective Laser Melting," Adv. Eng. Mater., vol. 12, pp. 184$188,2010$.

[81]A. J. Pinkerton and L. Li, "Direct additive laser manufacturing using gas- and wateratomised H13 tool steel powders," Int. J. Adv. Manuf. Technol., vol. 25, no. 5-6, pp. 471479, 2005.

[82]A. Simchi, F. Petzoldt, and H. Pohl, "Direct metal laser sintering: Material considerations and mechanisms of particle bonding," Int. J. Powder Metall. Princet. N. J., vol. 37, no. 2, pp. 49-61, 2001.

[83]A. Fedrizzi, M. Pellizzari, and M. Zadra, "Influence of particle size ratio on densification behaviour of AISI H13/AISI M3:2 powder mixture," Powder Technol., vol. 228, pp. 435-442, 2012.

[84]R. Materese, "The Influence of Post-Build Microstructure on the Electrochemical Behavior of Additively Manufactured 17-4 PH Stainless Steel," NIST, 01-Mar-2017. [Online]. Available: https://www.nist.gov/publications/influence-post-buildmicrostructure-electrochemical-behavior-additively-manufactured-17. [Accessed: 11May-2017].

[85]L. Zeng, N. Xiang, and B. Wei, "A comparison of corrosion resistance of cobaltchromium-molybdenum metal ceramic alloy fabricated with selective laser melting and traditional processing," J. Prosthet. Dent., vol. 112, no. 5, pp. 1217-1224, Nov. 2014. 
[86]Kurian Antony and Siva Prasad M, “A Comparison of Corrosion Resistance of Stainless Steel Fabricated with Selective Laser Melting and Conventional Processing," International Journal of ChemTech Research.

[87]B. Zhao, H. Wang, N. Qiao, C. Wang, and M. Hu, “Corrosion resistance characteristics of a Ti-6Al-4V alloy scaffold that is fabricated by electron beam melting and selective laser melting for implantation in vivo," Mater. Sci. Eng. C Mater. Biol. Appl., vol. 70, no. Pt 1, pp. 832-841, Jan. 2017.

[88]Costa, Isolda, Sizue Ota Rogero, Mitiko Saiki, Rogério Albuquerque Marques, and José Roberto Rogero. "Corrosion resistance and cytotoxicity study of 17-4PH steels produced by conventional metallurgy and powder injection molding." In Materials Science Forum, vol. 591, pp. 18-23. Trans Tech Publications, 2008.

[89]A. K. Singh, G. M. Reddy, and K. S. Rao, "Pitting corrosion resistance and bond strength of stainless steel overlay by friction surfacing on high strength low alloy steel," Def. Technol., vol. 11, no. 3, pp. 299-307, Sep. 2015.

[90]U. K. Mudali, A. K. Bhaduri, and J. B. Gnanamoorthy, "Localised corrosion behaviour of 17-4 PH stainless steel,” Mater. Sci. Technol., vol. 6, no. 5, pp. 475-481, May 1990. [91]A. G. dos Santos, L. V. Biehl, and L. M. Antonini, "Effect of chemical passivation treatment on pitting corrosion resistance of AISI 410 and 17-4 PH stainless steels," Mater. Corros., p. n/a-n/a, Feb. 2017.

[92]V. J. Pulikkottil, S. Chidambaram, P. U. Bejoy, P. K. Femin, P. Paul, and M. Rishad, "Corrosion resistance of stainless steel, nickel-titanium, titanium molybdenum alloy, and ion-implanted titanium molybdenum alloy archwires in acidic fluoride-containing artificial 
saliva: An in vitro study," J. Pharm. Bioallied Sci., vol. 8, no. Suppl 1, pp. S96-S99, Oct. 2016.

[93]Costa, I., Franco, C. V., Kunioshi, C. T., \& Rossi, J. L. "Corrosion resistance of injection-molded 17-4PH steel in sodium chloride solution." Corrosion, 62(4), 357-365, 2006.

[94]Yanjin Lu, Yiliang Gan, Junjie Lin, Sai Guo, Songquan Wu, and Jinxin Lin, "Effect of laser speeds on the mechanical property and corrosion resistance of $\mathrm{CoCrW}$ alloy fabricated by SLM," Rapid Prototyp. J., vol. 23, no. 1, pp. 28-33, Jan. 2017.

[95]A. K. Singh, G. M. Reddy, and K. S. Rao, "Pitting corrosion resistance and bond strength of stainless steel overlay by friction surfacing on high strength low alloy steel," Def. Technol., vol. 11, no. 3, pp. 299-307, Sep. 2015.

[96]Sutton, Austin T., Caitlin S. Kriewall, Ming C. Leu, and Joseph W. Newkirk. "Powders for additive manufacturing processes: Characterization techniques and effects on part properties." In Proceedings of the 26th Annual International Solid Freeform Fabrication Symposium-An Additive Manufacturing Conference. 2016.

[97]E. O. Olakanmi, "Effect of mixing time on the bed density, and microstructure of selective laser sintered (sls) aluminium powders," Mater. Res., vol. 15, no. 2, pp. 167-176, Apr. 2012.

[98] Liu, B., Wildman, R., Tuck, C., Ashcroft, I., \& Hague, R., "Investigation the effect of particle size distribution on processing parameters optimisation in selective laser melting process", Additive Manufacturing Research Group, Loughborough University, 227-238, 2011. 
[99]V. Manakari, G. Parande, and M. Gupta, "Selective Laser Melting of Magnesium and Magnesium Alloy Powders: A Review," Metals, vol. 7, no. 1, p. 2, Dec. 2016.

[100]G. S. Frankel, "Fundamentals of Corrosion Kinetics,” vol. 233, May 2016.

[101]R. F. Schaller, J. M. Taylor, J. Rodelas, and E. J. Schindelholz, “Corrosion Properties of Powder Bed Fusion Additively Manufactured 17-4 PH Stainless Steel," CORROSION, vol. 73, no. 7, pp. 796-807, Feb. 2017.

[102]"Powder Metallurgy Stainless Steels: Processing, Microstructures, and Properties ASM International.” [Online]. Available: https://www.asminternational.org/search//journal_content/56/10192/05200G/PUBLICATION.

[103]P. K. Samal, B. Hu, I. Hauer, and O. Mars, "Optimization of corrosion resistance and machinability of PM 316L stainless steel,” pp. 740-750, Jan. 2007.

[104]K. S. Raja and K. P. Rao, "Pitting Behavior of Type 17-4 PH Stainless Steel Weldments," CORROSION, vol. 51, no. 8, pp. 586-592, Aug. 1995.

[105]C. Lai and Z. Xiang, "Investigation the effect of porosity on corrosion of macroporous silicon in $1.0 \mathrm{M}$ sodium hydroxide solution using weight loss measurements, electrochemical methods and scanning electron microscope," Corros. Sci., vol. 99, pp. 178-184, Oct. 2015.

[106]E. Aghion and Y. Perez, "Effects of porosity on corrosion resistance of Mg alloy foam produced by powder metallurgy technology," Mater. Charact., vol. 96, pp. 78-83, Oct. 2014.

[107]M. R. Stoudt, R. E. Ricker, E. A. Lass, and L. E. Levine, "Influence of Postbuild Microstructure on the Electrochemical Behavior of Additively Manufactured 17-4 PH Stainless Steel," JOM, vol. 69, no. 3, pp. 506-515, Mar. 2017. 
[108]H. Irrinki, S. D. Nath, M. Alhofors, J. Stitzel, and S. V. Atre, "Property Gains from Hot Isostatic Pressing of 17-4 PH Stainless Steel Gas and Water-Atomized Parts Fabricated by Laser-Powder Bed Fusion," Prep.

[109]K. Geenen, A. Röttger, and W. Theisen, "Corrosion behavior of 316L austenitic steel processed by selective laser melting, hot-isostatic pressing, and casting," Mater. Corros., vol. 68, no. 7, pp. 764-775, Jul. 2017.

[110]A. B. Spierings, K. Dawson, P. Dumitraschkewitz, S. Pogatscher, and K. Wegener, "Microstructure characterization of SLM-processed Al-Mg-Sc-Zr alloy in the heat treated and HIP treated condition," Addit. Manuf., vol. 20, pp. 173-181, Mar. 2018.

[111]L. Chang, W. Sun, Y. Cui, and R. Yang, "Preparation of hot-isostatic-pressed powder metallurgy superalloy Inconel 718 free of prior particle boundaries," Mater. Sci. Eng. A, vol. 682, pp. 341-344, Jan. 2017.

[112]A. Szewczyk-Nykiel and J. Kazior, "Effect of Aging Temperature on Corrosion Behavior of Sintered 17-4 PH Stainless Steel in Dilute Sulfuric Acid Solution,” J. Mater. Eng. Perform., vol. 26, no. 7, pp. 3450-3456, Jul. 2017.

[113]M. Stoudt, R. Ricker, E. Lass, and L. E. Levine, "Influence of Postbuild Microstructure on the Electrochemical Behavior of Additively Manufactured 17-4 PH Stainless Steel,” JOM, vol. 69, pp. 506-515, Mar. 2017.

[114]K. D. Ralston and N. Birbilis, "Effect of Grain Size on Corrosion: A Review," CORROSION, vol. 66, no. 7, pp. 075005-075005-13, Jul. 2010.

[115]“Standard Test Methods for Determining Average Grain Size,” E112 vols., 1996. [116]S. Gollapudi, "Grain size distribution effects on the corrosion behaviour of materials," Corros. Sci., vol. 62, pp. 90-94, Sep. 2012. 
[117]C. S. Obayi et al., "Effect of grain sizes on mechanical properties and biodegradation behavior of pure iron for cardiovascular stent application," Biomatter, vol. 6, p. e959874, 2016.

[118]A. Abbasi Aghuy, M. Zakeri, M. H. Moayed, and M. Mazinani, "Effect of grain size on pitting corrosion of 304L austenitic stainless steel," Corros. Sci., vol. 94, pp. 368376,2015 . 


\section{APPENDIX A \\ EFFECTS OF ATOMIZING MEDIA AND POST PROCESSING ON MECHANICAL PROPERTIES OF 17-4 PH STAINLESS STEEL MANUFACTURED VIA SELECTIVE LASER MELTING}

\section{A.1 INTRODUCTION}

17-4 PH stainless steel is known as AISI 630 stainless steel and is a lath martensitic stainless steel hardened by precipitation of $\mathrm{Cu}$-rich spherical particles in the martensitic matrix. 17-4 PH stainless steels have good mechanical properties and corrosion resistance at typical service temperatures below $300{ }^{\circ} \mathrm{C}[1,2]$ and are used in marine environments, power plants (light-water and pressurized water reactors) and powder metal injection molding industries. With solution annealing of $17-4 \mathrm{PH}$ stainless steel at $1050^{\circ} \mathrm{C}$ and aging at $482{ }^{\circ} \mathrm{C}, \mathrm{Cu}$-rich phase precipitate as coherent spherical bec structures that would result in increased tensile strength and toughness [3]. Coherent (bcc) Cu-rich precipitates usually transform to non-coherent fcc-Cu-rich particles upon extended aging at $400{ }^{\circ} \mathrm{C}$ [4]. Reversion of martensite to the austenite during aging is explained by the concentration of austenite stabilizing elements led by diffusion and lower martensitic transformation start (Ms) temperature [5]. 
Selective Selective laser melting (SLM) is an additive manufacturing (AM) technology to produce complex three-dimensional parts through solidifying successive layers of powder materialson the basis of a 3D computer aided design (CAD) model. SLM is associated with complete melting of the powder material [6,7]. Because the weldability of 17-4 $\mathrm{PH}$ martensitic stainless steel is good for the usual arc welding processes, this class of steels is a promising alloy for SLM method [8,9]. Researchers have manufactured 17-4 PH components via SLM technique and have reported formation of metastable austenite and martensite phase as a result [10,11]. Murr et al. [12] explored the role of nitrogen and argon as the atmosphere of SLM chamber on formation of austenitic structure and ferritic/martensitic, respectively. Co-existence of both martensite and retained austenite in the SLM manufactured parts produced in nitrogen atmosphere clearly indicates that the nitrogen atmosphere has influenced the stabilization of austenite [12]. Facchini et al. [11] analysis showed that the as-fabricated 17-4 PH stainless steel has 70\% mass fraction of metastable austenite, which transformed to the martensite phase during tensile deformation $[13,14]$

Farshidianfar et al. [15] has carried experiments to control the microstructure of Laser Additive Manufacturing (LAM) parts by controlling the cooling rate. Yadollahi et al. and Luecke $[8,16]$ investigated the effect of build rotation during SLM on tensile and fatigue properties of 17-4 PH steel parts and found un-melted regions caused by lack of fusion significantly reduced their tensile and fatigue strength. Rafi et al. [17] investigated the mechanical properties and microstructure of 17-4 PH manufactured by SLM and found that columnar grains with smaller diameters $(<2 \mu \mathrm{m})$ which appear in the melt pool had a 
combination of martensite and retained austenite phases. They found that the processing environment, grain size and chemistry of powder had a great influence on the phase content of sample.

Recently, powder characteristic such as size, distribution and morphology of particles got special concern in SLM process [18-20]. In all of the SLM process of 17-4 PH SS, gas atomized 17-4 PH was used as feedstock $[8,12,17,21]$. However, the production cost of per kilogram of water atomized powder is relatively lower than that of gas atomized powder [22]. Considering 17-4 PH water-atomized powder that has much less nitrogen (0.02 wt.\%) at a cheaper production rate is a novel approach that will mitigate the aforementioned issues of cost and high nitrogen content. Few studies have evaluated the final properties of wateratomized $316 \mathrm{~L}$ stainless steel and H13 tool steel powder equivalent to those produced with gas-atomized powder. Comparing those made with gas-atomized and water-atomized powder, the water-atomized samples shows superior surface finish, uniformity in deposition and bonding between layers. [23-25]. In our former study [18], gas-atomized 17-4 PH powders when processed at lower energy densities (80-84 J/mm3) showed better densification and mechanical properties compare to high energy density (104 J/mm3). Using high energy density of $104 \mathrm{~J} / \mathrm{mm} 3$ for water-atomized powder, made the relative density and mechanical properties, comparable to the gas atomized powder. Only as printed parts were characterized in our former study [18], and no data were provided on the postprocessing of 17-4 PH components manufactured by SLM process. 
The objective of this study is to investigate the effects of atomizing media (water atomization versus gas atomization) as well as heat treatment (solution annealing and aging) temperature on phase transformation and mechanical properties of laser melted 17$4 \mathrm{PH}$ parts. Our results (as shown later) will demonstrate the practicality of using relatively cheaper water-atomized 17-4 PH powders as feedstock strongly depends on designing a non-standard and effective thermal post processing.

\section{A.2 MATERIALS AND METHODS}

Gas-atomized and water-atomized 17-4 PH SS powders procured from Sandvik and North American Hoganas (NAH), respectively. The chemical composition of gas-atomized and water-atomized powder, which is provided by vendors, is given in Table A.1. Wateratomized 17-4 PH powder had higher carbon content than gas-atomized powder because it was designed for conventional powder metallurgy (pressing and sintering) and metal injection molding. It is because higher carbon content of water-atomized 17-4 PH would result in higher green strength required in conventional powder metallurgy [22]. Wateratomized 17-4 PH powder with chemical composition similar to that of gas-atomized powder is not available.

Table A.1. Chemical composition of 17-4 PH stainless steel for gas-atomized and wateratomized powders (wt.\%).

\begin{tabular}{llllllllll}
\hline Powder & $\mathrm{C}$ & $\mathrm{Cr}$ & $\mathrm{Cu}$ & $\mathrm{Mn}$ & $\mathrm{Ni}$ & $\mathrm{P}$ & $\mathrm{S}$ & $\mathrm{Si}$ & $\mathrm{Nb}$ \\
\hline $\begin{array}{l}\text { Gas-atomized } \\
\begin{array}{c}\text { Water- } \\
\quad \text { atomized }\end{array}\end{array}$ & 0.03 & $15-17.5$ & $3-5$ & 1 & $3-5$ & 0.04 & 0.03 & 1 & 0.25 \\
$\quad$ & & 17.74 & 3.94 & 0.13 & 3.54 & 0.013 & 0.008 & 0.3 & 0.35 \\
\hline
\end{tabular}


A 3D Systems ProX 200 machine with an yttrium fiber laser system with maximum power of $300 \mathrm{~W}$ was used to manufacture the tensile specimens under argon atmosphere as per specifications of ASTM E8 standard. The specimens were printed using two different laser energy densities $\left(64\right.$ and $\left.104 \mathrm{~J} / \mathrm{mm}^{3}\right)$. Two different post processing regimes were used in this study; (1) specimens were solutionized at $1051^{\circ} \mathrm{C}$ for $1 \mathrm{~h}$ in $\mathrm{H} 2$ atmosphere and then aged at $482{ }^{\circ} \mathrm{C}$ in $\mathrm{N}_{2}$ atmosphere for $1 \mathrm{~h}$ (H900) and (2) specimens were solutionized at $1315{ }^{\circ} \mathrm{C}$ for $45 \mathrm{~min}$ in $\mathrm{H}_{2}$ atmosphere and then aged at $482{ }^{\circ} \mathrm{C}$ for $1 \mathrm{~h}$ in $\mathrm{N}_{2}$ atmosphere. The specimens were then polished using a standard polishing procedure and electro-etched in a solution of $(\mathrm{NaOH} 33 \%$ Electrolyte at $5 \mathrm{~V}$ for $2 \mathrm{~min})$. An Instron 5982 dual column testing system utilized with a $100 \mathrm{kN}$ force load cell and strain rate of $10-3 \mathrm{~s}-1$ was used for tensile tests.

Hardness was measured using the Rockwell C hardness scale (150kg load). Density of specimens were measured by Archimedes method using a Metter Toledo XS104 weighing balance equipped with a density measurement kit. Leica optical microscope was utilized to study the microstructure of printed components. A Bruker D8 discover X-ray diffraction instrument was used to analyze the phase structure. Scheil model for non-equilibrium solidification and prediction of phase fraction during SLM process were performed using Thermo-Calc software integrated with TCFE8 database. The simulation were performed for a step size of $1{ }^{\circ} \mathrm{C}$ from liquid phase up to remaining liquid fraction reach the 0.1 . Microstructure of heat treated samples were studied by transmission electron microscopy (TEM) using FEI Titan TEM/STEM with ChemiSTEM capabilities. FEI Quanta 3D field emission dual beam scanning electron microscope (SEM/FIB) was used to prepare samples for TEM. 


\section{A.3 RESULTS AND DISCUSSION}

The powder feedstock characteristics such as particle size distribution (PSD), apparent density (AD), tap density (TD) and Hausner ratio values were measured as shown in Table A.2. The $\mathrm{AD}$ of powder is defined by mass per unit volume of loose powder which provides a measure of the "fluffiness" of a powder [26].

Table A.2. Particle size distribution of the17-4 PH stainless steel gas-atomized and water-atomized powders.

\begin{tabular}{|c|c|c|c|c|c|c|}
\hline \multirow[b]{2}{*}{ Powder } & \multicolumn{3}{|c|}{ Particle distribution } & \multirow[b]{2}{*}{$\begin{array}{c}\text { Tap } \\
\text { density } \\
(\mathrm{g} / \mathrm{cc})\end{array}$} & \multirow[b]{2}{*}{$\begin{array}{c}\text { Apparent } \\
\text { density } \\
\text { (g/cc) }\end{array}$} & \multirow[b]{2}{*}{$\begin{array}{c}\text { Hausner } \\
\text { Ratio }\end{array}$} \\
\hline & $\begin{array}{c}D_{10} \\
(\mu \mathrm{m})\end{array}$ & $\begin{array}{c}\text { D50 }_{(\mu \mathrm{m})}\end{array}$ & $\begin{array}{c}D_{90} \\
(\mu \mathrm{m})\end{array}$ & & & \\
\hline Gas-atomized (G) & 5 & 13 & 27 & $4 \pm 0.05$ & $3 \pm 0.002$ & 1.324 \\
\hline Water-atomized (W) & 26 & 43 & 67 & $3.7 \pm 0.05$ & $2.8 \pm 0.05$ & 1.301 \\
\hline
\end{tabular}

The median particle size of gas atomized and water atomized powder were 13 and $43 \mu \mathrm{m}$, respectively. PSD selected here was similar to PSD used by Rafi et al. [17] with the mean particle size of $39 \mu \mathrm{m}$ and PSD used by Murr et al. [27] with two different mean particles sizes of $19 \mu \mathrm{m}$ and $25 \mu \mathrm{m}$. In our former study [16], four different PSD were used with mean particle size of 13,17, 24 and $43 \mu \mathrm{m}$, however our primary focus of this study is on mean particle size of 13 and $43 \mu \mathrm{m}$. The density of manufactured part is related to the density of powder bed. Many factors influence the density of powder bed such as particle shape, particle size, powder surface morphology and flowability of the powder [28]. Therefore, powder flowability is one of the topics of concern when producing parts in SLM process. If the powder does not spread in a consistent manner, the density of manufactured part varies from region to other region and the porosity emerged in the manufactured parts 
and reduces the mechanical properties. The Hausner ratio is a number which is correlated to the powder flowability and is a useful measure of cohesion [26]. It is calculated using the equation shown below [11]:

$$
H=\frac{\rho_{T}}{\rho_{A}}
$$

Where $\rho_{\mathrm{T}}$ is tap density and $\rho_{\mathrm{A}}$ is apparent density. Hausner ratio of water-atomized (1.301) was less than gas-atomized (1.324). Many factors play rolls in flowability of powders such as the shape and size of particles. In general, gas atomized powders, because of having spherical shape, show better flowability rather than water-atomized powders which have irregular shape [28]. However, in this study, because water-atomized powders have bigger particle size, the interlocking forces between the particles reduce and eliminate the roll of particle shape, therefore, the flowability of water-atomized powders is comparable to gasatomized powder. Figure A.1 shows the SEM micrographs of the two powders used in this study. Gas-atomized powders shown in Figure A.1a are spherical particles with $\mathrm{D}_{50}=13$ $\mu \mathrm{m}$. Water-atomized powder shown in Figure A.1b had a mixture of semi-spherical and roundedshapes with relatively clean particles without satellites and $\mathrm{D}_{50}=43 \mu \mathrm{m}$. 


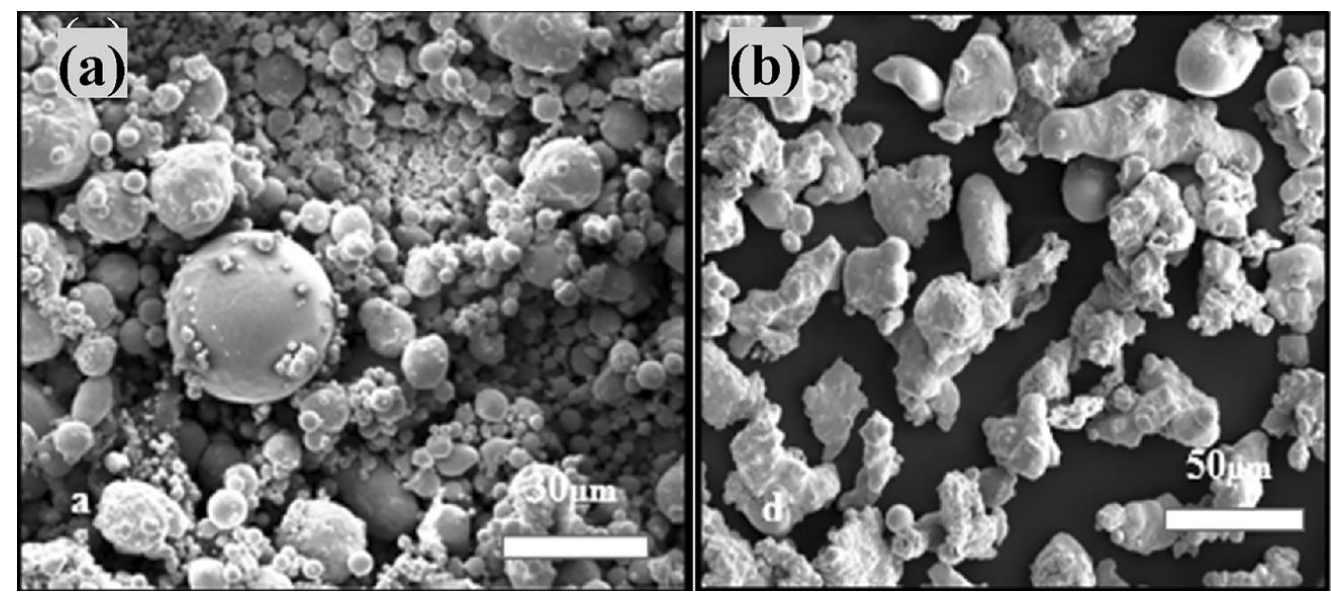

Figure A.0.1.Morphology of 17-4 PH SS powder: (a) gas atomized powder and (b) water atomized powder [29].

Figure A.2a and $\mathbf{b}$ shows the XRD-patterns of gas-atomized and water-atomized powders, respectively. While gas-atomized and water-atomized powders contain both austenite and martensite phases, austenitic phase of water-atomized is more dominant in volume fraction. On the other hand, gas-atomized powder has a higher volume fraction of martensitic phase. The austenite phase in gas-atomized powder is because of using nitrogen as atomizing media for atomization of the melt with relatively a slower cooling rate [12]. As Table A.1 shows, the carbon content of water-atomized powder $(0.208 \mathrm{wt} . \%)$ is much higher than gas-atomized carbon content $(0.03$ wt.\%). Furthermore, the cooling rate for wateratomized powder are 10-100 times larger than gas atomized powders [30]. Therefore, combined effect of higher carbon as an austenite stabilizer [11] and faster cooling rate in water atomization led to the presence of higher amount of austenite phase in the powder feedstock. Furthermore, nitrogen can be picked up during gas atomization process and along with martensitic crystal lattice expansion can lead to deformation, smaller grains and broader peaks [31] as observed in Figure A.2a. In case of water-atomized powder, grain size of austenite is coarser than that of gas-atomized. The average crystallite size of gas 
and water-atomized powder were calculated to be $235 \mathrm{~nm}$ and $552 \mathrm{~nm}$, respectively by using Williamson-Hall method [32]. The microstructure of as printed 17-4 PH gasatomized powder perpendicular to the build direction at energy density of $64 \mathrm{~J} / \mathrm{mm} 3$ and $104 \mathrm{~J} / \mathrm{mm} 3$ are shown in Figure A.3a and b, respectively. The microstructure printed at $64 \mathrm{~J} / \mathrm{mm} 3$ exhibited coarser lath martensitic structure as shown in Figure A.3a, and ultrafine martensitic structure was observed in Figure A.3b. Single martensitic phase was observed in samples manufactured from gas-atomized powder independent of energy density. Microstructure of water-atomized powder printed at energy density of $64 \mathrm{~J} / \mathrm{mm}^{3}$ and $104 \mathrm{~J} / \mathrm{mm}^{3}$ are shown in Figure A.3c and d, respectively. Similar lath martensitic structure located in islands of retained austenite were observed in Figure A.3c and d. Water-atomized powder printed at $64 \mathrm{~J} / \mathrm{mm}^{3}$, showed formation of a continuous network of precipitates along the grain boundaries (as shown in Figure A.3c) that are likely enriched in carbon. As shown in Figure A.3c, significant amount of large porosity (larger than $10 \mu \mathrm{m}$ ) can be due to lack of fusion at lower energy density of $64 \mathrm{~J} / \mathrm{mm}^{3}$. In Figure A.3d, the precipitates formation was not observed along the grain boundaries likely due to dissolution at higher laser power and slower scan rate (larger melt pool region with slower solidification rate). Both austenite and martensite phases were present in samples manufactured from water-atomized powder, because of combined effect of dissolution of carbon that can stabilize formation of austenite and rapid solidification during SLM that can lead to formation of martensite [17].

The XRD-patterns for both water and gas-atomized specimens at both the laser energy densities $\left(64 \mathrm{~J} / \mathrm{mm}^{3}\right.$ and $\left.104 \mathrm{~J} / \mathrm{mm}^{3}\right)$ are shown in Figure A.4a and b, respectively. Printed 
gas-atomized powder showed only martensitic phase. The phases for gas-atomized remained unchanged after increasing energy density from 64 to $104 \mathrm{~J} / \mathrm{mm}^{3}$ (Figure A.4a). The as printed water-atomized powder samples dual austenitic and martensitic structure at both energy density of 64 and $104 \mathrm{~J} / \mathrm{mm}^{3}$. At energy density of $64 \mathrm{~J} / \mathrm{mm}^{3}$, the laser power and scan speed was at $150 \mathrm{~W}$ and $1550 \mathrm{~mm} / \mathrm{s}$, respectively. At energy density of $104 \mathrm{~J} / \mathrm{mm}^{3}$, the laser power and scan speed was at $195 \mathrm{~W}$ and $1250 \mathrm{~mm} / \mathrm{s}$, respectively. At higher energy density of $104 \mathrm{~J} / \mathrm{mm}^{3}$, the fraction of martensitic phase increased. The presence of retained austenite phase after printing of water-atomized powder was found to be independent of laser energy density (Figure A.4b). This could likely due to the higher carbon content in water-atomized powder feedstock. This could imply that the phase transformation during SLM is highly dependent to initial feedstock chemistry. Therefore, feedstock chemistry and cooling rate can have a significant role on phase transformation upon rapid solidification during SLM process [33]. Water-atomized powder used in this study was not commercially manufactured and modified for SLM process. This study is only a preliminary evaluation of water-atomized powder capability to be used as a cheaper alternative feedstock for SLM.

Figure A.5 shows cross section of gas-atomized and water-atomized samples, parallel to the build direction. Gas-atomized powder printed at low energy density (Figure A.5a) shows a pattern of repeated rectangular with the mean height of about $50 \mu \mathrm{m}$, which is the same as the thickness of each layer of powder bed. Saeidi et al. [2] reported similar pattern in SLM of duplex stainless steel. On the other hand, water-atomized sample printed at energy density of $64 \mathrm{~J} / \mathrm{mm}^{3}$ (Figure A.5b) did not show such pattern. This may be 
attributed to the lower apparent density of water-atomized powder $\left(2.813 \mathrm{~g} / \mathrm{cm}^{3}\right)$ compare to gas-atomized powder $\left(3.040 \mathrm{~g} / \mathrm{cm}^{3}\right)$. The particles in water-atomized powders after melting may collapse into the empty spaces between the particles, so the melting pool boundaries can change and became very hard to distinguish the melting pool boundaries. With increasing the energy density to $104 \mathrm{~J} / \mathrm{mm}^{3}$ (Figure A.5c and d), the melt pool boundaries are no longer distinct. Therefore, the temperature is high enough for melting and mixing all the particles to make a fully austenite liquid that could transform to martensite.
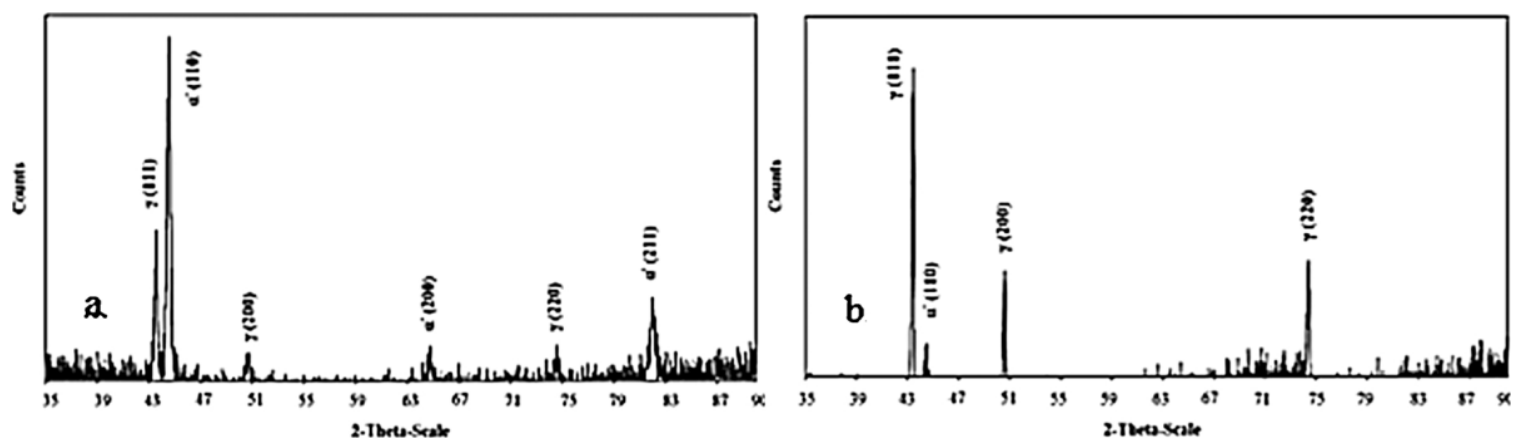

Figure A.0.2.The XRD pattern of 17-4 PH powders (a) gas-atomized and (b) wateratomized.

The optical micrographs, perpendicular to the build direction, obtained from gasatomized powder printed at 64 and $104 \mathrm{~J} / \mathrm{mm}^{3}$ and solutionized at $1051{ }^{\circ} \mathrm{C}$ and aged at $482{ }^{\circ} \mathrm{C}$ are shown in Figure A.6a and b, respectively. Microstructure of gas atomized samples printed at 64 and $104 \mathrm{~J} / \mathrm{mm}^{3}$, revealed martensitic structure. Furthermore, fine martensitic structure transformed to coarser martensitic structure at energy density of $104 \mathrm{~J} / \mathrm{mm}^{3}$ after heat treatment. The microstructure of heat treated water-atomized powder revealed single martensitic phase at energy density of $64 \mathrm{~J} / \mathrm{mm}^{3}$ and dual martensitic and austenitic 
structure at energy density of $104 \mathrm{~J} / \mathrm{mm}^{3}$ as presented in Figure A.6c and d, respectively. After heat treatment, the microstructure became uniform and predominately a martensitic structure with no trace of the melt pools for $64 \mathrm{~J} / \mathrm{mm}^{3}$ sample for both water-atomized and gas-atomized powder. Presence of austenite in Figure A.6d could be due to reversion austenite phenomena. Reversion austenite was also observed in selective laser melting of 17-4 PH [5]. Process of austenite reversion has been generally attributed to the chemical stabilization by the diffusion of alloying element constituents, commonly toward lath boundaries. More specifically, as $\mathrm{Cu}$ diffuses to form precipitates, the local $\mathrm{M}_{\mathrm{f}}$ temperature is effectively lowered at the sites of their formation and thereby permits austenite chemical stabilization at room temperature [5].
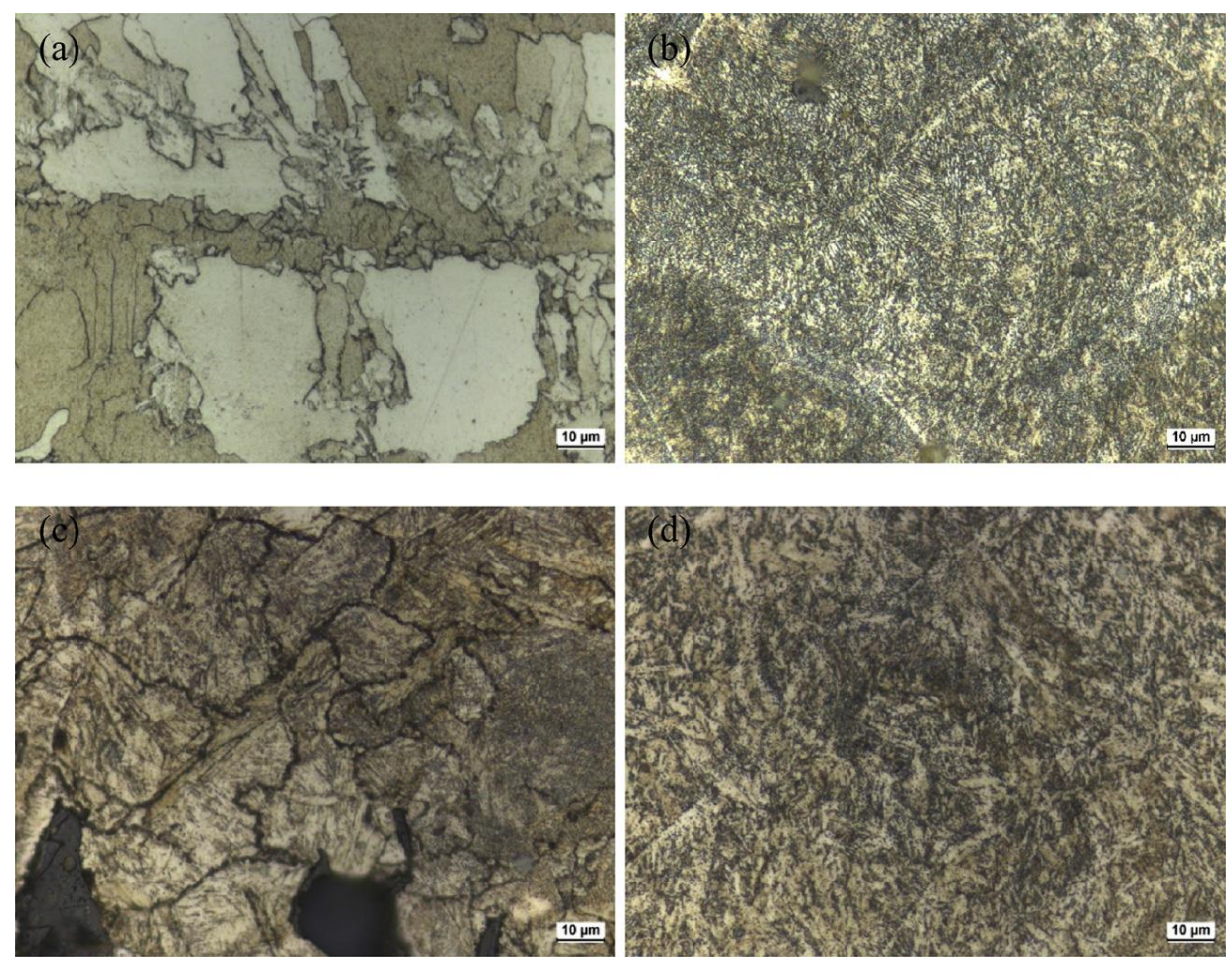

Figure A.0.3.Optical micrographs of as printed 17-4 PH SS powder perpendicular to the build direction: (a) gas-atomized at $64 \mathrm{~J} / \mathrm{mm}^{3}$, (b) gas-atomized at $104 \mathrm{~J} / \mathrm{mm}^{3}$, (c) wateratomized at $64 \mathrm{~J} / \mathrm{mm}^{3}$ and (d) water-atomized at $104 \mathrm{~J} / \mathrm{mm}^{3}$. 
The XRD patterns for gas-atomized and water-atomized powder after printing at energy density of 64 and $104 \mathrm{~J} / \mathrm{mm}^{3}$ and solution annealing at $1051{ }^{\circ} \mathrm{C}$ and aging at $482{ }^{\circ} \mathrm{C}$ are shown in Figure A.7a. and Figure A.7b, respectively. In gas-atomized powder, single martensite phase was observed. In water-atomized powder, after thermal aging, single martensite phase was observed at energy density of $64 \mathrm{~J} / \mathrm{mm}^{3}$. This is likely because of the austenite formed during solutionizing transforms to martensite while quenching through the Ms temperature. However, at energy density of $104 \mathrm{~J} / \mathrm{mm}^{3}$ dual martensite and reverse austenite phases were observed as shown in Figure A.6d. Reversion or local stabilization of austenite by the diffusion of $\mathrm{Cu}$ and $\mathrm{Ni}$ in water-atomized powder during aging could lead to austenite concentrations at energy density of $104 \mathrm{~J} / \mathrm{mm}^{3}$. The activation energy for forming of reverse austenite is $240 \mathrm{~kJ} / \mathrm{mol}$ which is very close to the activation energy needed for diffusion of $\mathrm{Ni}$ in martensitic matrix ( $245 \mathrm{~kJ} / \mathrm{mol}$ ) [34]. Higher carbon content in water-atomized powder and dissolutions of these carbon at higher energy density of 104 $\mathrm{J} / \mathrm{mm}^{3}$ (higher laser powder $195 \mathrm{~W}$ and slower scan rate $1250 \mathrm{mms}$ ) would lead in to local enrichment of carbon, which is an austenite stabilizer elements, as shown in Figure A.3d. Increasing localized concentration of austenite stabilizing elements would locally lower the martensitic transformation start (Ms) temperature below room temperature and increase the amount of austenite [5]. This phenomenon became significant after aging and as a result, led to significant reverse austenite formation in water-atomized powder printed at $104 \mathrm{~J} / \mathrm{mm}^{3}$ as can be seen in Figure A.6d and in XRD plot of Figure A.7b. 

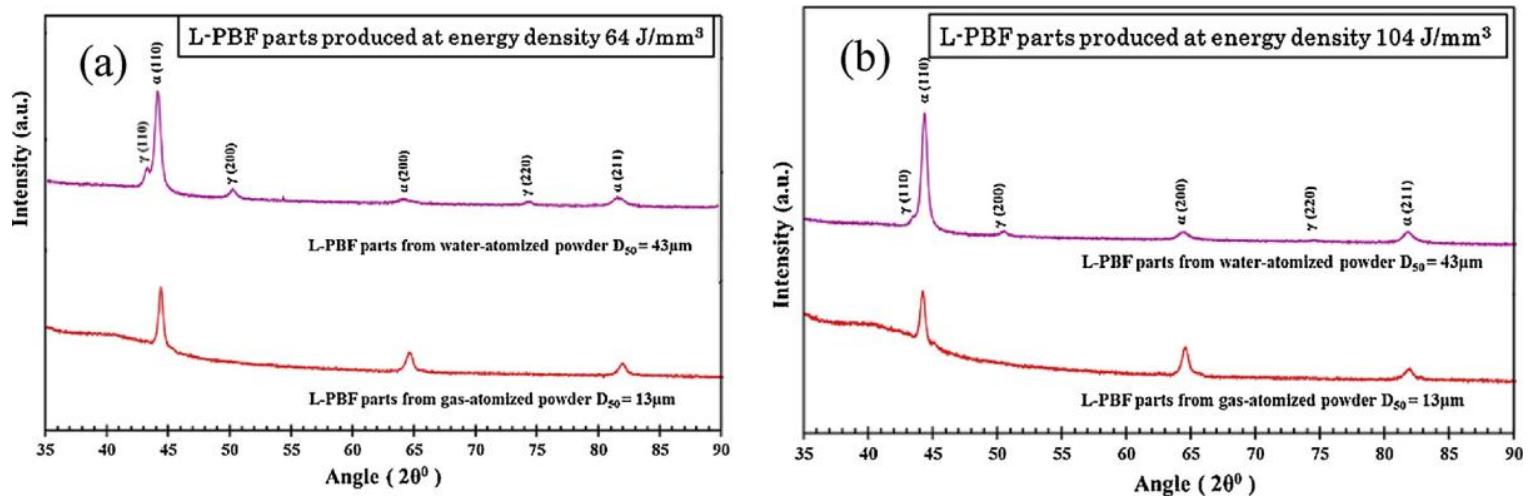

Figure A.0.4. The XRD patterns of gas-atomized and water-atomized powder printed at (a) $64 \mathrm{~J} / \mathrm{mm}^{3}$ and (b) $104 \mathrm{~J} / \mathrm{mm}^{3}$

While 17-4 PH water-atomized powder has higher content of carbides (MX and M23C6), these carbides can potentially get dissolved at higher energy density $\left(104 \mathrm{~J} / \mathrm{mm}^{3}\right)$ due to higher power and lower scanning speed. However, at lower energy density $\left(64 \mathrm{~J} / \mathrm{mm}^{3}\right)$, lower input energy and higher scanning speed does not lead to dissolution of carbides. Relationship between energy density and dissolution of carbides can be explained due to more fusion and larger melt pool at higher energy density and higher diffusion rate of $\mathrm{Ni}$ and $\mathrm{Cu}$ in the matrix.

According to Ziewiec et al. [35] in non-equilibrium solidification conditions of the weld 17-4PH, segregation and the diffusion of copper and the elements stabilizing the austenite (such as carbon and nitrogen) cause the occurrence of the reverse transformation of the martensite into austenite as fast as just $1 \mathrm{~h}$ at $620^{\circ} \mathrm{C}$. The increase of copper-carbides solubility in the austenite causes dissolution of the fcc-Cu precipitates and carbides would lead to segregation and local enrichment of austenite stabilizer elements. In the regions where segregation of the austenite stabilizer elements occurred, a stable austenite is formed 
as a result of $\alpha \rightarrow \gamma$ transformation. Similarly, after SLM and upon solutionizing, if the carbides are dissolved (at $104 \mathrm{~J} / \mathrm{mm}^{3}$ ), the combined effect of carbon segregation and $\mathrm{Cu}$ enrichment would likely lead to austenite stabilization, and this will facilitate formation of reverse austenite. Such austenite is stable after cooling down to the ambient temperature. But if carbides are not dissolved (at $64 \mathrm{~J} / \mathrm{mm}^{3}$ ), then carbon enrichment will not occur and reverse austenite does not form. Therefore, in water-atomized powder, reverse austenite is more plausible at higher energy density and less likely at lower energy. Gas-atomized powder did not exhibit any reverse austenite due to much lower carbon content. Yield stress (YS), ultimate tensile strength (UTS), hardness values, elongation (\%) and density after solution annealing at $1051^{\circ} \mathrm{C}$ and aging at $482^{\circ} \mathrm{C}$ are shown in Table A.3. For comparison, the properties of wrought 17-4 $\mathrm{PH}$ alloy is also provided. The hardness values of gas atomized powder showed similar hardness values (42-45HRC) at energy density of 64 and $104 \mathrm{~J} / \mathrm{mm}^{3}$, which was found to be higher than hardness of wrought alloy ( $39 \mathrm{HRC}$ ). This is attributed to the rapid melting and solidification of laser additive manufacturing process which resulted to finer grain size and increase in hardness value and potentially higher dislocation density. On the other hand, hardness value of water-atomized powder was significantly less than gas-atomized and wrought alloy, but increased from 18 to 24 HRC with increasing energy density from 64 to $104 \mathrm{~J} / \mathrm{mm}^{3}$. This hardness increase could be attributed to the higher relative density of manufactured part at higher energy density (Table A.3). Similar results were observed for yield strength (YS) and ultimate tensile strength (UTS) of gas-atomized powder and water-atomized powder. While YS and UTS values of gas-atomized powder were comparable with wrought values, these values were much lower for water-atomized powder. 

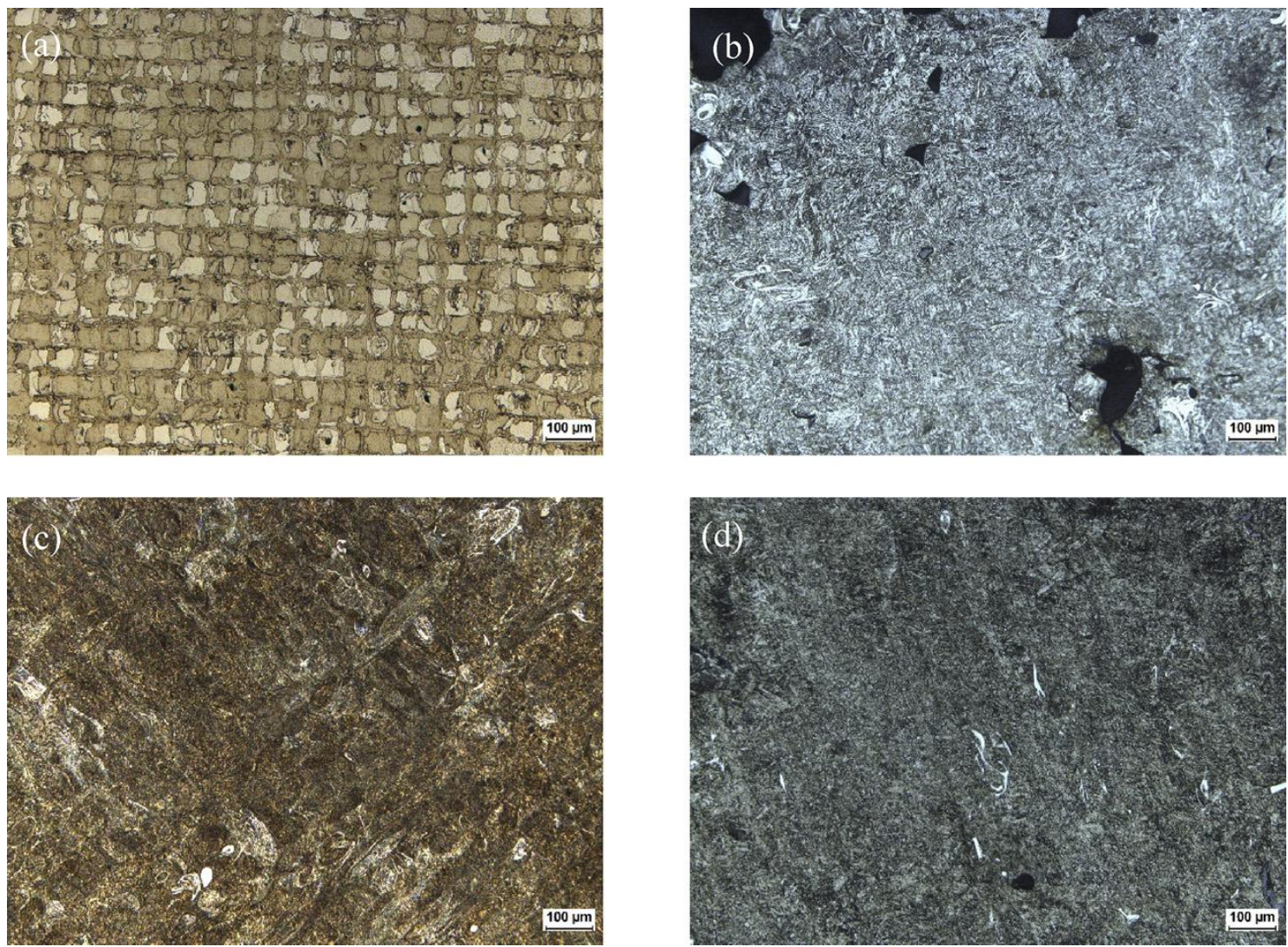

Figure A.0.5. Optical micrographs, parallel to the build direction, of as printed 17-4 PH SS powder at $64 \mathrm{~J} / \mathrm{mm}^{3}$ (a) gas-atomized, (b) water-atomized and at $104 \mathrm{~J} / \mathrm{mm}^{3}$ (c) gasatomized, (d) water-atomized. 

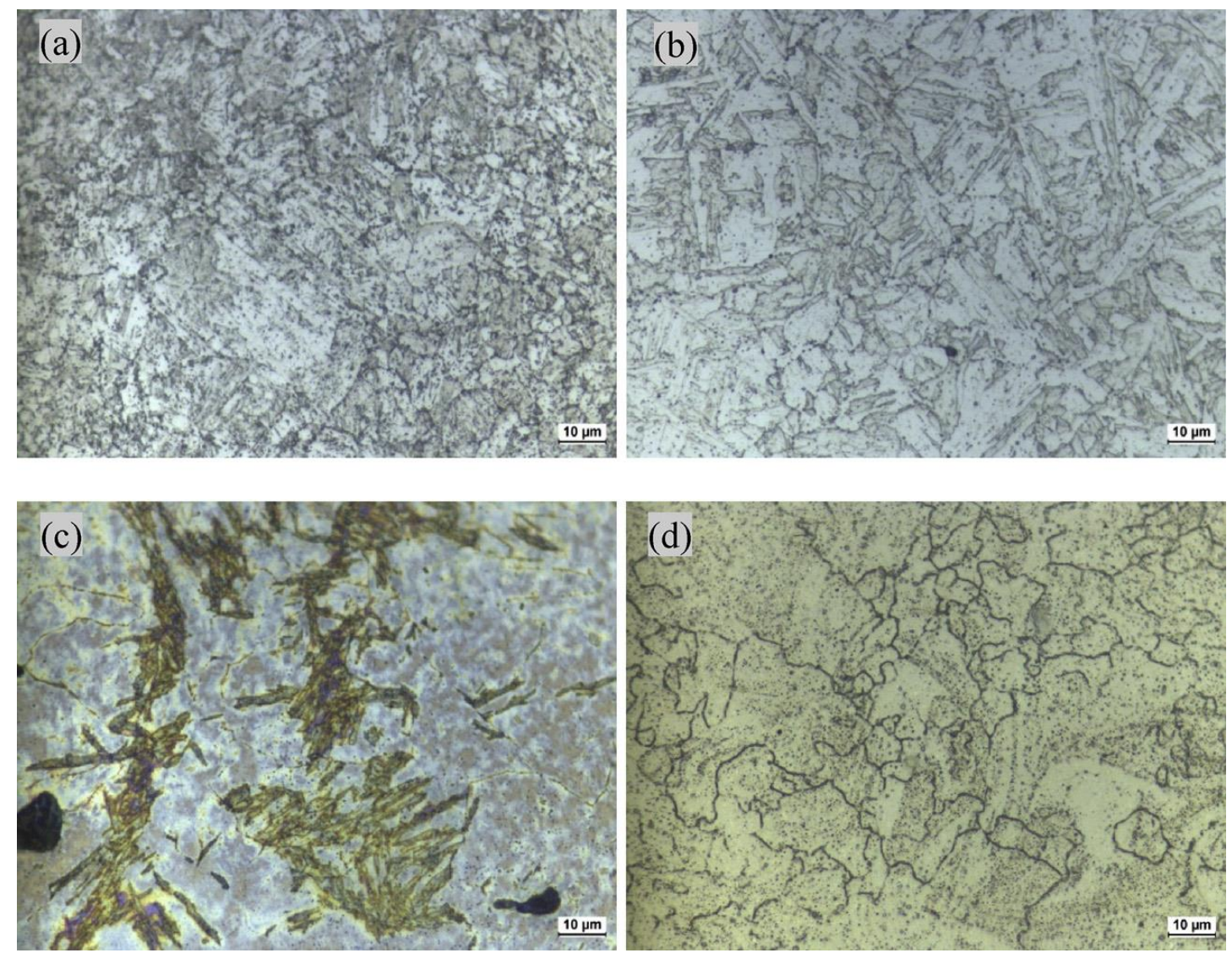

Figure A.0.6. The optical micrographs of heat treated parts (solutionized at $1051{ }^{\circ} \mathrm{C}$ and aged at $482{ }^{\circ} \mathrm{C}$ ) perpendicular to the build direction: (1) gas-atomized at $64 \mathrm{~J} / \mathrm{mm}^{3}$,

(b) gas-atomized at $104 \mathrm{~J} / \mathrm{mm}^{3}$, (c) water-atomized at $64 \mathrm{~J} / \mathrm{mm}^{3}$ and (d) water-atomized at $104 \mathrm{~J} / \mathrm{mm}^{3}$.
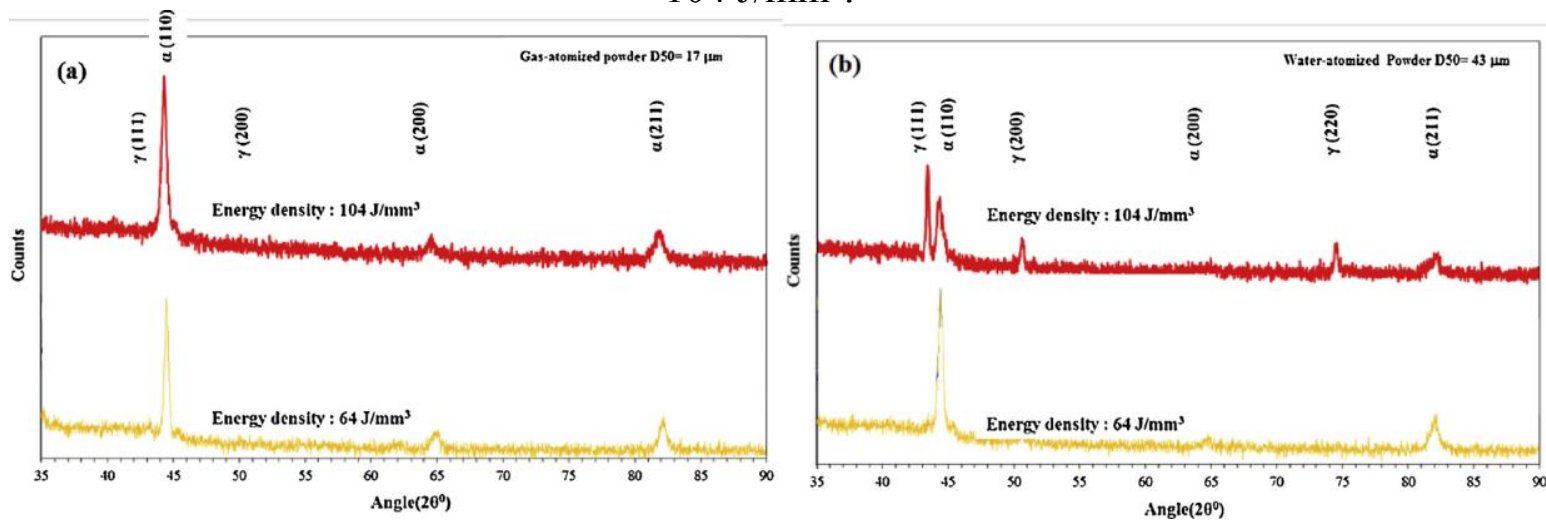

Figure A.0.7. The XRD pattern of (a) gas-atomized and (b) water-atomized printed at 64 and $104 \mathrm{~J} / \mathrm{mm}^{3}$ and heat treated (solutionized at $1051{ }^{\circ} \mathrm{C}$ and aged at $482{ }^{\circ} \mathrm{C}$ ). 
Table A.3. Mechanical properties at energy density of 64 and $104 \mathrm{~J} / \mathrm{mm}^{3}$ - solutionized at $1051{ }^{\circ} \mathrm{C}$ and aged at $482{ }^{\circ} \mathrm{C}$ (wrought values are taken from literature [36]).

\begin{tabular}{|c|c|c|c|c|c|c|}
\hline Powders & $\begin{array}{c}\text { Energy } \\
\mathbf{d e n s i t y} \\
\left(\mathbf{J} / \mathbf{m m}^{\mathbf{3}}\right)\end{array}$ & $\begin{array}{c}\text { Yield } \\
\text { stress } \\
(\mathbf{M P a})\end{array}$ & $\begin{array}{c}\text { UTS } \\
(\mathbf{M P a})\end{array}$ & $\begin{array}{c}\text { Hardness } \\
(\mathbf{H R C})\end{array}$ & $\begin{array}{c}\text { Elongation } \\
(\mathbf{\%})\end{array}$ & $\begin{array}{c}\text { Density } \\
\left(\mathbf{g} / \mathbf{c m}^{\mathbf{3}}\right)\end{array}$ \\
\hline $\begin{array}{c}\text { Gas- } \\
\text { atomized } \\
\mathrm{D}_{50}=13 \mu \mathrm{m}\end{array}$ & 64 & 1116 & 1358 & 45 & 5.1 & 7.7 \\
\cline { 2 - 7 } & 104 & 1200 & 1368 & 42 & 2.6 & 7.7 \\
\hline $\begin{array}{c}\text { Water- } \\
\text { atomized } \\
\mathrm{D}_{50}=43 \mu \mathrm{m}\end{array}$ & 64 & 365 & 510 & 18 & 1 & 7.3 \\
\cline { 2 - 7 } & 104 & 500 & 990 & 24 & 3.3 & 7.5 \\
\hline Wrought & - & 1170 & 1310 & 39 & 5 & 7.9 \\
\hline
\end{tabular}

The relative density of manufactured part after heat treatment for gas-atomized powder at both low and high energy densities were $97 \%$. Comparing these data with relative density of parts before heat treatment ( $94 \%$ for energy density of $64 \mathrm{~J} / \mathrm{mm}^{3}$ and $95 \%$ for energy density of $104 \mathrm{~J} / \mathrm{mm}^{3}$ ) [18] showed slight increase in density by elimination of porosities [22]. The relative density of water-atomized powder at energy density of $104 \mathrm{~J} / \mathrm{mm}^{3}$ was approximately the same as $95 \%$, before and after the heat treatment. The YS and UTS were lower than expected for water-atomized powder at energy density of $64 \mathrm{~J} / \mathrm{mm}^{3}$, due to porosities and unmelted particles, as shown in Fig. 5b. Elongation values of water-atomized powder were higher than gas-atomized powder at energy density of $104 \mathrm{~J} / \mathrm{mm}^{3}$, consistent with the presence of reversed austenite in parts printed at higher energy density. To reduce the retained austenite in water-atomized powder, the samples were solutionized at a higher temperature of $1315{ }^{\circ} \mathrm{C}$ in $\mathrm{H} 2$ atmosphere for 45 min followed by $1 \mathrm{~h}$ of aging at $482{ }^{\circ} \mathrm{C}$. The microstructure of heat treated gas-atomized powder are fully martensitic as shown in 
Figure A.8a and b. Martensite lath were found to be coarser at energy density of 104 $\mathrm{J} / \mathrm{mm}^{3}$ due to higher laser energy and slower cooling rate. Similarly, microstructure of water-atomized powder after heat treatment are shown in Figure A.8c and d for energy density of 64 and $104 \mathrm{~J} / \mathrm{mm}^{3}$, respectively. Fully martensitic microstructure was observed at 64 and $104 \mathrm{~J} / \mathrm{mm}^{3}$ energy densities with finer lath martensite at $104 \mathrm{~J} / \mathrm{mm} 3$.
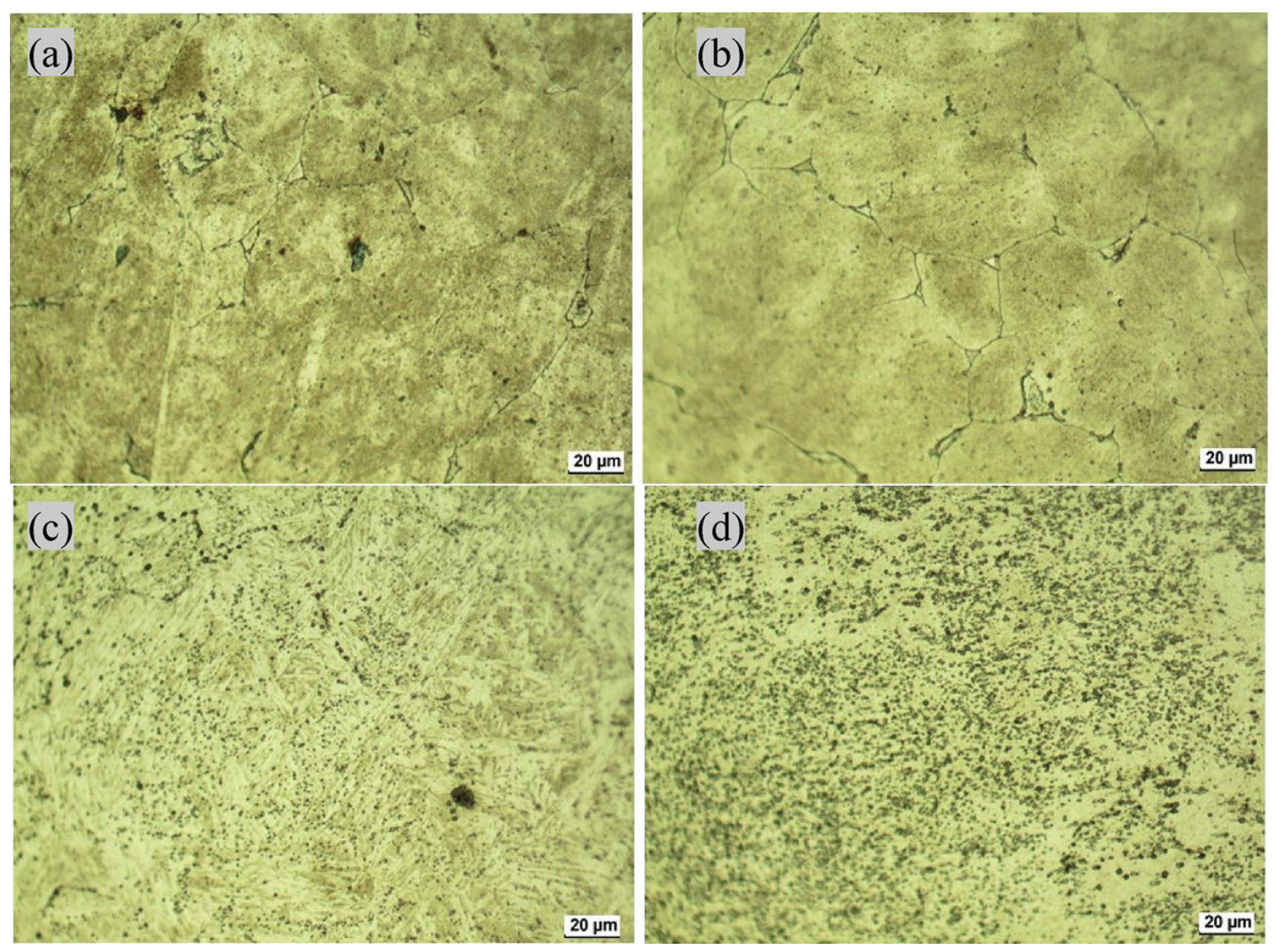

Figure A.0.8. The optical micrographs of heat treated parts (solutionized at $1315{ }^{\circ} \mathrm{C}$ and aged at $482{ }^{\circ} \mathrm{C}$ ) perpendicular to the build direction: (1) gas-atomized at $64 \mathrm{~J} / \mathrm{mm}^{3}$, (b) $\mathrm{G}$ at $104 \mathrm{~J} / \mathrm{mm}^{3}$, (c) W at $64 \mathrm{~J} / \mathrm{mm}^{3}$ and (d) W at $104 \mathrm{~J} / \mathrm{mm}^{3}$.

Table A.4 shows the YS, UTS, hardness, elongation and density values for two different laser energy densities after being solutionized at $1315^{\circ} \mathrm{C}$ and aged at $482{ }^{\circ} \mathrm{C}$. Hardness for water atomized powder at energy density of $104 \mathrm{~J} / \mathrm{mm}^{3}$ is $40 \mathrm{HRC}$, which is comparable 
to hardness values for gas-atomized and wrought alloy, reported 43 and $39 \mathrm{HRC}$, respectively. The YS and UTS values for water-atomized powder at low energy density are relatively lower, because of low relative density $(92 \%$ due to presence of porosity and unmelted or partially melted particles) that would cause weak metallurgical bonds. The elongation for water-atomized powder at $104 \mathrm{~J} / \mathrm{mm}^{3}$ shows considerably higher magnitude (5.5\%) compare to gas-atomized $(2 \%)$ and slightly higher than wrought alloy $(5 \%)$. The YS and UTS values for gas atomized at both energy densities didn't show a considerable change with solutionizing at the temperature of $1315^{\circ} \mathrm{C}$ and the density values remained the same $\left(7.7 \mathrm{~g} / \mathrm{cm}^{3}\right)$. The UTS values for water-atomized powder $(1261 \mathrm{MPa})$ at 104 $\mathrm{J} / \mathrm{mm}^{3}$ is nearly the same as gas-atomized powder and wrought alloy, 1300 and $1310 \mathrm{MPa}$, respectively.

Table A.4. Variation in mechanical properties at energy density of 64 and $104 \mathrm{~J} / \mathrm{mm}^{3}$ solutionized at $1315^{\circ} \mathrm{C}$ and aged at $482^{\circ} \mathrm{C}$.

\begin{tabular}{|c|c|c|c|c|c|c|}
\hline Powders & $\begin{array}{l}\text { Energy } \\
\text { density } \\
\left(\mathrm{J} / \mathbf{m m}^{3}\right)\end{array}$ & $\begin{array}{c}\text { Yield } \\
\text { stress } \\
\text { (MPa) }\end{array}$ & $\begin{array}{c}\text { UTS } \\
\text { (MPa) }\end{array}$ & $\begin{array}{c}\text { Hardness } \\
\text { (HRC) }\end{array}$ & $\begin{array}{c}\text { Elongation } \\
(\%)\end{array}$ & $\begin{array}{r}\text { Density } \\
\left(\mathrm{g} / \mathrm{cm}^{\mathbf{3}}\right)\end{array}$ \\
\hline \multirow{2}{*}{$\begin{array}{c}\text { Gas- } \\
\text { atomized } \\
\mathrm{D}_{50}=13 \mu \mathrm{m}\end{array}$} & 64 & 1186 & 1308 & 45 & 2.6 & 7.7 \\
\hline & 104 & 1255 & 1300 & 43 & 2 & 7.7 \\
\hline \multirow{2}{*}{$\begin{array}{c}\text { Water- } \\
\text { atomized } \\
\mathrm{D}_{50}=43 \mu \mathrm{m}\end{array}$} & 64 & 650 & 780 & 24 & 0.7 & 7.3 \\
\hline & 104 & 1000 & 1261 & 40 & 5.5 & 7.5 \\
\hline Wrought & - & 1170 & 1310 & 39 & 5 & 7.9 \\
\hline
\end{tabular}

Comparing the relative densities of parts for water-atomized powder at two different heat treatments showed that there isn't a considerable change in the densities due to higher 
temperature heat treatment, however, at high energy density $\left(104 \mathrm{~J} / \mathrm{mm}^{3}\right)$, a considerable increase (500 MPa in YS and $271 \mathrm{MPa}$ in UTS) happened after solutionizing at $1315{ }^{\circ} \mathrm{C}$ comparing to solutionizing at lower temperature $\left(1051^{\circ} \mathrm{C}\right)$. Furthermore, the water atomized powder at energy density of $64 \mathrm{~J} / \mathrm{mm}^{3}$ showed an increase of $285 \mathrm{MPa}$ in YS and $270 \mathrm{MPa}$ in UTS. Therefore, this is likely due to finer martensitic microstructure achieved in water atomized samples after solutionizing at $1315^{\circ} \mathrm{C}$. Furthermore, carbides and other second phase particles were dissolved and then reprecipitated homogenously during aging with furnace cooling. This could also lead to higher elongation in wateratomized powder. In order to understand phase transformation during solutionizing at 1315 ${ }^{\circ} \mathrm{C}$ followed by aging at $482{ }^{\circ} \mathrm{C}$, Thermo-Calc simulation was used. High cooling rate in SLM process may result in micro segregation features, therefore, it is reasonable to assume no diffusion occurs in solid state. In this case, we can use Scheil model for solidification [37]. Figure A.9 shows the mole fraction of solid for different phase with temperature through cooling from liquid phase to solid phase for water atomized and gas atomized powders. The simulation for gas-atomized powder (Figure A.9a) shows that the first phase which forms from liquid is ferrite- $\mathrm{BBC}$ and the second phase which forms during cooling is austenite-FCC. The phases which form at the end of solidification process are ferrite$\mathrm{BCC}+$ austenite-FCC $(\mathrm{FCC \# 1})+\mathrm{Cu}$-rich $(\mathrm{FCCH})+$ Laves Phase + MnS phases. The simulation for water-atomized powder (Figure A.9b) shows the first phase is ferrite-BCC followed by ferrite-BCC + austenite-FCC.

At the last stage of solidification process, the simulation shows ferrite-BCC + austeniteFCC $($ FCC\#1) + Cu-rich $($ FCC\#2) + M23C6 (a Nb-rich carbide) phases. The presence of 
M23C6 is attributed to the higher carbon content of water-atomized powder (0.208 wt.\%) compare to gas atomized (0.03 wt.\%) which doesn't show any carbide formation in Thermo-Calc simulation (Figure A.9a). With increasing temperature above $1075{ }^{\circ} \mathrm{C}$, the M23C6 phase gets dissolved in the austenitic matrix. During aging, carbide phase in martensitic stainless steel can act as nuclei forprecipitation of M23C6 and hence accelerate the coarsening and spheroidization of M23C6 due to Ostwald ripening [38]. Agglomeration of carbide would increase the mobility of boundaries, because the large particles are no longer effective like small particles to pin the boundaries [39]. Solutionizing of wateratomized powder at the temperature of $1315{ }^{\circ} \mathrm{C}$ completely dissolve the M23C6 and lead to local enrichment of the carbide-forming elements such as $\mathrm{Cr}$ and $\mathrm{Nb}$ in martensitic matrix. The Thermo-Calc analysis shows that after quenching and heat treatment at 482 ${ }^{\circ} \mathrm{C}$, the $\mathrm{M} 23 \mathrm{C} 6$ precipitate in martensitic matrix and cooperate with $\mathrm{Cu}$-rich precipitation in pining the grain boundaries. This cooperation could result to increase the strength of water-atomized samples which was solutionized at the high temperature of $1315{ }^{\circ} \mathrm{C}$ compare to low temperature solutionizing at $1051{ }^{\circ} \mathrm{C}$.

Microstructure of gas-atomized and water-atomized powder printedat energy density of $104 \mathrm{~J} / \mathrm{mm}^{3}$, solutionized at $1315^{\circ} \mathrm{C}$ and aged at $482{ }^{\circ} \mathrm{C}$ were studied using TEM. Figure A.10a and $\mathbf{c}$ shows bright field (BF) TEM micrograph, high angle annular dark field (HAADF) scanning transmission electron microscope (STEM) micrograph and energy dispersive spectroscopy (EDS) mapping corresponding to gas-atomized powder. In Figure A.10a and $\mathbf{b}$, second phase precipitates with different size varying from approximately 30 
$\mathrm{nm}$ to $100 \mathrm{~nm}$ and larger were observed. These fine precipitates could form at the initial stage of aging with coherent structure and no obvious strain contrast. These coherent bcc clusters would then nucleate and grow in the supersaturated bcc matrix and lose coherency after exceeding a certain critical size and become incoherent precipitates with fcc structure [40]. The particle shown in Figure A.10b are found to be Cu-enriched according to EDS map shown in Figure A.10c. It is clear that they pose a rather small volume fraction in the microstructure and are not uniformly distributed in the matrix. The large precipitates would preferably form at the grain boundaries as shown in Figure A.10a and b. 

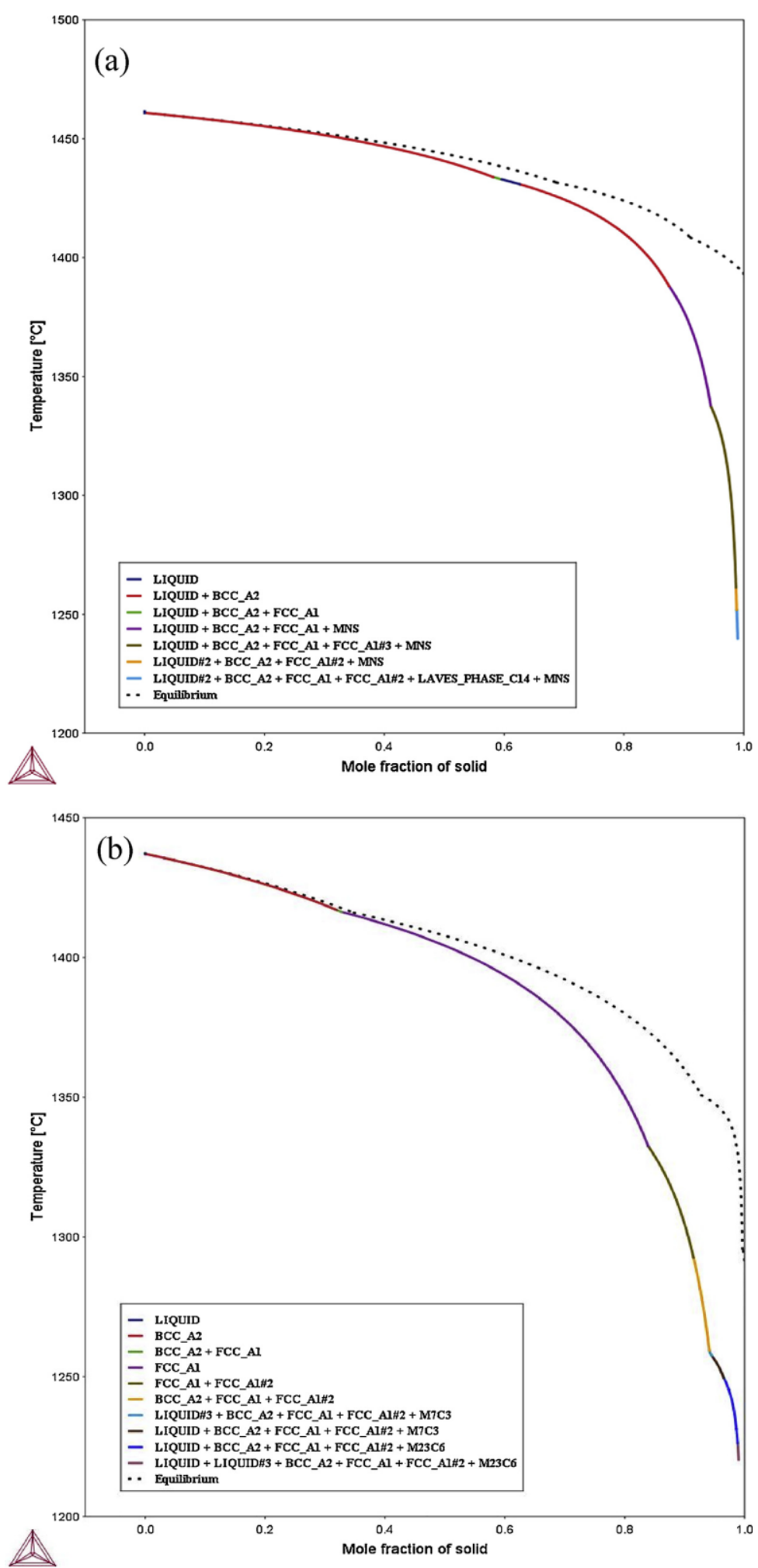

Figure A.0.9.Scheil mnon-equilibrium solidification of (a) gas-atomized and (b) wateratomized powder simulation show solid phase during solidification. 


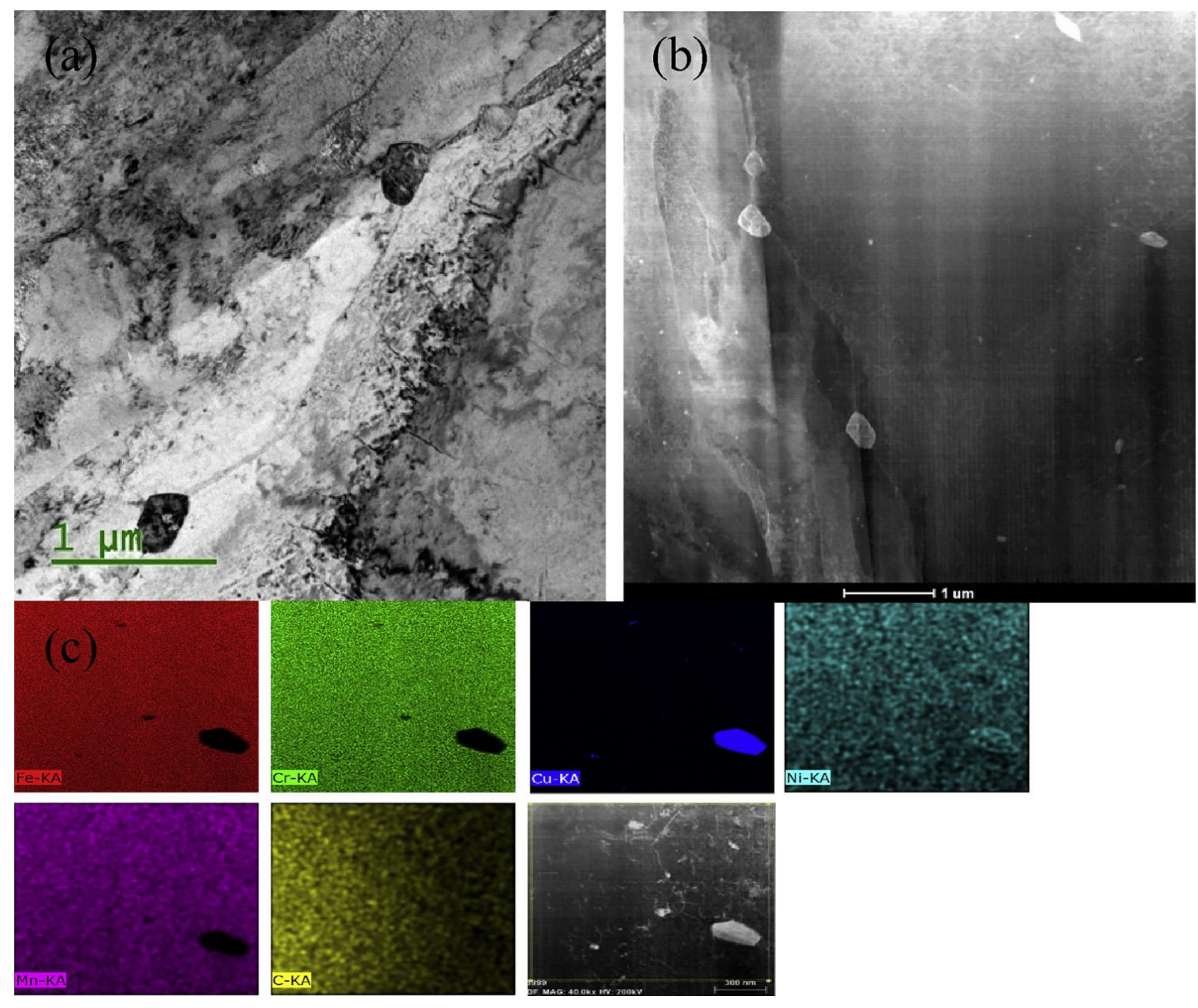

Figure A.0.10. TEM micrographs from gas-atomized 17-4 PH powder after SLM at energy density of $104 \mathrm{~J} / \mathrm{mm}^{3}$ - followed by solutionizing at $1315^{\circ} \mathrm{C}$ and aging at $482{ }^{\circ} \mathrm{C}$ :

(a) TEM BF micrograph, (b) HAADF STEM micrograph showing coarse and fine precipitates, (c) EDS mapping of $\mathrm{Cu}$-enriched precipitates.

Figure A.11a and $\mathbf{c}$ shows microstructure and EDS map corresponding to water-atomized powder after heat treatment. Narrow distribution of size and number density of second phase precipitates were present in the microstructure as shown in Figure A.11a and b. These precipitates are in the uniform size ranging from 20 to $35 \mathrm{~nm}$. There are nanoporosity in the microstructure and some of them could serve as nucleation sites for formation of larger $\mathrm{Cu}$-enriched precipitates $(>100 \mathrm{~nm})$ as shown in Fig. 11c. Absence of 
large precipitates could lead to higher ductility in water-atomized powder compared to gasatomized powder, but detailed investigation deems necessary.

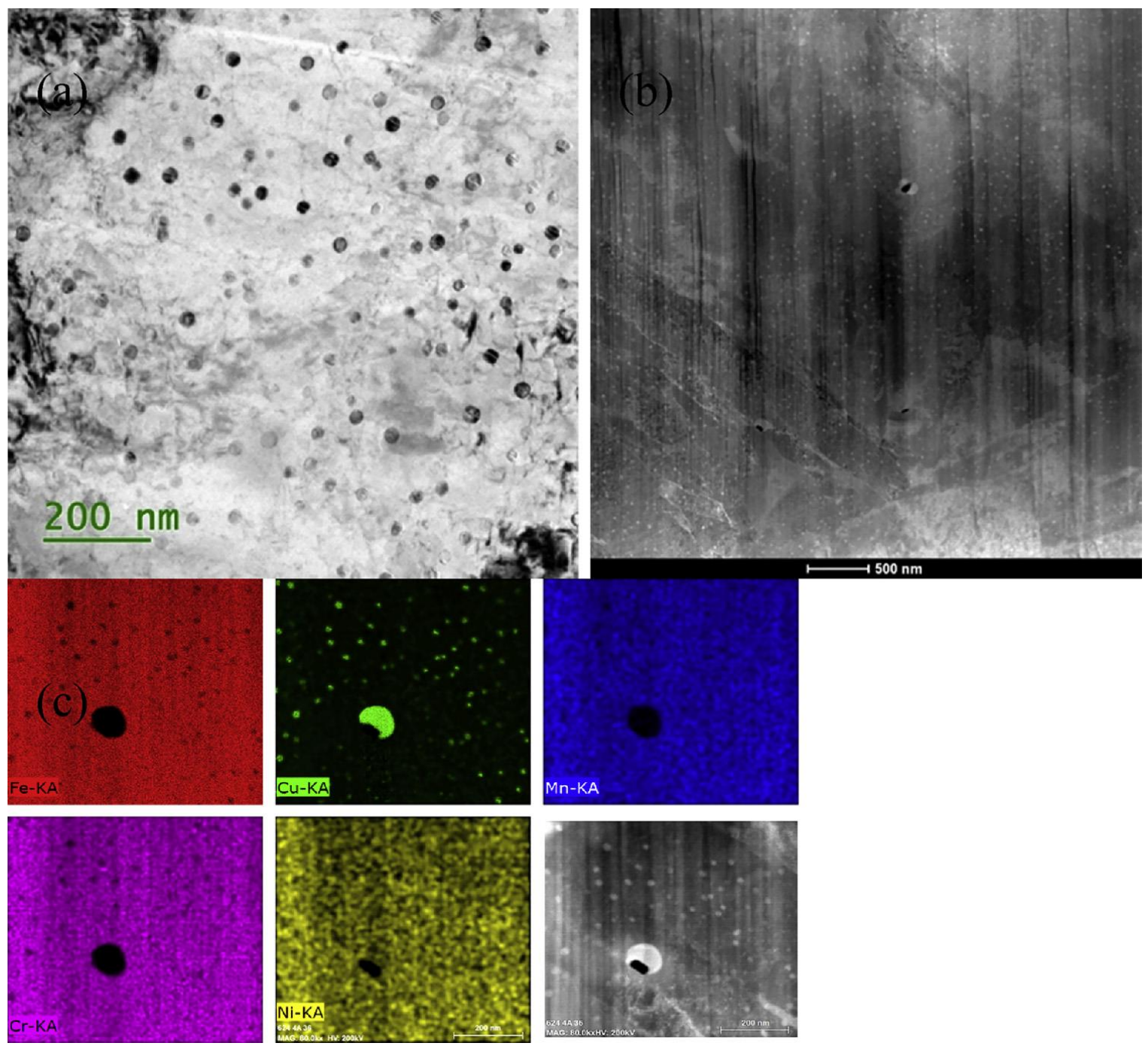

Figure A.0.11. TEM micrographs from water-atomized 17-4 PH powder after SLM at energy density of $104 \mathrm{~J} / \mathrm{mm}^{3}$ - followed by solutionizing at $1315^{\circ} \mathrm{C}$ and aging at $482{ }^{\circ} \mathrm{C}$ : (a) bright field micrograph, (b) HAADF STEM micrograph showing fine precipitates, (c) EDS mapping of $\mathrm{Cu}$-enriched precipitates. 


\section{A 4. CONCLUSIONS}

The effect of two different atomizing media (nitrogen atomized versus water atomized) and two different SLM post processing (solutionizing at $1050{ }^{\circ} \mathrm{C}$ and aging at $482{ }^{\circ} \mathrm{C}$ versus solutionizing at $1315{ }^{\circ} \mathrm{C}$ followed by aging at $482{ }^{\circ} \mathrm{C}$ ) on mechanical properties and microstructure of 17-4 PH SS, were investigated. Following results are concluded:

- Both as-printed water-atomized and gas-atomized samples of additively manufactured 17-4 PH SS consisted of mixture of dual austenitic phase and lath martensitic phase.

- Gas-atomized powder, after low temperature solutionizing $\left(1051^{\circ} \mathrm{C}\right)$ and aging $\left(482{ }^{\circ} \mathrm{C}\right)$, revealed single martensitic phase. However, water-atomized powder, at energy density of $104 \mathrm{~J} / \mathrm{mm}^{3}$, showed dual martensite and reversed austenite phase due to local carbon enrichment and higher diffusion rate and segregation of $\mathrm{Cu}$ and Ni into the matrix.

- After high temperature solutionizing $\left(1315^{\circ} \mathrm{C}\right)$ and aging $\left(482{ }^{\circ} \mathrm{C}\right)$, both gasatomized and water-atomized components exhibited fully martensitic structure (regardless of energy density values).

- Mechanical properties of water-atomized powder printed at energy density of 104 $\mathrm{J} / \mathrm{mm}^{3}$ and post processed at $1315{ }^{\circ} \mathrm{C}$ and aged at $482{ }^{\circ} \mathrm{C}$ was significantly improved and found to be comparable to UTS and YS values of gas-atomized and wrought alloy.

- Thermo-Calc simulation showed the dissolution of M23C6 at $1315^{\circ} \mathrm{C}$ for wateratomized powder with higher carbon content. After aging, M23C6 precipitate along 
with fine $\mathrm{Cu}$-enriched precipitate could result in pining the grain boundaries and improving the mechanical properties and ductility.

- Microstructure of gas-atomized powder after heat treatment at $1315^{\circ} \mathrm{C}$ and aged at $482{ }^{\circ} \mathrm{C}$ revealed small $(\sim 30-40 \mathrm{~nm})$ and large $(>100 \mathrm{~nm})$ Cu-enriched precipitates whereas water-atomized powder revealed presence of fine $(\sim 30 \mathrm{~nm}) \mathrm{Cu}$-enriched precipitates uniformly distributed in BCC martensitic structure.

\section{A. 5 ACKNOWLEDGEMENTS}

The first author acknowledges the Northwest Collaboratory for Sustainable Manufacturing for the financial support and the Oregon State University (OSU) College of Engineering for the start-up funds. The authors acknowledge the staff of OSU electron microscopy facility and ATAMI facility for their technical support and assistance.

\section{A. 6 REFERENCES}

[1] L. Facchini, Metastable austenite in 17-4 precipitation-hardening stainless steel produced by selective laser melting, Adv. Eng. Mater. (2010) 184-188.

[2] L.E. Murr, E. Martinez, J. Hernandez, S. Collins, K.N. Amato, S.M. Gaytan, P.W. Shindo, Microstructures and properties of 17-4 PH stainless steel fabricated by selective laser melting, J. Mater. Res. Technol. 1 (3) (2012) 167-177.

[3] J. Wang, H. Zou, C. Li, S. Qiu, B. Shen, The spinodal decomposition in 17-4PH stainless steel subjected to long-term aging at $350^{\circ} \mathrm{C}$, Mater. Charact. 59 (5) (2008) 587591. 
[4] M. Murayama, K. Hono, Y. Katayama, Microstructural evolution in a 17-4 PH stainless steel after aging at $400{ }^{\circ} \mathrm{C}$, Metall. Mater. Trans. A 30 (2) (1999) 345-353.

[5] T. LeBrun, T. Nakamoto, K. Horikawa, H. Kobayashi, Effect of retained austenite on subsequent thermal processing and resultant mechanical properties of selective laser melted 17-4 PH stainless steel, Mater. Des. 81 (2015) 44-53.

[6] L. Thijs, F. Verhaeghe, T. Craeghs, J.V. Humbeeck, J.-P. Kruth, A study of the microstructural evolution during selective laser melting of Ti-6Al-4V, Acta Mater. 58 (9) (2010) 3303-3312.

[7] A. Grigoriev, I. Polozov, V. Sufiiarov, A. Popovich, In-situ synthesis of Ti2AlNbbased intermetallic alloy by selective laser melting, J. Alloys Compd. 704 (2017) 434-442.

[8] A. Yadollahi, N. Shamsaei, S.M. Thompson, A. Elwany, L. Bian, Effects of building orientation and heat treatment on fatigue behavior of selective laser melted 17-4 PH stainless steel, Int. J. Fatigue 94 (Part 2) (2017) 218-235.

[9] J. Ma, M.M. Atabaki, W. Liu, R. Pillai, B. Kumar, U. Vasudevan, R. Kovacevic, Laserbased welding of 17-4 $\mathrm{PH}$ martensitic stainless steel in a tubular butt joint configuration with a built-in backing bar, Opt. Laser Technol. 82 (2016) 38-52.

[10] P.G.E. Jerrard, L. Hao, K.E. Evans, Experimental investigation into selective laser melting of austenitic and martensitic stainless steel powder mixtures, Proc. Inst. Mech. Eng. Part B J. Eng. Manuf. 223 (11) (2009) 1409-1416.

[11] L. Facchini, Metastable austenite in 17-4 precipitation-hardening stainless steel produced by selective laser melting, Adv. Eng. Mater. (2010) 184-188. 
[12] L.E. Murr, E. Martinez, J. Hernandez, S. Collins, K.N. Amato, S.M. Gaytan, P.W. Shindo, Microstructures and properties of 17-4 PH stainless steel fabricated by selective laser melting, J. Mater. Res. Technol. 1 (3) (2012) 167-177.

[13] H.-J. Kim, Y.-G. Kweon, The effects of retained austenite on dry sliding wear behavior of carburized steels, Wear 193 (1) (1996) 8-15.

[14] A. Kokosza, J. Pacyna, Evaluation of retained austenite stability in heat treated cold work tool steel, J. Mater. Process. Technol. 162-163 (2005) 327-331.

[15] M.H. Farshidianfar, Control of Microstructure in Laser Additive Manufacturing, UWSpace, 2014.

[16] E. William, John A. Luecke, Slotwinski, Mechanical properties of austenitic stainless steel made by additive manufacturing, J. Res. Natl. Inst. Stand. Technol. 119 (2014) 398418.

[17] H.K. Rafi, D. Pal, N. Patil, T.L. Starr, B.E. Stucker, Microstructure and mechanical behavior of 17-4 precipitation hardenable steel processed by selective laser melting, J. Mater. Eng. Perform. 23 (12) (2014) 4421-4428.

[18] H. Irrinki, M. Dexter, B. Barmore, R. Enneti, S. Pasebani, S. Badwe, J. Stitzel, R. Malhotra, S.V. Atre, Effects of powder attributes and laser powder bed fusion (LPBF) process conditions on the densification and mechanical properties of 17-4 PH stainless steel, JOM 68 (3) (2016) 860-868.

[19] A. Simchi, H. Pohl, Effects of laser sintering processing parameters on the microstructure and densification of iron powder, Mater. Sci. Eng. A 359 (1-2) (2003) 119128. 
[20] A. Simchi, F. Petzoldt, H. Pohl, On the development of direct metal laser sintering for rapid tooling, J. Mater. Process. Technol. 141 (3) (2003) 319-328.

[21] B. AlMangour, Jenn-Ming Yang, Understanding the deformation behavior of 17-4 precipitate hardenable stainless steel produced by direct metal laser sintering using micropillar compression and TEM, Int. J. Adv. Manuf. Technol. (2016) 1-8.

[22] R.M. German, Powder Metallurgy and Particulate Materials Processing, Metal Powder Federation Industries (MPIF), Princeton, 2005.

[23] A.J. Pinkerton, L. Li, Multiple-layer laser deposition of steel components using gas and water-atomised powders: the differences and the mechanisms leading to them, Appl. Surf. Sci. 247 (1-4) (2005) 175-181.

[24] A.J. Pinkerton, L. Li, The behaviour of water- and gas-atomised tool steel powders in coaxial laser freeform fabrication, Thin Solid Films 453-454 (2004) 600-605.

[25] A.J. Pinkerton, L. Li, W.S. Lau, Effects of powder geometry and composition in coaxial laser deposition of 316L steel for rapid prototyping, CIRP Ann. Manuf. Technol. 52 (1) (2003) 181-184.

[26] S. Sivasankaran, K. Sivaprasad, R. Narayanasamy, V.K. Iyer, An investigation on flowability and compressibility of AA 6061100 - x-x wt.\% TiO2 micro and nanocomposite powder prepared by blending and mechanical alloying, Powder Technol. 201 (1) (2010) $70-82$.

[27] K.N. Amato, S.M. Gaytan, L.E. Murr, E. Martinez, P.W. Shindo, J. Hernandez, S. Collins, F. Medina, Microstructures and mechanical behavior of Inconel 718 fabricated by selective laser melting, Acta Mater. 60 (5) (2012) 2229-2239. 
[28] M. Krantz, H. Zhang, J. Zhu, Characterization of powder flow: static and dynamic testing, Powder Technol. 194 (3) (2009) 239-245.

[29] H. Irrinki, J. Samuel, D. Janagam, S. Pasebani, S. Badwe, J. Stitzel, K. Kate, O. Gulsoy, S.V. Atre, Effects of particle characteristics on the microstructure and mechanical properties of 17-4 PH stainless steel fabricated by laser-powder bed fusion, Powder Technol. 331 (2018) 192-203.

[30] S. Hoeges, A. Zwiren, C. Schade, Additive manufacturing using water atomized steel powders, Metal Powder Rep. 72 (2017) 111-117.

[31] C.E. Pinedo, S.I.V. Larrotta, A.S. Nishikawa, H. Dong, X.-Y. Li, R. Magnabosco, A.P. Tschiptschin, Low temperature active screen plasma nitriding of 17-4 PH stainless steel, Surf. Coat. Technol. 308 (2016) 189-194.

[32] B.D. Cullity, S.R. Stock, Elements of X-ray Diffraction, Prentice Hall Publication, India, 2001.

[33] M. Averyanova, P. Bertrand, B. Verquin, Effect of initial powder properties on final microstructure and mechanical properties of parts manufactured by selective laser melting, Annals of DAAAM \& Proceedings 21 (2010) 1531-1532.

[34] H. Nakagawa, T. Miyazaki, H. Yokota, Effects of aging temperature on the microstructure and mechanical properties of $1.8 \mathrm{Cu}-7.3 \mathrm{Ni}-15.9 \mathrm{Cr}-1.2 \mathrm{Mo}-\mathrm{low} \mathrm{C}, \mathrm{N}$ martensitic precipitation hardening stainless steel, J. Mater. Sci. 35 (9) (2000) 2245-2253. [35] A. Ziewiec, E. Zielinska, Tasak, Microstructure of welded joints of X5CrNiCuNb16 4(17-4PH) martensitic stainless steel after heat treatment, Arch. Metall. Mater. 59 (2014) 966-970. 
[36] H.-J. Sung, T.K. Ha, S. Ahn, Y.W. Chang, Powder injection molding of a 17-4 PH stainless steel and the effect of sintering temperature on its microstructure and mechanical properties, J. Mater. Process. Technol. 130-131 (2002) 321-327.

[37] P. Schaffnit, C. Stallybrass, J. Konrad, F. Stein, M. Weinberg, A Scheil-Gulliver model dedicated to the solidification of steel, Calphad 48 (2015) 184-188.

[38] F. Masoumi, M. Jahazi, D. Shahriari, J. Cormier, Coarsening and dissolution of $\gamma^{\prime}$ precipitates during solution treatment of $\mathrm{AD} 730^{\mathrm{TM}} \mathrm{Ni}$-based superalloy: mechanisms and kinetics models, J. Alloys Compd. 658 (2016) 981-995.

[39] G.Y. Lai, W.E. Wood, R.A. Clark, V.F. Zackay, E.R. Parker, The effect of austenitizing temperature on the microstructure and mechanical properties of as-quenched 4340 steel, Metall. Trans. 5 (7) (1974) 1663-1670.

[40] C. Hsiao, C. Chiou, J. Yang, Aging reactions in a 17-4 PH stainless steel, Mater. Chem. Phys. 74 (2) (2002) 134-142. 


\section{APPENDIX B \\ HEAT TREATMENT STUDIES ON 17-4 PH STAINLESS STEEL PARTS}

FABRICATED BY LASER-POWDER BED FUSION

\section{B.1 INTRODUCTION}

Laser-powder bed fusion (L-PBF), is an additive manufacturing (AM) process that uses a focused laser beam as an energy source to melt fine layers of powders to yield a solid threedimensional part [1 - 5]. The L-PBF process has received attention to produce complex three-dimensional parts for functional applications such as tooling for injection molding, customized implants for medical industries, and lightweight components for aerospace industries [1 - 5]. Many independent investigations have been carried out in the past decade on different materials $s$ and indicated that defect-free L-PBF parts can be produced if appropriate conditions and materials are used [6 - 8]. The porosity and microstructures in the L-PBF manufactured parts have a direct effect on the resulting mechanical properties. For instance, micro-flaws and grain dislocations would serve as stress raisers for crack initiation and compromise the mechanical performance of the L-PBF parts [1 - 12]. Most of the studies indicated that L-PBF as-built parts fabricated from powders of different powder shape and size produce different porosities and microstructures under various processing conditions [1 - 12]. Studies have also shown that in the L-PBF process, the material is subjected to repeated cycles of rapid heating, melting, solidification and cooling 
[1 -12]. Due to this phenomenon, the microstructures and mechanical properties of the asbuilt samples are different for various processing conditions and powder characteristics such as powder shape and size. Heat-treatment is routinely used to improve the microstructure and enhance mechanical properties of metal components [2, 12]. However, there is limited fundamental understanding of the mechanical properties and microstructures of the 17-4 PH stainless steel heat-treated L-PBF parts when properties of starting powders such as powder shape and size are varied $[2,12]$.

The present study was carried out to understand the effect of the heat-treatment on the mechanical properties and microstructures of the L-PBF parts fabricated from 17-4 PH stainless steels powders varied in shape (gas- and water-atomized), size-distribution at various L-PBF processing conditions. Two different post processing regimes were used in this study; (1) Heat treatment-1: specimens were solutionized at $1051{ }^{\circ} \mathrm{C}$ for $1 \mathrm{~h}$ in $\mathrm{H}_{2}$ atmosphere and then aged at $482{ }^{\circ} \mathrm{C}$ in $\mathrm{N}_{2}$ atmosphere for 1 h (H900) and (2) Heat treatment-2: specimens were solutionized at $1315^{\circ} \mathrm{C}$ for $45 \mathrm{~min}$ in $\mathrm{H}_{2}$ atmosphere and then aged at $482{ }^{\circ} \mathrm{C}$ for $1 \mathrm{~h}$ in $\mathrm{N}_{2}$ atmosphere. The work presented in this study is an expansion of the work in Appendix A and will be the subject of future work to scale it into a refereed journal paper. 


\section{B.2 RESULTS}

Table B.1 The variation in density $\left(\mathrm{g} / \mathrm{cm}^{3}\right)$ of $17-4 \mathrm{PH}$ stainless steel L-PBF parts due to heat treatment at energy density $64 \mathrm{~J} / \mathrm{mm}^{3}$

\begin{tabular}{|c|c|c|c|}
\hline Condition & As printed & $\begin{array}{c}\text { Heat } \\
\text { treatment-1 }\end{array}$ & $\begin{array}{c}\text { Heat } \\
\text { treatment-2 }\end{array}$ \\
\hline Energy density $\left(\mathbf{J} / \mathbf{m m}^{\mathbf{3}}\right)$ & 64 & 64 & 64 \\
\hline Gas atomized $\mathbf{D}_{\mathbf{5 0}}=\mathbf{1 3} \boldsymbol{\mu \mathbf { m }}$ & $7.6 \pm 0.05$ & $7.6 \pm 0.05$ & $7.8 \pm 0.05$ \\
\hline Water atomized $\mathbf{D}_{\mathbf{5 0}}=\mathbf{2 4} \boldsymbol{\mu m}$ & $6.9 \pm 0.05$ & $6.9 \pm 0.05$ & $7.5 \pm 0.05$ \\
\hline Water atomized $\mathbf{D}_{\mathbf{5 0}}=\mathbf{1 7} \boldsymbol{\mu m}$ & $7.6 \pm 0.05$ & $7.6 \pm 0.05$ & $7.7 \pm 0.1$ \\
\hline Water atomized $\mathbf{D}_{\mathbf{5 0}}=\mathbf{4 3} \boldsymbol{\mu m}$ & $7.0 \pm 0.05$ & $7 \pm 0.05$ & $7.6 \pm 0.05$ \\
\hline
\end{tabular}

Table B.2 The variation in density $\left(\mathrm{g} / \mathrm{cm}^{3}\right)$ of $17-4 \mathrm{PH}$ stainless steel L-PBF parts due to heat treatment at energy density $104 \mathrm{~J} / \mathrm{mm}^{3}$

\begin{tabular}{|c|c|c|c|}
\hline Condition & As printed & $\begin{array}{c}\text { Heat } \\
\text { treatment-1 }\end{array}$ & $\begin{array}{c}\text { Heat } \\
\text { treatment-2 }\end{array}$ \\
\hline Energy density $\left(\mathbf{J} / \mathbf{m m}^{\mathbf{3}}\right)$ & 104 & 104 & 104 \\
\hline Gas atomized D50 = $\mathbf{1 3} \boldsymbol{\mu m}$ & $7.7 \pm 0.05$ & $7.7 \pm 0.05$ & $7.8 \pm 0.05$ \\
\hline Water atomized D50 $=\mathbf{2 4} \mathbf{\mu m}$ & $7.6 \pm 0.05$ & $7.6 \pm 0.05$ & $7.6 \pm 0.05$ \\
\hline Water atomized D50 $=\mathbf{1 7} \boldsymbol{\mu m}$ & $7.7 \pm 0.05$ & $7.7 \pm 0.05$ & $7.7 \pm 0.05$ \\
\hline Water atomized D50 $=\mathbf{4 3} \mathbf{\mu m}$ & $7.5 \pm 0.05$ & $7.5 \pm 0.05$ & $7.6 \pm 0.05$ \\
\hline
\end{tabular}




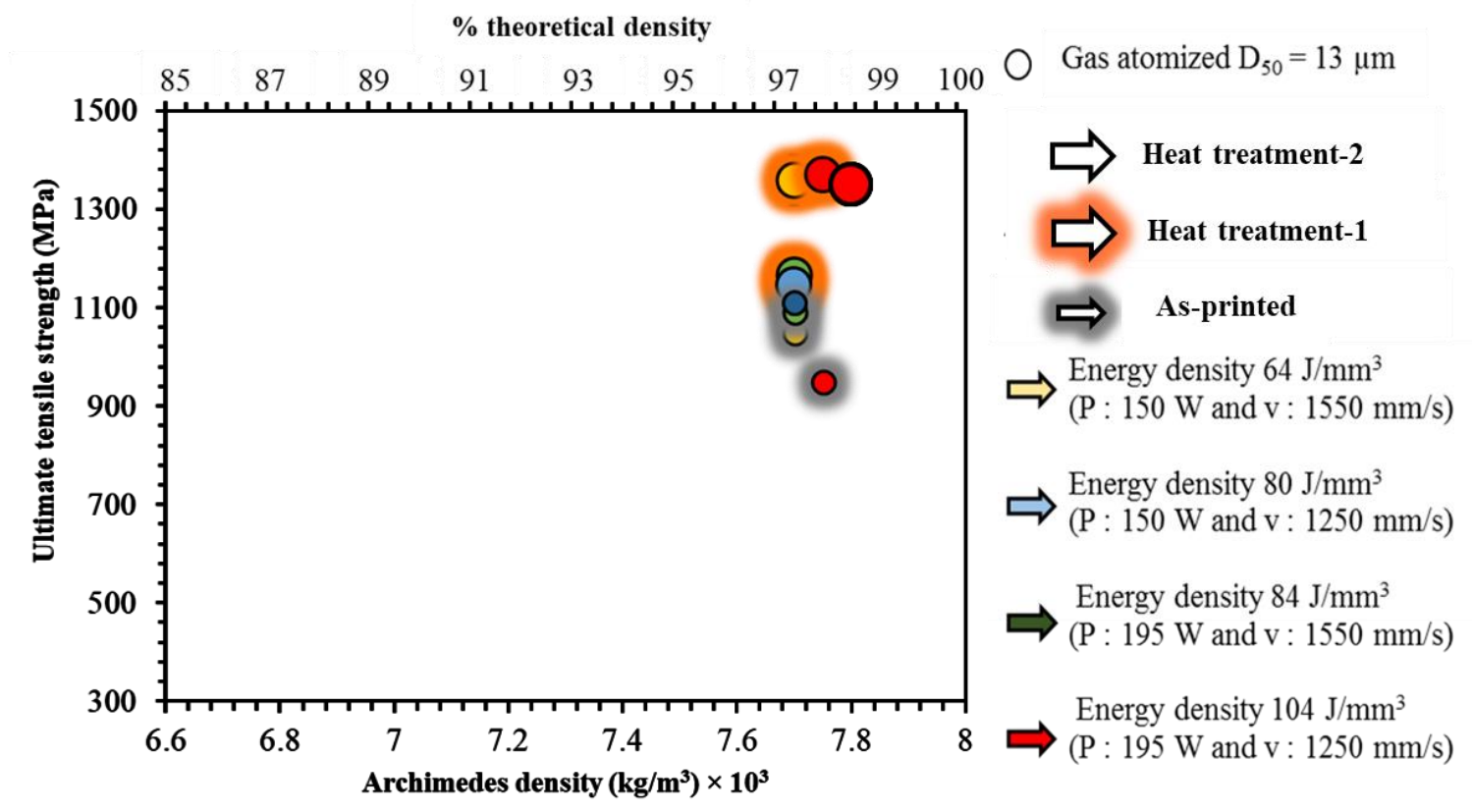

Figure B.1. The variation in the ultimate tensile strength of 17-4 PH stainless steel gasatomized $\mathrm{D}_{50}=13 \mu \mathrm{m}$ L-PBF parts due to heat treatment at various energy densities 


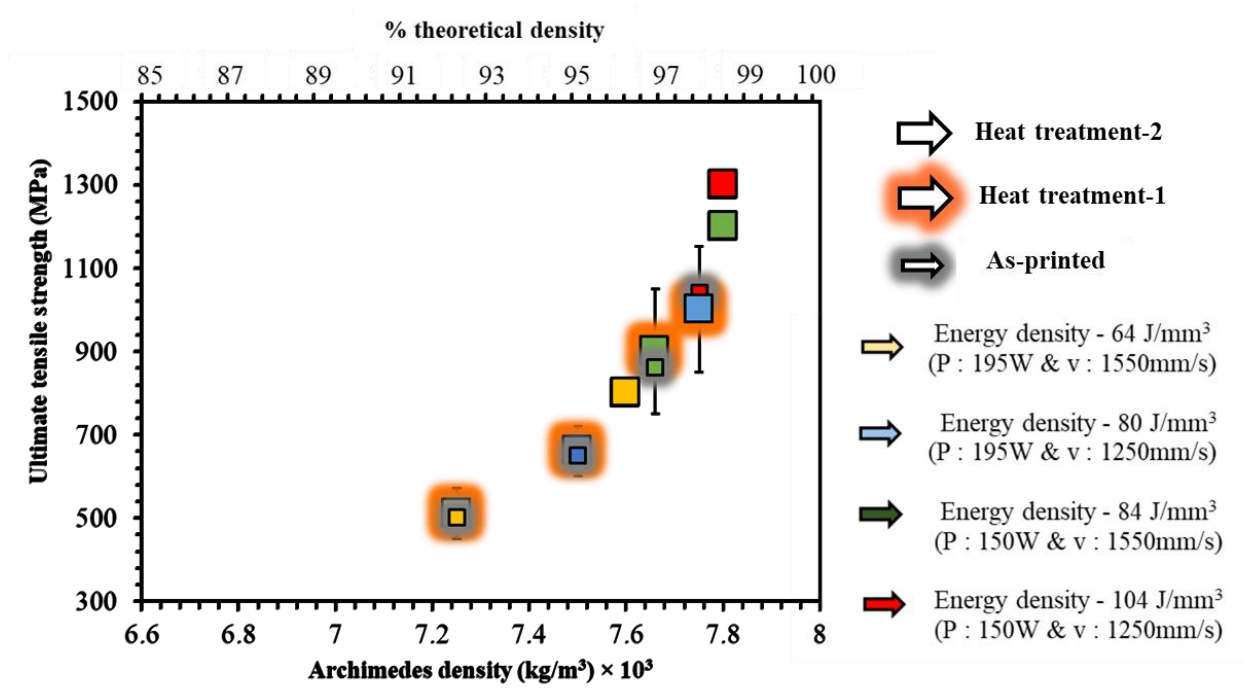

Figure B.0.12. The variation in the ultimate tensile strength of 17-4 PH stainless steel water- atomized $\mathrm{D}_{50}=43 \mu \mathrm{m}$ L-PBF parts due to heat treatment at various energy densities

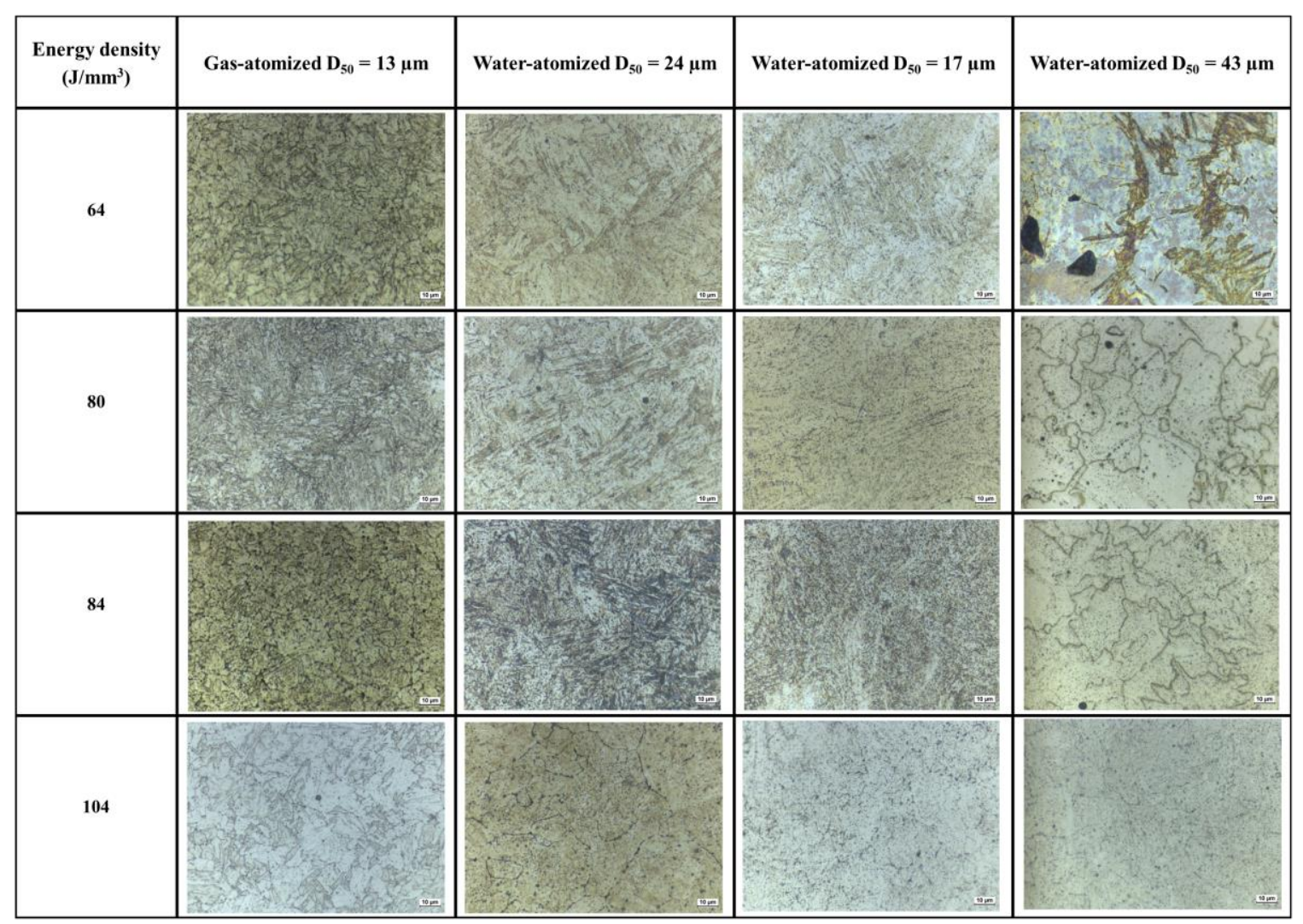

Figure B.0.13. The microstructures of 17-4 PH stainless steel water- atomized $\mathrm{D}_{50}=43$ $\mu \mathrm{m}$ L-PBF parts due to heat treatment-1 at various energy densities 


\section{B.3 REFERENCES}

[1] H. Irrinki, M. Dexter, B. Barmore, R. Enneti, S. Pasebani, S. Badwe, J. Stitzel, R. Malhotra, and S. V. Atre, "Effects of Powder Attributes and Laser Powder Bed Fusion (LPBF) Process Conditions on the Densification and Mechanical Properties of 17-4 PH Stainless Steel,” JOM, vol. 68, no. 3, pp. 860-868, Jan. 2016.

[2] A. Yadollahi, S. Nima, T. M. Scott, E. Alaa, and B. Linkan. "Mechanical and microstructural properties of selective laser melted 17-4 PH stainless steel." In ASME 2015 International Mechanical Engineering Congress and Exposition, pp. V02AT02A014V02AT02A014. American Society of Mechanical Engineers, 2015.

[3] A. Simchi and H. Asgharzadeh, "Densification and microstructural evaluation during laser sintering of M2 high speed steel powder," Mater. Sci. Technol., vol. 20, no. 11, pp. 1462-1468, Nov. 2004.

[4] H. Gu, H. Gong, D. Pal, K. Rafi, T. Starr, and B. Stucker, "Influences of energy density on porosity and microstructure of selective laser melted 17-4PH stainless steel." In Proceedings of Solid Freeform Fabrication Symposium (pp. 474-479).

[5] P. B. M. Averyanova, "Studying the influence of initial powder characteristics on the properties of final parts manufactured by the selective laser melting technology," Virtual Phys. Prototyp., pp. 1-9, 2011.

[6] A. Simchi, "Direct laser sintering of metal powders: Mechanism, kinetics and microstructural features," Mater. Sci. Eng. A, vol. 428, no. 1-2, pp. 148-158, Jul. 2006.

[7] B. Vrancken, T. Lore, K. Jean-Pierre, and H. Jan Van. "Heat treatment of Ti6Al4V produced by selective laser melting: microstructure and mechanical properties." Journal of Alloys and Compounds 541 (2012): 177-185. 
[8] T. H. C. Childs, C. Hauser, and M. Badrossamay, "Selective laser sintering (melting) of stainless and tool steel powders: Experiments and modelling," Proc. Inst. Mech. Eng. Part B J. Eng. Manuf., vol. 219, no. 4, pp. 339-357, Apr. 2005.

[9] W.-N. Su, P. Erasenthiran, and P. M. Dickens, "Investigation of fully dense laser sintering of tool steel powder using a pulsed Nd:YAG (neodymium-doped yttrium aluminum garnet) laser," Proc. Inst. Mech. Eng. Part C J. Mech. Eng. Sci., vol. 217, no. 1, pp. 127-138, Jan. 2003.

[10] M. Badrossamay and T. H. C. Childs, "Further studies in selective laser melting of stainless and tool steel powders," Int. J. Mach. Tools Manuf., vol. 47, no. 5, pp. 779-784, Apr. 2007.

[11] A. J. Pinkerton and L. Li, "Direct additive laser manufacturing using gas- and wateratomized H13 tool steel powders," Int. J. Adv. Manuf. Technol., vol. 25, no. 5-6, pp. 471479, 2005.

[12] T. LeBrun, T. Nakamoto, K. Horikawa, and H. Kobayashi, "Effect of retained austenite on subsequent thermal processing and resultant mechanical properties of selective laser melted 17-4 PH stainless steel," Mater. Des., vol. 81, pp. 44-53, Sep. 2015. 


\begin{abstract}
APPENDIX C
EFFECTS OF INITIAL POWDER ATTRIBUTES AND PROCESS CONDITIONS ON
\end{abstract}

THE RECYCLABILITY OF 17-4 PH STAINLESS STEEL POWDER IN

\author{
LASER-POWDER BED FUSION
}

\title{
C.1. INTRODUCTION
}

The desire to improve the sustainability and efficiency of the laser-powder bed fusion (L$\mathrm{PBF}$ ) process drives the requirement for recycling of starting powders that are recycled during the fabrication process. An initial study was carried out to understand the effect of L-PBF processing conditions and starting powder characteristics on the recyclability of the 17-4 PH stainless steel powders. To this effect, following a single L-PBF run, powder was collected in the vicinity of the part, potentially in the heat-affected zone after laser energy input. These powders were referred to as recycled powders or recycled powders, in contrast to the term, "initial powders" for the starting powders prior to use in an L-PBF run. The powders were characterized by SEM and XRD to detect any changes in morphological or chemistry.

Under all energy densities used in this study, no large changes in shape (qualitatively and quantitively) was observed in the 17-4 PH stainless steel gas and water-atomized powders after a single use. However, at a high energy density of 84 and $104 \mathrm{~J} / \mathrm{mm}^{3}$, the percentage of large spherical agglomerates qualitatively increased while fine spherical particles 
decreased in the used 17-4 PH stainless steel gas and water-atomized powders. The likely formation of sintered agglomerates in the recycled 17-4 PH stainless steel gas- and wateratomized powder will affect the powder flowability and density during the L-PBF process. $\mathrm{XRD}$ analysis also indicated minor changes possibly as a result of oxidation or volatilization of alloy constituents. These results pinpoint the need for detailed follow up to track the changes in microstructure and properties in parts printed with recycled powders following multiple uses. The work presented in this study will be the subject of future work to scale it into a refereed journal paper.

\section{C.2 RESULTS}

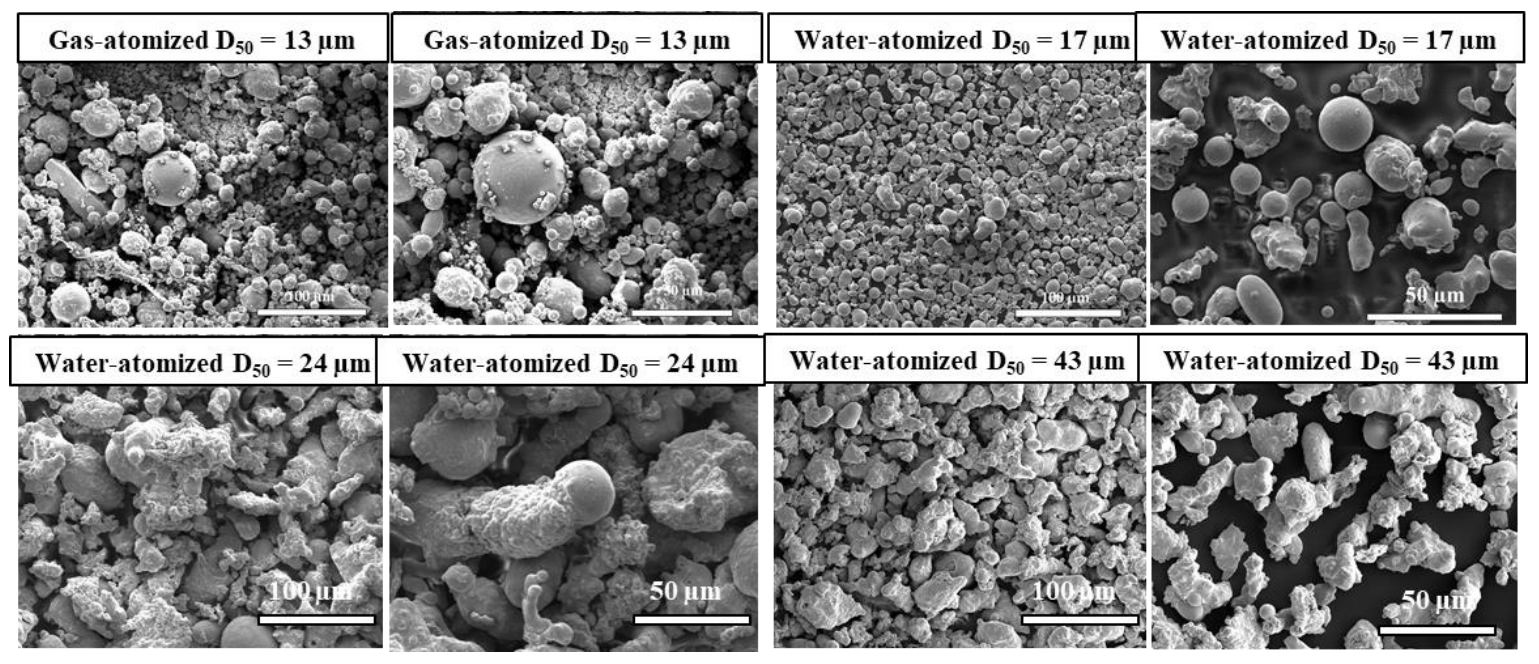

Figure C.1.SEM images of starting 17-4 PH stainless steel gas-and water-atomized powders 

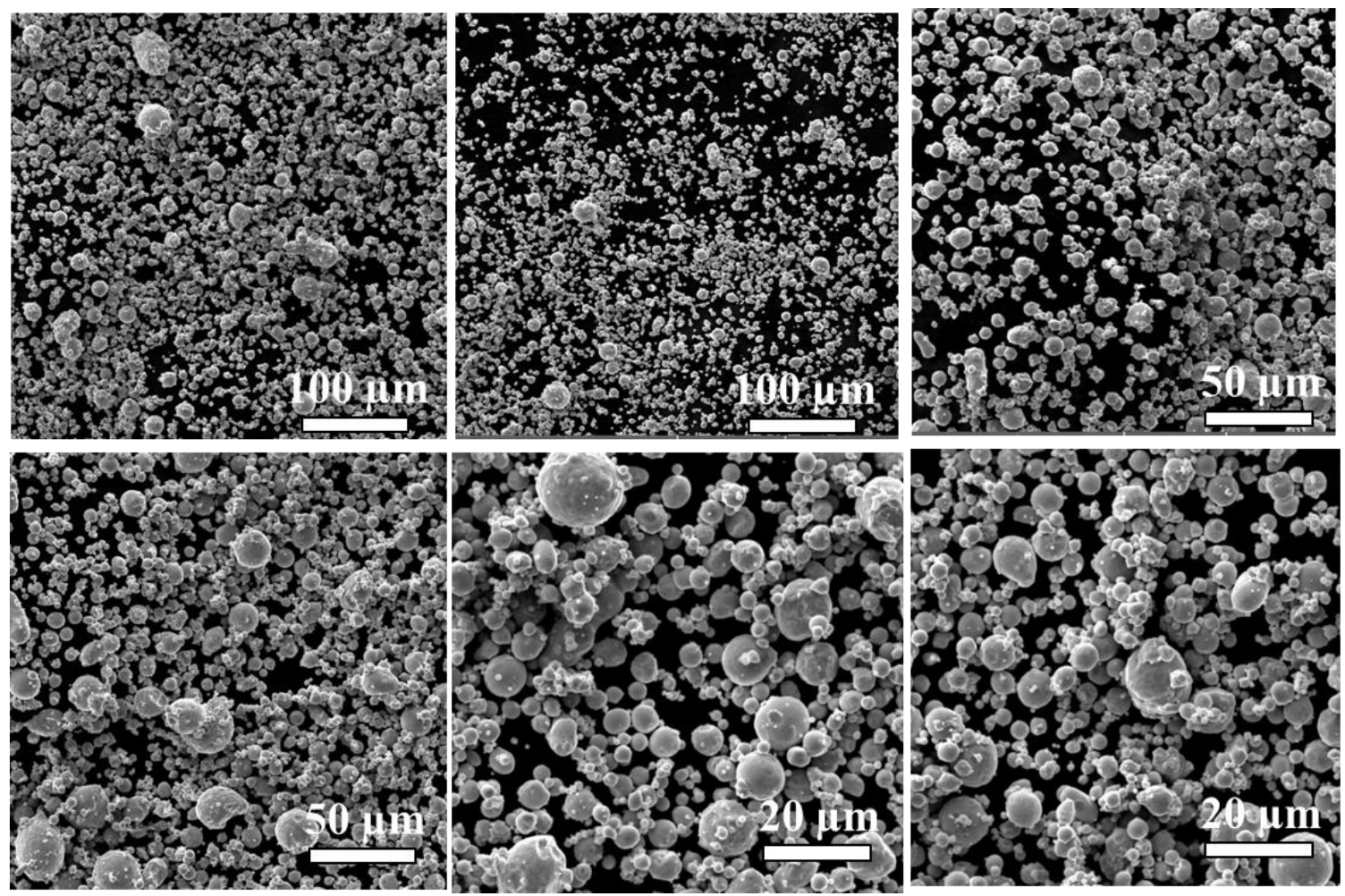

Figure C.2. SEM images of recycled 17-4 PH stainless steel gas-atomized powders at energy density $64 \mathrm{~J} / \mathrm{mm}^{3}$ 

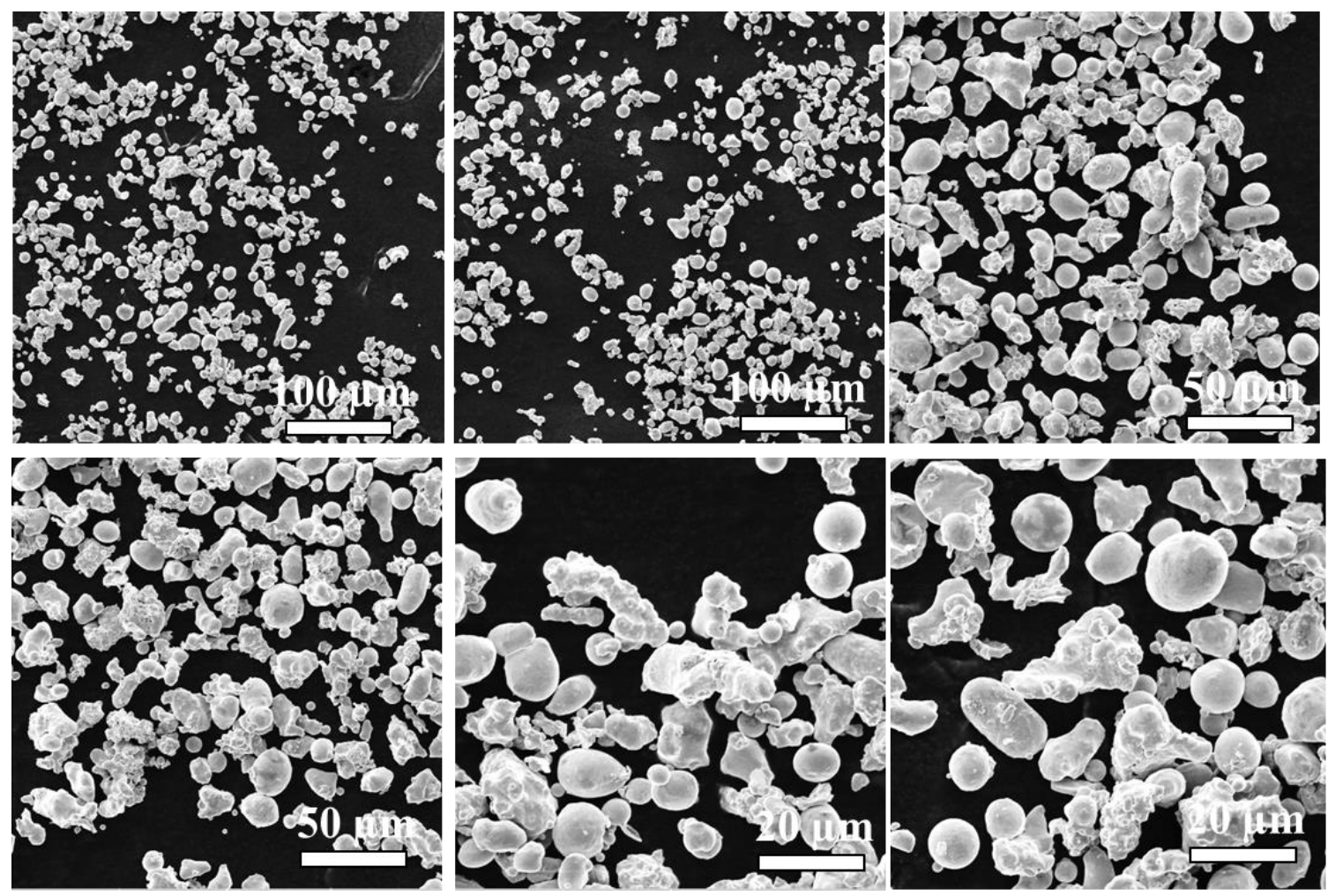

Figure C.3. SEM images of recycled 17-4 PH stainless steel water-atomized $\left(\mathrm{D}_{50}=17 \mu \mathrm{m}\right)$ powder at energy density $64 \mathrm{~J} / \mathrm{mm}^{3}$

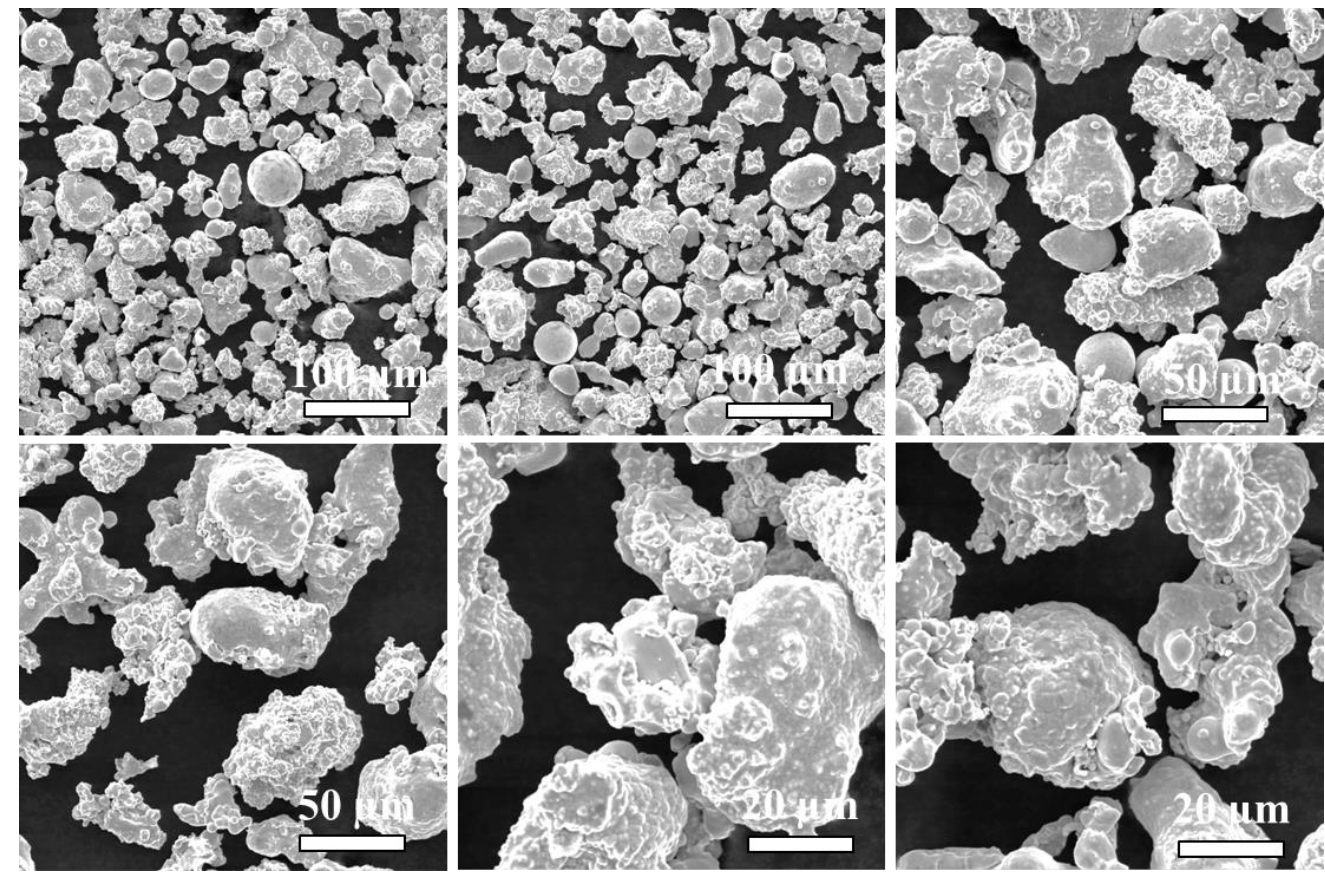

Figure C.4. SEM images of recycled 17-4 PH stainless steel water-atomized $\left(D_{50}=24 \mu \mathrm{m}\right)$ powder at energy density $64 \mathrm{~J} / \mathrm{mm}^{3}$ 


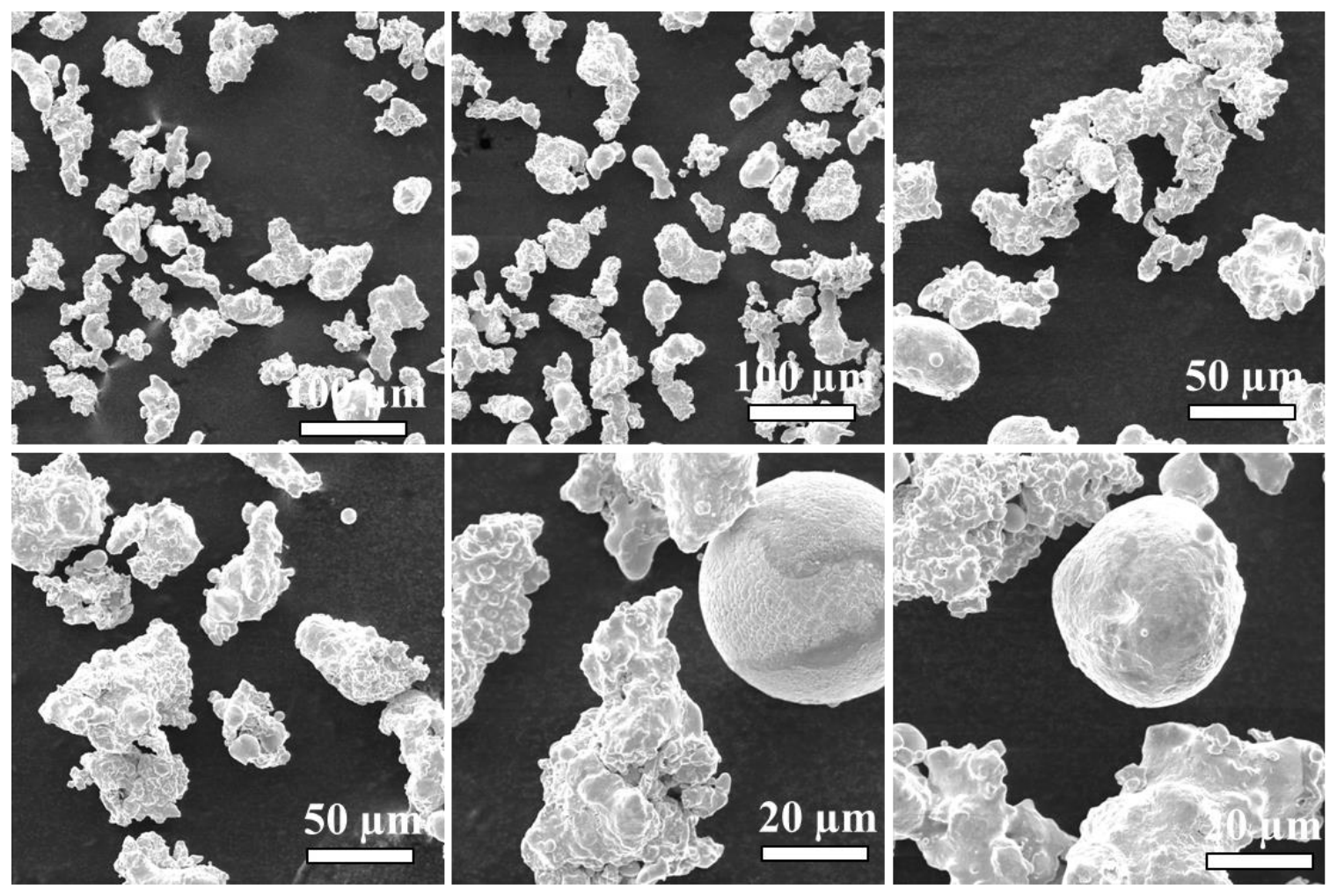

Figure C.5. SEM images of recycled 17-4 PH stainless steel water-atomized $\left(\mathrm{D}_{50}=43\right.$ $\mu \mathrm{m})$ powder at energy density $64 \mathrm{~J} / \mathrm{mm}^{3}$ 


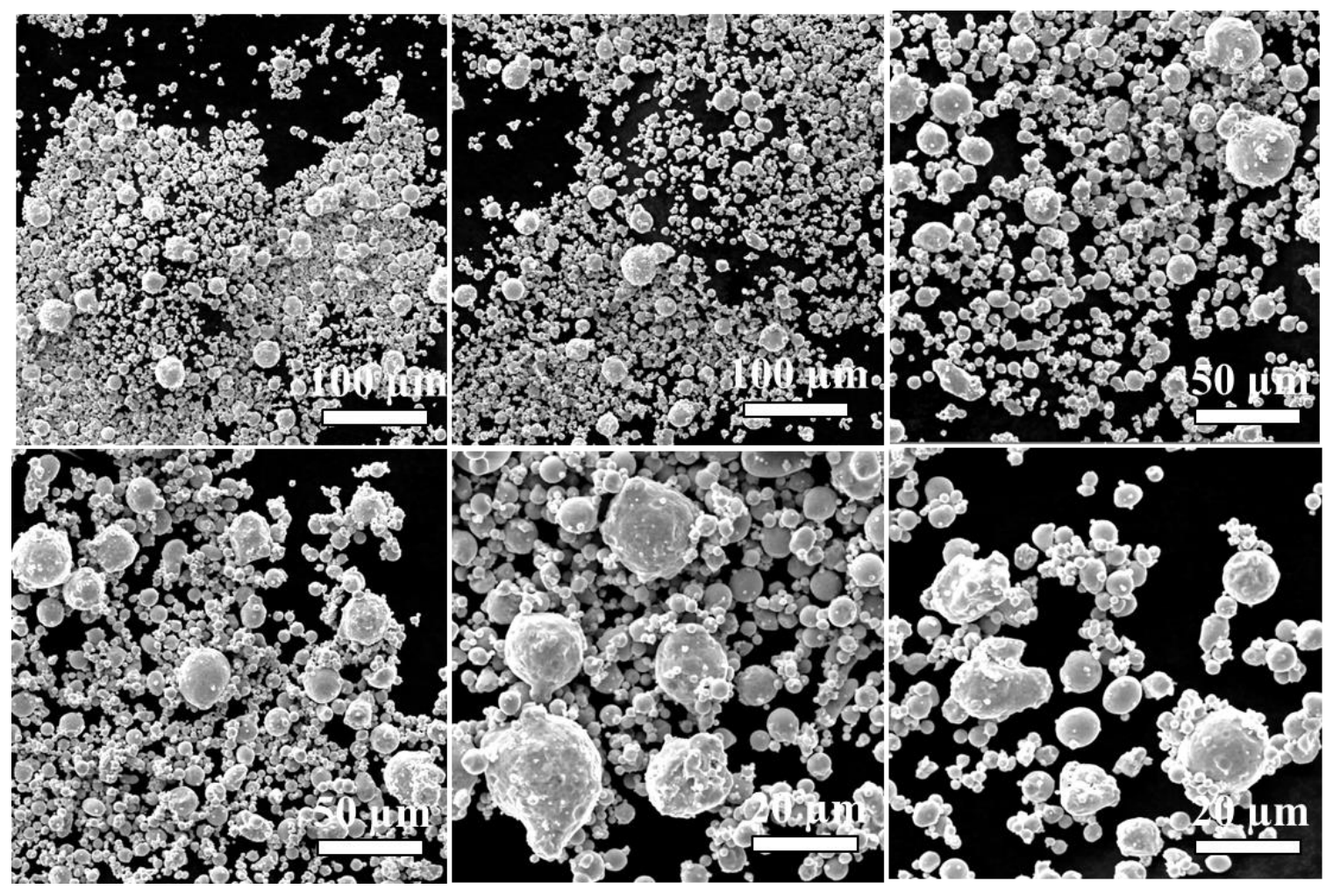

Figure C.6. SEM images of recycled 17-4 PH stainless steel gas-atomized $\left(\mathrm{D}_{50}=13 \mu \mathrm{m}\right)$ powder at energy density $80 \mathrm{~J} / \mathrm{mm}^{3}$ 


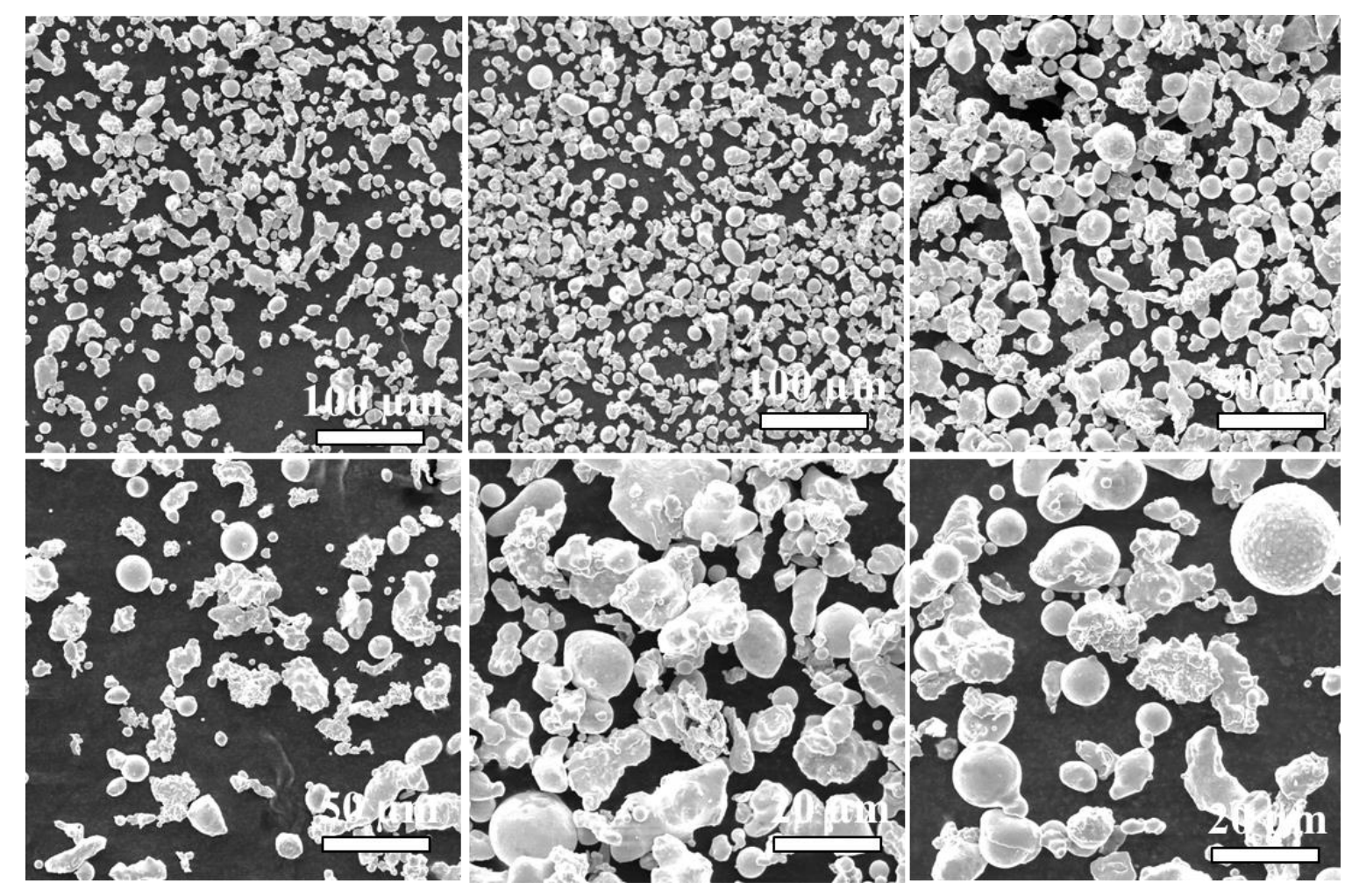

Figure C.7. SEM images of recycled 17-4 PH stainless steel water-atomized $\left(\mathrm{D}_{50}=17\right.$ $\mu \mathrm{m}$ ) powder at energy density $80 \mathrm{~J} / \mathrm{mm}^{3}$ 


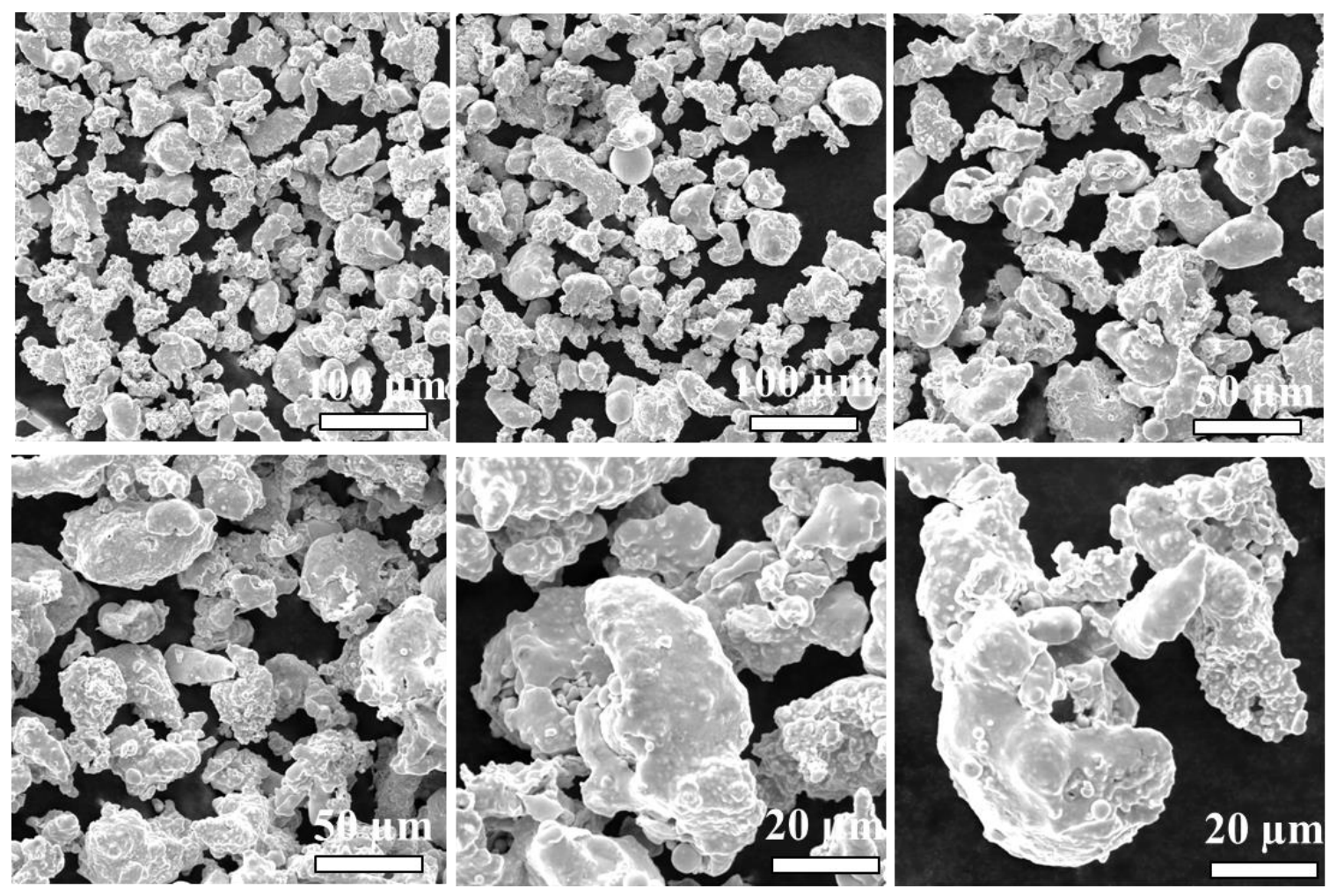

Figure C.8. SEM images of recycled 17-4 PH stainless steel water-atomized $\left(\mathrm{D}_{50}=24\right.$ $\mu \mathrm{m})$ powder at energy density $80 \mathrm{~J} / \mathrm{mm}^{3}$ 


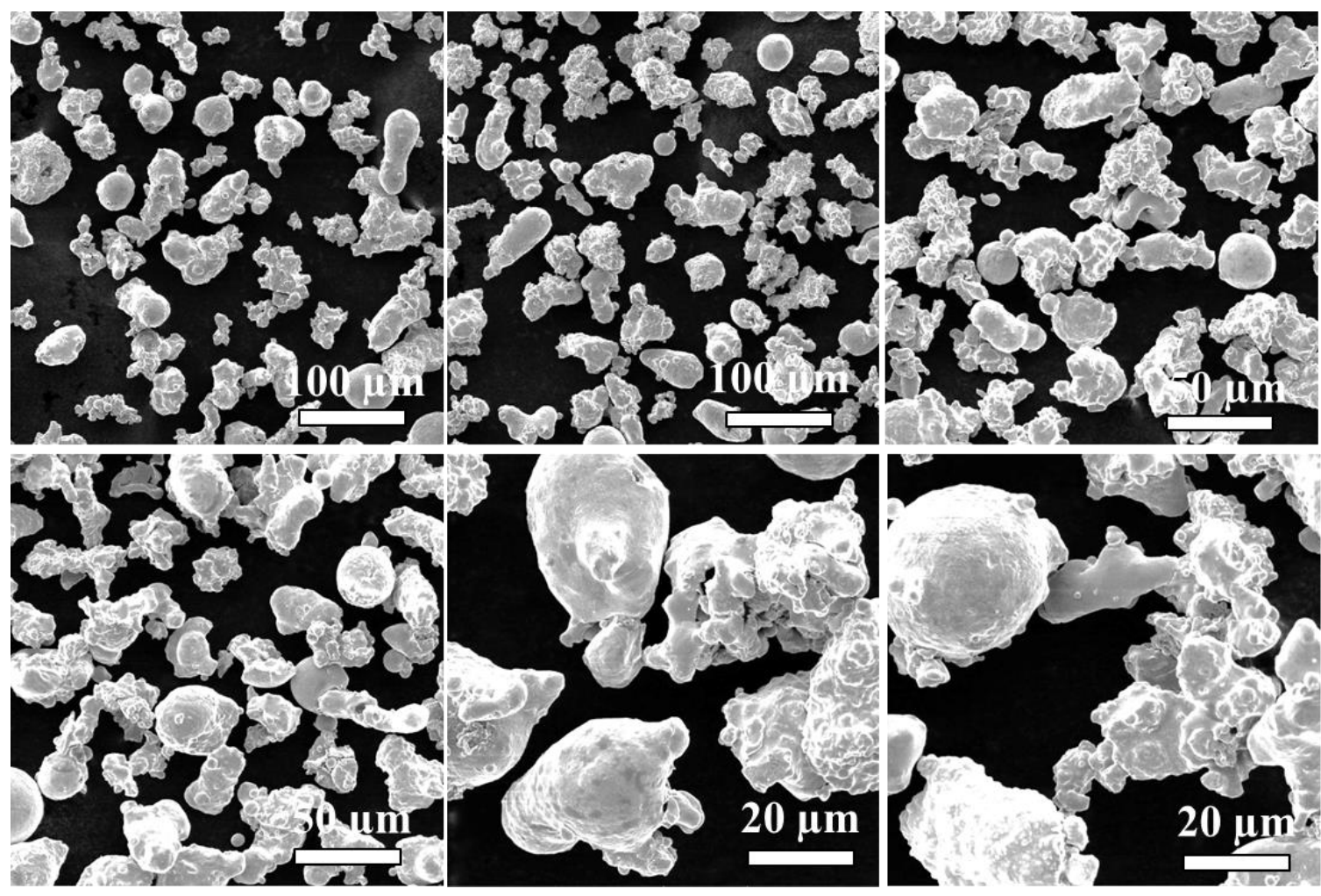

Figure C.9. SEM images of recycled 17-4 PH stainless steel water-atomized $\left(\mathrm{D}_{50}=43\right.$ $\mu \mathrm{m})$ powder at energy density $80 \mathrm{~J} / \mathrm{mm}^{3}$ 


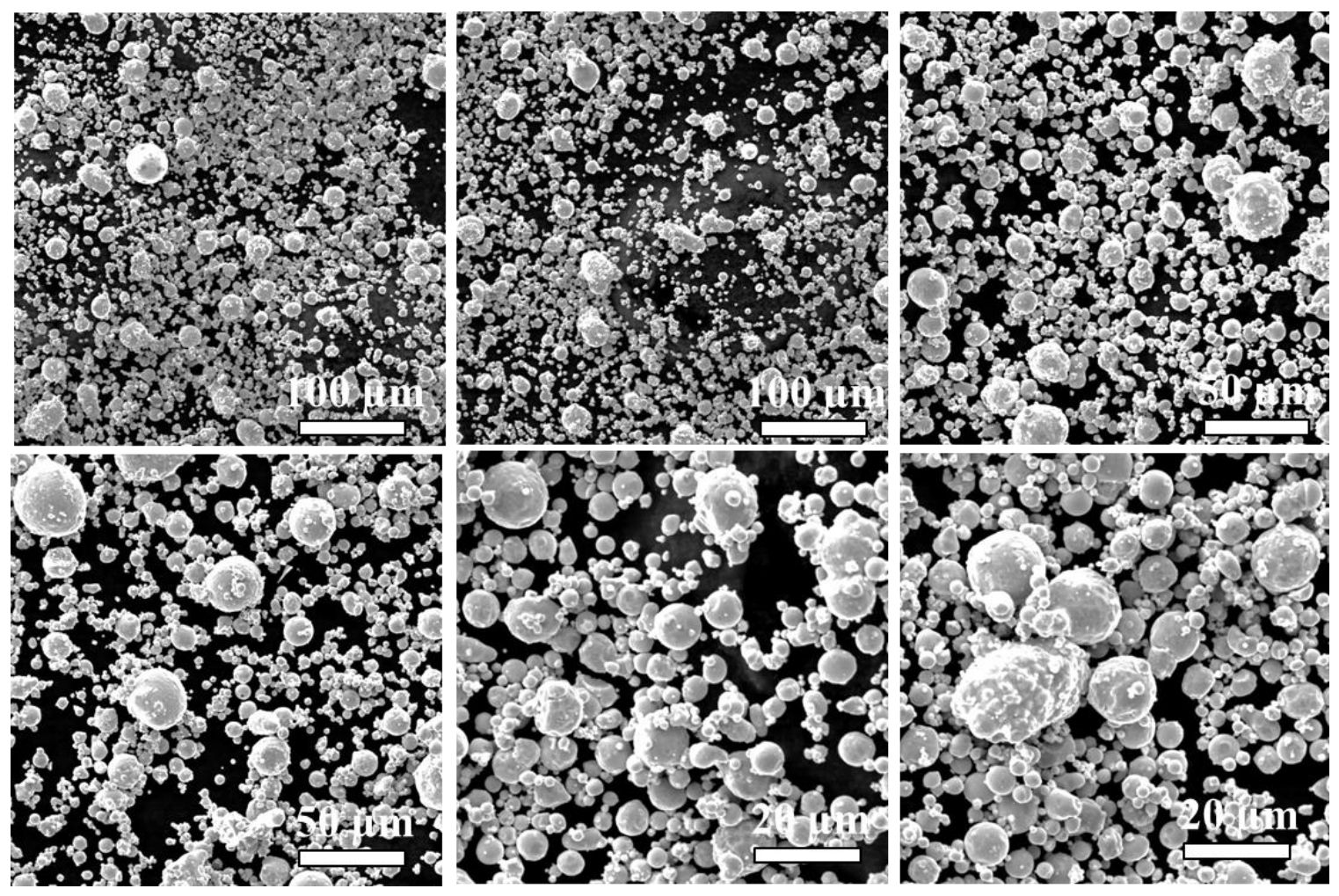

Figure C.10. SEM images of recycled 17-4 PH stainless steel gas-atomized $\left(\mathrm{D}_{50}=13 \mu \mathrm{m}\right)$ powder at energy density $84 \mathrm{~J} / \mathrm{mm}^{3}$ 

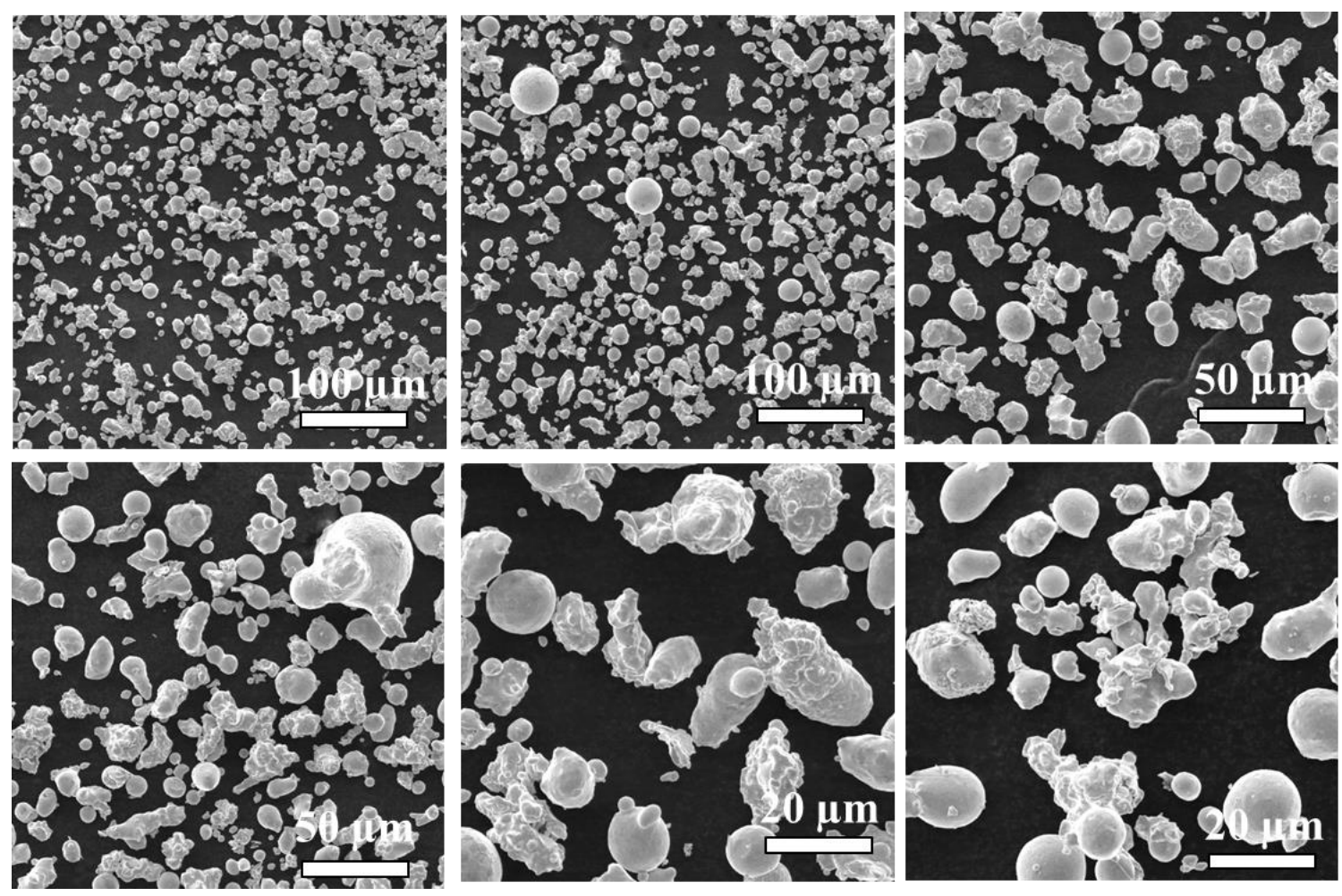

Figure C.11. SEM images of recycled 17-4 PH stainless steel water-atomized $\left(\mathrm{D}_{50}=17\right.$ $\mu \mathrm{m}$ ) powder at energy density $84 \mathrm{~J} / \mathrm{mm}^{3}$ 

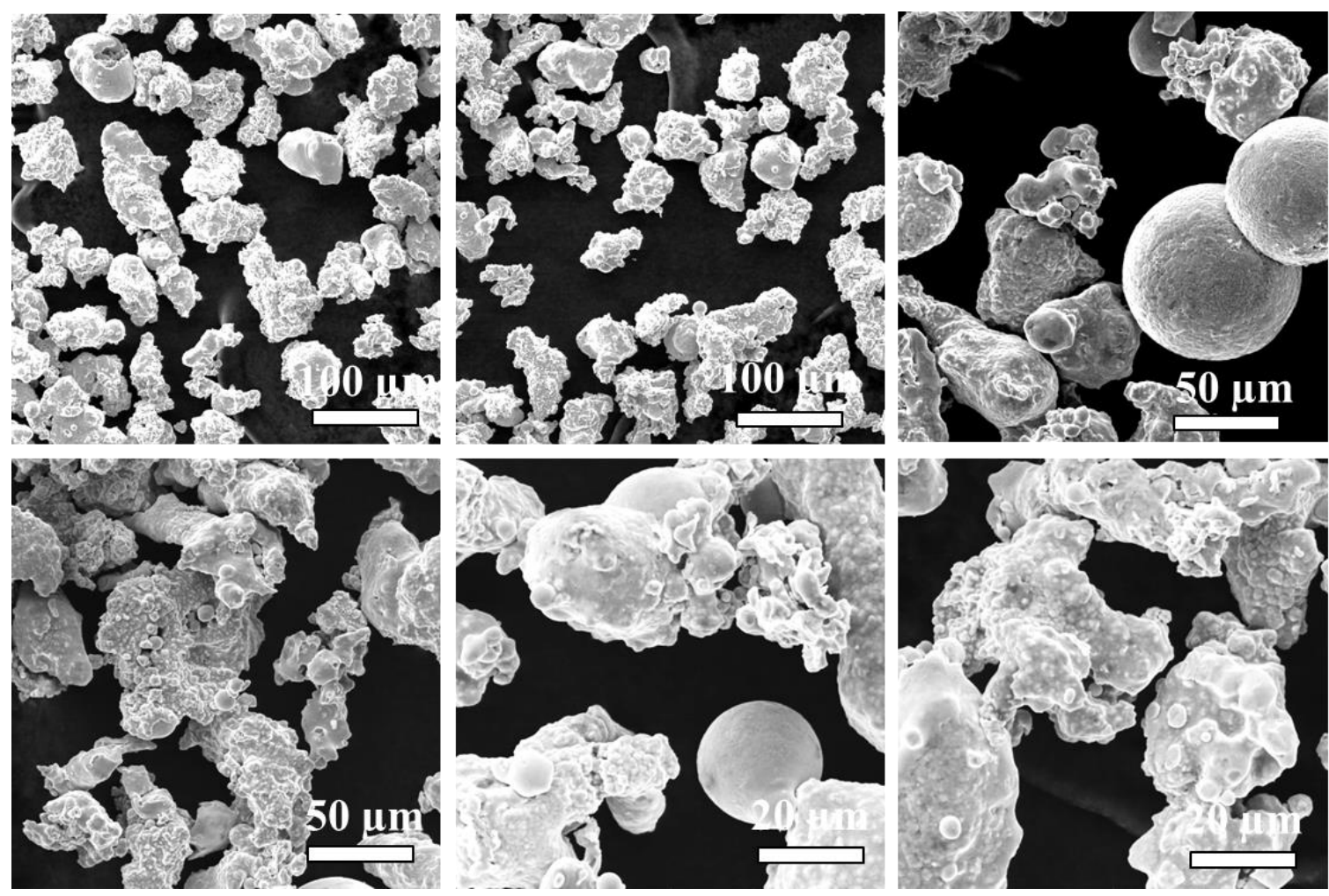

Figure C.12. SEM images of recycled 17-4 PH stainless steel water-atomized $\left(\mathrm{D}_{50}=24\right.$ $\mu \mathrm{m}$ ) powder at energy density $84 \mathrm{~J} / \mathrm{mm}^{3}$ 

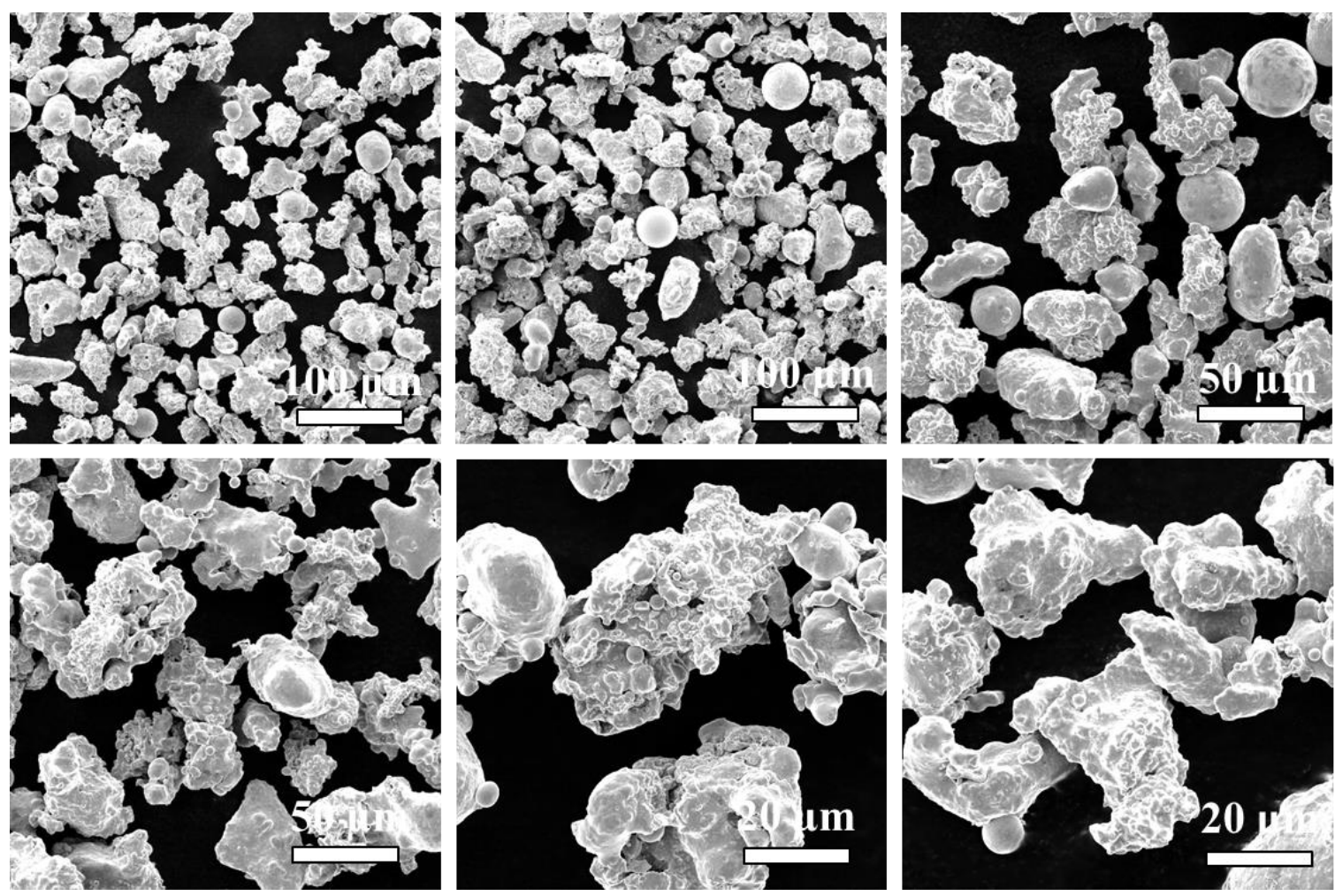

Figure C.13. SEM images of recycled 17-4 PH stainless steel water-atomized $\left(\mathrm{D}_{50}=43\right.$ $\mu \mathrm{m}$ ) powder at energy density $84 \mathrm{~J} / \mathrm{mm}^{3}$ 

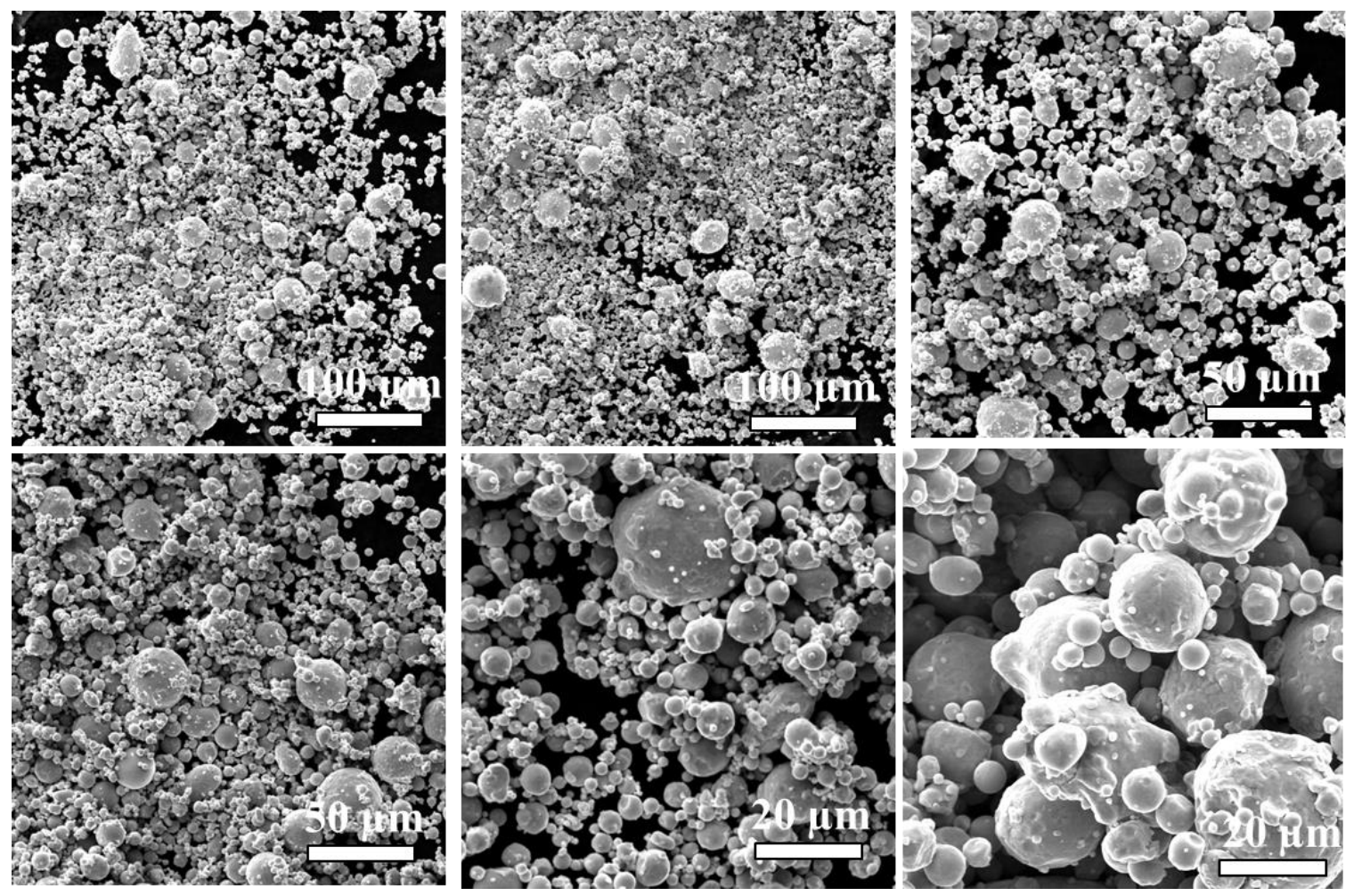

Figure C.0.14. SEM images of recycled 17-4 PH stainless steel gas-atomized $\left(\mathrm{D}_{50}=13\right.$ $\mu \mathrm{m}$ ) powder at energy density $104 \mathrm{~J} / \mathrm{mm}^{3}$
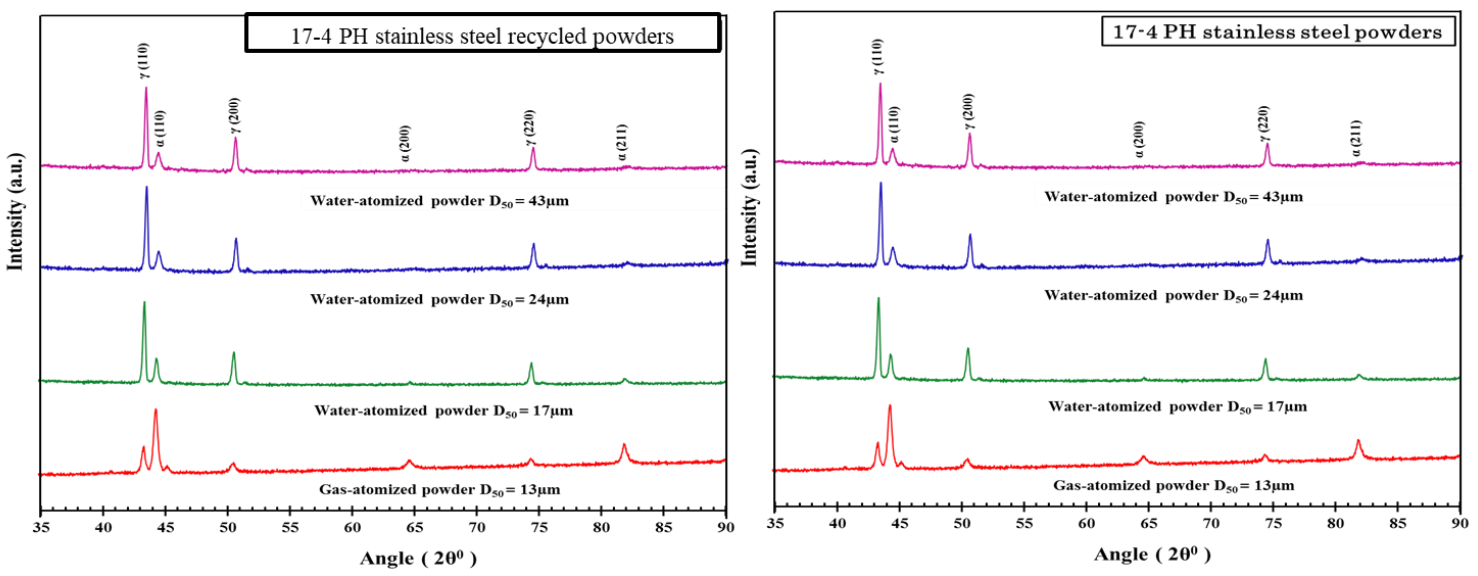

Figure C.0.15.XRD pattern of the recycled 17-4 PH stainless steel gas-and wateratomized powders (left) and starting powders (right) 

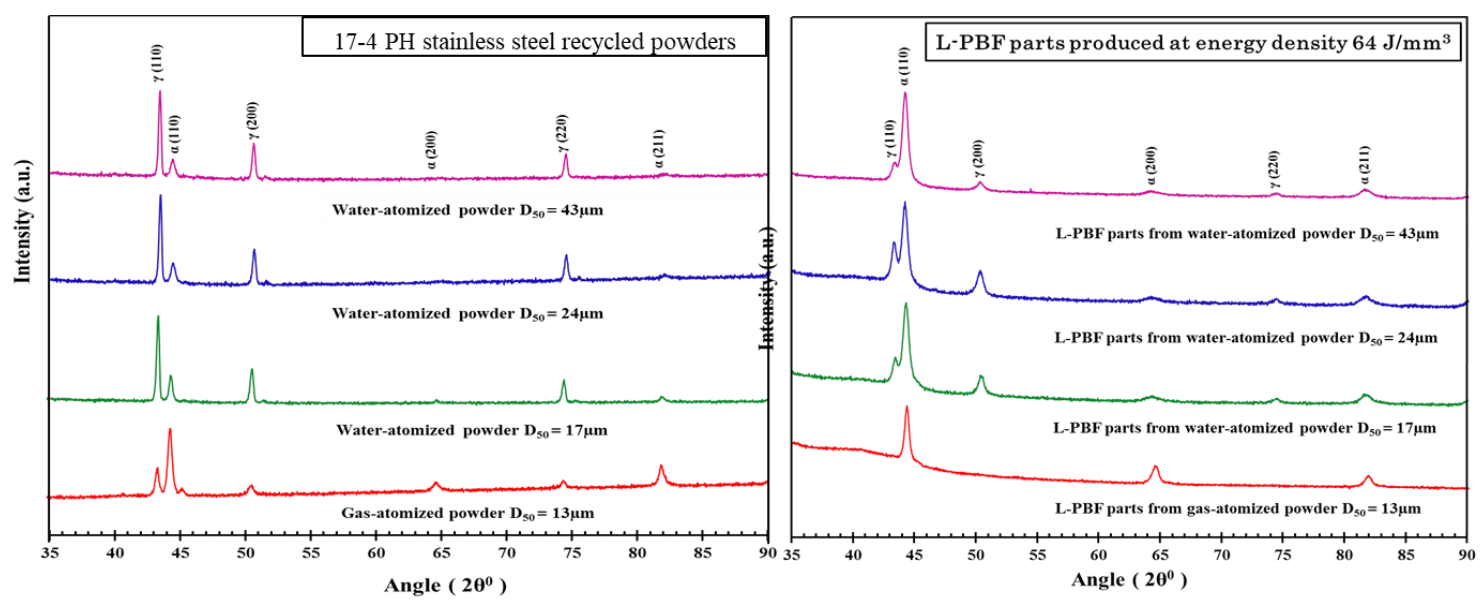

Figure C.0.16. XRD pattern of the recycled 17-4 PH stainless steel gas-and wateratomized powders (left) and corresponding L-PBF parts (right) processed at an energy density of $64 \mathrm{~J} / \mathrm{mm}^{3}$ 


\begin{abstract}
APPENDIX D
UOFL 3D PRINTING BUSINESS INCUBATOR: INTEGRATING PRODUCT

DESIGN, PROCESSING AND MARKET ANALYSIS FOR MANUFACTURING

WITH METAL POWDERS
\end{abstract}

\title{
D. 1 INTRODUCTION
}

Powder metallurgy and metal injection molding are proven net-shaping processes for the high volume fabrication of precision parts for a broad range of transportation, medical, electronics, industrial and consumer applications. However, the growth of applications and market size in these technologies depends to a good extent on design engineers being familiar with these prescribing parts based on processing metal powders. The advent of metal 3D printing provides an opportunity for design engineers to get acquainted with powder metallurgy and metal injection molding technologies at an early stage of their education and training. A new academic program at the University of Louisville has been addressing this very bottleneck during the last year.

The lead time to translate a new product design into manufacturing is time-consuming and expensive [1]-[10]. In each design cycle, the production moves through various stages involving physical prototype is created to test and validate the design. Implementing 
additive manufacturing or 3D printing in the design cycle of a new product can disrupt the product design and supply chain of various aerospace, defense, automotive and healthcare industries [1]-[10]. However, understanding material-process-properties relationship is one current barrier to broader adoption of metal 3D printing to complement and integrate with the traditional process in industries [1]-[3].

The research performed at the Materials Innovation Guild, University of Louisville (3dmaterials.us) focuses on obtaining a fundamental understanding of metal 3D printing processing conditions and ensuing materials properties and microstructure through the integration of carefully designed experiments to enable optimization of the materialsdesign-process relationship as shown in Figure D.1. With an understanding of the materials-design-process relationships in metal 3D printing could emerge an opportunity that allows new design innovations and products in aerospace, defense, automotive and healthcare industries.

In this regard, University of Louisville developed a pilot project, UofL 3D Printing Business Incubator (uofl3dpbiz.com) that connected capstone student design teams with various industries to understand the techno-economic points through case studies. 


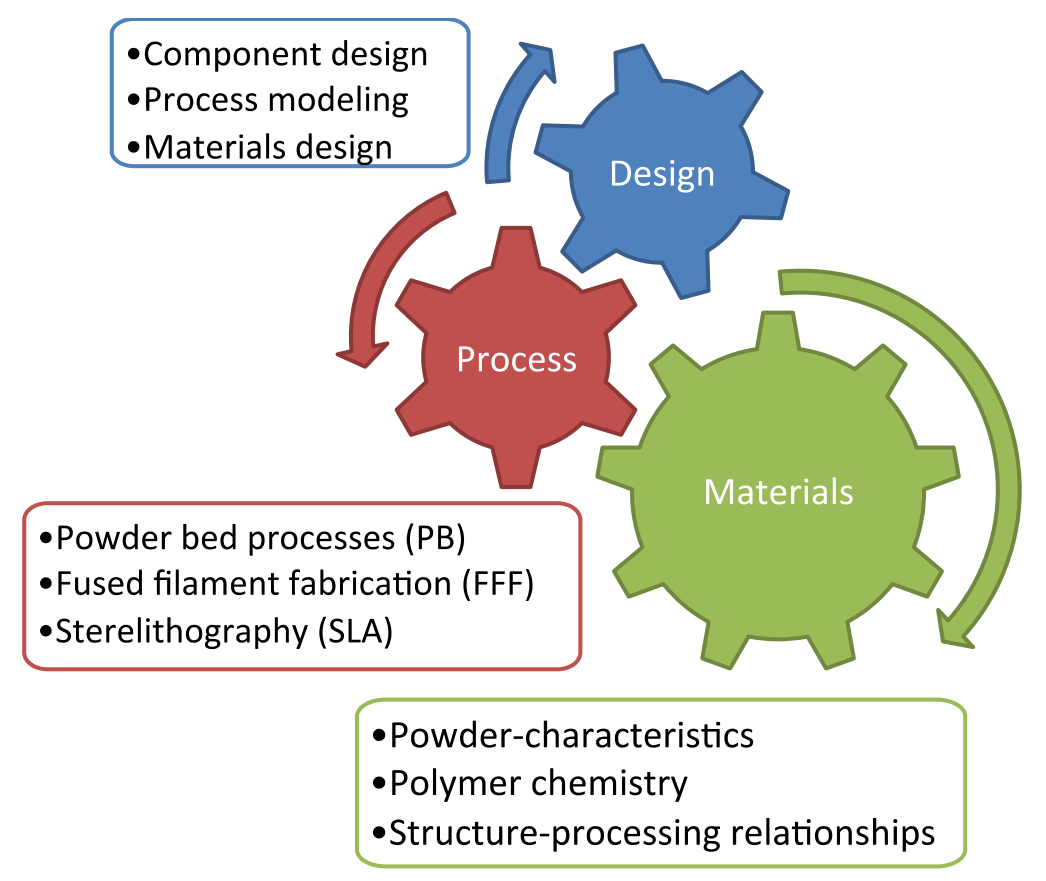

Figure D.1.Material-process-design relationship in 3D printing

A total of 20 design teams compromised of 100 engineering students shown in Figure D.2 were trained and educated in techno-economic aspects of 3D printing. During the 9 months pilot project period, students worked with academia and industry partners. Industry partners defined a real-world capstone project and whereas, academia provided them necessary research support. This support helped capstone students to redesign parts for 3D printing to produce and test them technical and business aspects (surface, geometric, mechanical and material requirements, cost and economic batch analysis).

In this article, one interesting case study is presented that shows the potential of $3 \mathrm{D}$ printing in automotive industries. In addition to the designing and manufacturing the prototypes, the business case is also developed by students to demonstrate how 3D printing can complement the traditional processes like powder metallurgy by saving time and costs. 


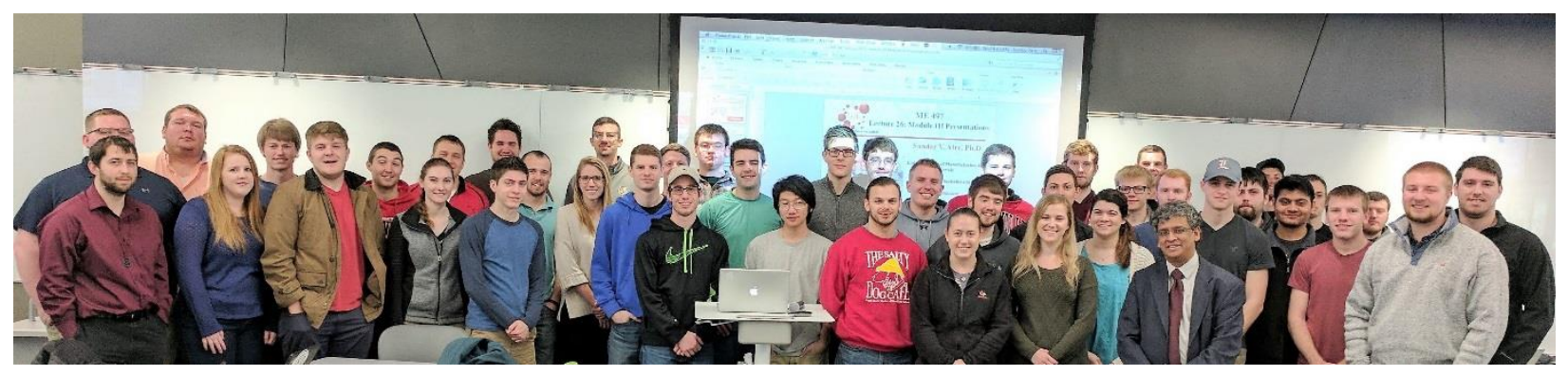

Figure D.2. Mechanical engineering capstone students (Spring 2017) were involved in the

UofL 3D Printing Business Incubator

\section{2 AUTOMOTIVE ENGINE GEARS}

The automotive industry, among other manufacturing industries, is constantly driving towards a shorter lead time-to-market for its new products. New cars and trucks need to be designed, tested and released for production in a much shorter period [4], [5], [7], [8], [10]. The shorter time-to-market evolution has also influence on the gearbox manufacturers who must design and test their products in a much shorter period. This can also speed up the process by placing a high-volume production order of gears using powder metallurgy for various automotive industries. The critical aspect of this process is the lead time to create new gear prototypes, which is currently around 10 weeks. This is mostly caused by the need to develop custom hobbing and grinding tools, a process which is time-consuming and expensive [4], [8], [10]. This long lead time limits the number of designs which can be tested and makes it difficult to achieve the best tribological and acoustic performance. For this reason, gearbox manufacturers need a faster production technology such as 3D printing to create precision gears for prototyping purposes. The 3D printing process has the potential to significantly accelerate the process of prototyping new product designs and 
validating them under real conditions. In this regard, a student startup team at the University of Louisville, Bluegrass Engineering Solutions (Figure D.3), worked with an automobile engine manufacturer to decrease the lead time to produce the gear prototypes using 3D printing process.

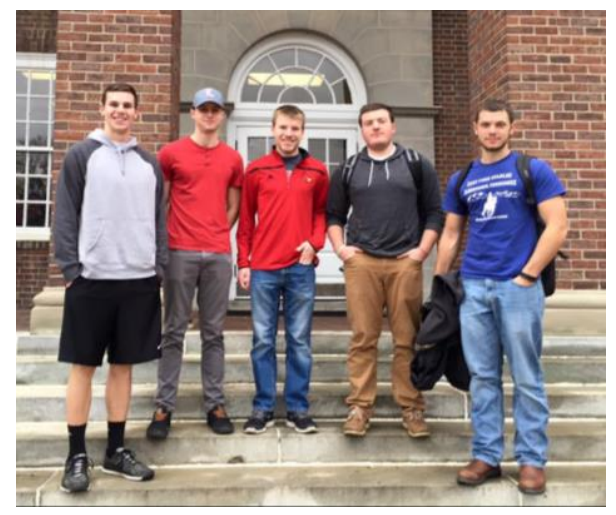

Figure D.3.The Bluegrass Engineering Solutions student startup team that worked on the automobile engine gear: Austin Anderson, Brad Gootee, Michael Kjelby, Devon Warman, Gunnar Wagoner

The primary challenge for design engineers for choosing a prototype production method for a specific product like automotive engine gear depends on batch size and cost of the production. The economic batch size and cost analysis of L-PBF process were performed using CES Edupack as shown in Figure D.4. It can be concluded that L-PBF process is the cost-effective and efficient low volume production process for the prototype fabrication. 

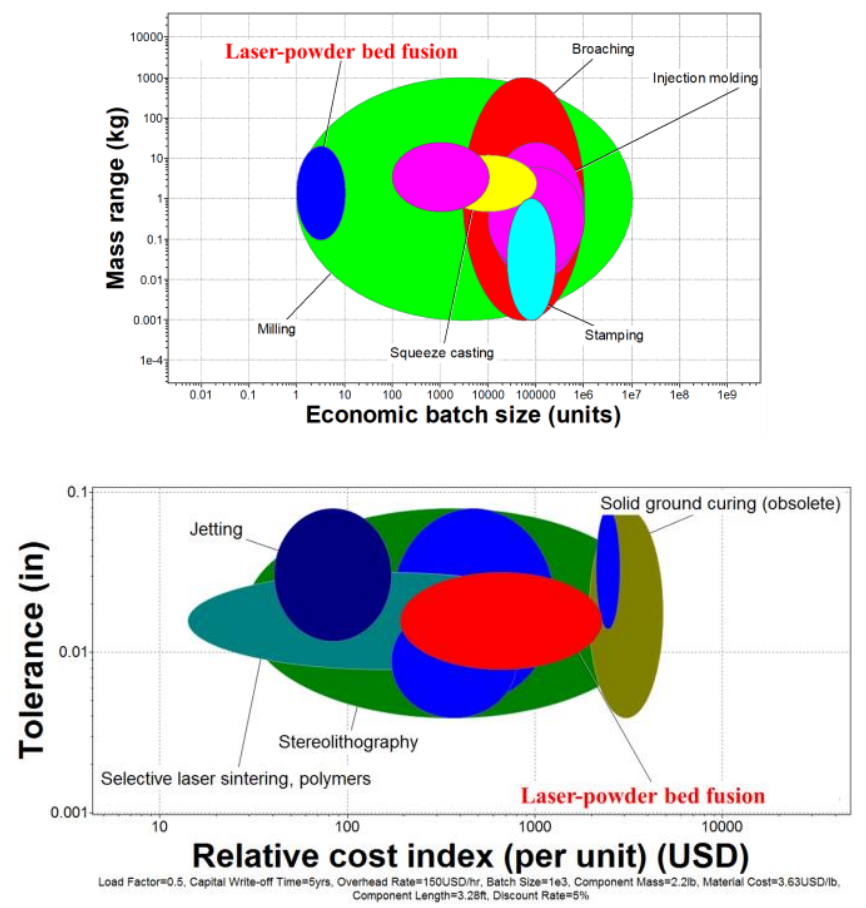

Figure D.4. Economic batch size and cost analysis of L-PBF process using CES Edupack

The gear geometry was designed using commercially available CAD software (Figure D.5). The initial strength verification was performed using FEM techniques (ANSYS software) (Figure D.5). Through various testing and studies, it has been found that laserpowder bed fusion process can manufacture functional gear prototypes (Figure D.6) and can reduce the design and testing lead time for new products. The gear is redesigned as per the design principles of L-PBF process and fabricated in EOS M 290 machine using 17-4 PH stainless steel powder. 17-4 PH stainless steel is chosen because of its high strength and corrosion resistance which is widely used in automotive, medical and aerospace industries. 


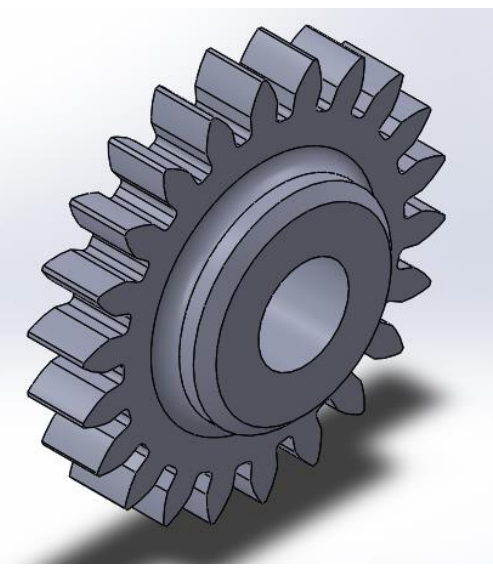

4.5414e-6 Max

$4.0368 \mathrm{e}-6$

$3.5322 \mathrm{e}-6$

$3.0276 \mathrm{e}-6$

$2.523 e-6$

$2.0184 \mathrm{e}-6$

$1.5138 \mathrm{e}-6$

$1.0092 \mathrm{e}-6$

$5.046 \mathrm{e}-7$

0 Min

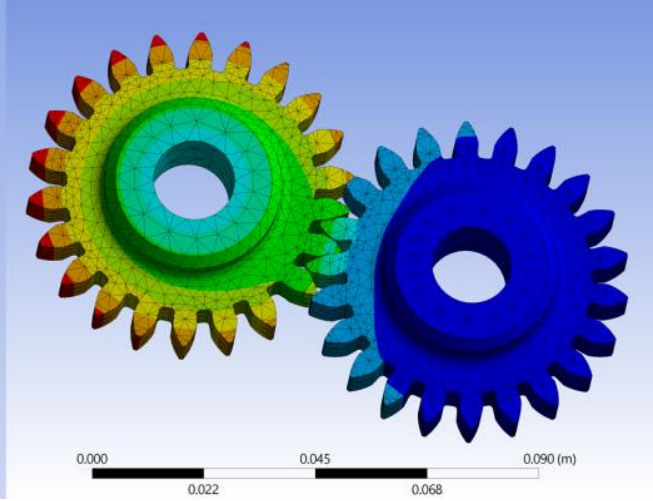

Figure D.5.Distortion analysis of gears using ANSYS software

The geometric analysis on the 3D printed gear and powder metallurgy gear was performed and results are shown in Table D.1. The geometric dimensions of the 3D printed gear were comparable to the gear manufactured by powder metallurgy. However, to test the 3D printed gear experimentally requires additional surface finishing by machining. For comparison, Boquet et al.[4] compared machining time and surface finish of the spur gears manufactured using wire EDM, milling, L-PBF process. Boquet et al. concluded that LPBF process is a potential technology to fabricate prototype gears, but additional finishing is required for further testing of the gears. 
The time and cost analysis are performed using the cost models when prototype gears were produced by L-PBF process [1] -[10]. It is estimated that using 3D printing in the design phase could reduce the prototyping costs by $50 \%$ and design cycle time by $90 \%$ compared to the current methods used by the engine manufacturer. This study could provide the pathway for decreasing the turn around time in the automobile industry for sending the optimized designs to powder metallurgy companies for high volume production. Thus, a case of how 3D printing can help the powder metallurgy companies and automobile manufacturers by decreasing the lead time and cost of manufacturing was demonstrated in this article. Future work includes working with powder metallurgy alloys specific to powder metallurgy using binder jetting as well as incorporating functional features such as weight reduction and noise reduction. Further testing of the gear will be performed using test setup at the automotive engine manufacturer's facility to validate the 3D printed part.
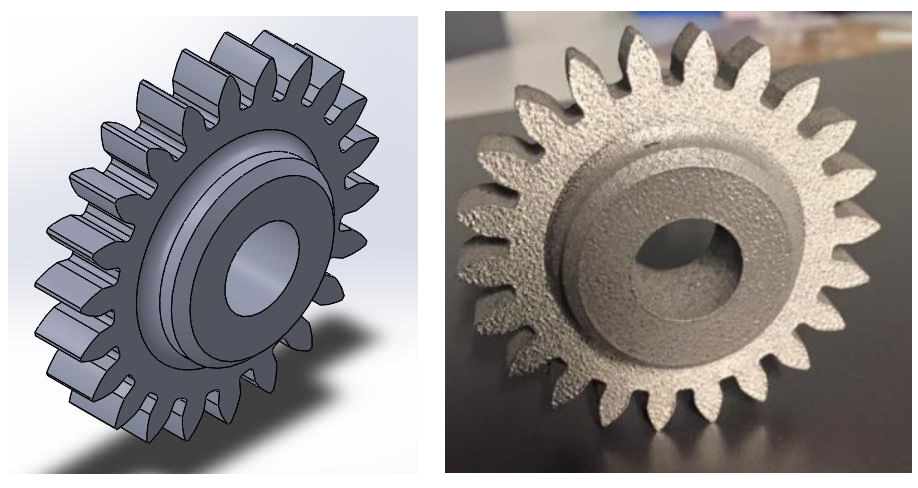

Figure D.6. Automotive engine gear re-designed and produced using the L-PBF process 
Table D.1. Comparison of dimensions of 3D printed, powder metallurgy gears with CAD model

\begin{tabular}{|c|c|c|c|}
\hline Dimension & $\begin{array}{c}\text { 3D printed part } \\
(\mathbf{m m})\end{array}$ & $\begin{array}{c}\text { Powder metallurgy } \\
\text { part }(\mathbf{m m})\end{array}$ & $\begin{array}{c}\text { CAD model } \\
(\mathbf{m m})\end{array}$ \\
\hline Tooth thickness & 9.75 & 9.8 & 9.8 \\
\hline Overall diameter & 64.5 & 64.5 & 64.6 \\
\hline Base diameter & 49.5 & 49.5 & 49.5 \\
\hline $\begin{array}{c}\text { Overall gear } \\
\text { thickness }\end{array}$ & 16.5 & 16.6 & 16.8 \\
\hline \begin{tabular}{c} 
Shaft diameter \\
\hline
\end{tabular} & 15.8 & 16 & 16 \\
\hline
\end{tabular}

\section{3 CUSTOMIZED FUEL INJECTOR}

In the automobile industry, fuel injector designs developed for traditional manufacturing have been constrained by processes that require the creation of separate components that are assembled to create the product. 3-D printing has the potential to create complex geometries at no additional cost. This provided freedom to a team of 5 students at the University of Louisville shown in Figure D.7 to create a consolidated fuel injector (design provided by automobile engine manufacturer) to decrease products weight and manufacturing steps. Furthermore, students have demonstrated efficient design for fuel injector as shown in Figure D.8 and Table D.2 with complex internal cooling channels. However, further analysis needs to perform to evaluate and validate this fuel injector for production. 


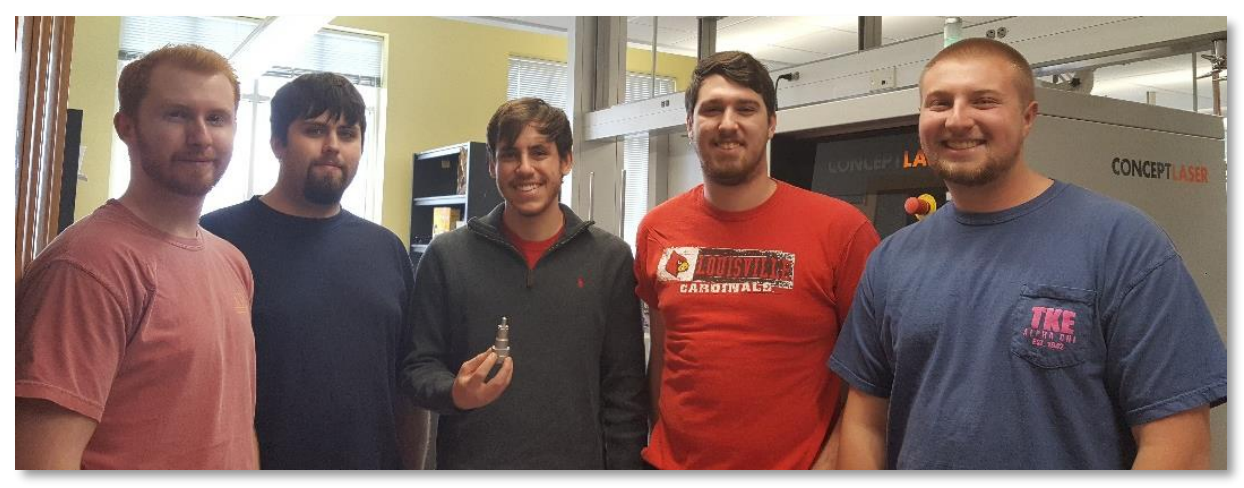

Figure D.7. Students worked on automobile fuel injector case study: Ian Yockey, Kyle Swenson,

Nick Bowling, Wil Johnson, Zach Winfield

Table D.2. Performance comparison of 3D printed fuel injector with and without cooling channels

\begin{tabular}{|c|c|}
\hline Fuel injector tip failure temperature & $662^{\circ} \mathrm{F}$ \\
\hline Maximum heat input rate with cooling channels & $35.3 \mathrm{~W}$ \\
\hline Maximum heat input rate without cooling channels & $40.1 \mathrm{~W}$ \\
\hline Percent increase in performance & $14 \%$ \\
\hline
\end{tabular}



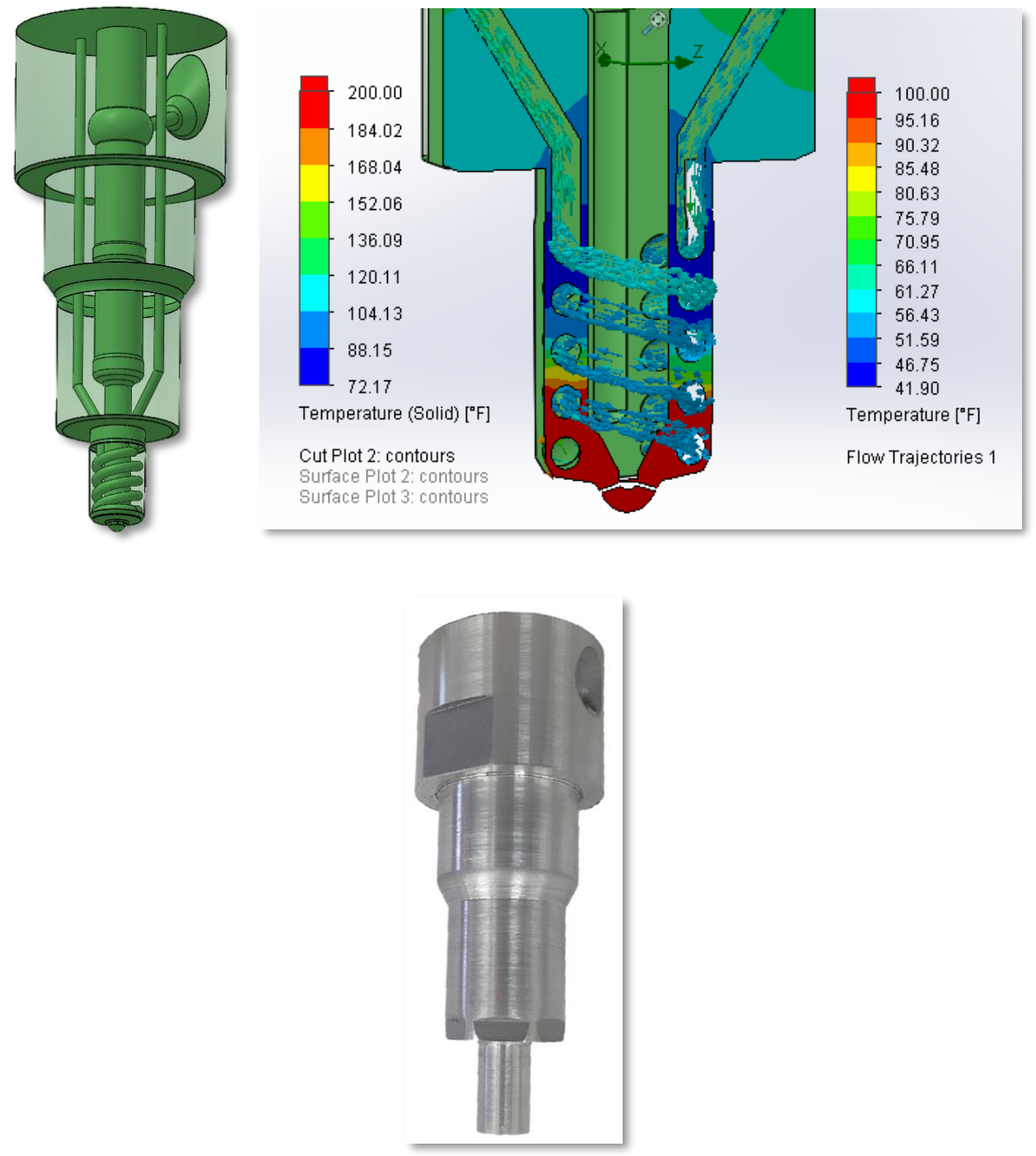

Figure D.8. Fuel injector re-designed, simulated and 3D printed by students

\section{D.4. TOOLING FOR INJECTION MOLDING}

In plastic injection molding industry, the production of injection molding tools is one of the most expensive aspects of the production processes. It is expensive, time consuming and very technically demanding to use traditional processes to manufacture the tools for injection molding. A company which does plastic injection molding to produce various 
commercial products indicated that it takes them 40 to 50 weeks and spends several thousands of dollars to manufacture a production grade tooling.

A team of 8 students shown in Figure D.9. identified this niche and worked with injection molding company to demonstrate the potential of 3D printing in manufacturing the tooling by decreasing the cost and time. Students redesigned the existing tool and integrated cooling channels in them to improve the performance of the tool when compared to traditional made tools shown in Figure D.10. The performance of the 3D printed tool when compared to traditional tools is shown in Table D.3. In addition, students demonstrated the business case and potential of $3 \mathrm{D}$ printing by reducing the tool cycle time by $80 \%$ and improving the performance of the tools $20 \%$.
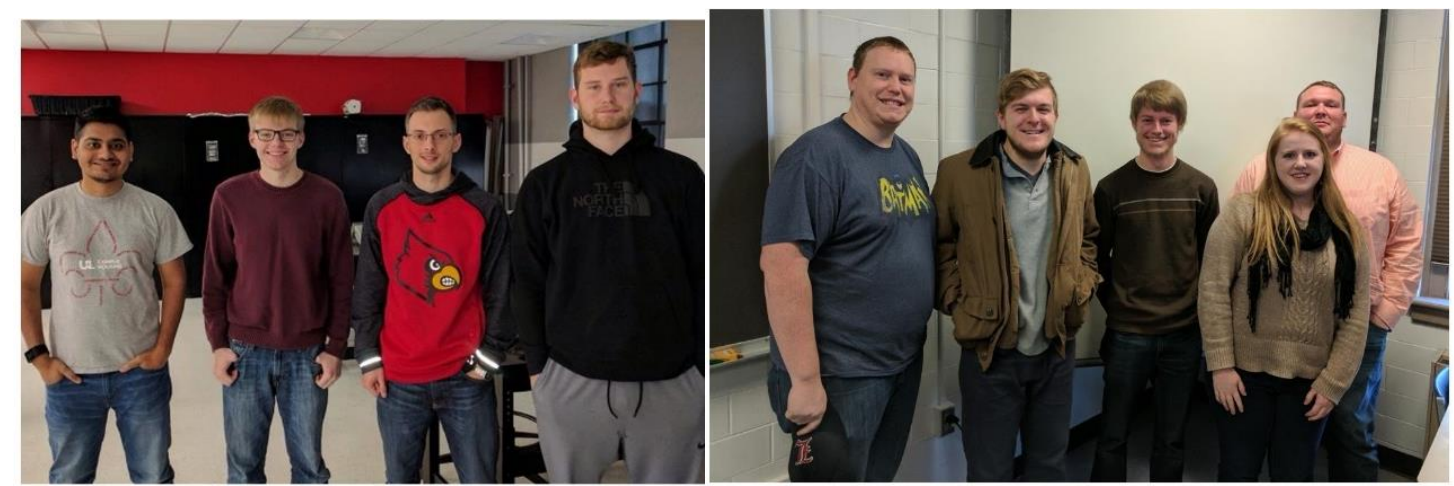

Figure D.9. Students worked on tooling case study: Nathan Westurn, Shri Patel, Aaron Hartpence, David Campbell,Robin Winebrenner, Chris Barnett, Bradley Ford, Joe Tobbe, Travis Wickizer 

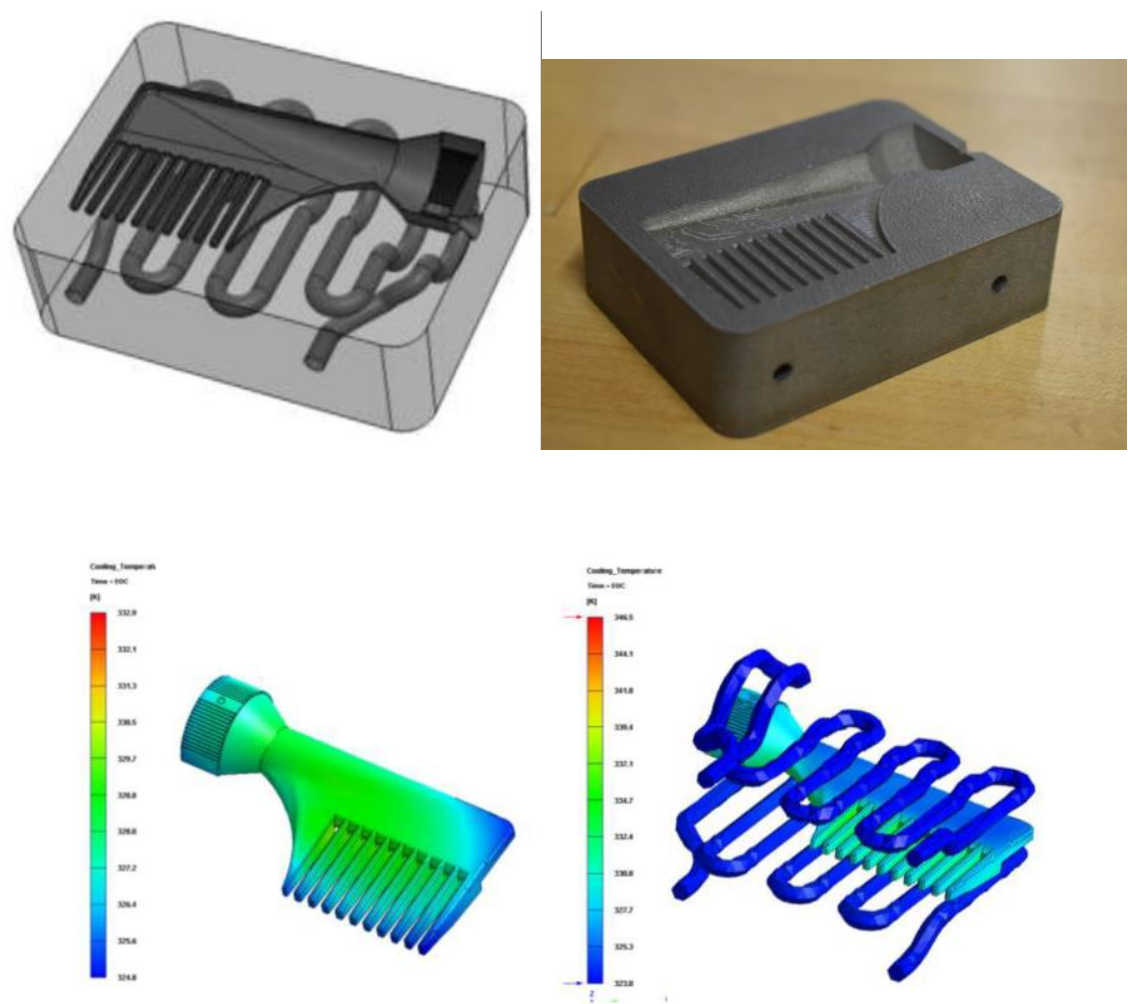

Figure D.10. Design and simulation of conformal cooling channels of a 3D printed mold

Table D.3. Performance evaluation of a 3D printed mold

\begin{tabular}{cc}
\hline Type of cooling channel & $\begin{array}{c}\text { Cycle time } \\
\text { (s) }\end{array}$ \\
\hline $\begin{array}{c}\text { Mold with no cooling } \\
\text { channel }\end{array}$ & 14.4 \\
\hline $\begin{array}{c}\text { Mold with non-conformal } \\
\text { cooling channel }\end{array}$ & 13.5 \\
\hline $\begin{array}{c}\text { Mold with conformal } \\
\text { cooling channel }\end{array}$ & 12.4 \\
\hline
\end{tabular}




\section{D.5. SUMMARY AND FUTURE OUTLOOK}

A total of 20 design teams compromised of 100 engineering students were trained and educated in techno-economic aspects of 3D printing as a part of 3D Printing Business Incubator program at the University of Louisville. During the 9 months pilot project period, students worked with academia and industry partners on various case studies. These case studies demonstrated the feasibility of using 3D printing in multiple industries that support traditional manufacturing technologies by decreasing lead time and cost. Further, the academic program strongly suggests a pathway for powder metallurgy and metal injection molding industries to benefit from new products as well as fresh engineering talent. Efforts are underway to scale the program to achieve a regional economic impact in the form of an industry-government-academia collaboration, MADE IN KY: MAnufacturing and DEsign Innovation Network of Kentucky. 


\section{D.6 REFERENCES}

[1] H. Irrinki, B. Barmore, B. K. Kate, and S. V. Atre, "Material Selection For The Production Of Injection Molding Tooling By Additive Manufacturing," Metal Additive Manufacturing, 2016, 2, pp. 76-89.

[2] H. Irrinki, M. Dexter, B. Barmore, R.K. Enneti, S. Pasebani, S. Badwe, J. Stitzel, R. Malhotra, and S.V. Atre, "Effects of Powder Attributes and Laser Powder Bed Fusion (LPBF) Process Conditions on the Densification and Mechanical Properties of 17-4 PH Stainless Steel,” JOM, 2016, 68, pp. 860-868.

[3] H. Irrinki, G. Gupta, J. Stitzel, S. Badwe, and S.V. Atre, "Evaluation of Corrosion Properties of 17-4 PH Stainless Steel Fabricated using Laser-Powder Bed Fusion,” AMPM, June 2017, Las Vegas, USA.

[4]J. Bouquet, L. Hensgen, A. Klink, T. Jacobs, F. Klocke and B. Lauwers, "Fast Production of Gear Prototypes - A Comparison of Technologies," Procedia CIRP, vol. 14, pp. 77-82, Jan. 2014.

[5]O. Malek, K. Mielnik, K. Martens, T. Jacobs, J. Bouquet, W. Auwers, P. Ten Haaf and B. Lauwers "Lead Time Reduction by High Precision 5-axis Milling of a Prototype Gear," Procedia CIRP, vol. 46, pp. 440-443, Jan. 2016.

[6]T. Schmitz, M. Davies, B. Dutterer and J. Ziegert, "The application of high-speed CNC machining to prototype production," Int. J. Mach. Tools Manuf., vol. 41, no. 8, pp. 12091228, Jun. 2001.

[7] K.Sambhavi and K. A. Prabha, "Design, Analysis and Manufacturing of Planetary Gear System by using Rapid Prototype Technique used as Clock Mechanism," Int. J. Sci. Res. Dev., vol. 3, no. 7, pp. 43-47, Oct. 2015. 
[8]T. Kamps, M. Lutter-Guenther, C. Seidel, T. Gutowski and G. Reinhart, "Cost- and energy-efficient manufacture of gears by laser beam melting," CIRP J. Manuf. Sci. Technol., Feb. 2018.

[9] P. Rokicki, B. Kozik, G. Budzik, T. Dziubek, J. Bernaczek, L. Przeszlowski, O. Markowska, B. Sobolewski and A. Rzucidlo, "Manufacturing of aircraft engine transmission gear with SLS (DMLS) method," Aircr. Eng. Aerosp. Technol., vol. 88, no. 3, pp. 397-403, May 2016. 


\section{CURRICULUM VITAE}

Harish Irrinki

harish.irrinki@louisville.edu

325 W Cardinal Blvd

925-364-1528

Louisville, KY 40208

\section{$\underline{\text { Education }}$}

University of Louisville

Ph.D. Mechanical Engineering; GPA 4.0/4.0

Louisville, $\mathrm{KY}$

Structure-process-property relationship of 17-4 PH stainless steel processed by laserpowder bed fusion

Advisor: Dr. Sundar Atre

University of Louisville

M.S. Mechanical Engineering; GPA 4.0/4.0

Louisville, KY

Jawaharlal Nehru Technological University

B.Tech. Mechanical Engineering; GPA 3.8/4.0

April 2016

Hyderabad, INDIA

June 2014

Selected Awards and Recognitions

Hsing Chuang Award for Excellence in Graduate Study -2018

NSF Student Travel Award, AMPM Conference- 2018

MIMA Student Travel Grant, MIM Conference-2017

NSF I-CORP Award -2017

Grosscurth Fellowship, University of Louisville -2016-18

AMPM Best Poster Award - 2016

CPMT Axel Madison Award - 2016

ASME Best Presentation Award -2016

Tesla

$\underline{\text { Research Experience }}$

Fremont, CA

Manufacturing Engineering Intern

Sep. 2017 -Dec. 2017

- Led the project to identify the additive manufacturing (AM) opportunities in automobile industry using a scientific model

- Developed a techno-economic model to demonstrate the techno-economic merits in resulted in adapting AM technology for fabricating the BIW of Tesla cars 
University of Louisville

Louisville, KY

Grosscurth Fellow and Graduate Research Assistant

June 2016 - present

- Experience in powder-based additive manufacturing design, process, materials and applications development

- Developed a fundamental understanding of the role of powder attributes, L-PBF process and post-process conditions on the densification, mechanical and electrochemical properties and microstructures of L-PBF parts

- Evaluated different polymer and metal 3D printers and responsible for the purchase of $\$ 300 \mathrm{~K}$ metal 3D printer, $\$ 10 \mathrm{~K}$ polymer 3D printers

- Developed the applications based on the understanding of relationship between: design to process, process to microstructure; microstructure to properties

- Designed and evaluated the performance of various 3D printed functional parts for various OEM

- Applications and process development for various OEM's (Cummins, Walmart, Amaray, GE Concept Laser, HTS, Mirus, NAH, Sandvik Osprey) based on research, technical and business merits

- Communicated technical results with collaborators and business leaders at all levels through formal technical presentations and informal discussions

Materials: 17-4 PH, 420 and duplex stainless steel, bronze, niobium, tungsten, molybdenum-rhenium

3D Printing: Concept Laser Mlab, EOS M 290, 3DSystem ProX 320, FDM

Design Skills: SolidWorks, Inspire, Catia 3D Experience, Materialise, Limitstate, MatLab, Ansys, C

Characterization: SEM, XRD, EDAX, hardness and tensile testing

\section{Leadership Experience}

University of Louisville

Louisville, $\mathrm{KY}$

Graduate Mentor-3D Printing Business

Aug. 2016 - Apr. 2017

Incubator

- Planned and executed 4 mechanical engineering undergraduate projects that support technology-based business opportunities on metal additive manufacturing platforms 
University of Louisville and Oregon State University

Graduate Teaching Assistant

Sep. 2015 - Apr. 2017

- Taught and helped students to design and fabrication techniques to develop various applications

- Topics mainly focused on CAD, ANSYS simulations, manufacturing and prototype development

\section{$\underline{\text { Publications }}$}

H.Irrinki, T. Harper, G.Gupta, J.Stitzel, S.Badwe, O. Gulsoy, S.V.Atre, "Effects of powder characteristics and processing conditions on the corrosion performance of 17-4 $\mathrm{PH}$ stainless steel fabricated by laser-powder bed fusion," Progress in Additive Manufacturing, vol. 3 , pp $1-11,2018$

S.Pasebani, S.Badwe, H.Irrinki, S.V.Atre "Effect of Atomizing Media and Post Processing on the Mechanical Properties of 17-4 PH Stainless Steel Processed via Laser-Powder Bed Fusion," Additive Manufacturing, vol. 22, pp 127- 137, 2018

H.Irrinki, J.J.Dilip, J.Stitzel, S.Pasebani, S.Badwe, K.H.Kate, O. Gulsoy, S.V.Atre "Mechanical Properties and Microstructures of 17-4 PH Stainless Steel Processed by Laser-Powder Bed Fusion,” Powder Technology, vol. 331, pp 192 - 203, 2018

H.Irrinki, B.Barmore, M.Dexter, R.K.Enneti, J.Stitzel, S.Pasebani, S.Badwe, S.V. Atre, R.Malhotra "Effects of Powder Attributes and Laser Powder Bed Fusion (L-PBF) Process Conditions on the Densification and Mechanical Properties of 17-4 PH Stainless Steel," JOM, vol.68, pp $860-868,2016$

H.Irrinki, B.Barmore, K.H.Kate, S.V. Atre, "Material Selection for the Production of Injection Molds using Additive Manufacturing," Metal AM, vol. 2, no. 2, pp 77- 89, 2016

H.Irrinki, S. Nath, M. Ahlfors, O. Gulsoy, J. Stitzel, S.V.Atre "Effect of Hot isostatic Pressing on the Mechanical Properties and Microstructures of 17-4 PH Stainless Steel Processed via Laser-Powder Bed Fusion," American Ceramics Society, 2018 (under review)

S.D. Nath, H.Irrinki, M.Kearns, O. Gulsoy, S.V.Atre, "Mechanical Properties and Microstructures of 420 Stainless Steel Processed by Laser-Powder Bed Fusion," Additive Manufacturing, 2018 (under review) 


\section{Conference Talks and Proceedings}

H.Irrinki, S. Nath, M. Ahlfors, O. Gulsoy, J. Stitzel, S.V.Atre "Effect of Powder Attributes and Hot isostatic Pressing on the Mechanical Properties and Microstructures of 17-4 PH Stainless Steel Processed via Laser-Powder Bed Fusion," AMPM, June, 2018, San Antonio, USA

H.Irrinki, S.D. Nath, S.V.Atre, "Mechanical Properties and Microstructures of Bronze Processed by Laser-Powder Bed Fusion,” AMPM, June, 2018, San Antonio, USA

H.Irrinki, M.Buxani, J.Ballaro, M.Gatsche, K.H.Kate, S.V.Atre, “ Design and Evaluation of Injection Mold Tool Fabricated by Laser Powder-Bed Fusion with Conformal Cooling Channels," AMPM, June, 2018, San Antonio, USA

S.D. Nath, H.Irrinki, M.Kearns, O. Gulsoy, S.V.Atre, "Mechanical Properties and Microstructures of 420 Stainless Steel Processed by Laser-Powder Bed Fusion," AMPM, June, 2018, San Antonio, USA

S.D. Nath, H.Irrinki, M.Kearns, O. Gulsoy, S.V.Atre, "Role of Powder Attributes on the Mechanical Properties and Microstructures of 420 Stainless Steel Processed by LaserPowder Bed Fusion,” AMPM, June, 2018, San Antonio, USA

S.D. Nath, H.Irrinki, G. Gupta, M.Kearns, O. Gulsoy, S.V.Atre, "Evaluationn of Corrosion Properties of 420 Stainless Steel Processed by Laser-Powder Bed Fusion," AMPM, June, 2018, San Antonio, USA

H.Irrinki, G.Gupta, J.Stitzel, S.Badwe, K.H.Kate, S.V.Atre, "Evaluation of Corrosion Properties of 17-4 PH Stainless Steel Fabricated using Laser-Powder Bed Fusion," AMPM, June, 2017, Las Vegas, USA

H.Irrinki, D.Lin, J.Stitzel, S.V.Atre, "Mechanical Properties and Microstructures of C-103 Alloy Processed by Laser-Powder Bed Fusion,” AMPM, June, 2017, Las Vegas, USA

S.D. Nath, H.Irrinki, J.J.Dilip, K.H.Kate, S.V.Atre, "Mechanical Properties and Microstructures of 420 Stainless Steel Processed by Laser-Powder Bed Fusion," AMPM, June, 2017, Las Vegas, USA

H.Irrinki, M.Buxani, J.Ballaro, M.Gatsche, J.Stitzel, K.H.Kate, S.V.Atre, "Simulations and Experiments on Injection Mold Tool Fabricated by Laser Powder-Bed Fusion," World PM, Oct., 2016, Hamburg, Germany 